\title{
A Parametric Study of Containment Emergency-Sump Performance: Results of Vertical-Outlet Sump Tests
}

Prepared by M. S. Krein/The M. S. Krein Co.

M. J. Wester/The Dikewood Corporation

P. O. Strom, G. G. Weigand/Sandia National Laboratories

Sandia National Laboratories

Prepared for

U.S. Nuclear Regulatory

Commission

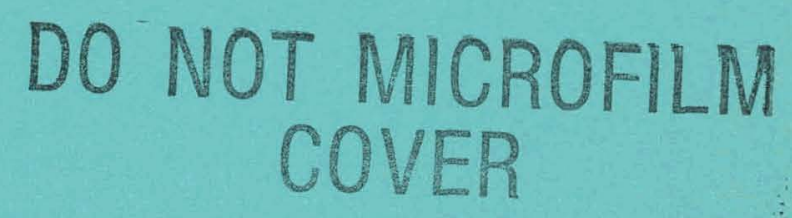




\section{DISCLAIMER}

This report was prepared as an account of work sponsored by an agency of the United States Government. Neither the United States Government nor any agency Thereof, nor any of their employees, makes any warranty, express or implied, or assumes any legal liability or responsibility for the accuracy, completeness, or usefulness of any information, apparatus, product, or process disclosed, or represents that its use would not infringe privately owned rights. Reference herein to any specific commercial product, process, or service by trade name, trademark, manufacturer, or otherwise does not necessarily constitute or imply its endorsement, recommendation, or favoring by the United States Government or any agency thereof. The views and opinions of authors expressed herein do not necessarily state or reflect those of the United States Government or any agency thereof. 


\section{DISCLAIMER}

Portions of this document may be illegible in electronic image products. Images are produced from the best available original document. 


\section{NOTICE}

This report was prepared as an account of work sponsored by an agency of the United States Government. Neither the United States Government nor any agency thereof, or any of their employees, makes any warranty, expressed or implied, or assumes any legal liability of responsibility for any third party's use, or the results of such use, of any information, apparatus, product or process disclosed in this report, or represents that its use by such third party would not infringe privately owned rights.

\section{Availability of Reference Materials Cited in NRC Publications}

Most documents cited in NRC publications will be available from one of the following sources:

1. The NRC Public Document Room, 1717 H Street, N.W. Washington, DC 20555

2. The NRC/GPO Sales Program, U.S. Nuclear Regulatory Commission, Washington, DC 20555

3. The National Technical Information Service, Springfield, VA 22161

Although the listing that follows represents the majority of documents cited in NRC publications, it is not intended to be exhaustive.

Referenced documents available for inspection and copying for a fee from the NRC Public Document Room include NRC correspondence and irternal NRC memoranda; NRC Office of Inspection and Enforcement bulletins, circulars, information notices, inspection and investigation notices; Licensee Event Reports; vendor reports and correspondence; Commission papers; and applicant and licensee documents and correspondence.

The following documents in the NUREG series are available for purchase from the NRC/GPO Sales Program: formal NRC staff and contractor reports, NRC-sponsored conference proceedings, and NRC booklets and brochures. Also available are Regulatory Guides, NRC regulations in the Code of Federal Regulations, and Nuclear Regulatory Commission Issuances.

Documents available from the National Technical Information Service include NUREG series reports and technical reports prepared by other federal agencies and reports prepared by the Atomic Energy Commission, forerunner agency to the Nuclear Regulatory Commission.

Documents available from public and special technical libraries include all open literature items, such as books, journal and periodical articles, and transactions. Federal Register notices, federal and state legislation, and congressional reports can usually be obtained from these libraries.

Documents such as theses, dissertations, foreign reports and translations, and non-NRC conference proceedings are available for purchase from the organization sponsoring the publication cited.

Single copies of NRC draft reports are available free upon written request to the Division of Technical Information and Document Control, U.S. Nuclear Regulatory Commission, Washington, DC 20555.

Copies of industry codes and standards used in a substantive manner in the NRC regulatory process are maintained at the NRC Library, 7920 Norfolk Avenue, Bethesda, Maryland, and are available there for reference use by the public. Codes and standards are usually copyrighted and may be purchased from the originating organization or, if they are American National Standards, from the American National Standards Institute, 1430 Broadway, New York, NY 10018. 


\section{A Parametric Study of Containment Emergency-Sump Performance: Results of Vertical-Outlet Sump Tests}

Manuscript Completed: September 1982

Date Published: October 1982

Prepared by

M. S. Krein/The M. S. Kreln Co.

M. J. Wester/The Dikewood Corporation

P. O. Strom, G. G. Weigand/Sandia National Laboratories

Sandia National Laboratories

Albuquerque, NM 87185

\section{Prepared for}

Division of Safety Technology

Office of Nuclear Regulatory Research

U.S. Nuclear Regulatory Commission

Washington, D.C. 20555

NRC' FIN A1237
NUREG/CR--2759

DE83 001608

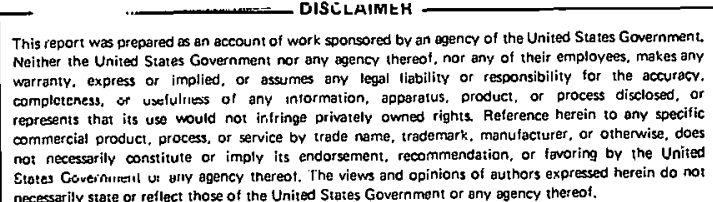




\section{$\underline{\text { ABSTRACT }}$}

This report presents the results of a systematically structured test program designed to characterize the hydraulic performance of full-scale Energy Core Cooling Sumps with vertical outlets. The tests were performed for a wide range of geometric and flow variables typical of ECCS sumps. The work on vertical outlet sumps presented here is supplemental to a broader test program which has provided the performance characterization of sumps with horizontal outlets.

In addition to a parametric evaluation of the operating characteristics of vertical outlet sumps under normal approach flow conditions, the effects of perturbations to the approach flow, such as those which could develop during an accident situation, have also been considered. These approach flow perturbations included sump screen blockage, nonuniform approach flows and break-flow jet impingement. The effectiveness of two vortex suppression devices, under these conditions, was also demonstrated.

Vortex severity was found to be an unreliable indicator of air ingestion levels or outlet swirl performance. Air ingestion levels were found to be generally less than 2 percent void fraction under the test conditions, while outlet swirl angles remained generally below 3 degrees. Screen blockage and nonuniform approach flows perturbations resulted in some increased levels of air ingestion and outlet swirl angle over those found for unperturbed approach conditions. Envelope curves of the data are presented that have defined the maximum observed levels of critical sump performance parameters as functions of the flow parameters.

The results of this test series indicate that no major differences exist between the performance of vertical and horizontal outlet sumps.

The results presented here, coupled with the results from horizontal outlet sump studies, can be used to develop comprehensive design, review and remedial action ECCS sump guidelines. Test results from the complete sump performance program can be used to aid in the resolution of unresolved safety Issue A-43, "Containment Emergency Sump Performance." 
TABLE OF CONTENTS

Section

Page

Summary................................. 1

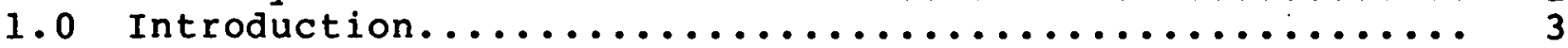

2.0 Conclusions................................ 5

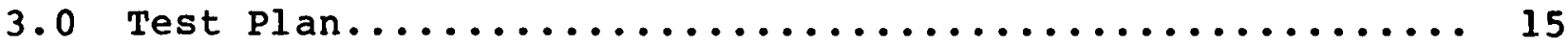

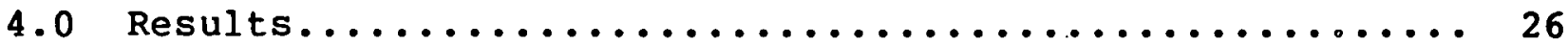

4.1 General Overview of sump Performance................ 26

4.1.1 General Hydraulic Performance.................. 26

4.1.2 Maximum Response Levels (All Tests) ............ 33

4.2 Envelope Analysis.............................. 36

4.3 Unperturbed Flow Tests (Uniform Flow Tests)...........40

4.3.1 Typical Unperturbed Flow Response.............. 40

4.3.2 Maximum Response in Unperturbed Sumps........... 45

4.3 .3 Suction p1pe Location Tests..................45

4.3.4 Suction Pipe Protrusion l'ests................ 50

4.4 Perturbed Flow Tests............................ 50

4.4.1 Maximum Response in Perturbed Flow Sumps........ 55

4.4.2 The Effects of Screen Blockage............... 70

4.4.3 The Effects of Nonuniform Approach Flow........ 71

4.4.4 The Effects of Break-Flow Jet Impingement....... 72

4.4.5 The Effects of Transient Flow Conditions....... 72

4.5 Vortex suppressor Tests........................ 73

4.6 Comparison with Horizontal Suction Results........... 73

4.6.1 Unperturbed Flow Comparisons................ 76

4.6.2 Perturbed Flow Comparisons................... 80

Appendix A Facility Description, Data Aquisition

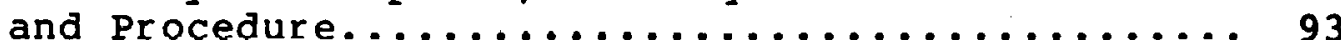




\section{LIST OF ILLUSTRATIONS}

Figure

Page

3.1 Sump Layout and Geometric Parameters.............. 16

3.2 Outlet Orientations Defined by the Geometric

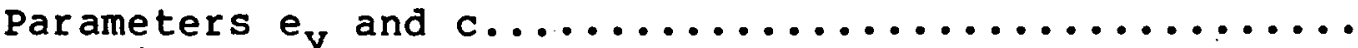

3.3 Nonuniform Approach Flow and Screen Blockage

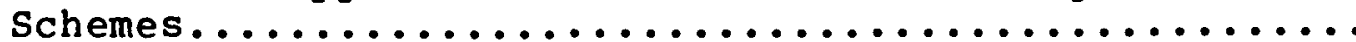

Break and Drain-Flow Jet Impingement............. 21

3.5

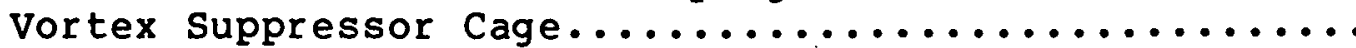

3.6

Vortex Classification Scale.

4.1 Vortex Type as a Function of the Froude Number

for All 30-Minute Average Data.................

4.2 Outlet Swirl Angle as a Function of the Froude

4.3 Void Fraction as a Function of the Froude

Number for All 30-Minute Average Data..............
Void Fraction as a Function of the Submergence

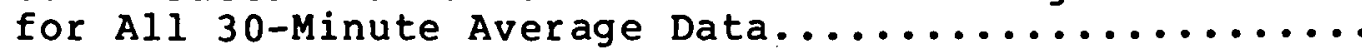

Loss Coefficient as a Function of the Froude

4.6 Outlet Swirl Angle as a Function of Vortex

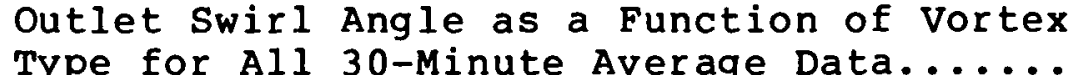

4.7 Void Fraction as a Function of the Vortex

Type for All 30-Minute Average Data.............. 30

4.8 Loss Coefficient as a Function of the Vortex

Type for All 30-Minute Average Data.............. 30

4.9 Void Fraction as a Function of the Outlet

Swirl Angle for All 30-Minute Average

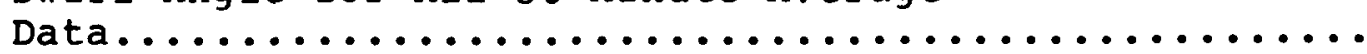

4.10 Loss Coefficient as a Function of the Outlet

Angle for All 30-Minute Average Data..............

4.11 Maximum Surface Vortex Type as a Function of

the Froude Number for All 30-Minute Average

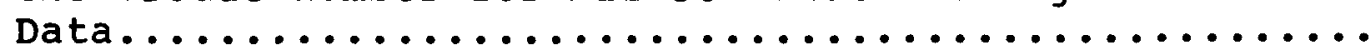

4.12 Maximum Outlet Swirl Angle as a Function of the Froude Number for All 30-Minute Average

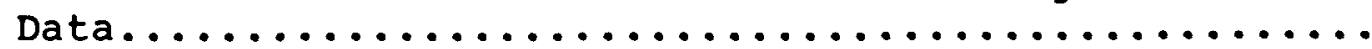

4.13 Maximum Void Fraction as a Function of the Froude Number for All 30-Minute Average

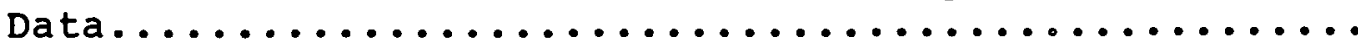

4.14 Maximum Loss Coefficient as a Function of

Lhe Froude Number for All 30-Minule Average

4.15 Envelope of vortex Type Data as a runction of the Froude Number for All 30-Minute and

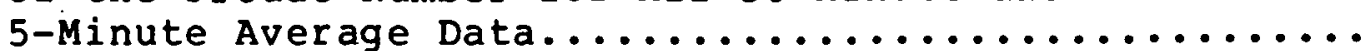

4.16 Envelope of Air Ingestion Data for, a) 1-Minute Average, b) 5-Minute or 30-Minute Average, as a Function of the Froude Number............................. 
Continued

Figure

Page

4.17 Envelope of Air Ingestion as a Function of Pipe Velocity for 5-Minute and 30-Minute

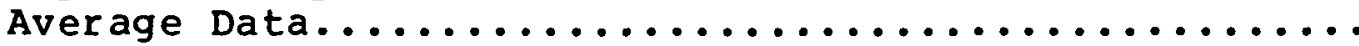

4.18 Envelope of Air Ingestion as a Function of the Submergence for 5-Minute and 30-Minute

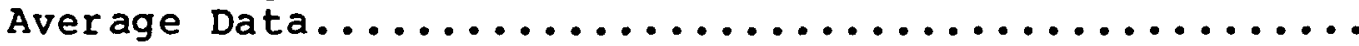

4.19 Envelope of Outlet Swirl Angle as a Function

of the Froude Number for 5-Minute and

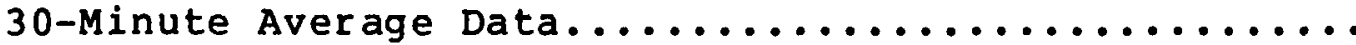

4.20 Envelope of Loss Coefficients as a Function of the Froude Number for All 30-Minute

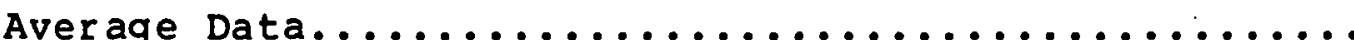

4.21 Vortex Type as a Function of the Froude Number for Configurations 58,59 , and $60 \ldots \ldots \ldots \ldots$

4.22 Void Fraction as a Function of the Froude Number for Configurations 58,59 , and 60.

Outlet Swirl Angle as a Function of the

4.23

Froude Number for Configurations 58, 59,

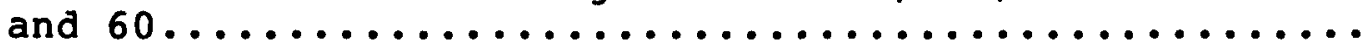

4.24 Loss Coefficient as a Function of the Froude Number for Configurations 58,59 , and $60 \ldots \ldots \ldots \ldots \ldots$

4.25 Maximum Vortex Type as a Function of the

Froude Number for All Uniform Flow,

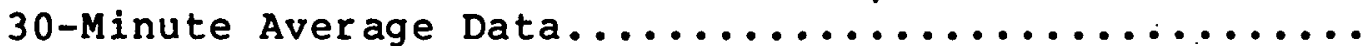

4.26 Maximum Outlet Swirl Angle as a Function of the Froude Number for All Uniform Flow,

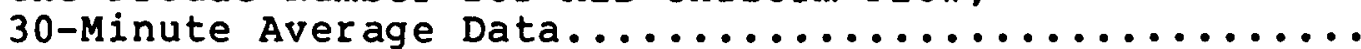

4.27 Maximum Void Fraction as a Function of the Froude Number for All Uniform Flow,

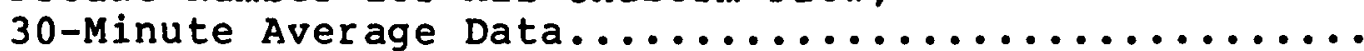

4.28 Maximum Loss Coefficient as a Function of the Froude Number for All Uniform Flow, 30-Minute

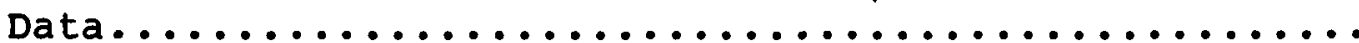

4.29 The Effect of Outlet Location On Vortex

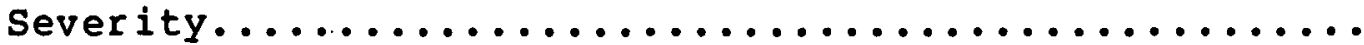

4.30 The Effect of Outlet Location on Swirl Angle

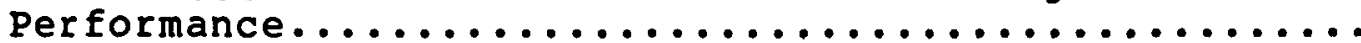

4.31 The Effect of Outlet Protrusion On Vortex

Severity.................................

4.32 The Effect of Outlet Protrusion on Swirl

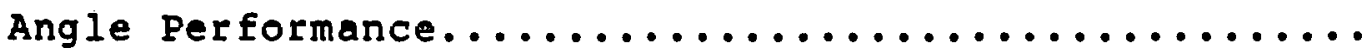

4.33 The Effect of Outlet Protrusion on Void

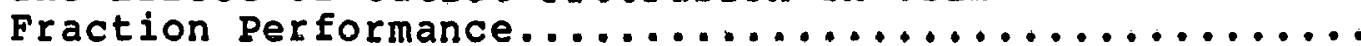

4.34 The Effect of Outlet Protrusion on Loss

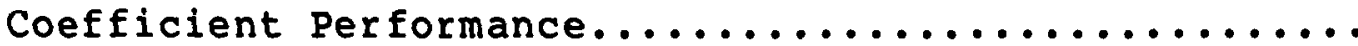

4.35 Maximum Vortex Type as a Function of the

Froude Number for Perturbed Flow Conditions...........

4.36 Maximum Outlet Swirl Angle as a Function of

the Froude Number for Perturbed Flow

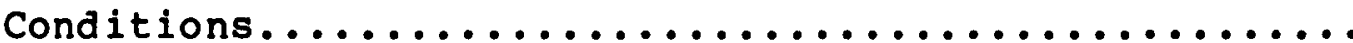

4.37 Maximum Void Fraction as a Function of the

Froude Number for Perturbed Flow Conditions.......... 
Continued

Eigure

Page

4.38 Maximum Loss Coefficient as a Function of the

Froude Number for Perturbed Flow Conditions..........

4.39 Average Vortex Type as a Function of the

Froude Number for Screen Blockage,

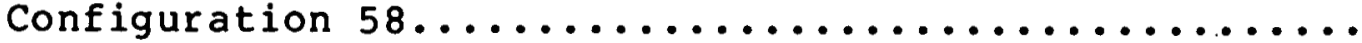

4.40 Average Void Fraction as a Function of the

Froude Number for Screen Blockage,

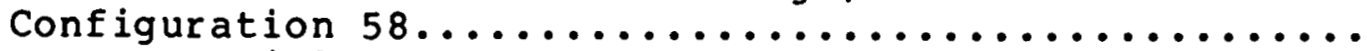

4.41 Average Swirl Angle as a Function of the

Froude Number for Screen Blockage,

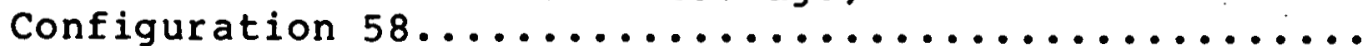

56

4.42 Loss Coefficient as a Function of the

Froude Number for Screen Blockage,

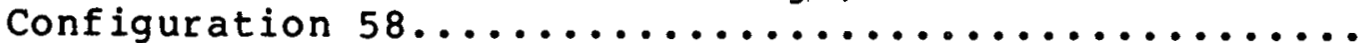

4.43 Typical Air-Core Vortex in Configuration 58

During a Screen Blockage Test. Submergence $=8 \mathrm{ft}$

and Flowrate $=5300 \mathrm{gpm} / \mathrm{pipe} \ldots \ldots \ldots \ldots \ldots \ldots \ldots$

4.44 Typical Air-Core Vortex in Configuration 58

During a Screen Blockage Test. Submergence $=5 \mathrm{ft}$

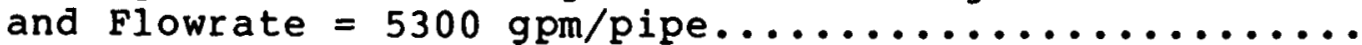

4.45 Typical Air-Core Vortex in Configuration $60 \mathrm{~A}$

During a Screen Blockage Test. Submergence $=3 \mathrm{ft}$

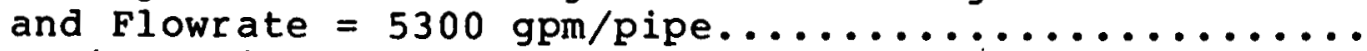

4.46 Typical Air-Core Vortex in Configuration $60 \mathrm{~A}$

During a Screen Blockage Test. Submergence $=6 \mathrm{ft}$

and Flowrate $=5300 \mathrm{gpm} / \mathrm{pipe} \ldots \ldots \ldots \ldots \ldots \ldots \ldots \ldots$

4.47 The Effect of Screen Blockage on Vortex

Severity...............................

4.48 The Effect of Screen Blockage on Outlet

Swirl Angle Performance....................... 60

4.49 The Effect of Screen Blockage on Void

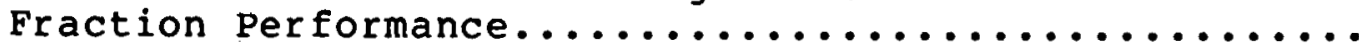

The Effect of Screen Blockage On Loss

4.51 Vortex Type as a Function of the Froude

Number for Nonuniform Approach Flow

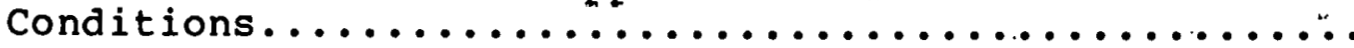

4.52 Void Fraction as a Function of the Froude

Number for Nonuniform Approach Flow

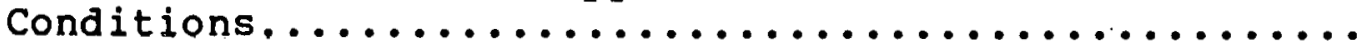

4.53 Outlet Swirl Angle as a Function of the

Froude Number for Nonuniform Approach

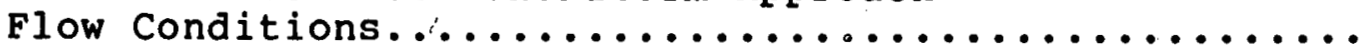

4.54 Loss Coefficient as a Function of the Froude

Number for Nonuniform Approach Flow

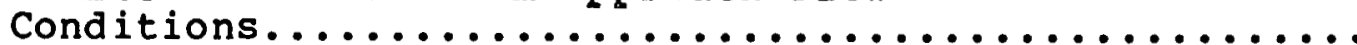

The Effect of Nonuniform Approach Flow on

4.55

Vortex severity...........................

The Effect of Nonuniform Approach Flow On

4.56

Outlet Swirl Angle........................

The Effect of Nonuniform Approach Flow on

4.57

Void Fraction. 
Continued

Figure

Page

4.58 The Effect of Nonuniform Approach Flow On

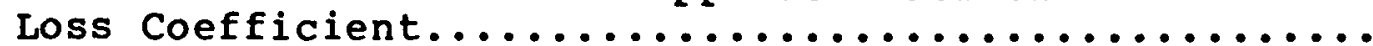

4.59

The Effect of Break-flow Jet Impingement on

4.60

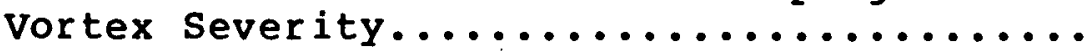

The Effect of Break-flow Jet Impingement on

4.61 The Effect of Break-fiow Jet Impingement on

Void Fraction.............................

4.62 The Effect of Break-flow Jet Impingement On

Loss Coefficient...........................

4.63 Flow Rate Versus Time Schedule for Transient

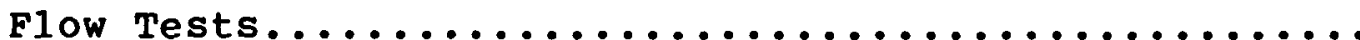

4.64 The Effect of Transient Flow Conditions on

Outlet Swirl Angle and Void Fraction..............

4.65 Performance Comparisons Between Vertical and

Horizontal outlet Configurations.................

4.66 Comparison of Vortex Type Between Vertical

and Horizontal Outlet Sumps for Comparison

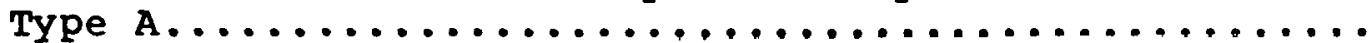

4.67 Comparison of Outlet Swirl Angle Performance

Between Vertical and Horizontal Outlet Sumps

for Comparison Type A........................

4.68 Comparison of Void Fraction Performance

Between Vertical and Horizontal Outlet

Sumps for Comparison Type A...................

4.69 Comparison of Loss Coefficient Performance

Between Vertical and Horizontal Outlet

Sumps for Comparison Type A...................

4.70 Comparison of Vortex Type Between Vertical

and Horizontal Outlet Sumps for Comparison

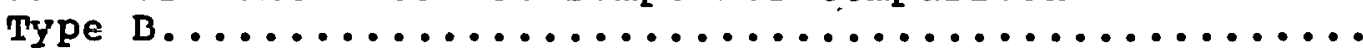

4.71 Comparison of Outlet Swirl Angle Performance

Between Vertical and Horizontal outlet Sumps

for Comparison Type B.......................

4.72 Comparison of Void Fraction Performance

Between Vertical and Horizontal Outlet sumps

for Comparison Type B.........................

4.73 Comparison of Loss Coefficient Performance

Between Vertical and Horizontal Outlet Sumps

for Comparison Type B........................

4.74 Comparison of Vortex Type Between Vertical

and Horizontal outlet Sumps for Comparison

Type C..................................

4.75 Comparison of Outlet Swirl Angle Performance

Between Vertical and Horizontal Outlet Sumps

for Comparison Type C........................

4.76 Comparison of Void Fraction Performance

Between Vertical and Horizontal outlet Sumps

for Comparison Type c........................

4.77 Comparison of Loss Coefficient Performance

Between Vertical and Horizontal Outlet Sumps

for Comparison Type C........................ 


\section{Continued}

Figure

4.78 Comparison of Vortex Type Under Perturbed

Flow Conditions Between Vertical and Horizontal

Outlet Sumps for Comparison Type A...............

4.79 Comparison of Outlet Swirl Angle Performance

Under Perturbed Flow Conditions Between Vertical

and Horizontal outlet Sumps for Comparison

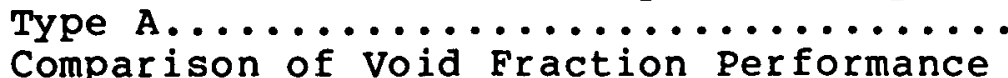

4.80

Under Perturbed Flow Conditions Between Vertical

and Horizontal outlet Sumps for Comparison

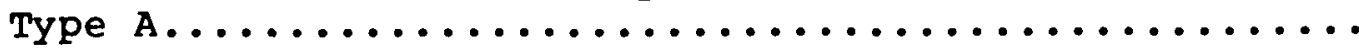

4.81 Comparison of Loss Coefficient Performance

Under Perturbed Flow Conditions Between Vertical

and Horizontal Outlet Sumps for Comparison

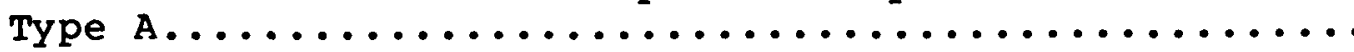

4.82 Comparison of Vortex Type Under Perturbed Flow

Conditions Between Vertical and Horizontal

Outlet Sumps for Comparison Type B...............

4.83 Comparison of Outlet Swirl Angle Performance

Under Perturbed Flow Conditions Between

Vertical and Horizontal Outlet Sumps for

Comparison Type B.........................

4.84 Comparison of Void Fraction Performance

Under Perturbed Flow Conditions Between

Vertical and Horizontal Outlet Sumps for

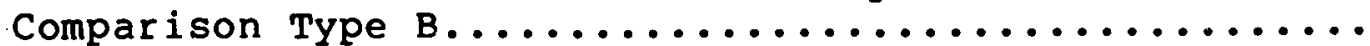

4.85 Comparison of Loss Coefficient Performance

Under Perturbed Flow Conditions Between

vertical and Horizontal Outlet Sumps for

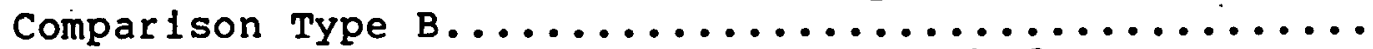

4.86 Comparison of Vortex Type Under Perturbed

Flow Conditions Between Vertical and Horizontal

Outlet Sumps for Comparison Type C................

4.87 Comparison of Outlet Swirl Angle Performance
Under Perturbed Flow Conditions Between

Vertical and Horizontal Outlet sumps for

Comparison Type C.........................

4.88 Comparison of Void Fraction Performance

Under Perturbed Flow Conditions Between

Vertical and Horizontal Outlet sumps for

Comparison Type C.........................

4.89 Comparison of Loss coefficient Performance
Under Perturbed Flow Conditions Between

Vertical and Horizontal outlet sumps for

Comparison Type C..........................

A. 1

Details of the sump Test Facility................

A. 2

Typical piping Arrangement for Vertical

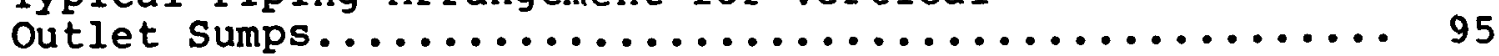

A. 3

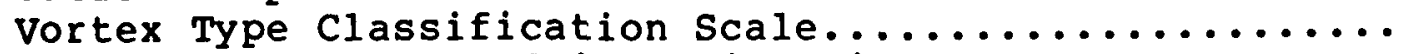

Swirl Meter Installed in 12 in. Pipe.............. 97

A. 4

Method for the Determination of outlet

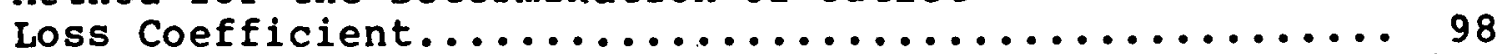

A. 6

Data Acquisition Scheme..

vi i 
Table

2.1 Significant Findings summary Vertical

2.2 Maximum Recorded Values for vertical

Outlet Tests.............................. 14

3.1 Geometric Definitions and Flow Variables........... 17

3.2 Dimensions for Vertical outlet sumps................ 18

3.3 Test Flows and submergences..................... 23

4.1 Results of Vortex Suppressor Tests................ 74 


\section{ACKNOWLEDGEMENTS}

The authors would like to acknowledge Dr. Mahadevan Padmanabhan and all of the staff of the Alden Research Laboratory involved in performing the tests and providing Sandia with the test results. Also, thanks are due Mr. Aleck Serkiz of the NRC. 
The full scale hydraulic tests performed on vertical outlet containment emergency sumps, the results of which have been presented here, are part of a larger test program--the main objective of which was to provide a data base for the evaluation of the overall hydraulic performance of containment emergency sumps. The basic objectives of the vertical outlet program were;

1) To perform a sensitivity study of the hydraulic performance of vertical outlet sumps applicable to the development of design and review guidelines.

2) To identify and characterize any major differences between the hydraulic performance of vertical outlet sumps and that of sumps with horizontal outlets. (An extensive test program for sumps with horizontal outlets has been conducted [Reference 1]).

A secondary objective was to test the effectiveness of two vortex suppression devices to establish a reliable, remedial action that may be necessary for plants that may be found to have deficient sumps.

Tests on vertical outlet sumps, although 1 imited to a subset of the tests performed on horizontal outlet sumps, were configured to be representative of typical containment emergency sump designs. Accident-induced effects, including severe perturbations in the approach flow such as screen blockage (up to 75 percent blockage), nonuniform approach flows including streaming, and break-flow jet impingement, were also considered.

Because the tests that were performed on horizontal outlet sumps represent a much larger data base than the data base for vertical outlet sumps, emphasis was placed on the comparative behavior of horizontal versus vertical configurations. These comparisons have permitted the application of the larger data base to vertical outlet performance. In addition this study has provided a supplement to the overall test program which is specific to vertical outlet sumps.

Envelope analyses of the data from vertical outlet performance tests were performed and found to be effective means of presenting the hydraulic behavior of the sump. Sump performance parameters, such as vortex severity, air ingestion, outlet swirl, and loss coefficient were examined. The lack of consistent correlations between dependent and independent parameters precluded the possibility of using the data of this report to predict the performance of any specific sump. Instead, the envelope analysis can provide an upper bound to the performance of any sump as long as the geometric and flow parameters of the sump in question fall within the same general range as those represented in the test program.

The significant findings of this test program are summarized as follows: 
1) Surface vortex activity is not a reliable indicator of sump performance. Air ingestion, outlet swirl, and loss coefficient exhibited no consistant correlation with vortex activity.

2). Air ingestion levels remained generally below 2 percent void fraction. A few tests, under conditions of severely perturbed approach flows, coupled with low submergence and high flow rates, produced air ingestion levels up to 13 percent void fraction.

3 ) Outlet swirl angle generally remained less than 3

degrees--even with screen blockage and nonuniform approach flow. The maximum observed swirl angle of 8 degrees was produced during a screen blockage test.

4) Loss coefficients were found to be generally independent of geometric and flow parameters and are consistent with recommended handbook values.

5) The effects of severe, accident-induced flow perturbations, such as screen blockage, nonuniform approach flow and break-flow jet impingement, were minimal. in the majority of tests. In a few tests, however, a substantial increase in air ingestion was observed as a result of screen blockage or nonuniform approach flow. Also, several notable increases in outlet swirl angle were observed as a result of screen blockage.

6) The impingement of a break-flow jet and subsequent entrainment of air bubbles immediately outside of the sump screens did not result in increased air ingestion.

7) A cage-type vortex suppressor placed over each outlet, or a horizontal suppressor that was placed over the entire sump area, proved completely effective in reducing strong, air-core vortices to surface swirls--resulting in the elinlnation of all air ingestion.

8) In general, the performance of vertical outlet sumps is similar to that of horizontal outlet sumps. The only significant difference that was found was that higher levels of air ingestion were recorded for vertical outlet sumps during perturbed, low submergence and high flow rate conditions.

The results of tests on vertical outlet sumps, coupled with the results obtained previously for sumps with horizontal outlets, provide a substantial data base unon which design and review criteria can be formulated without resorting to full- or reduced-scale plant demonstrations. The results of this testing will aid in the resolution of Unresolved Safety Issue $A-43$

"Containment Emergency Sump Performance." 


\subsection{INTRODUCTION}

A general understanding of the operating characteristics of the emergency core cooling sump, including an assessment of any adverse effects resulting from factors associated with accident situations, is of importance to assuring adequate core cooling under recirculation conditions; improper sump hydraulic performance resulting from design deficiencies, and/or combinations of flow rate, submergence and geometric parameters or accident-related factors, may adversely affect the ability of an emergency core cooling system to adequately perform its function. Tests that have characterized the performance of sumps with horizontally oriented outlet pipes are reported in reference 1. The primary intent of the test program on vertical outlet sumps, reported here, was to characterize the overall hydraulic performance of vertical outlet sumps and identify any significant differences between the performance of horizontal and vertical outlet sumps. For this reason, the vertical outlet test program was reduced in magnitude from that of the horizontal outlet test program. Although reduced in scope from that of the work on horizontal outlets, the vertical outlet test program retains the same broad range of geometric and flow parameters that were considered for the horizontal outlet tests. The results of the current work are presented in such a manner so as to allow a direct comparison between the two sets of test results. The results of the test program presented here, coupled with those of the more extensive program for horizontal outlet sumps, has provided a significant data base characterizing the performance of emergency core cooling sumps.

Eight vertical outlet sump configurations were tested using two basic sump sizes; an $8 \mathrm{ft} \times 10 \mathrm{ft}$ sump with a depth of $4.5 \mathrm{ft}$ and a 16 ft $x 10 \mathrm{ft}$ sump with depths of $2.5 \mathrm{ft}$ and $4.5 \mathrm{ft}$. A11 eight sump configurations were tested under conditions of uniform approach flow. The uniform approach flow tests included the effects of outlet pipe location within the sump (with respect to the sump walls), and outlet protrusion (with respect to the sump floor).

Tests which established the effects of flow perturbations on sump performance were conducted for two of the eight configurations. Four approach flow perturbations, representative of accident produced flow conditions, were tested:

1) Screen blockage effects, such as would result if large quantities of miscellaneous debris were to be transported to the sump area and become trapped on the screens.

2) Nonuniform approach flow, resulting in large, specific circulations in the flow approaching the sump such as might arise from large obstructions or accumulated debris in the region of the sump.

3) Break-flow jet impingement immediately outside of the sump screens resulting in surface air entrainment and modification of the approach flow patterns.

4) The effects of transient flow conditions in the sump, such as those that might result during pump start-up, switch-over and shut-off procedures." 
The two perturbed flow configurations were also utilized to establish the effectiveness of two vortex suppression devices--a cage-type suppressor, similar to what was used in the horizontal outlet tests, and a horizontal suppressor that extended over the entire sump area. Both types were constructed of standard $1-1 / 2$ inch floor grating.

The behavior of the sump has been defined using four response parameters; vortex type, void fraction, outlet swirl angle and loss coefficient. The vortex type is a measure of an observed surface swirl and is based upon a scale of vortex severity that $r$ anges from a type 1 vortex (an incoherent surface swirl) to a type 6 vortex (a fully developed swirl with an air core to the outlet). Void

fraction indicates the quantity of air, by volume, that was ingested into the sump outlets. The outlet swirl angle is a measure of the average rotation of the flow field in the outlet pipes. The loss coefficient provided a measure of the hydraulic losses associated with the sump and outlet.

The values of the response parameters were monitored periodically durinq each test, then averaged over the duration of the test. Test durations were either 5-minutes or 30-minutes. The data therefore has been referred to as either 5-minute average or $30-m i n u t e$ average. Some references to shorter time averages of the data, specifically 1 -minute or .5 minute averages, have also been made. A detailed discussion of the effects of data averaging $t$ ime is $g$ iven in Reference 1 .

The three remaining chapters of this report consist of the following:

Chapter 2.0 presents the overall significant findings and conclusions obtained from the vertical outlet test program. A summary table of significant findings with supporting figures is also included in Chapter 2.0 .

Chapter 3.0 gives a description of the test plan, including definitions of geometric and response parameters, as they apply to vertical outlet tests. (Details of the overall test program, including that portion pertaining to horizontal outlet sumps, can be found in Reference 1.)

A detailed presentation of the hydraulic performance of the sump is given in Chapter 4.0. Chapter 4 has been divided into several subsections and includes the general hydraulic performance as a function of the Froude number, including maximum response plots (4.1), an upper bound envelope analysis (4.2), results of uniform flow tests and outlet location effects (4.3), the effects of flow perturbations (4.4), vortex suppressor effectiveness (4.5), and comparisons with comparable horizontal outlet tests (4.6).

The envelope, or bounding curves, presented in Chapter 4, are particularly useful in the definition of upper bound values of sump response. The maximum values of response for any specific sump can be determined as long as its geometric and flow parameters fall within the range of those included in the test program. 
Data compiled from tests of eight vertical outlet sump configurations have shown, in general, no major differences from the data that was obtained for sumps with horizontal outlets (Reference 1 ). The hydraulic behavior of vertical outlet sumps, which has been characterized with data from approximately 100 30-minute tests and 4005 -minute tests was seen to deviate in only a few specific tests from the behavior of sumps with horizontal outlets. Vertical outlet sumps and horizontal outlet sumps appeared primarily to differ in levels ( 8 by volume) of air ingestion. Values for swirl angle, vortex activity, and loss coefficient (excluding losses incurred for the $90^{\circ}$ elbow of the vertical outlet) remained essentially unchanged from those values for the horizontal outlet tests. A brief discussion of the hydraulic performance of sumps with two vertical outlets is given below. A summary of the conclusions, with supporting figures, is given in Table 2.1.

\subsection{Air Withdrawal (All Tests)}

Air ingestion levels for vertical outlet configurations remained generally below 2 percent void fraction for 30-minute averages and remained below 4 percent void fraction for 1 -minute averages: Several tests with severely perturbed flow conditions did, however, produce air ingestion levels as high as 12 percent void fraction for 30-minute averages and as high as 19 percent void fraction for 1 -minute averages. Higher levels of air ingestion ( $>2$ percent) were seen to occur for tests with Froude Numbers greater than 0.8 (Flow rate $>4000 \mathrm{gpm} / \mathrm{pipe}$ and submergence $<6 \mathrm{ft}$ ). Air ingestion greater than 2 percent void fraction (30-minute coverage) was not observed for submergences greater than $6 \mathrm{ft}$, regardless of flow perturbations or flow rate. The corresponding 1 -minute averages were less than 4 percent void fraction. There was no correlation seen between air ingestion and vortex severity; Type 6, air-core vortices resulted in air ingestion which ranged from less than 0.3 percent to 13.0 percent void fraction (30-minute average).

In general, air ingestion for vertical outlet sumps was slightly higher than the air ingestion levels recorded for sumps with horizontal outlets under comparable conditions. The bulk of the data for vertical outlets (30-minute average) fell below 2 percent void fraction as compared with the horizontal outlet tests which resulted in the bulk of the air ingestion data falling below 1 percent void fraction (30-minute average). The maximum vertical outlet air ingestion was 13 percent void fraction (30-minute average) while the maximum horizontal outlet air ingestion was 7 percent void fraction (30-minute average). The maximum 1-minute average air ingestion for vertical outlets was 19 percent void fraction while the horizontal outlet tests produced a 1 -minute average maximum air ingestion of 15 percent void fraction.

\subsection{Free-Surface Vortices}

Vortex type data showed no functional dependence on swirl angle, air ingestion, or loss coefficient and are, therefore, not reliable indicators of overall sump performance other than to establish the occurence of pump air ingestion in the presence of an air-core vortex. 
No consistent trends of vortex severity with geometric or flow parameters were seen. Some tests showed an increase in vortex severity with an increase in the Froude number, whereas other tests indicated the opposite trend (a decrease in vortex activity with an increase in the Froude number), especially at higher froude

numbers. (Note that the Froude number, $U / \sqrt{g s}$, can be increased by an increase in the flow velocity, $U$, for a constant submergence, $s$, or also by a decrease in the submergence for a constant flow velocity. The gravitational constant is g.) An increase in the general level of turbulence in the sump, as a result of a higher flow rate and a lower submergence, tended to inhibit the formation of vortices in some tests.

Sumps with vertical outlets showed vortex behavior consistent with the vortex behavior that was seen in sumps with horizontal outlets.

\subsection{Outlet Swirl}

The outlet swirl angle (measured at 25.5 to 29.5 diameters downstream trom the outlets) did not exceed 3 degrees for the majority of the tests, including those tests with severe approach flow perturbations. Several larger values of outlet swirl were, however, recorded; the maximum .5 minute average value for outlet swirl was 8 degrees and was produced during a screen blockage test. The corresponding 30-minute average was 7 degrees.

No functional dependence between the swirl angle and vortex activity was found--possibly the result of submerged vortices which were present during many of the tests and were sometimes seen attached to the sump wall. (The contributions of submerged vortices to the outlet swirl, without their inclusion in the vortex type data, may be responsible, in part, for the lack of correlation between outlet swirl and vortex severity.) Some evidence of increased outlet swirl with decreased submergence, at a constant flow rate, was seen for configurations with the outlet close to the sump wall. This trend may also be a result of submerged vortex activity, in that no such trend was observed for tests where the outlets were located at the center of the sump.

The outlet swirl performance for vertical outlet sumps showed no major deviation from the performance of outlet swirl observed for sumps with horizontal outlets.

\subsection{Head Losses}

The loss coefficient, which includes screen losses, pipe entrance losses, and losses at a short radius bend downstream of the outlet, which was required by experimental constraints, fell within the range of 0.9 to 1.2 for the protruding pipe entrance. The loss coefficient for tests wi.th the outlet mounted flush with the floor ranged between 0.7 and 0.9 .

The values of loss coefflclent for both the protruding and flush mounted outlets agreed well with standard handbook values. very slight dependence of loss coefficient on swirl angle was evident--larger values of the swirl angle were accompanied by slightly greater values of the loss coefficient. Other than this slight swirl angle dependence, no general dependence on any other factor, including surface vortex activity and flow perturbation, was observed. 
No difference between the head loss data for vertical outlet sumps and that for sumps with horizontal outlets was observed, aside from the additional contribution of the $90^{\circ}$ elbow downstream of the vertical outlet (the loss coefficient for the elbow is, $\left.C_{1}=0.2-0.3\right)$, which was not present during the horizontal outlet tésts.

\subsection{The Effect of Flow Perturbations on Vertical Outlet Sumps}

\section{$\underline{2.5 .1}$ Screen Blockage}

Some increase in the outlet swirl angle was observed for tests that were repeated with several different screen blockage schemes. The general increase, as a result of screen blockage, for the majority of the vertical outlet tests was less than 2 degrees (30-minute average). Several tests, however, exhibited increases in outlet swirl as great as 6 degrees (30-minute average).

The typical increase in air ingestion, as a result of screen blockage, was approximately 1 percent void fraction (30-minute average) over the unperturbed case for all but three tests. The largest increase in 30-minute average air ingestion, as a result of screen blockage, was approximately 13 percent void fraction. This increase occurred during two tests.

\subsubsection{Nonuniform Approach Flow}

Some nonuniform approach flow schemes (particularly streaming) resulted in a few specific cases of increased air ingestion greater than 1-2 percent void fraction (30-minute average) over the unperturbed cases. The greatest of these exhibited an increase of approximately 7 percent void fraction. Increased air ingestion, as a result of nonuniform approach flow, was observed to be limited to about 1 percent void fraction for the majority of tests.

\subsubsection{Drain and Break Flow}

Although a quantity of surface air entrainment was produced by the impacting break-flow jet, there were no measurable increases in total air withdrawal. Surface turbulence, caused by the impacting jet of water, prevented any vortex formation and resulted in the low levels of air ingestion recorded for these tests. $A$ general increase of $1-2$ degrees in outlet swirl was observed.

\subsubsection{Transient Flow}

Under conditions of transient flow, momentary type 6 vortices were observed. However, no air withdrawals greater than 5 percent void fraction (1-minute average) were observed.

\subsubsection{Vortex Suppression Devices}

Standard 1-1/2 inch floor grating, whether placed horizontally over the entire sump or used to fabricate cage-type suppressors, which were then placed over each outlet pipe, proved totally effective in prohibiting the formation of air-core vortices. air ingestion was reduced to zero while outlet swirl and loss coefficient remained generally unaffected. 
2.6 Comparison Between The Perturbed Flow Performance of Vertical and Horizontal Outlet Sumps

With the exception of a few vertical outlet tests which produced maximum air ingestion levels somewhat higher than the maximum levels observed in tests of horizontal outlet sumps, the general performance of vertical outlet sumps and sumps with horizontal outlets was found to be comparable under conditions of severely perturbed approach flow.

\subsection{The Effects of Outlet Location and Protrusion}

There were no consistent trends or general effects that would indicate any performance sensitivity on outlet protrusion or location. The largest 1-minute average'air ingestion (19 percent void fraction) occurred, however, in a test with zero pipe projection at a high flow rate (5300 gpm/pipe) and a low submergence ( $3 \mathrm{ft}$ ) during a screen blockage test.

\subsection{Closure}

The maximum observed values of outlet swirl, air ingestion, and loss coefficient for all of the tests performed on vertical outlet sumps are provided in Table 2.2

Because of the lack of consistent trends or correlations between dependent and independent parameters, an envelope curve presentation of the results has proven to be an effective means for the characterization of sump hydraulic behavior. Although it is not possible to predict the hydraulic behavior of individual sumps, the envelope analysis can provide an upper bound to the response. The envelope curve is valid for any sump with geometric and flow conditions that fall within the wide range of conditions that were used to define the envelope curves. 
Table 2.1

\section{Significant Findings summary}

Vertical Outlet Sumps

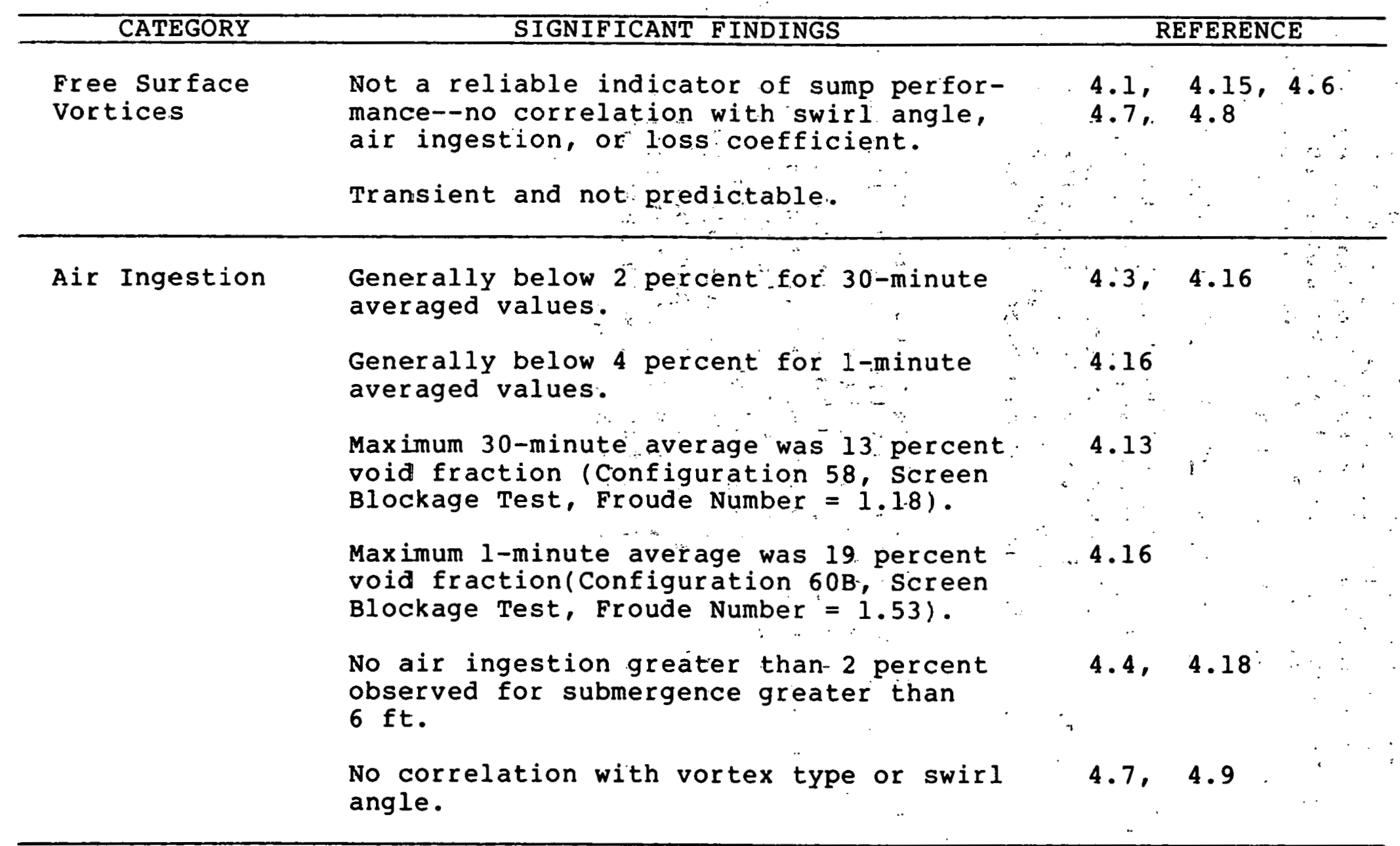


Table 2.l (Continued)

Significant Findings summary

Vertical Outlet Sumps

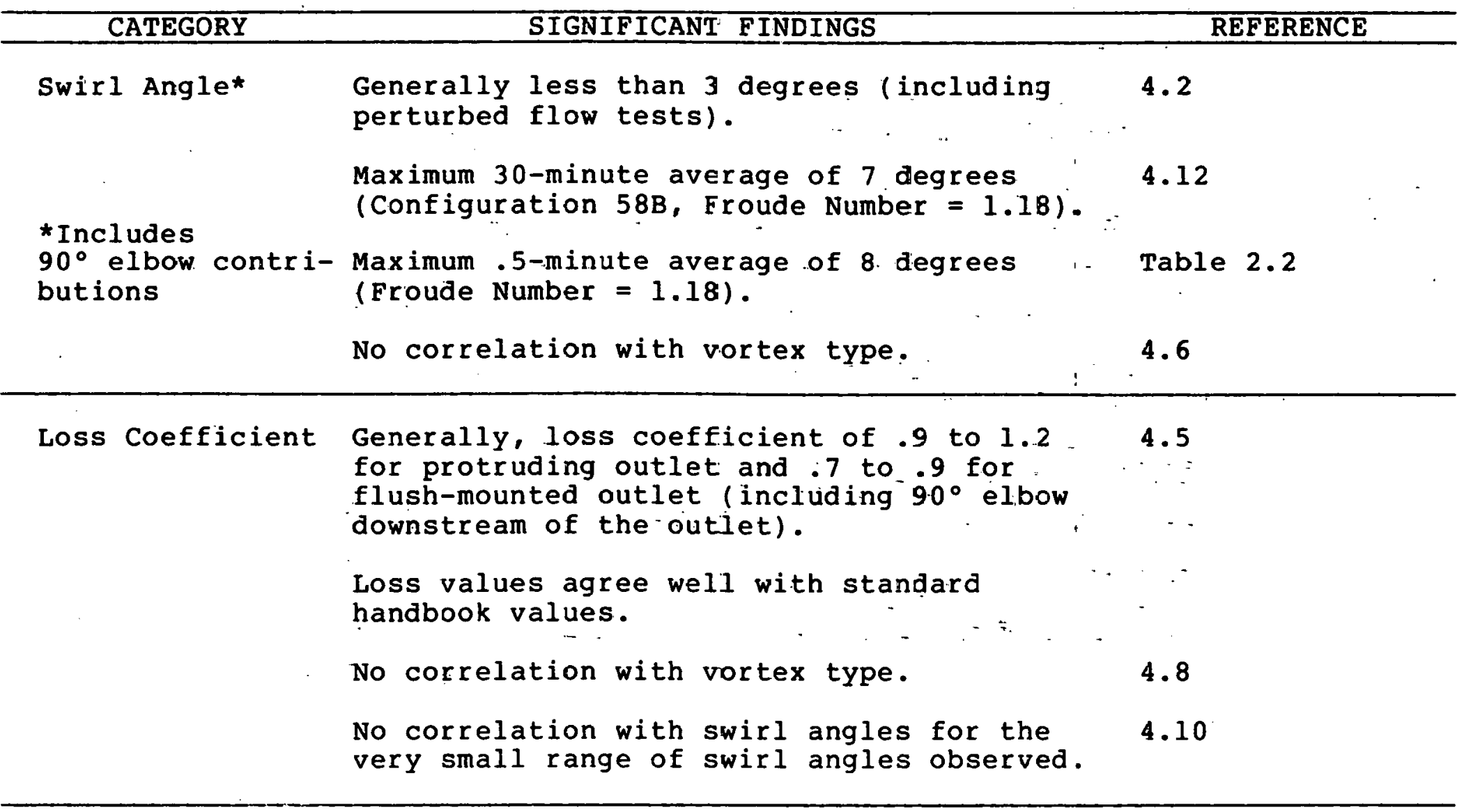


Table 2.1 (Continued)

significant Findings summary

Vertical outlet sumps

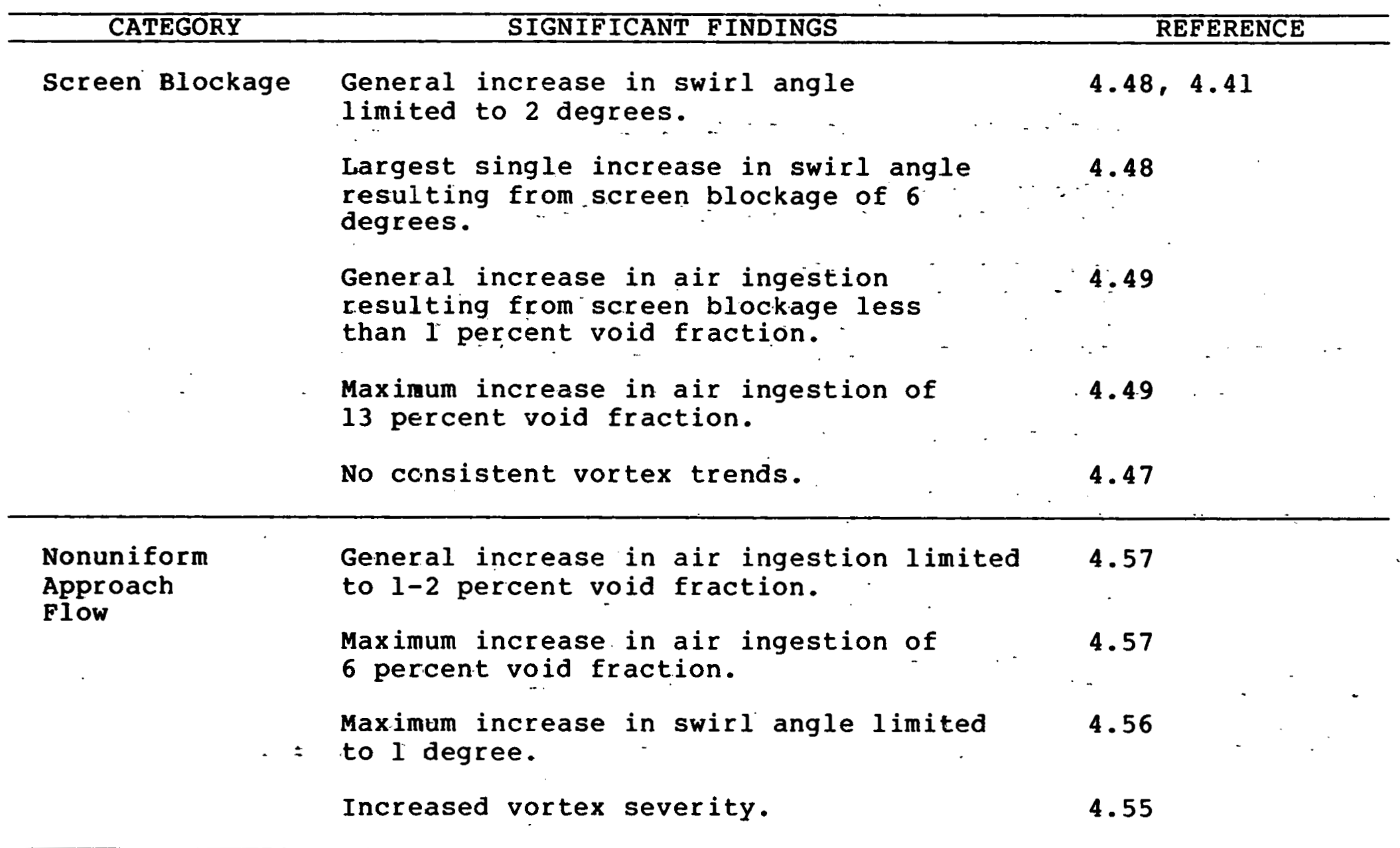


Table 2.1 (Continued)

\section{Significant Findings summary}

Vertical outlet sumps.

\begin{tabular}{|c|c|c|}
\hline CATEGORY & SIGNIFICANT FINDINGS & REFERENCE \\
\hline $\begin{array}{l}\text { Drain and Break- } \\
\text { flow Jet } \\
\text { Impingement }\end{array}$ & $\begin{array}{l}\text { No increase in air ingestion. } \\
\text { Increases in swirl angle limited to } \\
1-2 \text {.degrees. } \\
\text { vortex type unaffected. } \\
\text { Large quantities of entrained air near } \\
\text { surface not drawn into outlet. }\end{array}$ & $\begin{array}{l}4.61 \\
4.60 \\
4.59\end{array}$ \\
\hline Transient Flow & $\begin{array}{l}\text { strong momentary vcrtices. } \\
\text { Maximum } 5 \text {-minute averaged air ingestion } \\
\text { limited to } 4 \text { percert void fraction. } \\
\text { some increase in . } \\
\text { angle.minute average swirl }\end{array}$ & $\begin{array}{l}4.64 \\
4.64\end{array}$ \\
\hline $\begin{array}{l}\text { Vortex } \\
\text { Suppressors }\end{array}$ & $\begin{array}{l}\text { Complete suppressicn of air-ccre vortices. } \\
\text { Reduction of all air ingestior to zero. } \\
\text { Swirl angle increased slightly in some } \\
\text { tests and decreased slightly in other } \\
\text { tests. } \\
\text { Some reduction in loss coefficient. }\end{array}$ & Table 4.1 \\
\hline
\end{tabular}


Table 2.1 (Continued)

Significant Findings summary

Vertical Outlets sumps

Pexformance Comparison Between Vertical outlet and Horizontal Outlet Sumps

\section{Unperturbed Flow:}

In general, few significant differences for unperturbed flow tests.

$4.66-4.77$

single maximum swirl angle value slightly less for vertical outlet.

Single maximum air ingestion value for vertical outlet about 2.5 percent void fraction lower than that for unperturbed horizontal outlet sumps.

\section{Perturbed Flow:}

In general, few significant differences for perturbed flow tests.

30-minute air ingestion agree within 1 percent void fraction.

Single maximum air ingestion value for vertical outlet about 6 percent void fraction greater than that for horizontal outlet.

Single maximum swirl values were the same for both outlet orientations.

In general, vertical outlet slightly more sensitive to perturbed flow air ingestion. All other responses similar between vertical and horizontal outlet sumps. 
Table 2.2

Maximum Recorded Values for Verticai Outlet Tests

Swirl Angle

\begin{tabular}{c}
$\begin{array}{c}\text { Configuration } \\
\text { Number }\end{array}$ \\
\hline
\end{tabular}

58

$58 \mathrm{~B}$

$60 A$

$60 \mathrm{~B}$

$\begin{gathered}\text { Configuration } \\ \text { Number }\end{gathered}$
\[ \quad 58 \]
$58 \mathrm{~B}$
$60 \mathrm{~A}$
$60 \mathrm{~B}$
$\begin{gathered}\text { 30-Minute } \\ \text { Average }\end{gathered}$
0.5 Minute
Average $\quad \begin{gathered}\text { Flow Rate } \\ \text { (gpm/pipe) }\end{gathered}$

4.6
6.5
2.2
0.7

\begin{abstract}
5.6
\end{abstract}

$$
8.0
$$

3.3

2.2

3000
5300
5300
5300

Void Fraction

\begin{tabular}{rrr}
$\begin{array}{c}\text { 30-Minute } \\
\text { Average }\end{array}$ & $\begin{array}{c}\text { 1-Minute } \\
\text { Average }\end{array}$ \\
\cline { 1 - 1 } 12.8 & & 16.8 \\
7.4 & & 8.1 \\
7.3 & & 12.2 \\
12.8 & 19.1
\end{tabular}

\section{Loss Coefficient}

\begin{tabular}{c}
$\begin{array}{c}\text { Configuration } \\
\text { Number }\end{array}$ \\
\hline
\end{tabular}

58

$58 \mathrm{~B}$

$60 \mathrm{~A}$

$60 \mathrm{~B}$

\begin{abstract}
0.5 Minute Average
\end{abstract}

$$
\begin{aligned}
& 1.86 \\
& 1.43 \\
& 1.24 \\
& 1.65
\end{aligned}
$$

0.5 secor.d Average

$\begin{array}{ll}-- & 5300 \\ -- & 5300 \\ -- & 5300 \\ -- & 5300\end{array}$
Submergence ft)

\section{5}

\section{5}

2
3
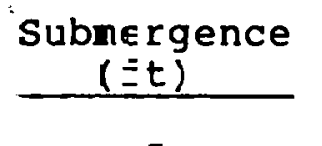

5
5
2
3

5300

5300
Froude Number

$$
\begin{aligned}
& 1.18 \\
& 1.18 \\
& 1.87 \\
& 1.53
\end{aligned}
$$

-

\begin{tabular}{r} 
Flow Rat \\
(gpm/pipe) \\
\hline 5300 \\
5300 \\
5300 \\
5300
\end{tabular}

\begin{tabular}{c}
$\begin{array}{c}\text { Subnergence } \\
(\mathbf{f t})\end{array}$ \\
\hline 5 \\
5 \\
2 \\
3
\end{tabular}

Froude Number

$$
\begin{aligned}
& 1.18 \\
& 1.18 \\
& 1.87 \\
& 1.53
\end{aligned}
$$

Froude

Number

$$
\begin{array}{r}
.67 \\
1.18 \\
1.87 \\
1.53
\end{array}
$$

Test Type

Screen blockage screen blockage Break-flow

Screen blockage

\section{Test Type}

Screen blockage screen blockage Streaming flow Screen blockage
Test Type

Screen blockage Screen blockage streaming flow Screen blockage 
Figure 3.1 shows the general layout of the sump and the. associated geometric parameters. The geometric parameters, given in Figure 3.1, although largely self-explanatory, have been defined in Table 3.1. The test matrix of values for each geometric variable is given in Table 3.2.

Two basic sump sizes were tested: $8 \mathrm{ft} \times 10 \mathrm{ft}$ (LxB) and 16 ft $\times 10 \mathrm{ft}$. The $8 \mathrm{ft} \times 10 \mathrm{ft}$ sump was tested with a depth of $3 \mathrm{ft}$, while the $16 \mathrm{ft} \times 10 \mathrm{ft}$ sump was tested at two depths: $3 \mathrm{ft}$ and 1 ft. Three outlet orientations, defined by the geometric parameters $e$ and $c$, were tested. The parameter $e_{y}$, which defines the distance between the outlet center 1 ine $y^{\prime}$ and the rear sump wall, was tested at values of $e_{y} / d=5 \mathrm{ft}$ and $e_{y} / d=1 \mathrm{ft}$. These values of e /d represented sumps with the outlets located both in the center of the sump width and one diameter from sump wall. The parameter $c$, defining the outlet pipe protrusion distance from the sump floor, was tested at $c / d=1.5 \mathrm{ft}$, representative of a typical outlet protrusion length, and also at $c / d=0$, representative of sumps with the outlets mounted flush with the floor. The three outlet orientations are shown in Figure 3.2. The geometric layout of the vertical outlet test has made several types of performance comparisons with horizontal outlet sumps possible.

While all of the test configurations shown in Table 3.2 were utilized for uniform (unperturbed) flow sump characterization, only two configurations, 58 and $60 \mathrm{~A}$, were tested under nonuniform (perturbed) flow conditions. Perturbed flow conditions included the effects of screen blockage, non-uniform approach flow and break-flow jet impingement. A separate test was also performed to determine sump response resulting from transient pump operations such as startup and switchover. The schemes used to produce screen blockage and non-uniform approach flows are shown in Figure 3.3 . Figure 3.4 illustrates the techniques used to model break and drain flow jet impingement.

Two test conflgurations found to result in the most severe vortices were used to test the effectiveness of two vortex suppression devices. The two configurations, configurations 58B and $60 \mathrm{~B}$, were tested with the cage type vortex suppressors shown in Figure 3.5 and also with a flat section of floor grating placed horizontally over the area of the sump (and always maintained below the water level).

The general procedure provided for tests to be conducted for periods of either 30 minutes (full tests) or for 5 minutes (survey tests). Full tests were performed for flow rates of $3000 \mathrm{gpm} / \mathrm{pipe}$ and $5300 \mathrm{gpm} / \mathrm{pipe}$. Survey tests were performed for flow rates ranging from $1500 \mathrm{gpm} / \mathrm{pipe}$ to $6000 \mathrm{gpm} / \mathrm{pipe}$. Table 3.3 shows the range of flow rates and water depths considered for each test series.

Sump performance was measured in terms of the following parameters:

a) Surface Vortex Severity - A defined scale of vortex severity was used to record vortex activity periodically during the course of any one test. A description of the surface vortex type scale is shown in Figure 3.6. The severity scale ranges from a type 1 vortex, describing an incoherent surface swirl, to a type 6 vortex, characterizen by a fully developed alr core to the outlet. 


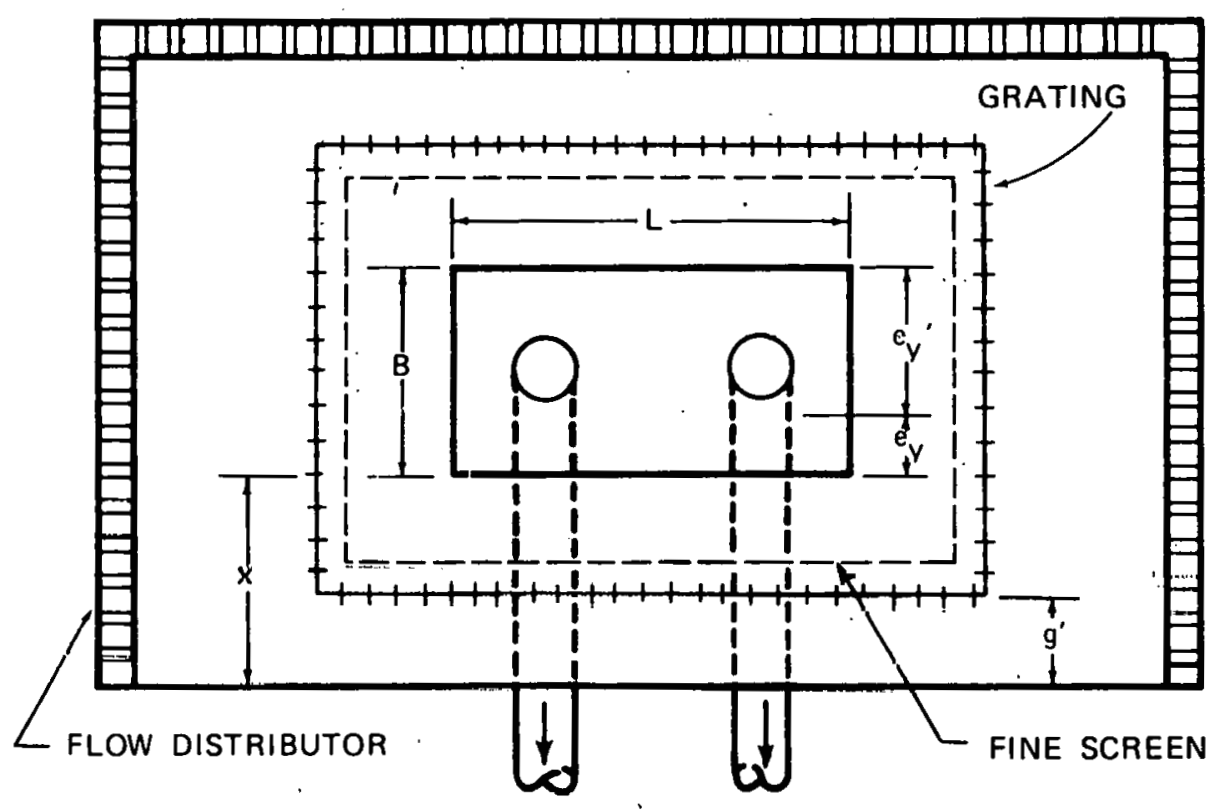

PLAN VIEW

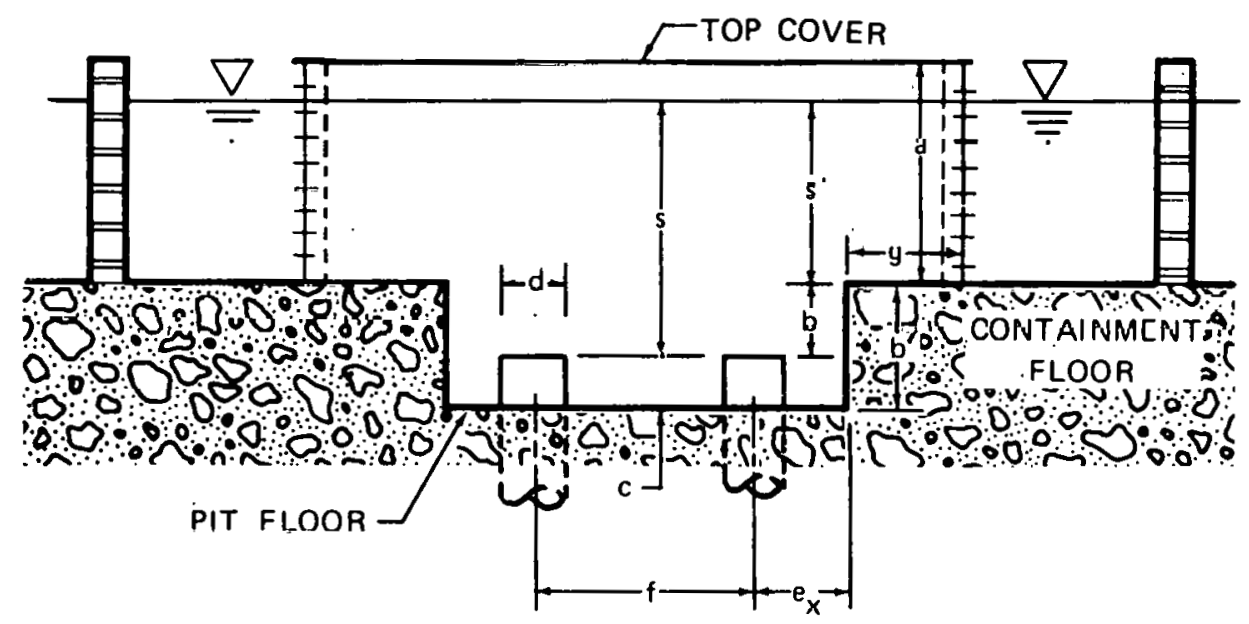

FRONT ELEVATION

Figure 3.1 Sump Layout and Geometric Parameters 


\section{Table 3.1}

Geometric Definitions and Flow Variables

$\mathbf{S}=$ Total outlet submergence (ft)

$s^{\prime}=$ Water depth above containment floor (ft)

$\mathrm{U}=$ outlet pipe velocity (ft/sec)

$\mathrm{Q}=\mathrm{Flow} / \mathrm{pipe}(\mathrm{gpm})$

d = Pipe diameter ( $f t)$

$L=$ Sump length $(f t)$

$B=$ Sump width (ft)

b $=$ sump depth to pipe entrance ( $f t$ )

$a=$ Cover plate height from containment floor (ft)

$\mathbf{x}=$ Distance from sump wall to containment wall (ft)

$c=$ Distance from pipe entrance to sump floor (ft)

$e_{x}=x$-direction pipe orientation length ( $\left.f t\right)$

$e_{y}=Y$-direction pipe orientation length ( $f t$ )

$\mathbf{f}=$ spacing between pipes (ft)

$g$ = Screen distance from sump wall ( $f t$ ) 
Table 3.2

\section{Dimensions for Vertical Outlet Sumps}

\begin{tabular}{|c|c|}
\hline & $\begin{array}{c}\text { Test } \\
\text { Configuration } \\
\text { Number }\end{array}$ \\
\hline & 58 \\
\hline & $58 A$ \\
\hline & $58 \mathrm{~B}$ \\
\hline \multirow{5}{*}{$\stackrel{\infty}{\infty}$} & 59 \\
\hline & $59 A$ \\
\hline & 60 \\
\hline & $60 \mathrm{~A}$ \\
\hline & $60 B$ \\
\hline
\end{tabular}

\begin{tabular}{l}
$\underset{\substack{\text { Sump } \\
(\mathrm{L} X \mathrm{~B})}}{\text { Size }}$ \\
\hline $8 \times 10$ \\
$8 \times 10$ \\
$8 \times 10$ \\
$16 \times 10$ \\
$16 \times 10$ \\
$16 \times 10$ \\
$16 \times 10$ \\
$16=10$
\end{tabular}

\begin{tabular}{cccccccccc}
\multicolumn{8}{c}{ Geometric Variables } & $(\mathrm{ft})$ \\
\hline $\mathrm{d}$ & $\mathrm{b}$ & $\mathrm{e}_{\mathrm{x}}$ & $\mathrm{g}$ & $\mathrm{f}$ & $\mathrm{c}$ & $\mathrm{a}$ & $\mathrm{x}$ & $\mathrm{e}_{\mathrm{y}}$ \\
\hline 1 & 3 & 2 & 1 & 4 & 1.5 & 6 & 7.5 & 5 \\
1 & 3 & 2 & 1 & 4 & 1.5 & 6 & 7.5 & 1 \\
1 & 3 & 2 & 1 & 4 & 0 & 6 & 7.5 & 1 \\
1 & 3 & 2 & 1 & 12 & 1.5 & 6 & 7.5 & 5 \\
1 & 3 & 2 & 1 & 12 & 1.5 & 6 & 7.5 & 1 \\
1 & 1 & 2 & 1 & 12 & 1.5 & 6 & 7.5 & 5 \\
1 & 1 & 2 & 1 & 12 & 1.5 & 6 & 7.5 & 1 \\
1 & 1 & 2 & 1 & 12 & 0 & 6 & 7.5 & 5
\end{tabular}



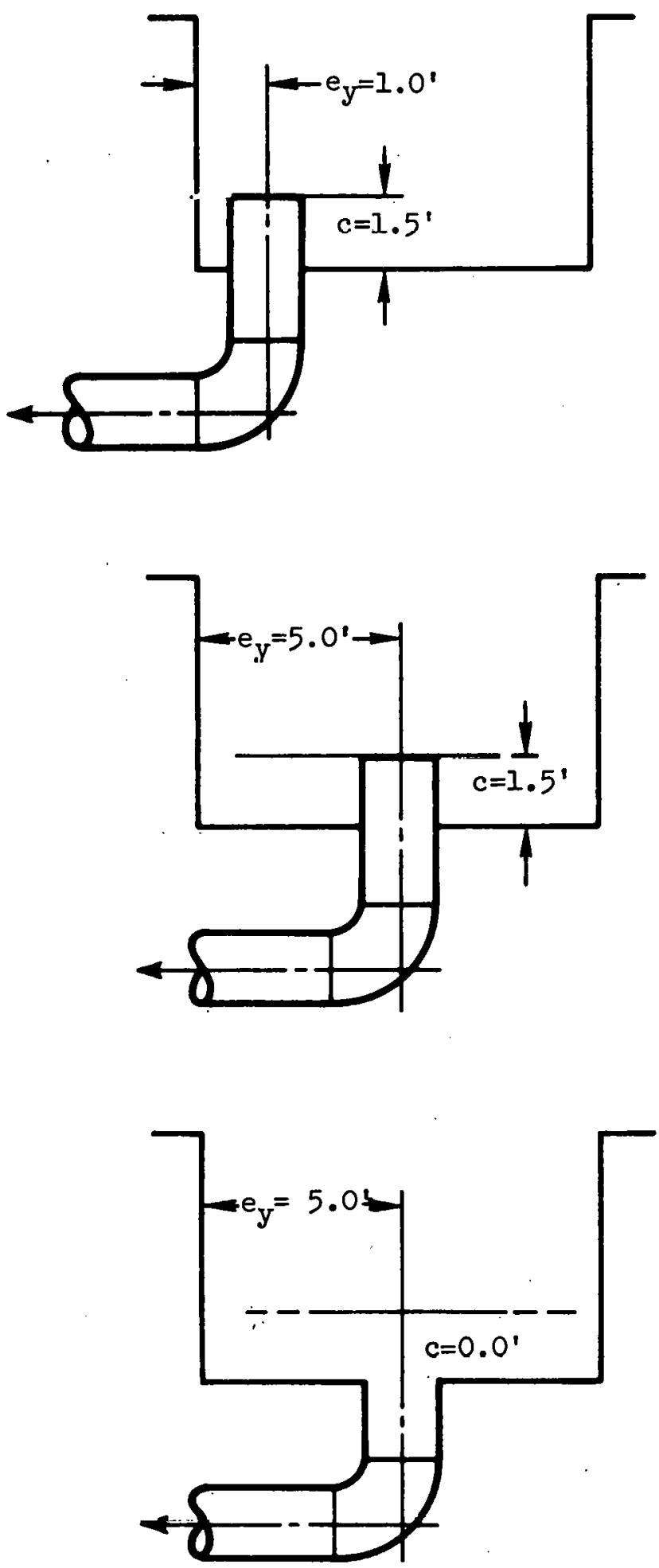

Figure 3.2 Outlet Orientations Defined by the Geometric Parameters $e_{y}$ and $c$ 


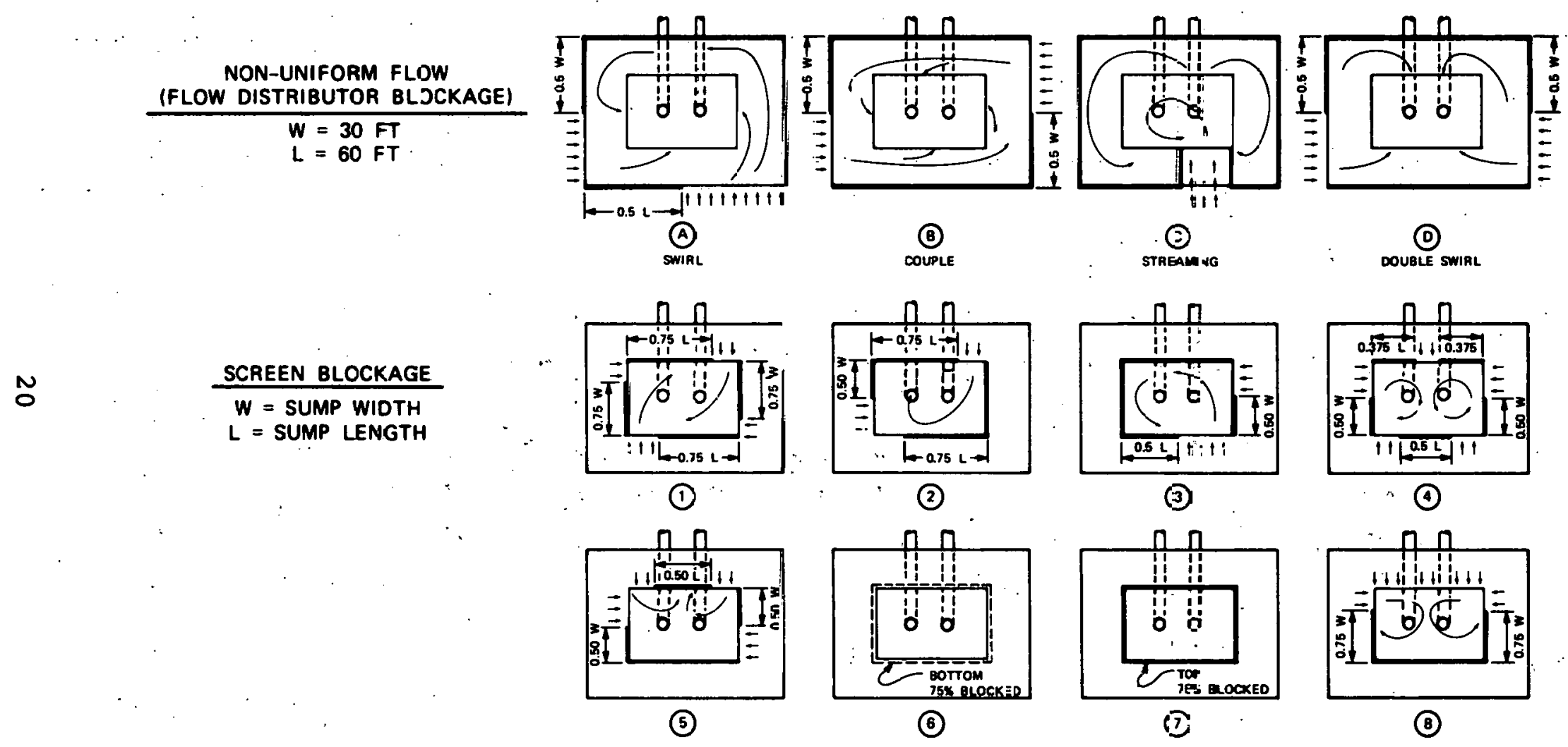

Figure 3.3 Nonuniform Epproach Flow and Screen Blockage Schemes 


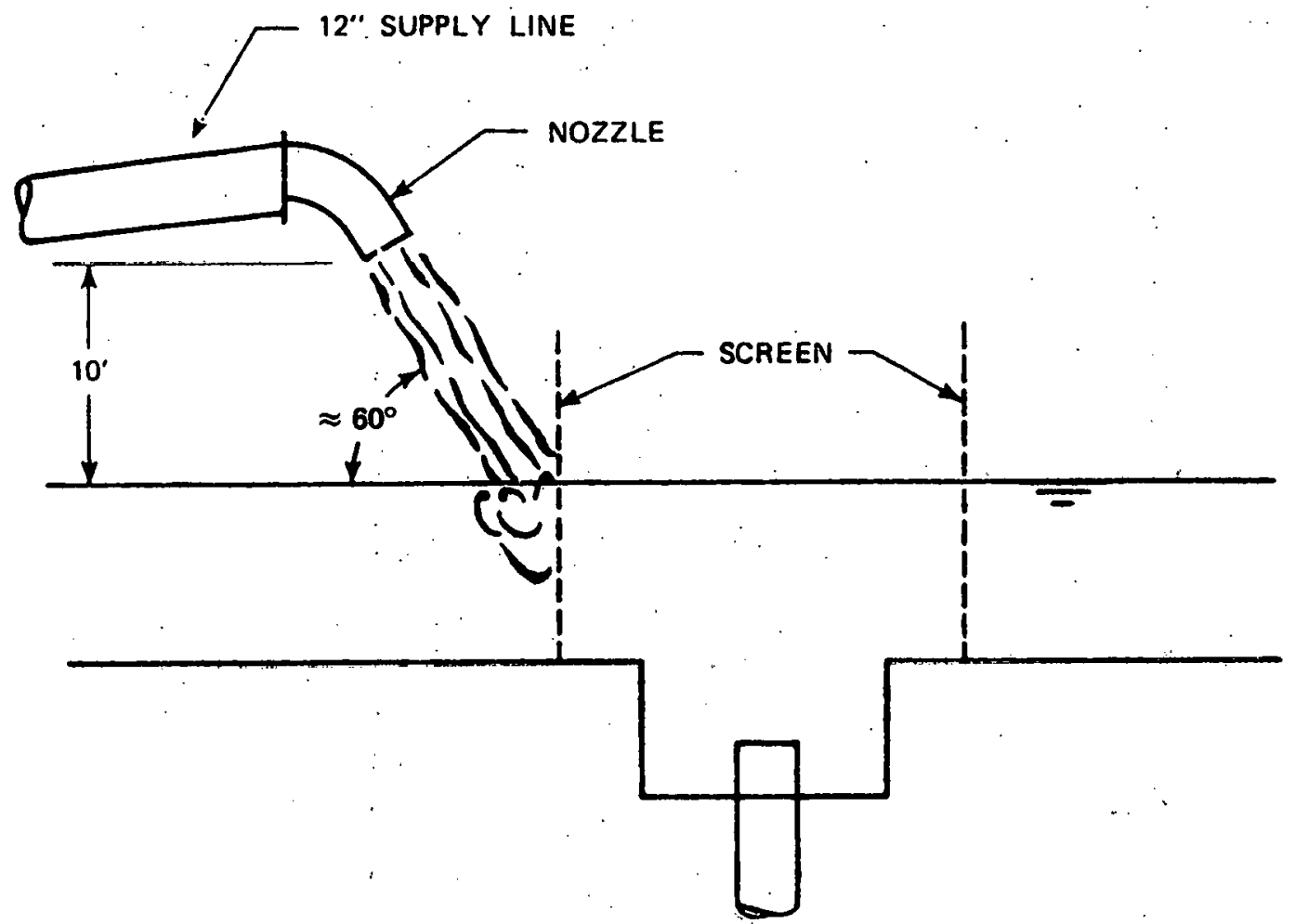

a. Break Flow Jet Impingement

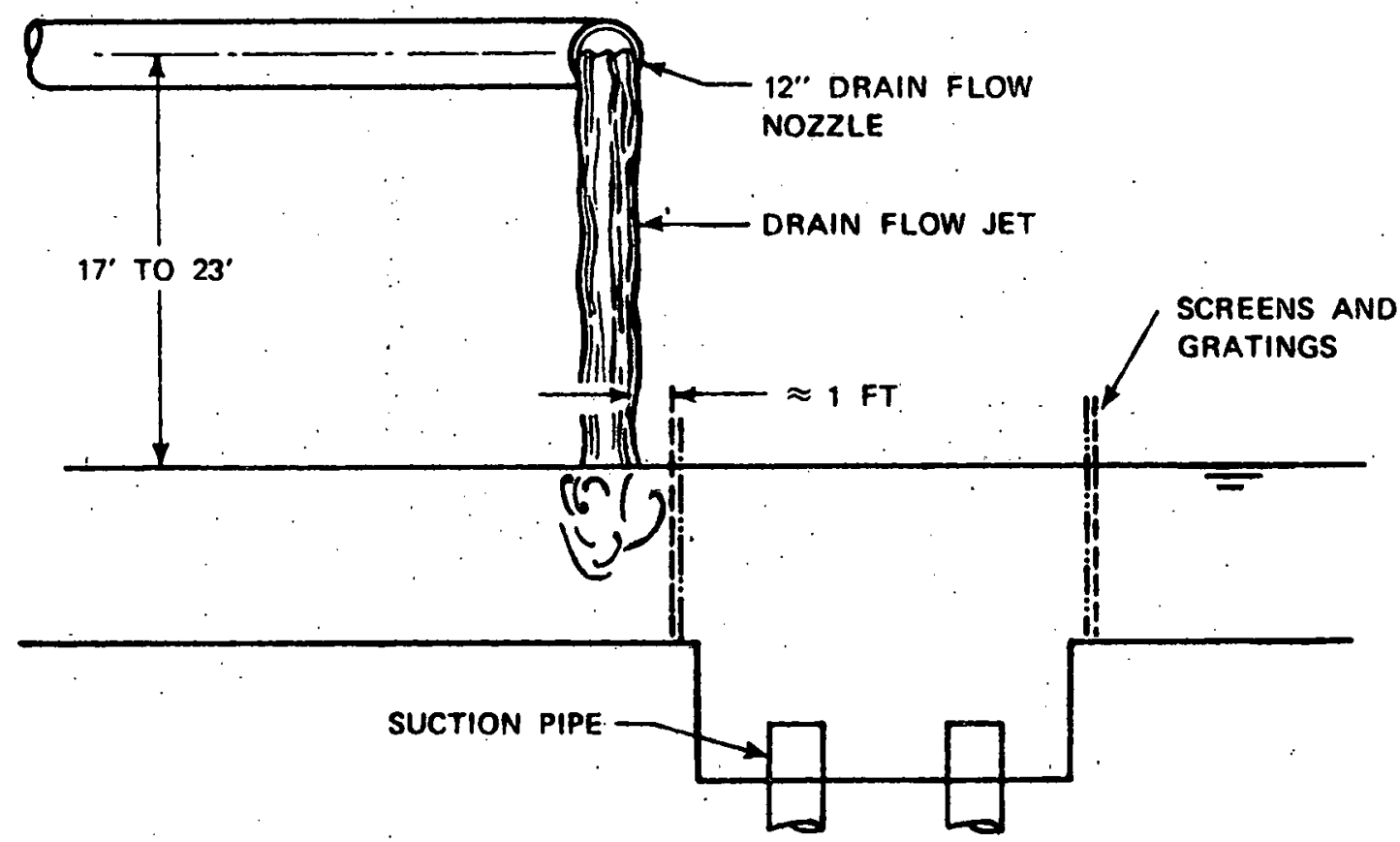

b. Drain Flow Jet Impingement

Figure 3.4. Break and Drain-Flow Jet Impingement 

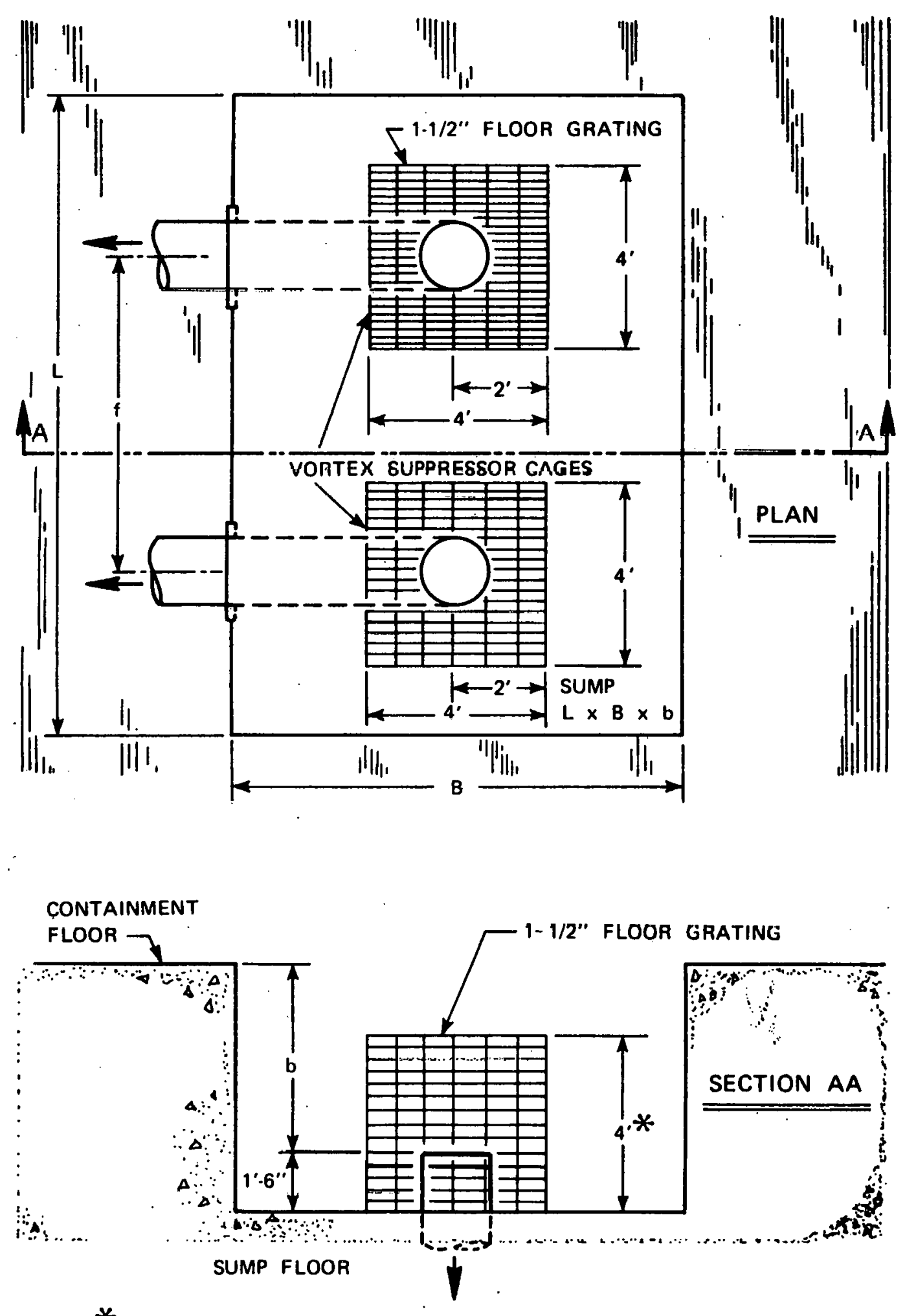

* height is 2' for b - 1' SUMPS

Figure 3.5 Vortex Suppressor Cage 
Table 3.3

Test Flows and Submergences

$\frac{\begin{array}{c}\text { Full Tests } \\ \text { (glows }\end{array}}{3000,5300} \begin{gathered}\begin{array}{c}(30 \text { Minutes }) \\ \text { Water Depth } \\ \left(s^{\prime}, \mathrm{ft}\right)\end{array} \\ 1,2,3,5\end{gathered}$

None Uniform Approach Flow Tests)

3. Perturbed Approach Flow Tests
a. Screen Blockage
b. Non-Uniform Approach Flow/
streaming
c. Break Flows Tested at Flows of 408 , and 608 of Total Flow

3000,5300

2,5

3000,5300

1,3

d. Transients

e. Vortex suppressors

$$
3000,5300
$$

Varied from 0 to 6000

3000,5300
1500,2500

3500,4500

$\frac{\text { Survey Tests }(5 \text { Minutes) }}{\text { Flows }}$ (gpm/pipe)

1500,2000 $(\mathrm{ft})$

2500,3500

4000,4500

5000,6000

5300

1

$1,2,3,5$

1500,2500

3500,4500

1,3

2,5

None

None

None

None:

1500,2500 3500,4500
2

*Above Containment Floor. 
VORTEX

TYPE

$\boldsymbol{1}$

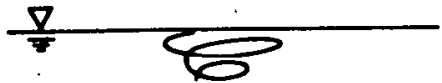

2

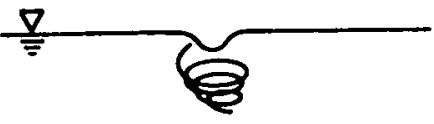

3

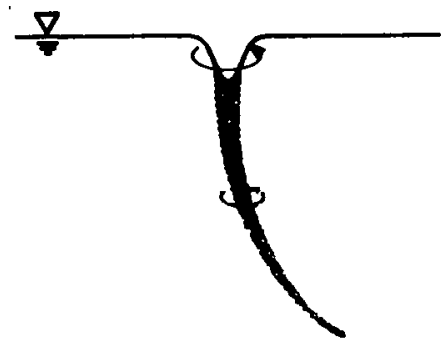

4

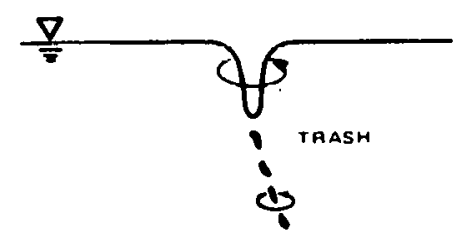

5

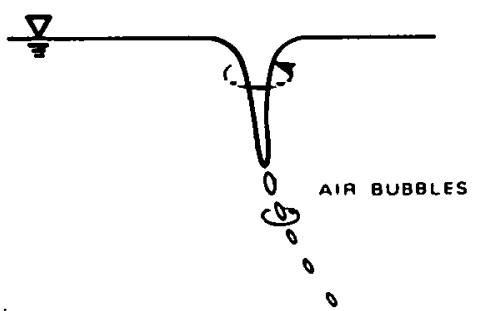

6

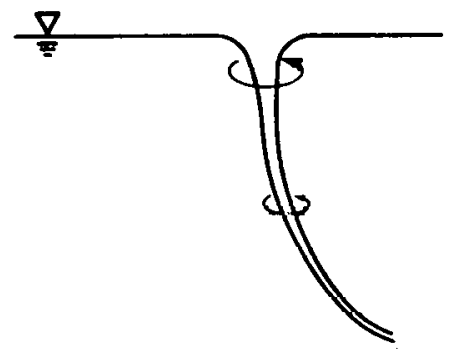

INCOHERENT SURFACE SWIRL

SURFACE DIMPLE;

COHERENT SWIRL AT SURFACE

DYE CORE TO INTAKE;

COHERENT SWIRL THROUGHOUT WATER COLUMN

VORTEX PULLING FLOATING TRASH, BUT NOT AIR
VORTEX PULLING AIR BUBBLES TO INTAKE

FULL AIR CORE

TO INTAKE

Figure 3.6 Vortex Classification Scale 
b) Outlet Swirl Angle - A measure of the swirl in the flow field within the outlet pipe was obtained with an instrument which letected the tangential component of flow velocity in the pipe. the outlet swirl angle was then calculated as the angle (in degrees) between the axial and tangential components of the velocity of the flow in the outlet pipes.

c) Air Ingestion - Air ingestion was determined by measurements of the void fraction (percent air) by volume of the flow in each outlet pipe.

d) Loss Coefficient - The overall sump loss coefficient was determined from an extrapolation of the hydraulic grade line measured in each outlet pipe back to the pipe entrance. The loss coefficient included contributions from screens and gratings, the pipe entrances, and a $90^{\circ}$ short radius elbow downstream of each entrance (required by experimental constraints).

Details concerning facility construction, measurement techniques and data acquisition methods are presented in Appendix $A$ and can also be found in references 1 and 2 . 


\subsection{RESULTS}

\subsection{General Overview of Sump Performance}

The general behavior of vertical outlet sumps is provided in this section and has been determined by: (1) a compilation of all of the 30-minute average test results, and (2), through plots of maximum observed, 30-minute average values of sump response. In the summary plots (section 4.1.1). two data sets present the general hydraulic performance of vertical outlet sumps: Figures 4.1 through 4.5 show the functional relationship between the dependent response parameters (vortex type, swirl angle, air ingestion and loss coefficient) and the independent flow parameters--primarily in terms of the Froude number. Both unperturbed and perturbed tests are represented in these Figures. Figures 4.6 through 4.10 show the relationships (or lack of) among the four above-noted response parameters. Finally, in section 4.1.2 single maximum observed values of sump response are plotted versus the Froude number, by configuration, for the case of unperturbed flow, and by configuration and perturbation type (screen blockage, non-uniform approach flow etc), for the case of perturbed flow tests.

\subsubsection{General Hydraulic Performance}

Vortex severity was found to be generally independent of geometric or flow conditions within the sump. Figure 4.1 shows this behavior; the full range of vortex types was seen to be represented at every value of the froude number that was tested. No trends or upper bounding curves are evident from Figure 4.1. The lack of consistency in the vortex activity of the sumps tested in this program has precluded the possibility of using vortex severity to define the performance of a sump.

Figure 4.2 shows the levels of outlet swirl angle plotted as a function of the Froude number. No dependence on the Froude number was found. The majority of all swirl angle data remained well below 3 degrees, and was distributed quite uniformly across the entire Froude number range. Although no dependence of swirl angle on flow parameters (Froude number) is evident, the results of Figure 4.2 can be used to develop an upper boundary of expected swirl angle intensities as a function of the froude number (Section 4.2).

Higher values of the Froude number resulted in greater 1 evels of air ingestion. This trend is shown on Figure 4.3, where void fraction has been plotted as a function of the Froude number. Most air ingestion, including that measured in sumps with severely perturbed flow conditions, was found to remain below 2 percent void fraction. Levels greater than 2 percent void fraction occurred for flow conditions where the Froude numbers greater than $F=1.0$. No air ingestion greater than about 1 percent void fraction was recorded for submergences deeper than 6 ft (Figure 4.4). 

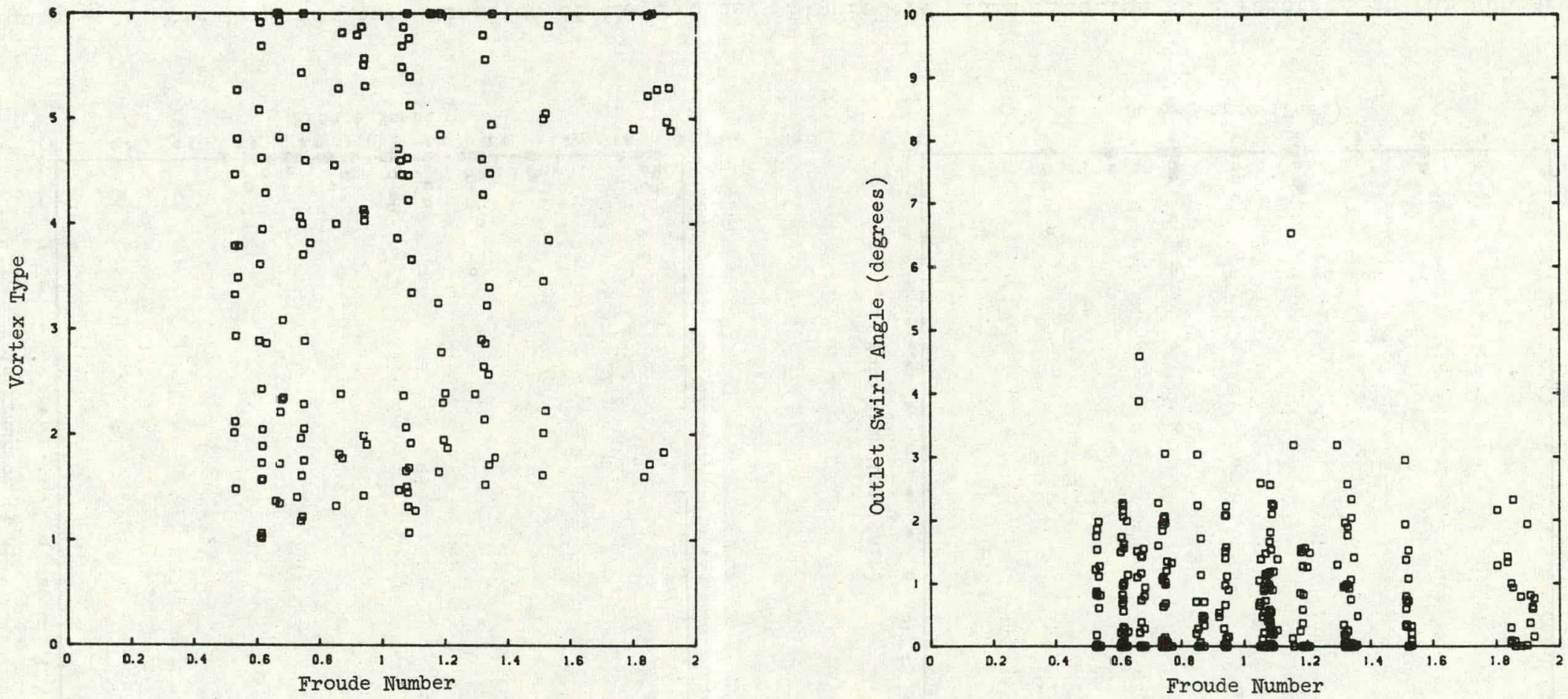

Figure 4.1 Vortex Type as a Function of the Froude Number for All 30-Minute Average Data

Figure 4.2 Outlet Swirl Angle as a Function of the Froude Number for All 30-Minute Average Data 

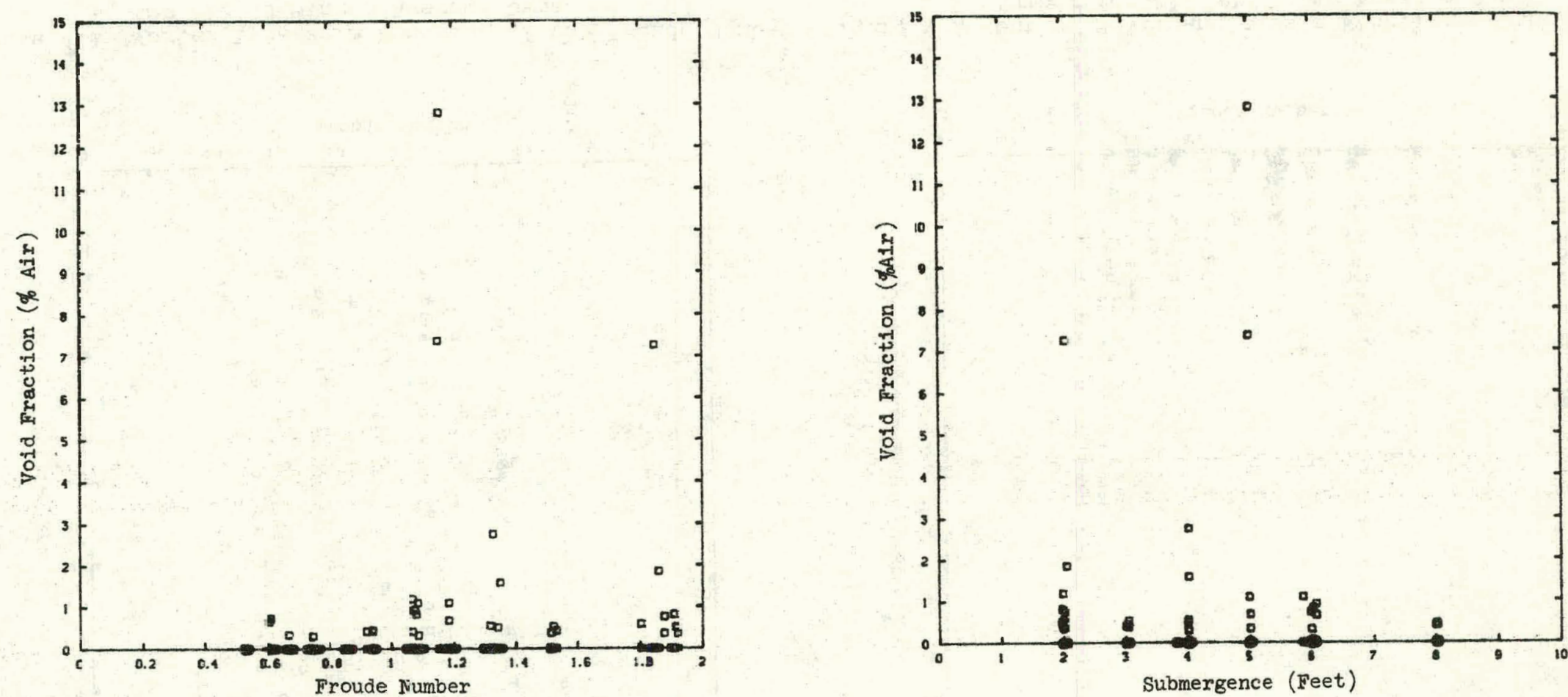

Figure 4.3 Void Fraction as a Function of the Froude Number for All 30-Minute Average Data

Figure 4.4 Void Frastion as a Function of the Submergence for $\mathrm{All}$ 30-Minute Average Data 


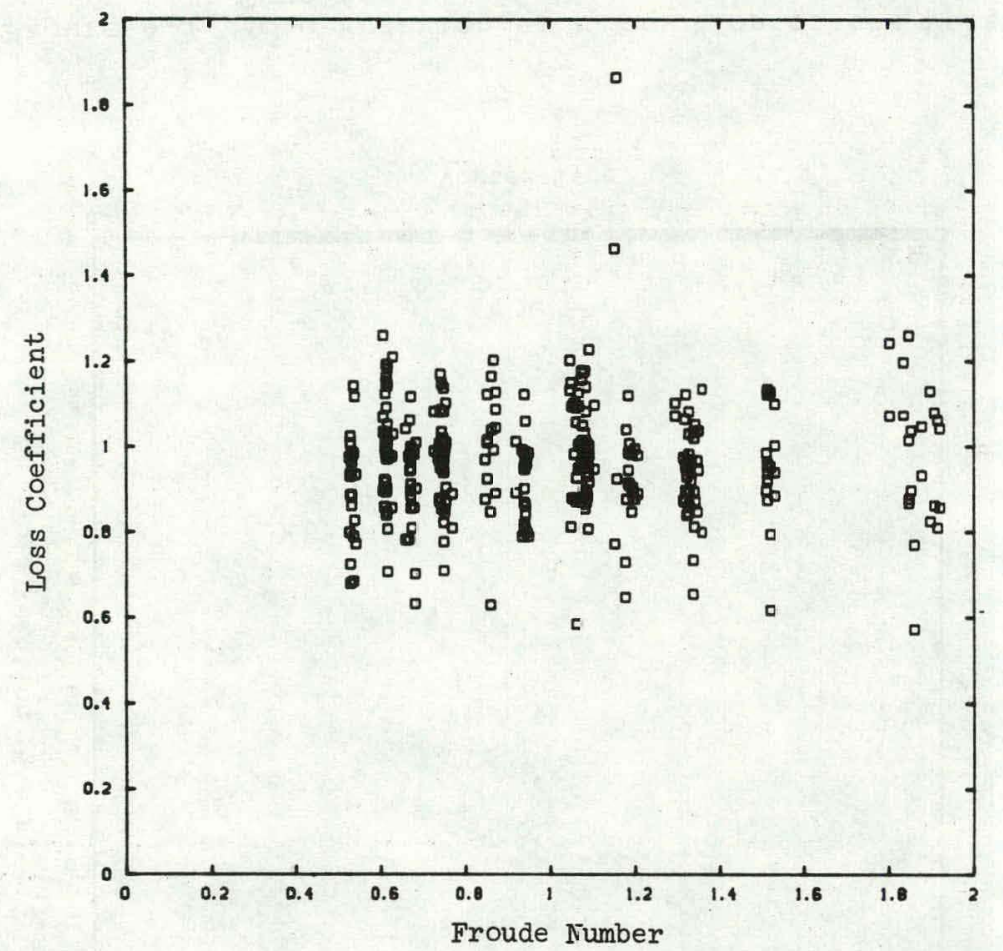

Figure 4.5 Loss Coefficient as a Function of the Froude Number for All 30-Minute Average Data

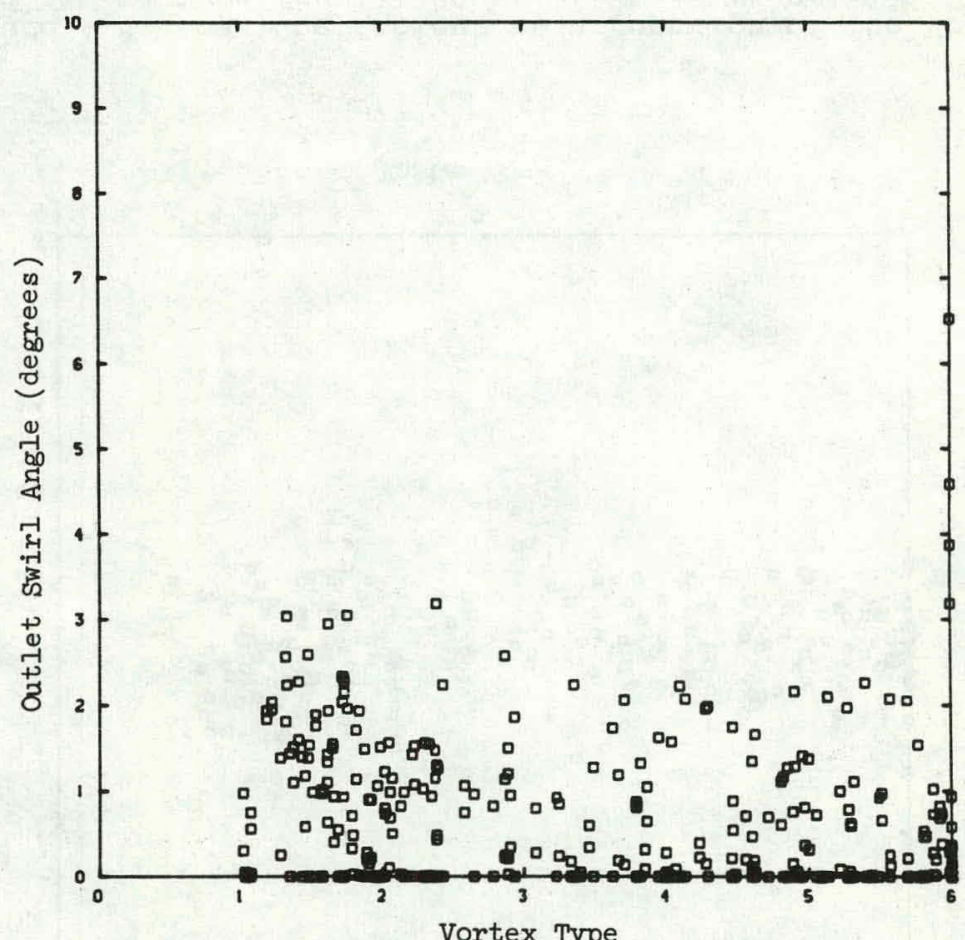

Figure 4.6 Outlet Swirl Angle as a Function of Vortex Type for All 30-Minute Average Data 


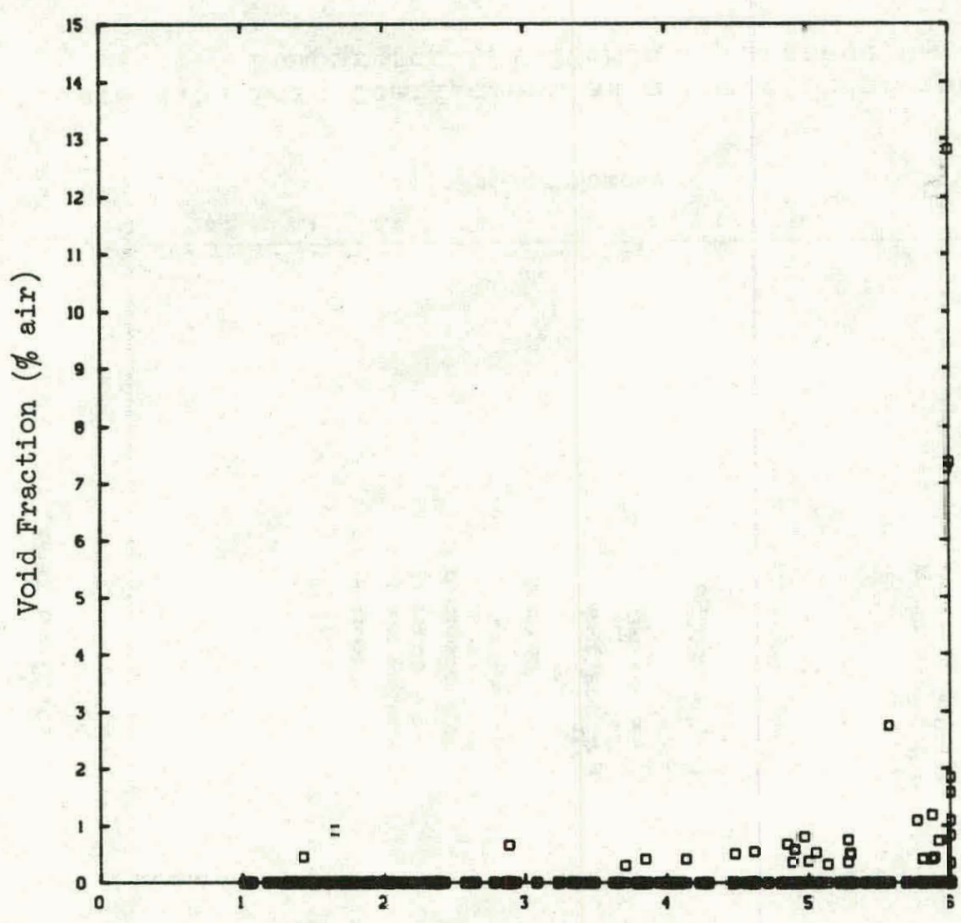

Vortex Type

Figure 4.7 Void Fraction as a Function of the Vortex Type for All 30-Minute Average Data

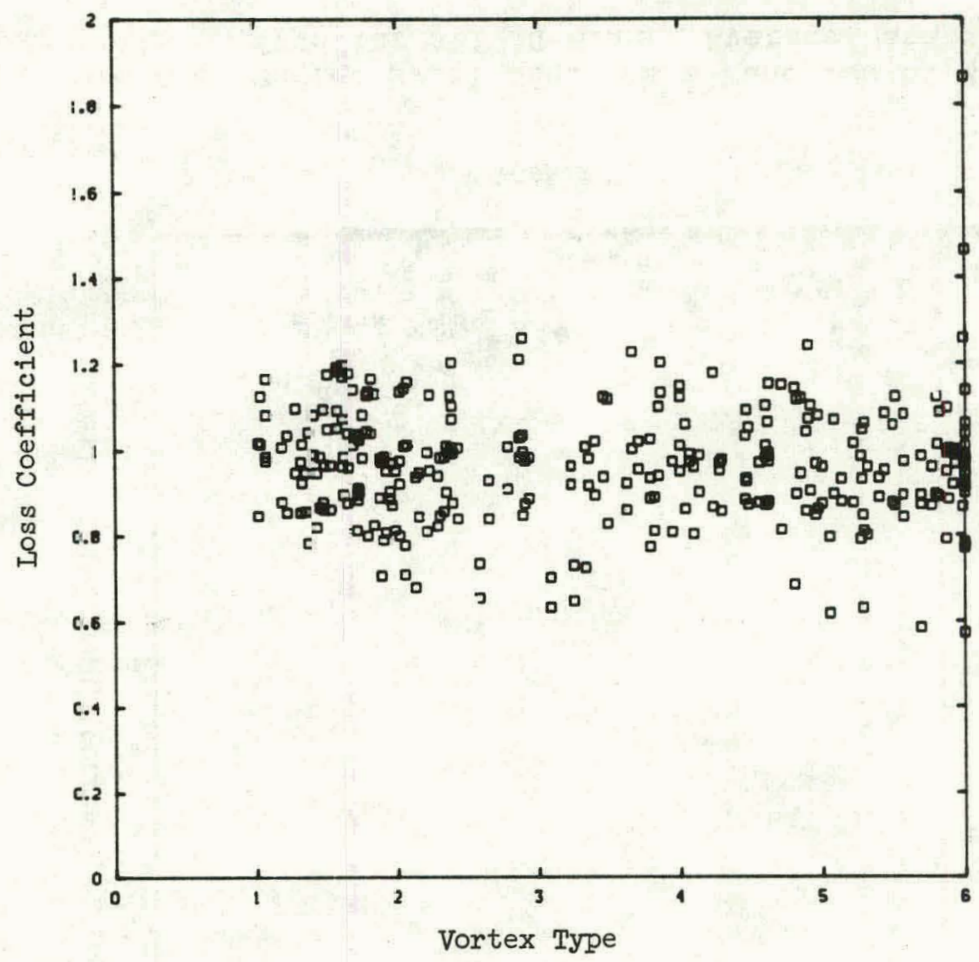

Figure 4.8 Loss Coefficient as a Function of the Vortex Type for All 30-Minute Average Data 


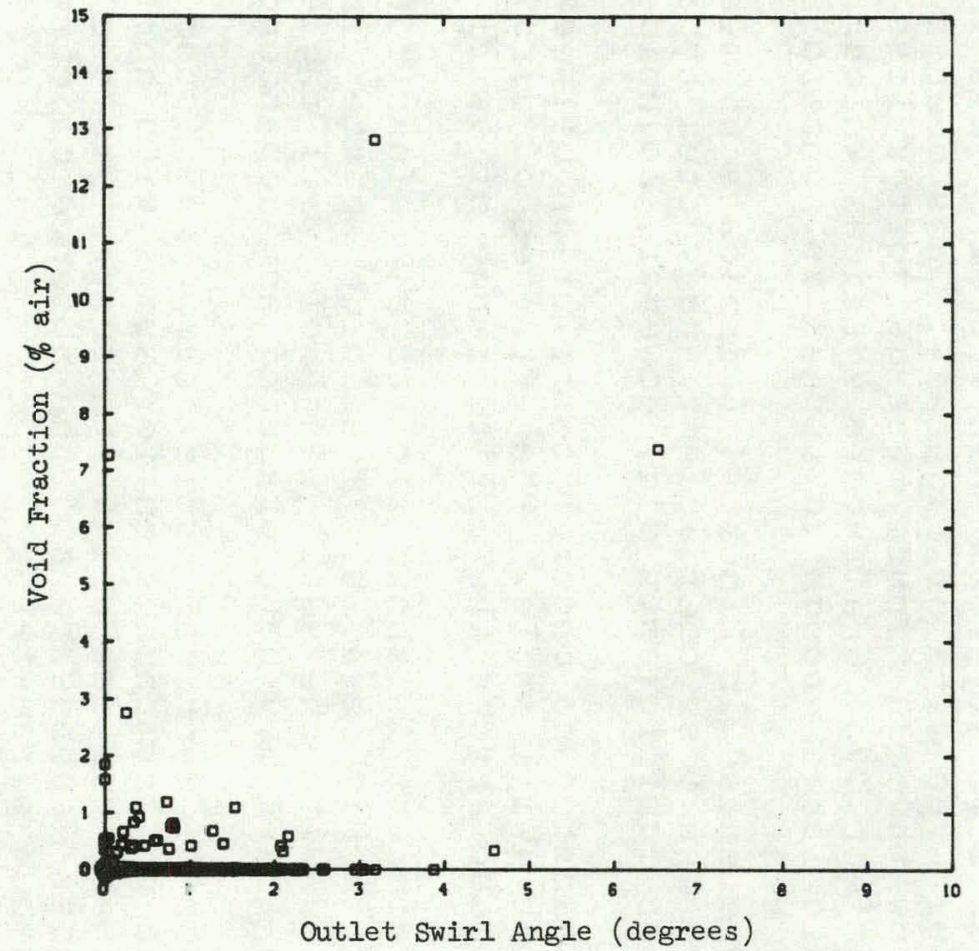

Figure 4.9 Void Fraction as a Function of the outlet Swirl Angle for All 30-Minute Average Data

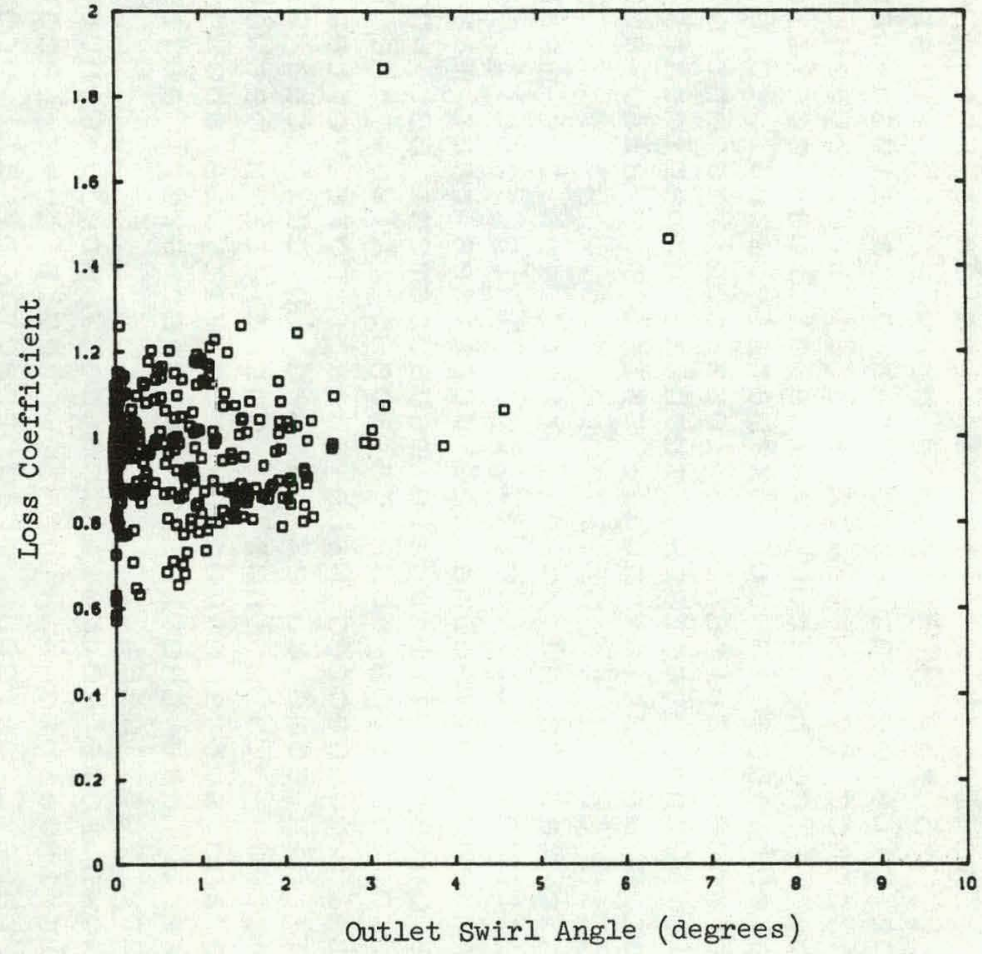

Figure 4.10 Loss Coefficient as a Function of the Outlet Angle for All 30-Minute Average Data 
The loss coefficient was found to be independent of flow conditions. Figure 4.5 shows the consistent behavior of the sump loss coefficient. The large scatter in the data shown on Figure 4.5 is due, in part, to the difference between the loss coefficient of a reentrant type pipe outlet, and that of a flush-mounted pipe entrance. Both entrance types (Figure 3.2) are represented in the data of Figure 4.5. (The handbook value of loss coefficient for a flush-mounted pipe entrance is approximately equal to 0.5 while a reentrant pipe entrance results in a loss coefficient of approximately 0.8). Other factors, such as experimental deviation and weak dependencies on outlet angle swirl may also account for some of the spread in the data of Figure 4.5.

No relationship was found to exist between the measured outlet swirl angle and surface vortex activity. This result may be due, in part, to the presence of submerged vortices that may have contributed to the oulet swirl angle measurement but which went unrecorded in the vortex type observations. Also, the small, localized swirl field connected with an air core vortex, entering the outlet, may have in somp sases passed through the vanes of the swirl meter undetected. This lack of correlation between the outlet swirl angle and surface vortex activity is shown on Figure 4.6. (Note, however, that the three largest swirl angles coincided with type 6 air-core vortices).

Figure 4.7 shows some correlation between 30-minute average vortex type and air ingestion. The few tests that recorded air ingestion greater than 2 percent void fraction, all produced air drawing, 30-minute average vortices. Note that, even though by definition (Figure 3.6), air ingestion is possible only for Type 5 or Type 6 vortices, measurable quantities of ingested air are indicated for vortex severity less than Type 2. This is due to the fact that the vortex type data of Fiqure 4.7 has been aver aged nver 30 minutes; a sump with a 30-minute average vortex less than 5 may have produced transient Type 6 air-core vortices which resulted in air ingestion levels large enough to appear as nonzero average air ingestions for the test.

The results presented in Figure 4.8 indicate no measurable correlation between the loss coefficient and vortex type. The extremes of the loss coefficients did, however, coincide with Type 6 vortex averages.

Figure 4.9 indicates no general correlation between air ingestion and outlet swirl angle. The extremes of air ingestion were observed to occur across the entire range of swirl angle meas ur ements.

The loss coefficient is shown plotted as a function of the outlet swirl angle in Figure 4.10. The large scatter in the loss coefficient, coupled with the small range of swirl angles represented in the tests may have obscured any dependency between these parameters.

The performance of vertical outlet sumps was found to be consistent with the performance seen for sumps with horizontally oriented outlet pipes--particularly with respect to the general lack of Froude number dependence and the absence of correlations among sump performance parameters. 


\subsubsection{Maximum Response Levels (All Tests)}

(Figures 4.11 through 4.14 show the maximum perturbed flow data points as square symbols with the perturbation type, $\mathrm{S}=$ screen blockage, $\mathrm{N}=$ nonuniform approach flow, $\mathrm{B}=$ break-flow jet impingement and $\mathrm{V}=$ vortex suppressor, above the symbol. The appropriate configuration number is shown below the symbol. Uniform flow tests are indicated by the configuration number below the symbol.)

The maximum observed 30-minute average vortex types are shown as a function of the Froude number on Figure 4.11. No general trend is evident and a broad range of vortex severity is represented across the entire range of Froude numbers that were tested. Nearly half of the maximum vortex data points that fell above a Type 5 (air ingesting vortices) were observed during uniform flow tests; no generally applicable evidence of increased vortex activity was found for sumps with perturbed flows when compared with the vortex activity observed for sumps with unperturbed approach flows.

The maximum recorded swirl angle averaged over 30 minutes occurred in Configuration 58B during a 75-percent screen blockage test. This is shown in Figure 4.12 where the swirl, recorded at a flow rate of $5300 \mathrm{gpm} / \mathrm{pipe}$ and a submergence of $5 \mathrm{ft}$, was found to be approximately 6.5 degrees. The majority of maximum swirl angle data, even with severe flow perturbation, remained at or below 3 degrees. (Only the largest swirl angles have been labeled.)

The maximum 30-minute average air ingestion levels are shown on Figure 4.13. Tests performed under conditions of severely perturbed approach flows were responsible for all observed levels of air ingestion greater than 2 percent void fraction. The greatest level of air ingestion was approximately 13 percent and was recorded in a screen blockage test of Configuration 58 at a Froude number, $F=1.18$ (flow rate $=5300 \mathrm{gpm} / \mathrm{pipe}$, total outlet submergence $=5 \mathrm{ft}$ ). Tests conducted for two other configurations resulted in air ingestion levels of approximately 7 percent void fraction each; Configuration 58B during a screen blockage test, Froude number, $F=1.18$ (submergence $=5 \mathrm{ft}$, flow rate $=5300$ $\mathrm{gpm} / \mathrm{pipe})$, and Configuration $60 \mathrm{~A}$ during a nonuniform approach flow test (streaming), Froude number, $F=1.18$ (submergence $=2 \mathrm{ft}$, flow rate $=5.300 \mathrm{gpm} / \mathrm{pipe}$.

The loss coefficient maxima are shown on Figure 4.14. The two largest loss coefficients observed correspond to those tests which produced the greatest air ingestion and outlet swirl angles: Configuration 58 during a screen blockage test, and Configuration 58B, also during a screen blockage test.

The maximum $0.5-$ minute or 1 -minute average response levels recorded during the vertical outlet test program are given in the conclusions section (2.0) in Table 2.2 .

In summary, the results that were presented in this section indicate the following concerning the general hydraulic performance of vertical outlet sumps:

a) Little or no consistant functional dependencies on flow parameters were observed.

b) Little or no consistant correlations among performance parameters (vortex type, void fraction; outlet swirl angle and loss coefficient) worc observed. 


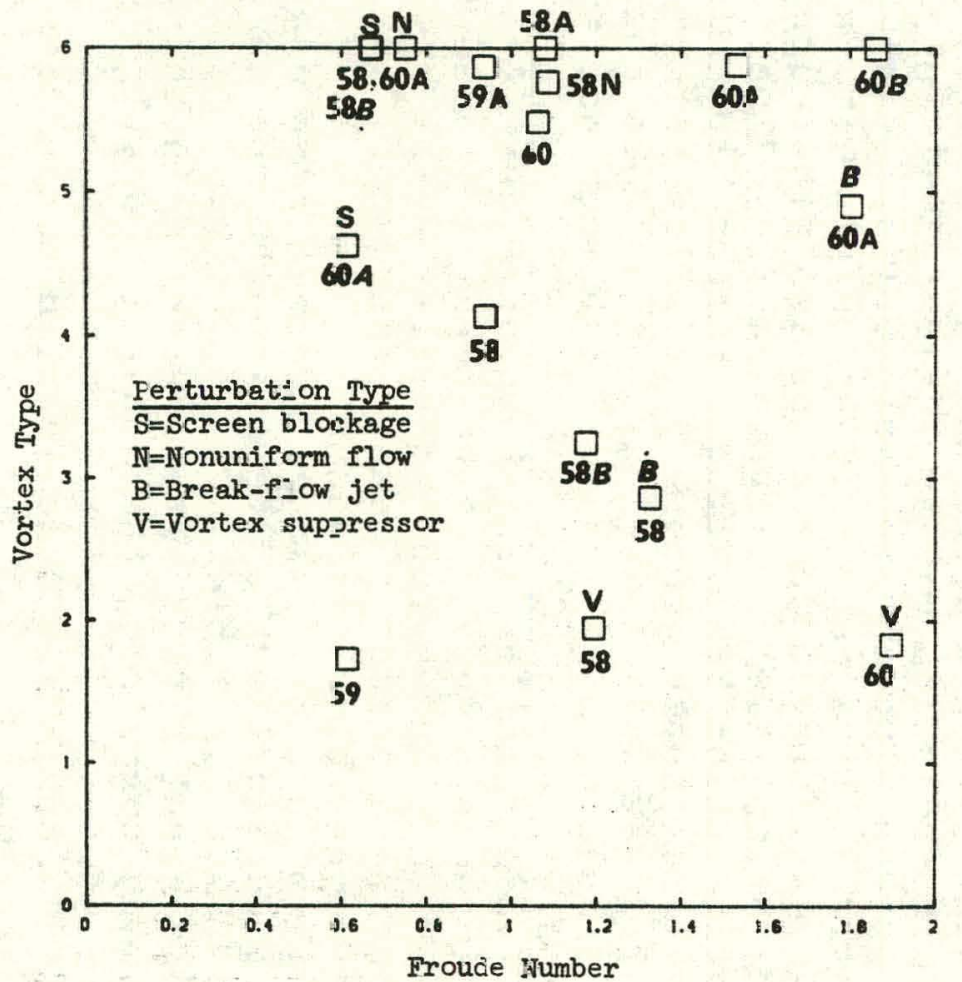

Figure 4.11 Maxinum Surface Vortex Type as a Function of the Froude wumber for AlI 3C-Minute Average Data

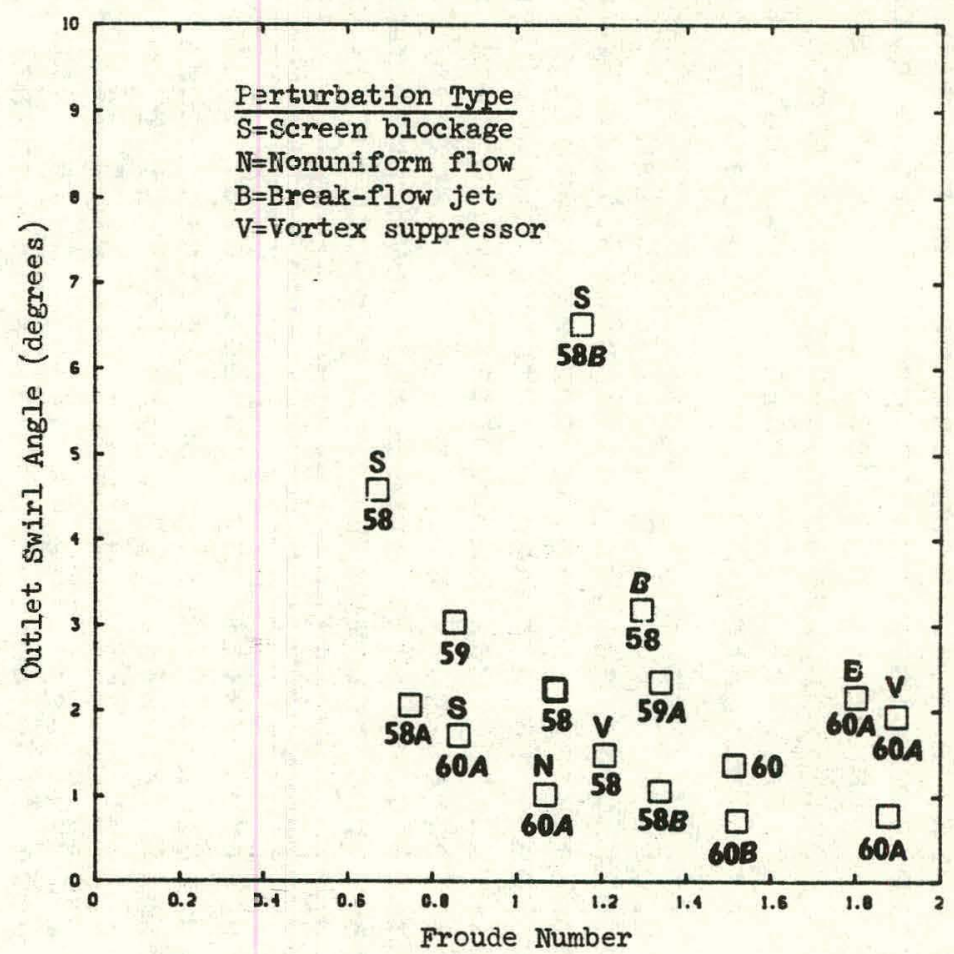

Figure 4.12 Maximum Outlet Swirl as a Function of the Froude Number for All 30-Minute Average Data 


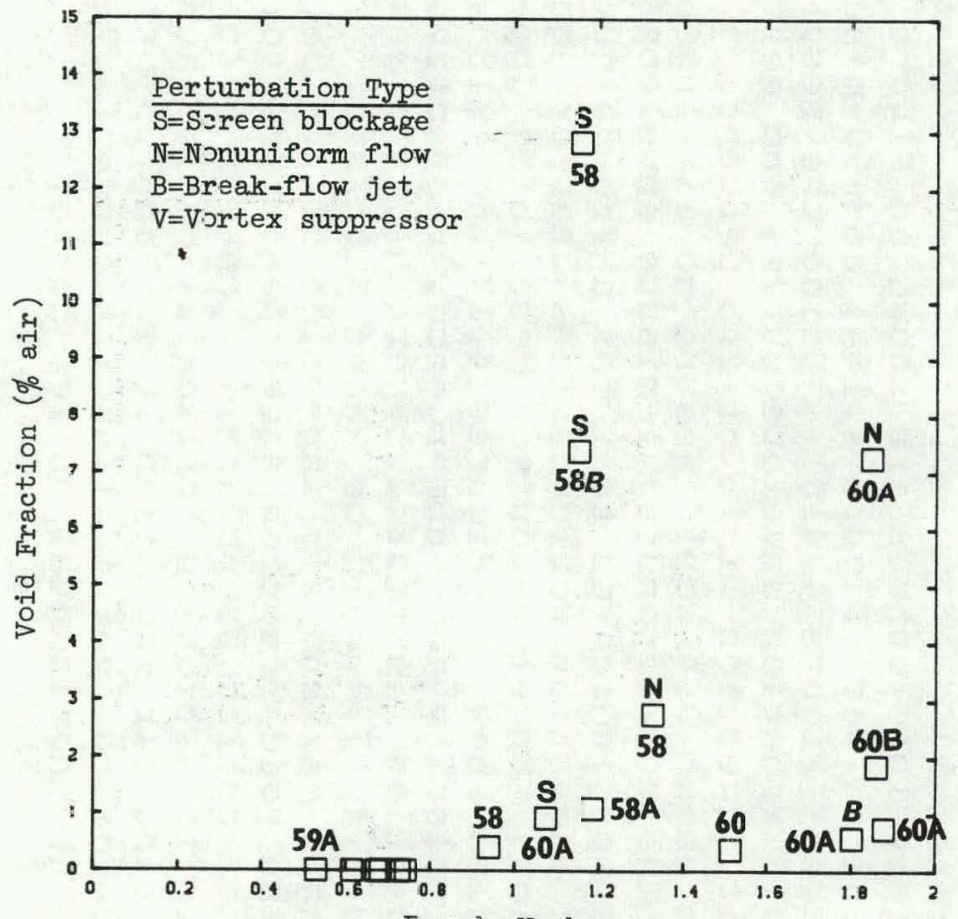

Froude Number

Figure 4.13 Maximum Void Fraction as a Function of the Froude Number for all 30-Minute Average Data

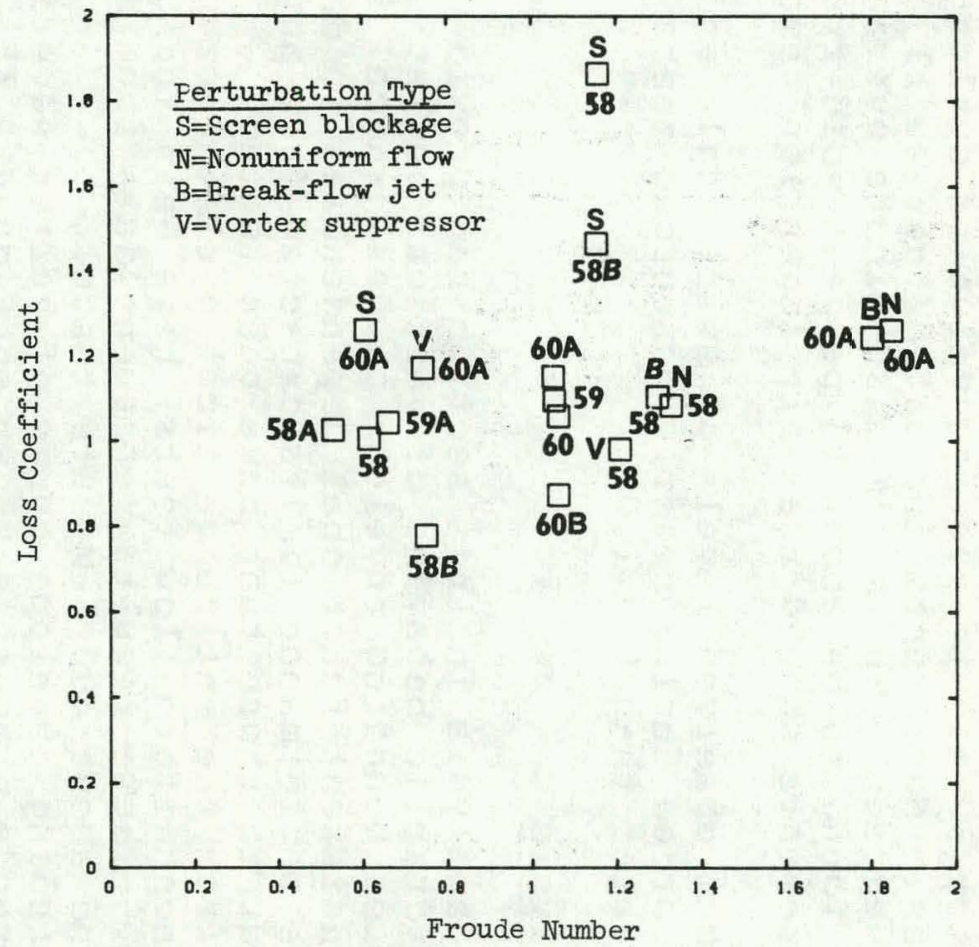

Figure 4.14 Maximum Loss Coefficient as a Function of the Froude Number for All 30-Minute Average Data 
c) Vortex activity was found to be inadequate as a measure of sump performance.

d) The maximum 30-minute average value of outlet swirl angle was about 7 degrees. Most tests indicated that swirl angles remained below 3 degrees. The maximum 30-minute average value of air ingestion was found to be about 13 percent void fraction. The majority of measurements showed that air ingestion remained well below 2 percent.

e) The maximum observed levels of swirl angle and air ingestion were recorded during severly perturbed tests and for Froude numbers greater than $F=1.0$.

\subsection{Envelope Analysis}

The envelope analysis in this section has provided a means for determining the hydraulic behavior of vertical outlet sumps. This is provided by upper bounding envelope curves, which, in the absence of any consistent functional dependencies in data, can be used to define the performance limits expected from any vertical outlet sump similar to those that have been tested.

The results from the entire vertical outlet test program (both uniform flow and nonuniform flow tests) have been included in the envelope analysis. These results represent data from about 100 30-minute tests and about 4005 -minute tests.

The upper bounding envelope curve of vortex severity as a function of the Froude number is shown on Figure 4.15. The envelope shown in this figure ensures that no air drawing vortices (Type 5 or 6 ) form for Froude numbers less than 0.3 . The maximum Froude number at which air drawing vortices do not occur in sumps with vertical outlet pipes is the same as that for horizontal outlet sumps (Reference 1 ).

Air ingestion envelope curves are shown on Figure 4.16 for both 1 -minute average values (Figure $4.16 \mathrm{~A}$ ) and $30-\mathrm{minute}$ or 5 -minute test averages (Figure $4.41 \mathrm{~B}$ ). Using the results of the 1-minute average void fraction envelope curve, and setting a 1 -minute maximum air ingestion 1 imit of 2.5 percent, a Froude number of less than about 0.4 would assure no air ingestion greater than 2.5 percent. The corresponding 1 -minute envelope for

horizontal outlet sumps indicates that for a Froude number of less than about .55 , air ingestion would be less than or equal to 2.5 percent void fraction. Envelope curves describing upper levels of air ingestion are also shown in Figures 4.17 and 4.18 as functions of the outlet pipe velocity and submergence, respectively. Using the example air ingestion limit of 2.5 percent, the maximum pipe velocity, from Figure 4.17, would be about $6 \mathrm{ft} / \mathrm{sec}$. The minimum submergence yielding a maximum air ingestion of 2.5 percent would be about $7.5 \mathrm{ft}$. The void fraction envelope curves for air ingestion in vertical outlet sumps are in general agreement with those describing air ingestion in horizontal outlet sumps for Froude numbers ensuring air ingestion less than 7.5 percent void fraction. The slope of the vertical outlet curve is, however, about twice that of the horizontal outlet curve. 


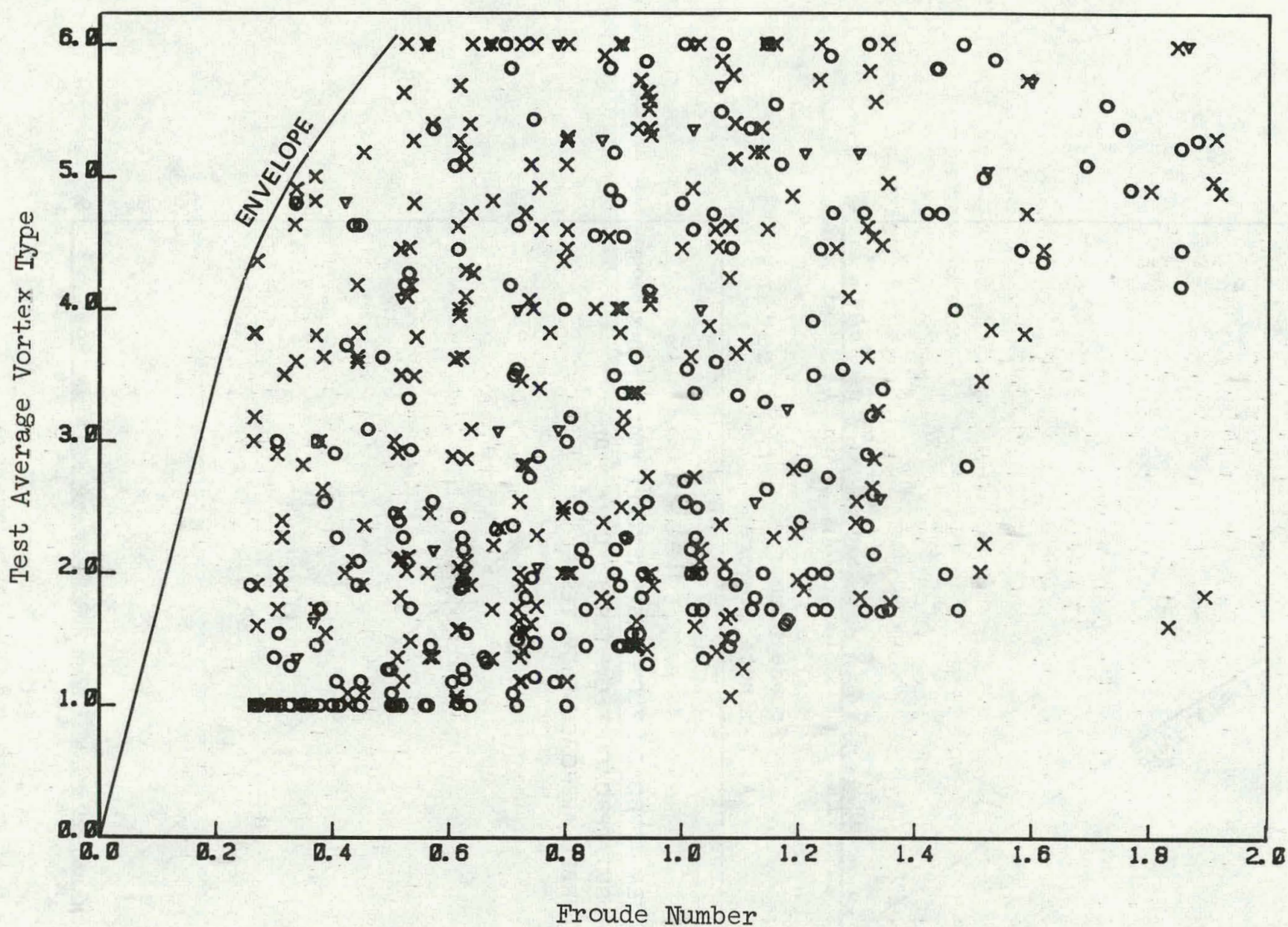

O UNIFORM APPROACH FLOW TESTS (EXCEPT FOR $\mathrm{c}=0$ )

$\nabla$ UNIFORM APPROACH FLOW TESTS (FOR $c=0$ )

$X$ PERTURBED APPROACH FLOW TESTS

Figure 4.15 Envelope of Vortex Type Data as a Function of the Froude Number for All 30-Minute and 5-Minute Average Data 


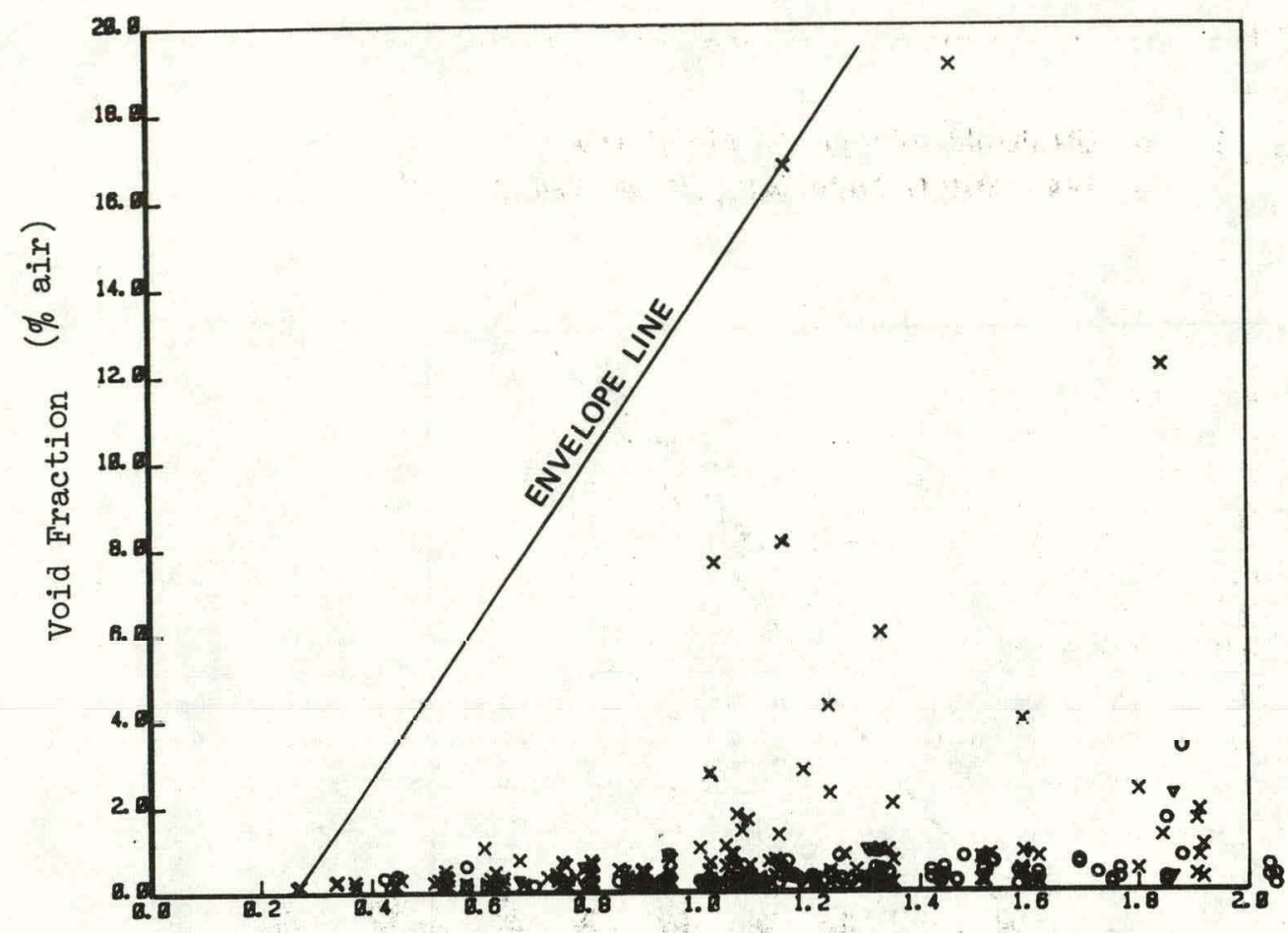

Froude Number

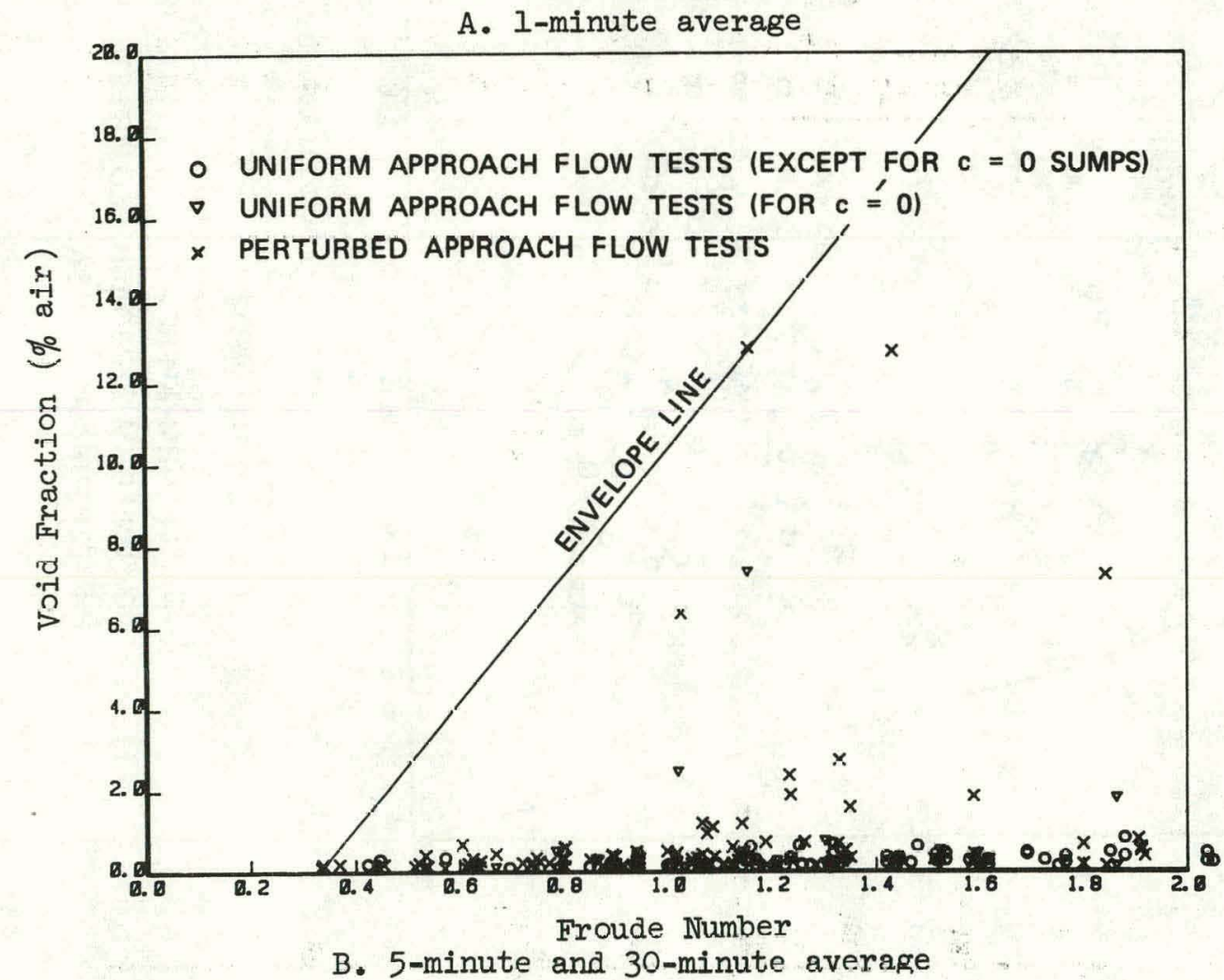

Figure 4.16 Envelope of Air Ingestion Data for, A) 1-Minute Average, B) 5-Minute or 30-Minute Average, as a Function of the Froude Number 


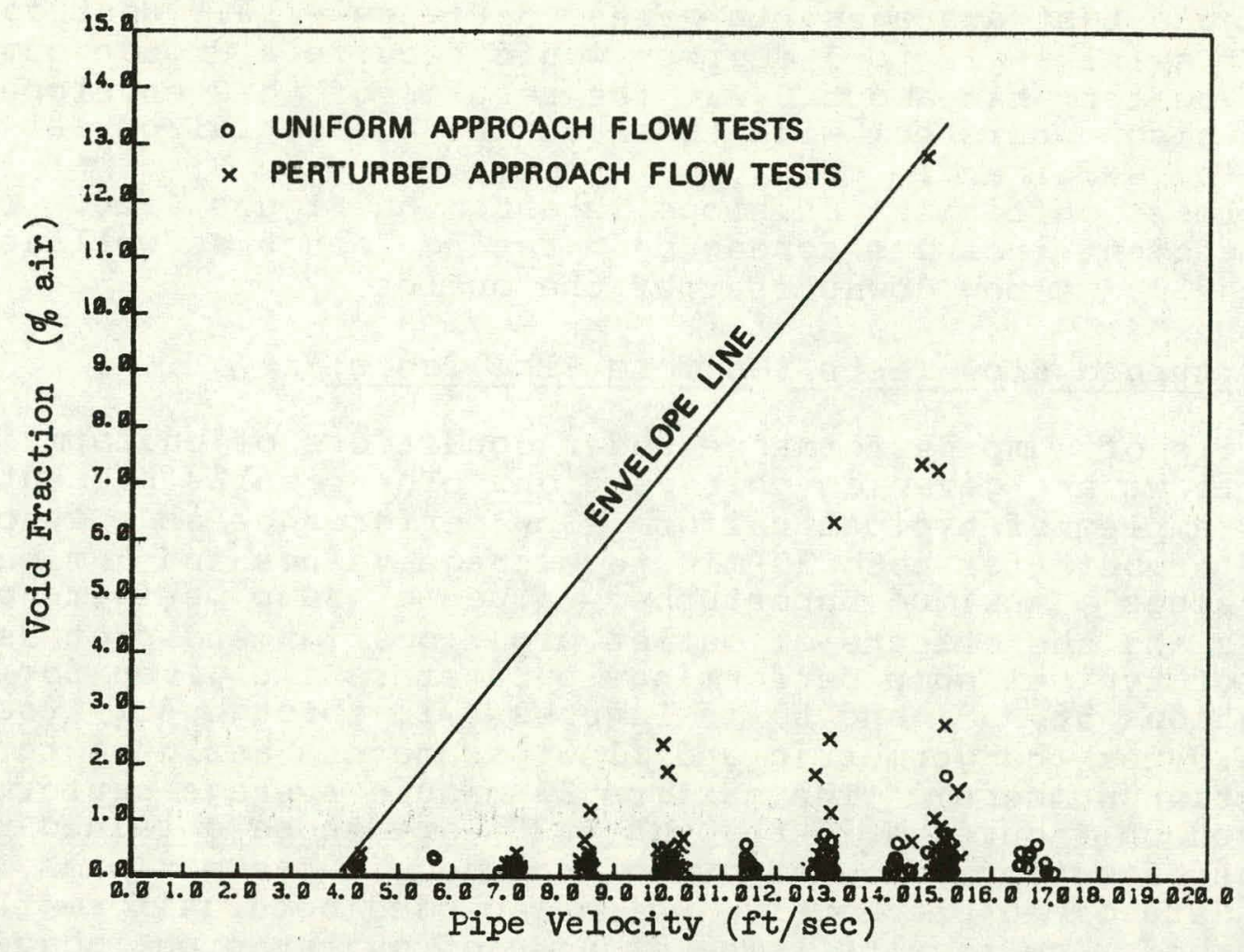

Figure 4.17 Envelope of Air Ingestion as a Function of Pipe Velocity for 5-Minute and 30-Minute Average Data

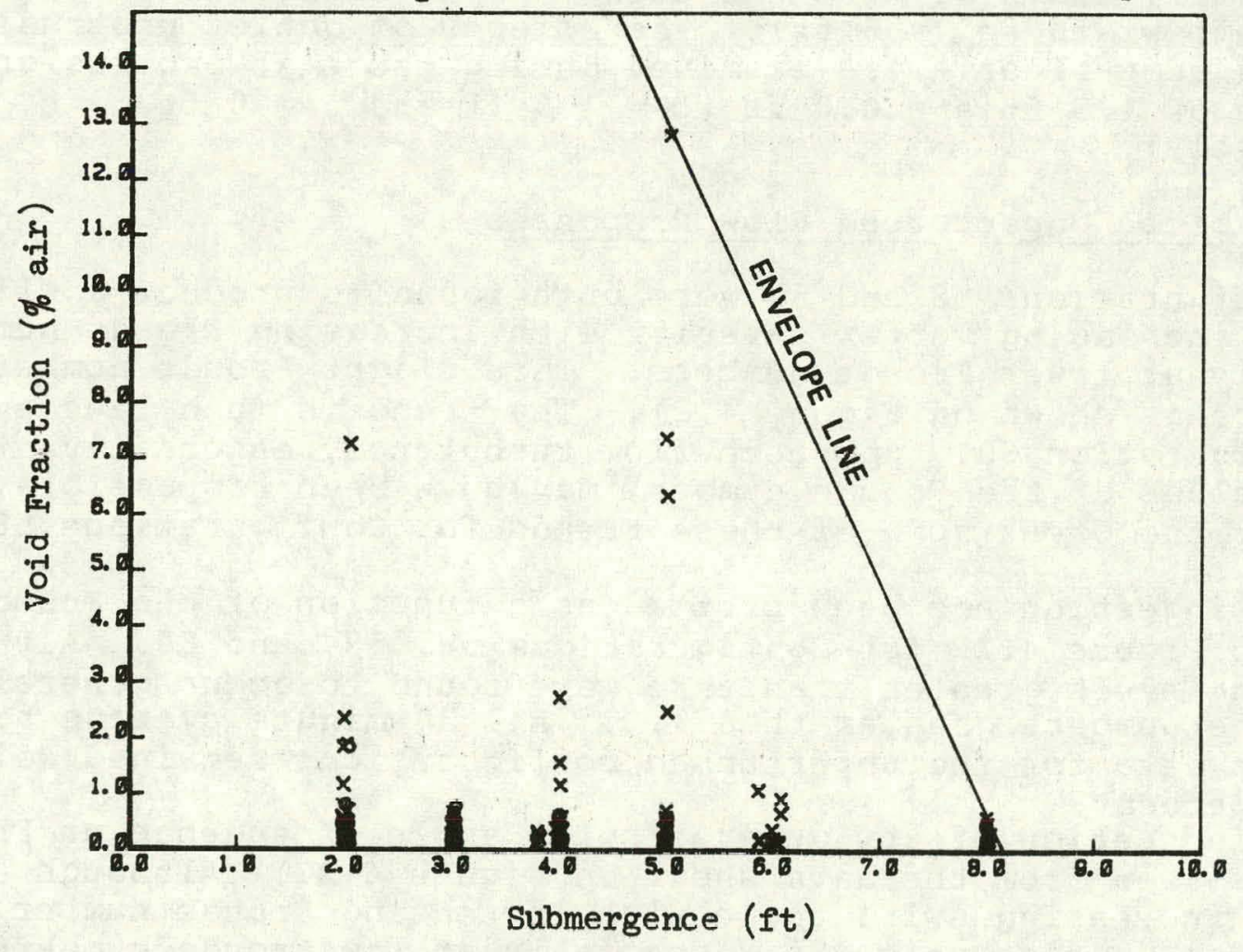

Figure 4.18 Envelope of Air Ingestion as a Function of the Submergence for 5-Minute and 30-Minute Average Data 
The envelope curve describing swirl angle, based upon 5-minute and 30-minute test averages, is given in Figure 4.19. Restricting the outlet swirl angle to 5 degrees would require a Froude number to be no greater than about 0.6 . The results of this envelope curve are also consistent with those of the horizontal outlet envelope for swirl angle.

The loss coefficient envelope is shown on Figure 4.20. The loss coefficient includes screen and grating losses as well as the loss at the $90^{\circ}$ elbow downstream of the outlet.

4.3 Unperturbed Flow Tests (Uniform Flow Tests)

Details of sump performance under conditions of uniform approach flows are given in this section. The results presented include examples of typical uniform flow performance as a function of Froude number (for both 30-minute average values and 5-minute average values), maximum unperturbed values of sump performance parameters and the effects of outlet pipe location and protrusion. Examples of typical sump performance parameters are given for Configurations 58,59, and 60 in Figures 4.21 through 4.24 (see chapter 3.0 for the geometric and flow parameters assigned to these configuration numbers). The maximum 30-minute average performance data, given on Figures 4.25 through 4.28 , are those obtained under conditions of uniform flow and were included in the maximum response data given previously, which included both uniform flow and perturbed flow results. The effects of outlet pipe location were studied by tests with the outlet pipes close to the sump wall $\left(e_{y}=1.5 \mathrm{ft}\right.$ ) and also with the outlet pipes located at the center of the sump width $\left(e_{y}=5 \mathrm{ft}\right)$. The effects of outlet protrusion (from the sump floory were examined during tests at protrusion distances of $1.5 \mathrm{ft}$ and $0.0 \mathrm{ft}(\mathrm{c}=1.5 \mathrm{ft}$ and $\mathrm{c}=0 \mathrm{ft}$ respectively).

\subsubsection{Typical Unperturbed Flow Responses}

Configurations 58 and 59 were both found to produce a slight trend of increasing vortex severity with increasing Froude number, especially at lower froude numbers. This slight Froude number dependence is shown on Figure 4.21. The trend is much less evident for Configuration 60. Approach flow turbulence, especially at higher values of the Froude number, may have been responsible, in part, for the break down of these trends for Configurations 58 and 59.

Air ingestion has been plotted as a function of the Froude number in Figure 4.22 for Configurations 58, 59, and 60. Air ingestion levels greater than zero were found to occur generally for Froude numbers greater than 1.0. All 30-minute average air ingestion data for the unperturbed configurations remained well below 1 percent.

No indication of any general swirl angle dependence on Froude number is seen from the data shown on Figure 4.23. Although a weak trend of increasing swirl angle with increasing Froude number is evident for Configuration 58, especially at low Froude numbers, no such behavior was evident for Configurations 59 or 60 . Swirl angles in unperturbed sumps were generally less than 2 or 3 degrees. 


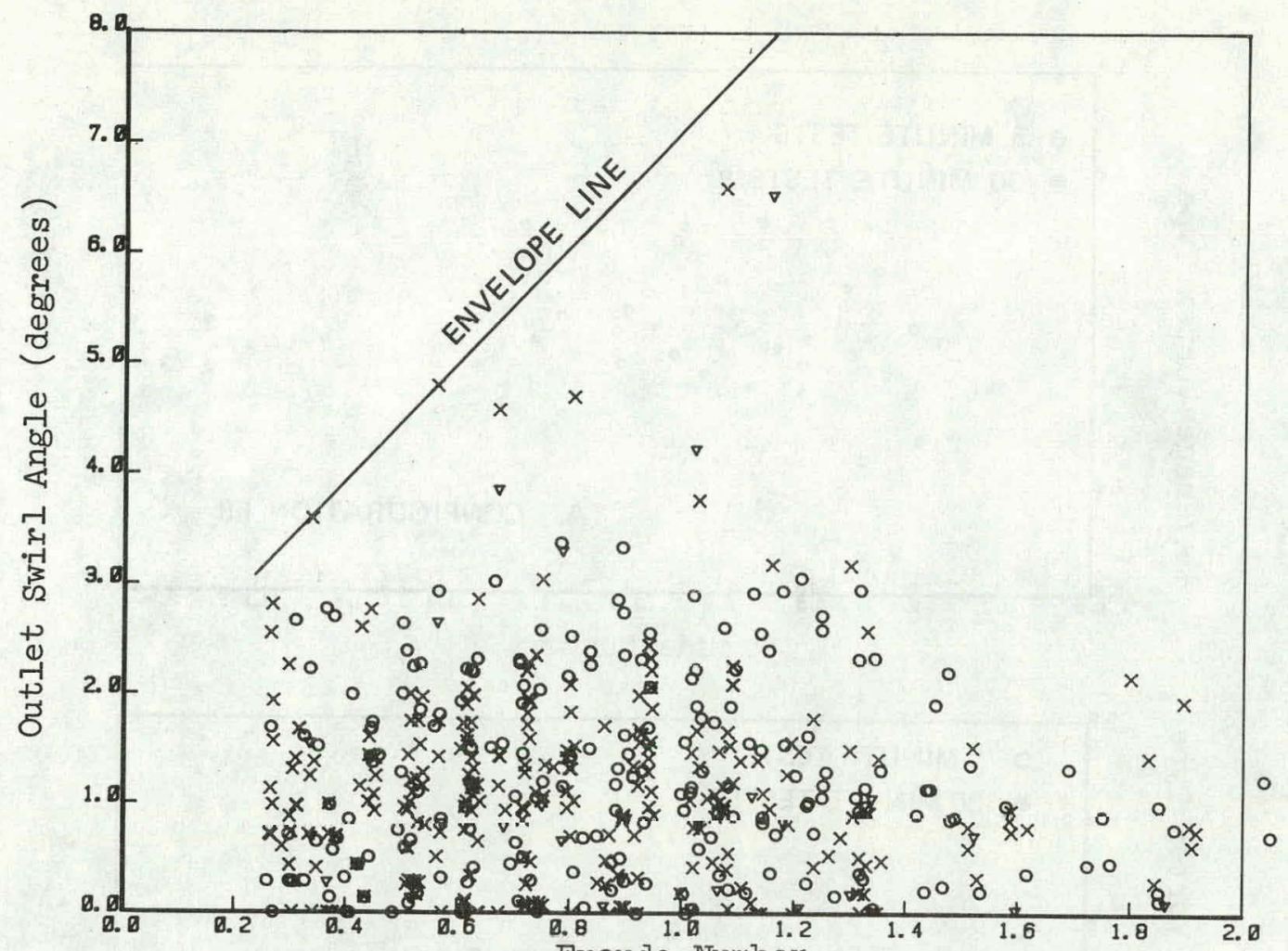

Froude Number 4.

Figure 4.19 Envelope of Outlet Swirl Angle as a Function of the Froude Number for 5-Minute and 30-Minute Average Data

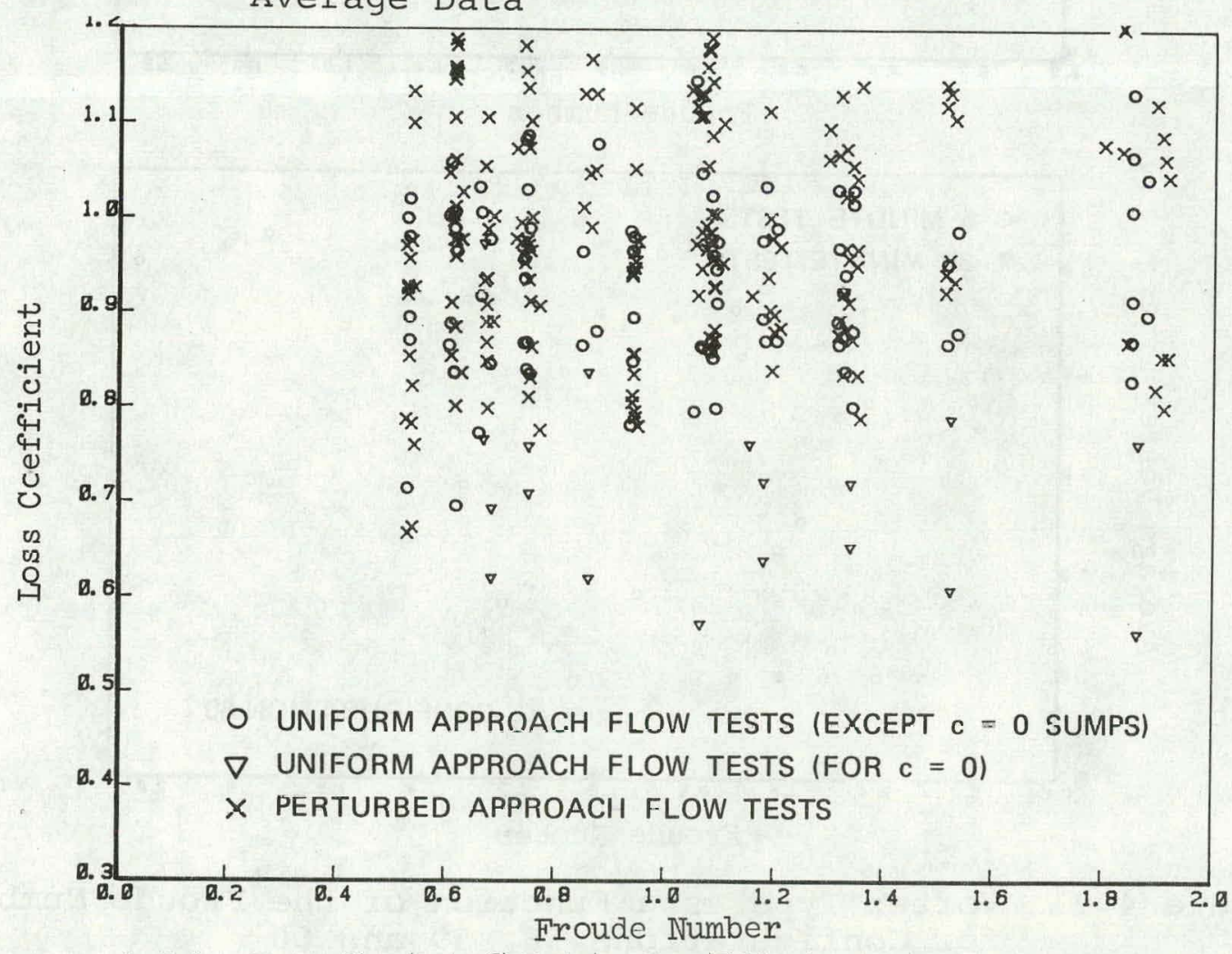

Figure 4.20 Envelope of Loss Coefficient as a Function of the Froude Number for All 30-Minute Average Data 

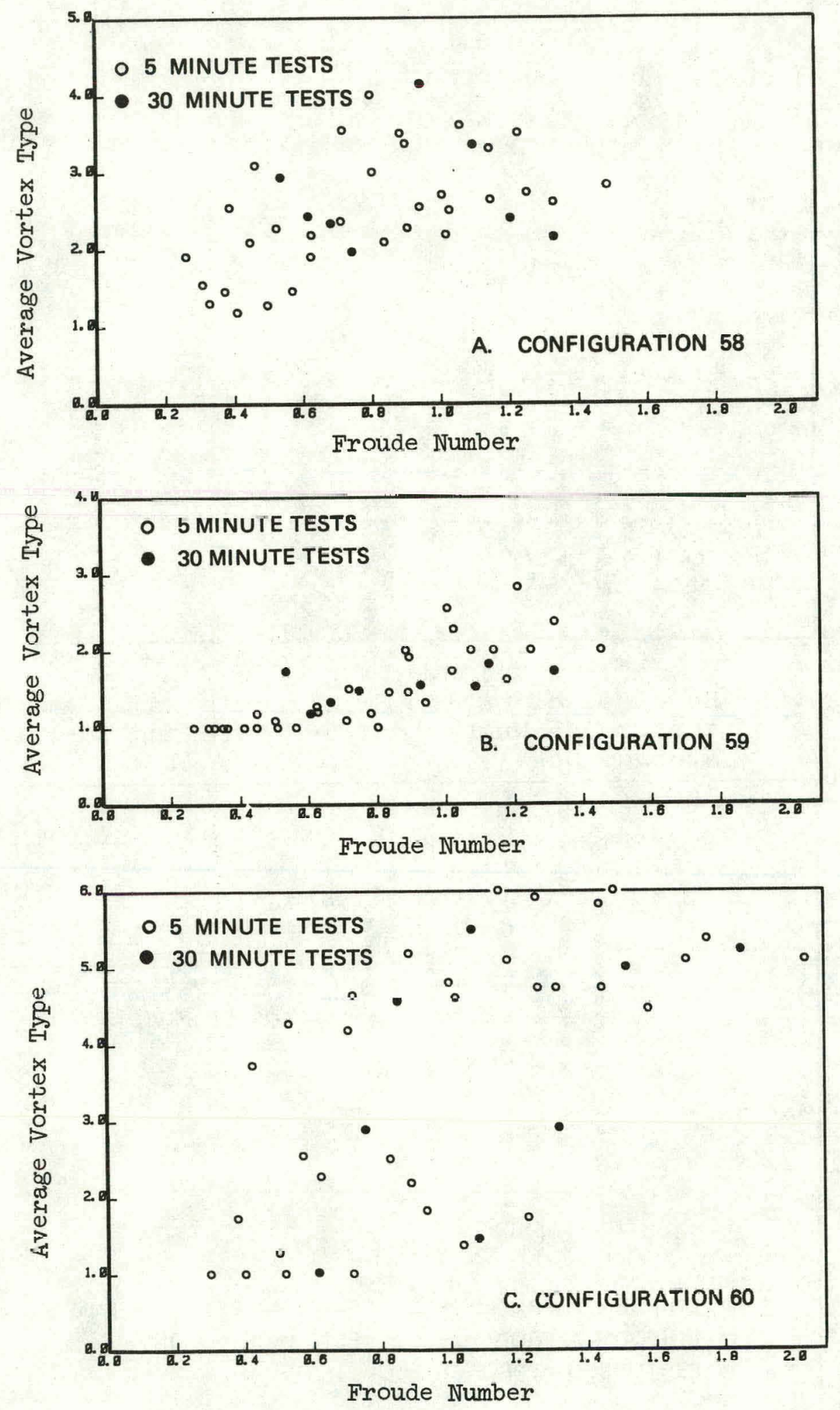

Figure 4.21 Vortex Type as a Function of the Froude Number for Configurations 58,59 and 60 

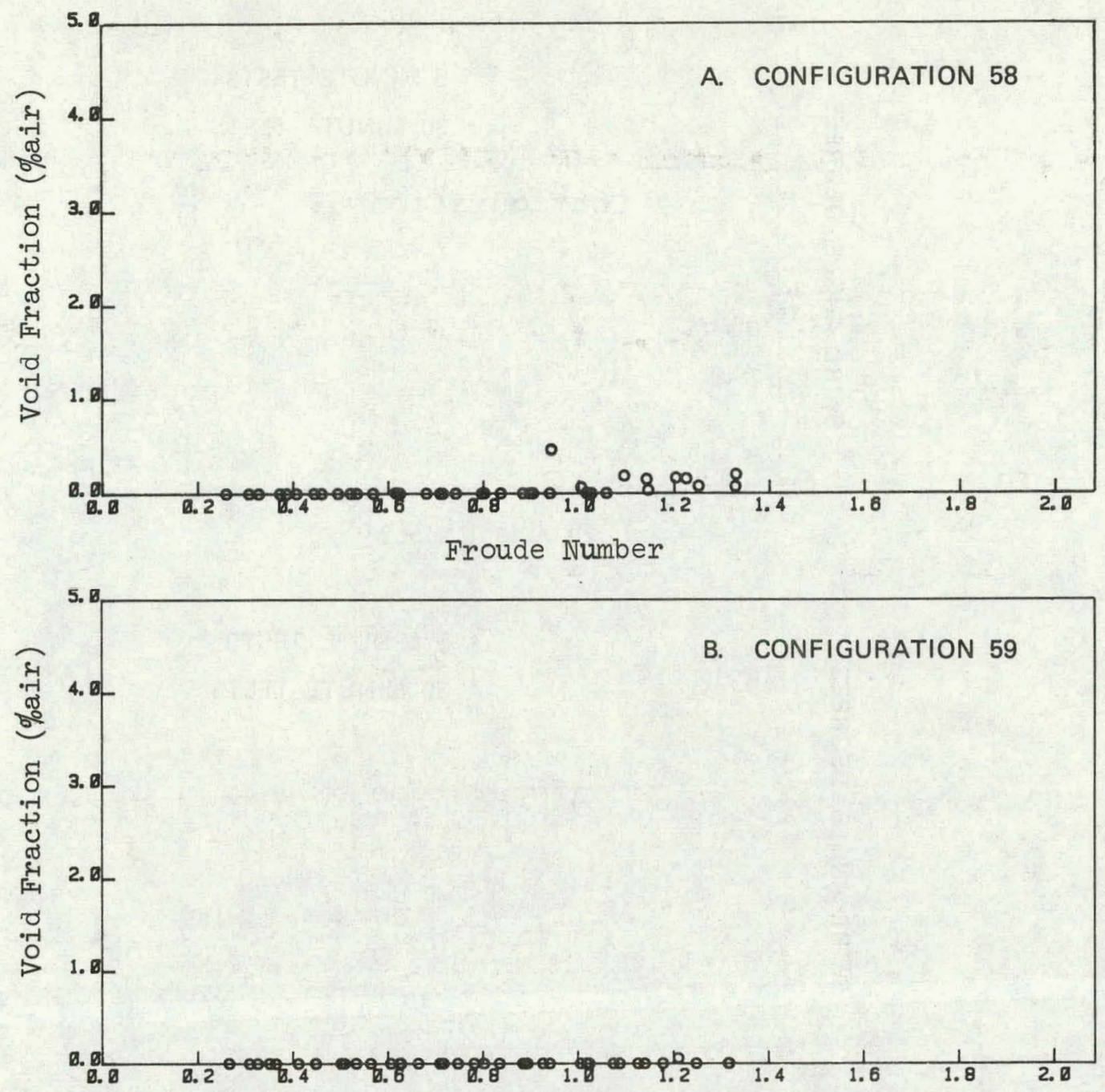

Froude Number

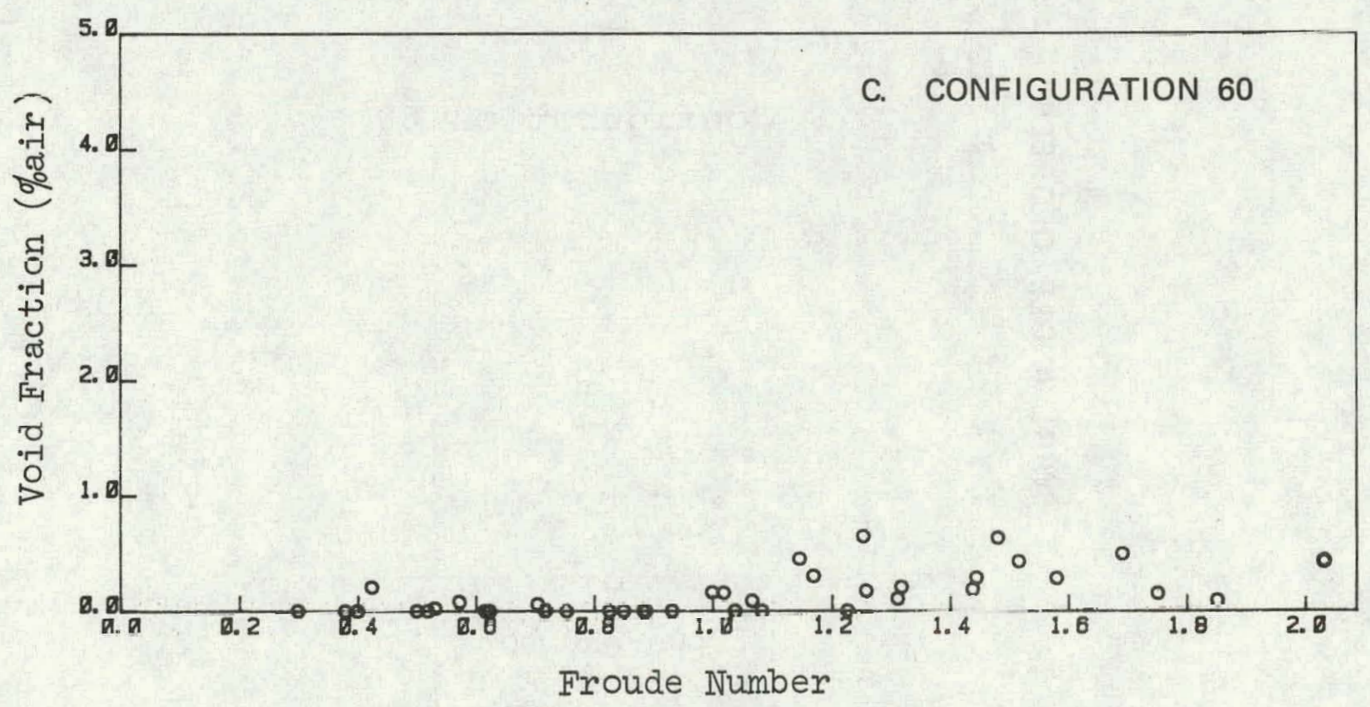

Figure 4.22 Void Fraction as a Function of the Froude Number for Configurations 58,59 and 60 

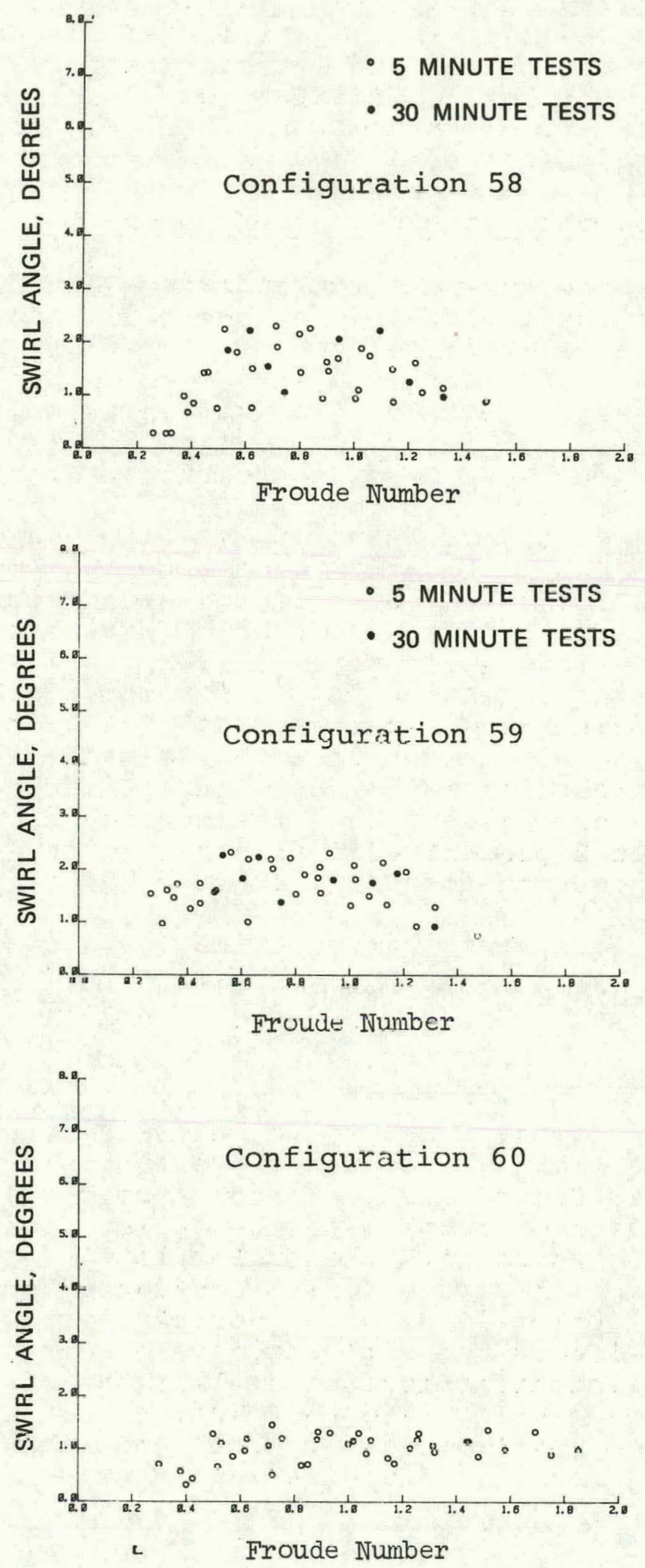

Figure 4.23 Outlet Swirl Angle as a Function of the Fraude Number for Configurations 58,59 and 60 
The loss coefficient data for Configurations 58, 59. and 60 are given in Figure 4.24. The behavior seen for these three configurations is typical of the behavior that was seen throughout the test program; the loss coefficient was found to be, within the measurement capability of the test facility, generally independent of virtually all geometric and flow variables.

\subsubsection{Maximum Response in Unperturbed Sumps}

Figure 4.25 shows the maximum observed 30-minute average vortex types, per configuration, for the eight configurations that were considered in the vertical outlet test program. Three of the Configurations, 58, 58B, and 59, were found to produce no vortex types capable of air ingestion. The remaining configurations, however, resulted in air ingesting vortices of Type 5 or Type 6 . The air-core vortices were found to occur for Froude numbers greater than 1.0 .

A slight trend of decreasing outlet swirl maxima with increasing Froude number is evident in Figure 4.26. The largest unperturbed swirl angle was about 3 degrees and occurred in Configuration 59 at a Froude number of, $F=0.85$ (submergence $=5$ ft and flow rate $=3000 \mathrm{gpm} / \mathrm{pipe}$ ).

The maximum air ingestion levels for unperturbed flow tests were found to remain below 2 percent void fraction. Also, a slight trend of increasing air ingestion with increasing Froude number is indicated. Air ingestion maxima, plotted as a function of Froude number, are shown on Figure 4.27. The maximum air ingestion, observed was about 2 percent void fraction under uniform flow conditions. It occurred for Configuration $60 \mathrm{~B}$ at a high Froude number, $F=1.85$.

Unperturbed loss coefficient maxima are shown in Figure 4.28. Loss coefficient maxima fell between 0.8 and 1.2 and showed no Froude number dependence.

\subsubsection{Outlet Pipe Location Tests}

Vortex severity was found to be generally greater for some sumps where the outlet was located close to the sump wall (for configurations see Figure 3.2). Vortex type comparisons, comparing the vortex type data of sumps with the outlet located close to the wall with that for sumps with the outlet located at the center of the sumps are given in Figure 4.29. Configuration $59^{\circ}$ showed very little effect of outlet location on vortex severity.

No general effects on swirl angle were seen for the two different outlet locations for the small range of swirl angles encountered in the testing (Figure 4.30).

Air ingestion levels were very small and showed no effect of outlet location. Loss coefficients were unaffected. 

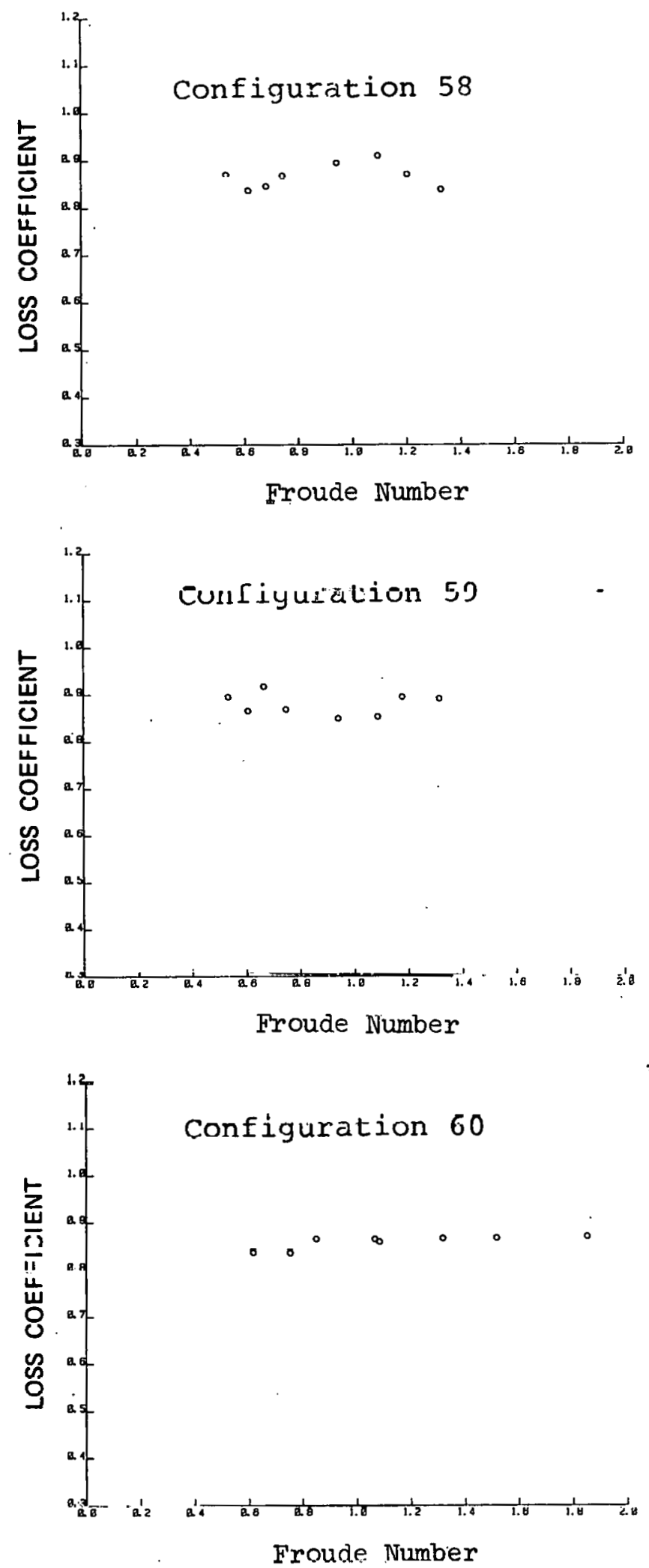

Figure 4.24 Loss Coefficient as a Function of the Froude Number for Configurations 58,59 and 60 


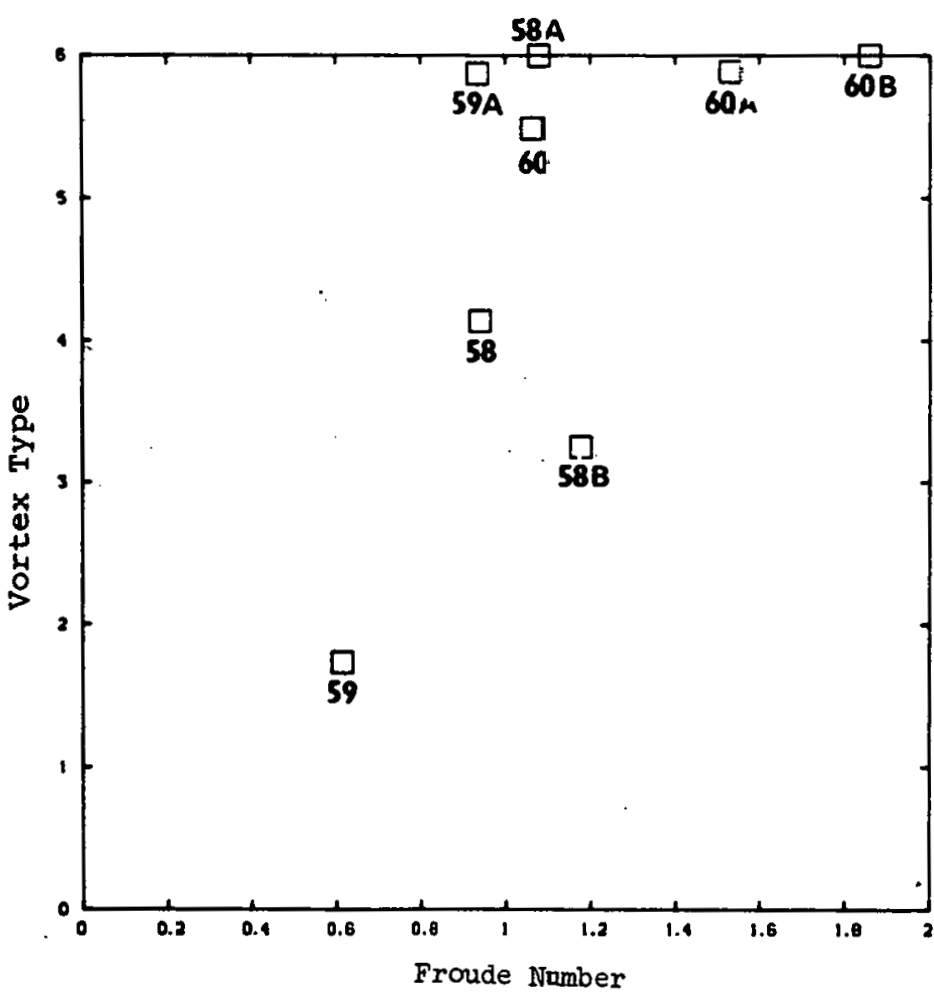

Figure 4.25 Maximum Vortex Type as a Function of the Froude Number for All Uniform Flow, 30-Minute Average Data

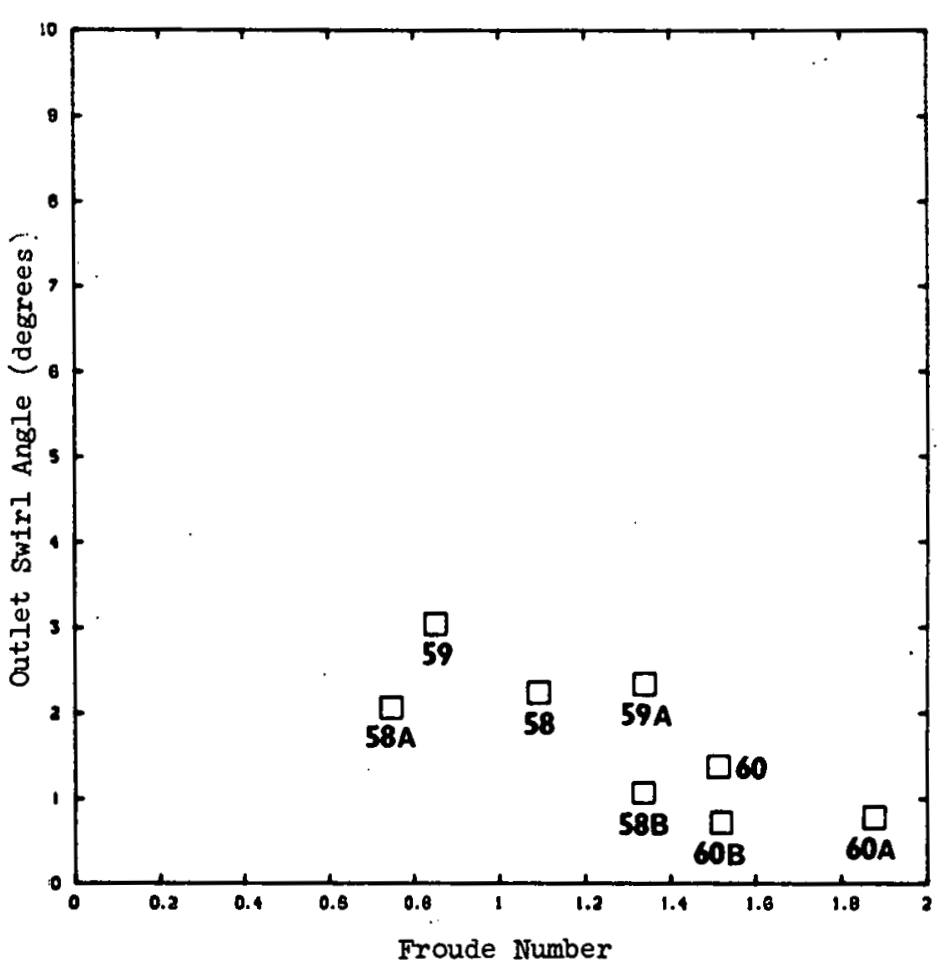

Figure 4.26 Maximur Outlet Swirl Angle as a Function of the Froude Number for All Uniform Flow, 30-Minute Average Data 


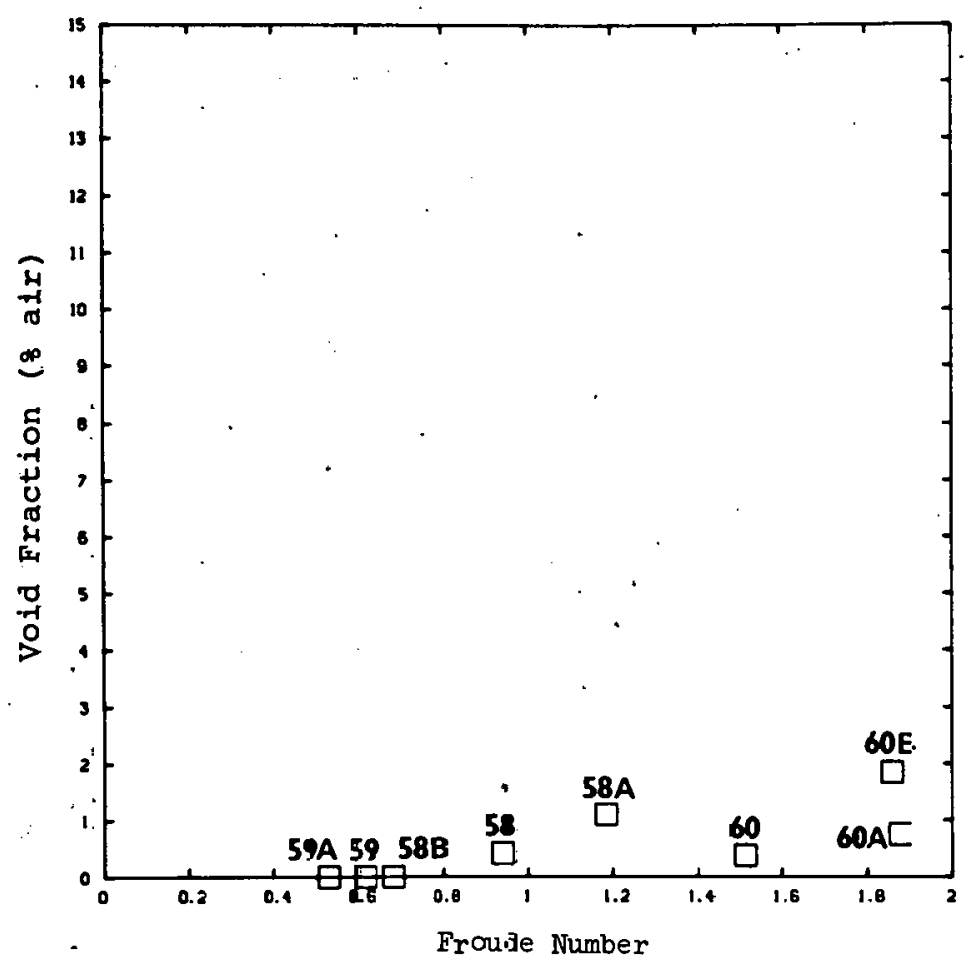

Figure 4.27 Mazimum Void Fraction as a Function of the Froude Number for All Uniform Flow, 30-Minute Average Data

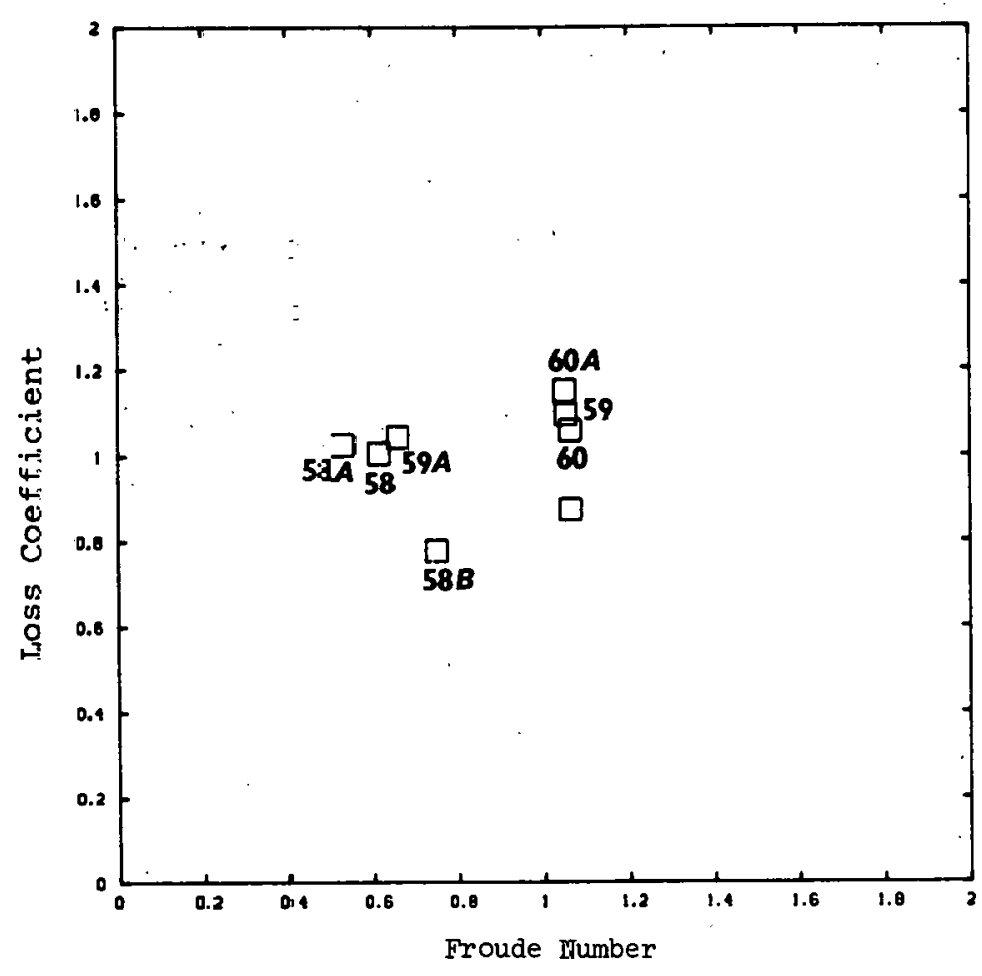

Figure 4.28 Maximum Loss Coefficient as a Function of the Froude Number for All Uniform Flow, 30-Minute Data 


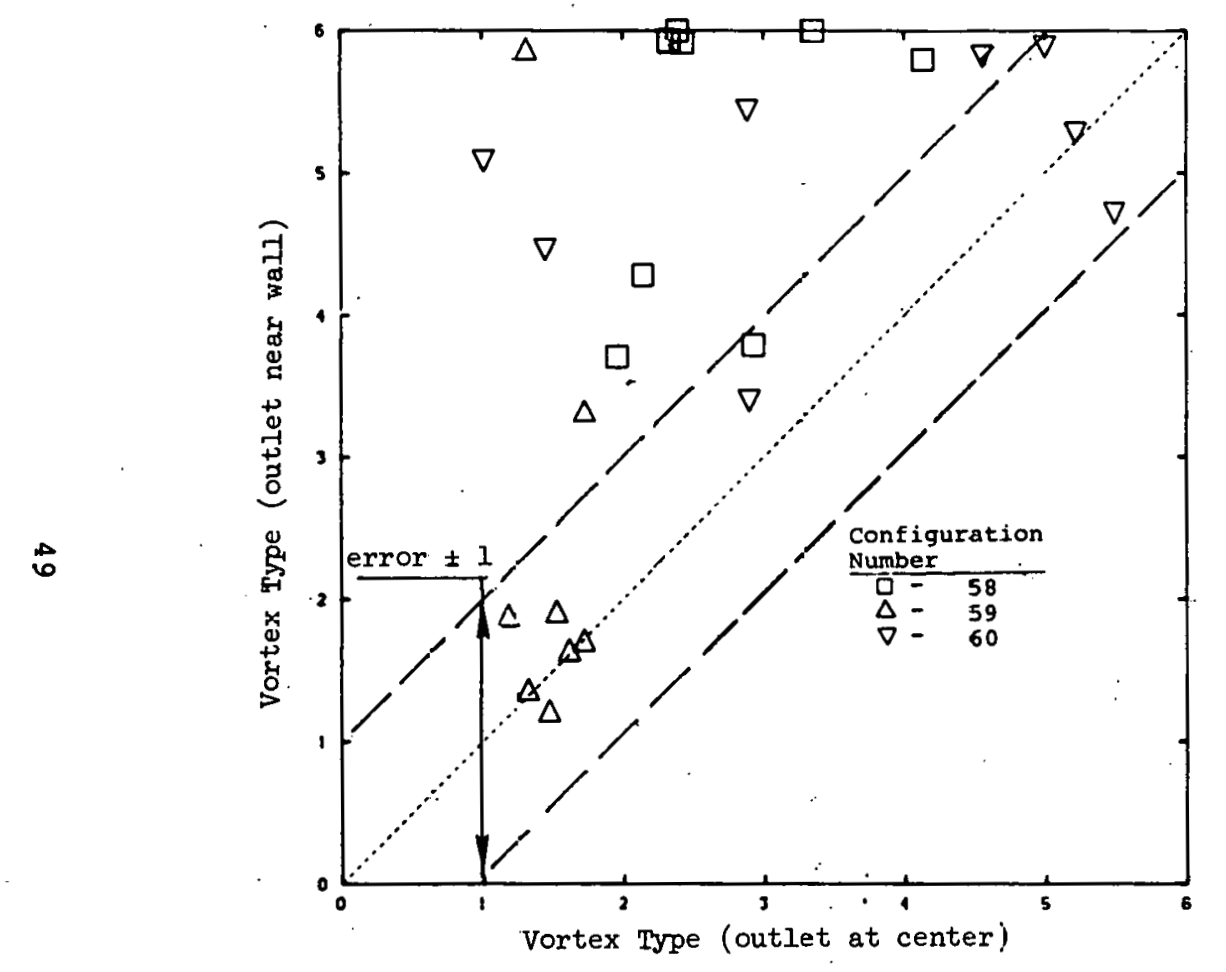

Figure 4.29 The Effect of outlet Location on Vortex Severity

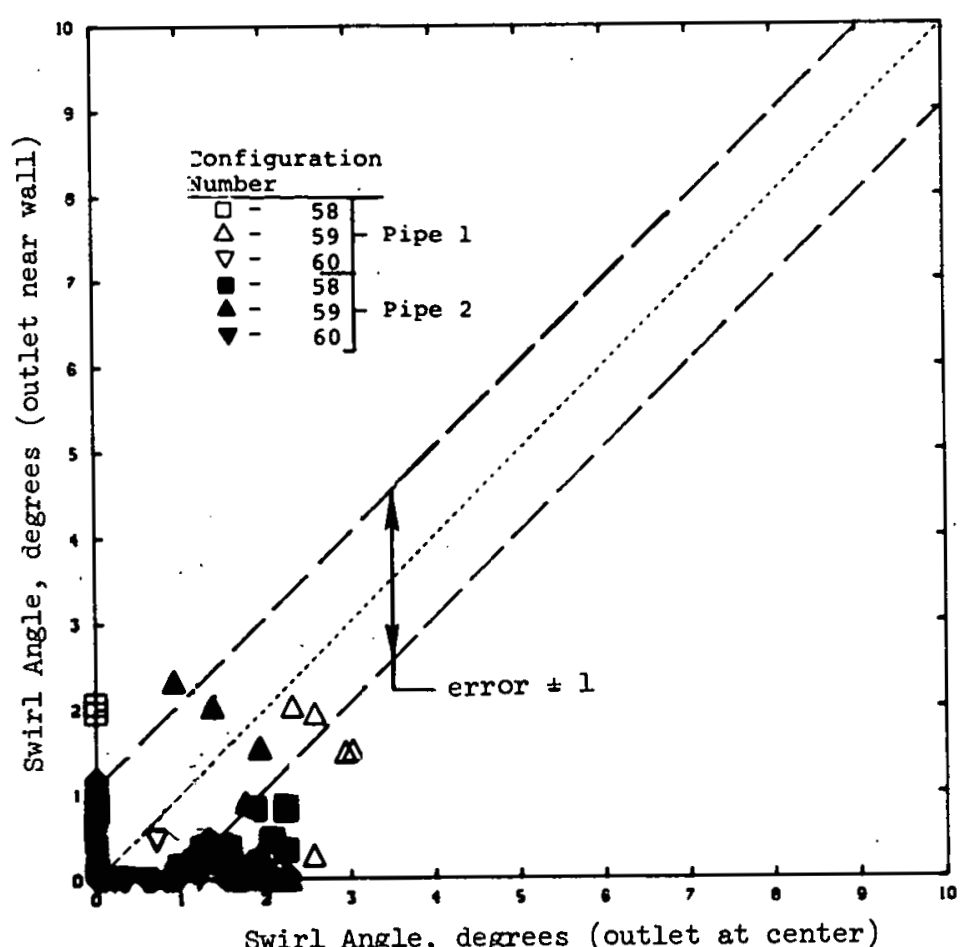

Figure 4.30 The Effect of Outlet Location on Swirl Angle Performance 


\subsubsection{Outlet Pipe Protrusion Tests}

Pipe protrusion was seen to have only a minimal effect on vortex severity; the comparison, given in Figure 4.31 , between flush-mounted and protruding outlets, shows a slightly higher average vortex type for the flush-mounted outlet than for the protruding outlet pipe. (Identical performance between the two configurations would be shown by all of the data points falling on the diagonal 1 ine of the comparison plot of Figure 4.31.) The difference in vortex activity between the two protrusion heights is within the expected error range for vortex type data (about 1 type classification).

For the small range of swirl angles represented on Figure 4.32 , only minor effects of protrusion height were observed. The flush-mounted outlet pipe resulted in slight reductions in the level of outlet swirl for some tests. Several tests, however, indicated slight increases in outlet swirl for the flush-mounted outlet pipe. All data however fell within the expected error band for outlet swirl measurements of about $1^{\circ}$ of swirl.

Air ingestion levels were zero or very small in all bue one of the outlet pipe protrusion tests thereby allowing no meaningful comparison of the results for the two protrusion lengths. The flush-mounted outlet pipe produced one 30-minute test average air ingestion that represented about 2 percent void fraction increase over the air ingestion observed in the corresponding test with a $1.5 \mathrm{ft}$ outlet projection. Figure 4.33 compares air ingestion observations.

The difference between the loss coefficient for a reentrant (protruding) pipe entrance and that of a flush-mounted pipe entrance may be seen in the results given in Figure 4.34. The flush-mounted entrance produced a lower loss coefficient than that produced by the reentrant entrance (from standard hydraulic handbooks, $C_{L}=0.5$ for flush mounted entrance and $C_{L}=0.8$ for reentrant entrance). No other effects are evident in Figure 4.34.

In summary, vertical outlet sumps were found to produce very low levels of outlet swirl angle and air ingestion under conditions of uniform approach flow. Five of the eight configurations produced air-core vortices, yet 30-minute average maximum air ingestion values remained below 2 percent void fraction at all times. Swirl angle remained well below 3 degrees. No significant effect of outlet protrusion distance was recorded. Uutlets that were located close to the sump wall produced more severe vortex activity than that produced by outlets located in the center of the sump. Swirl angle remained generally unaffected by outlet location. Air ingestion was not affected by outlet location.

\subsection{Perturbed Flow Tests}

Details of sump performance under conditions of severely perturbed approach flows are given in this section. The results presented include maximum perturbed flow values of sump response parameters, the effects of screen blockage, the effects of nonuniform approach flow, the effects of break-flow jet impingement and the effects of transient pump operation.

The maximum 30-minute average performance data, given in Figures 4.35 through 4.38 , represent that portion of the maximum response data, of section 4.1 .2 , pertaining only to perturbed flow tests. 


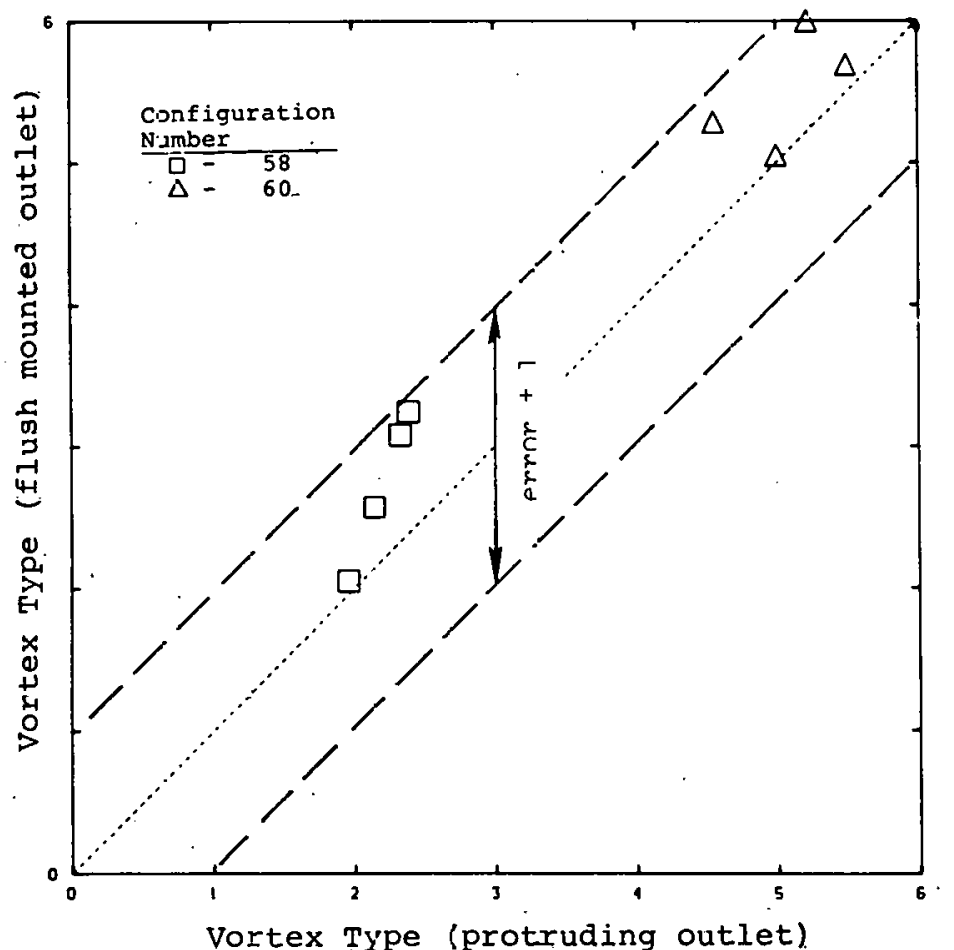

Figure 4.31 The Effect of Outlet Protrusion on Vortex Severity

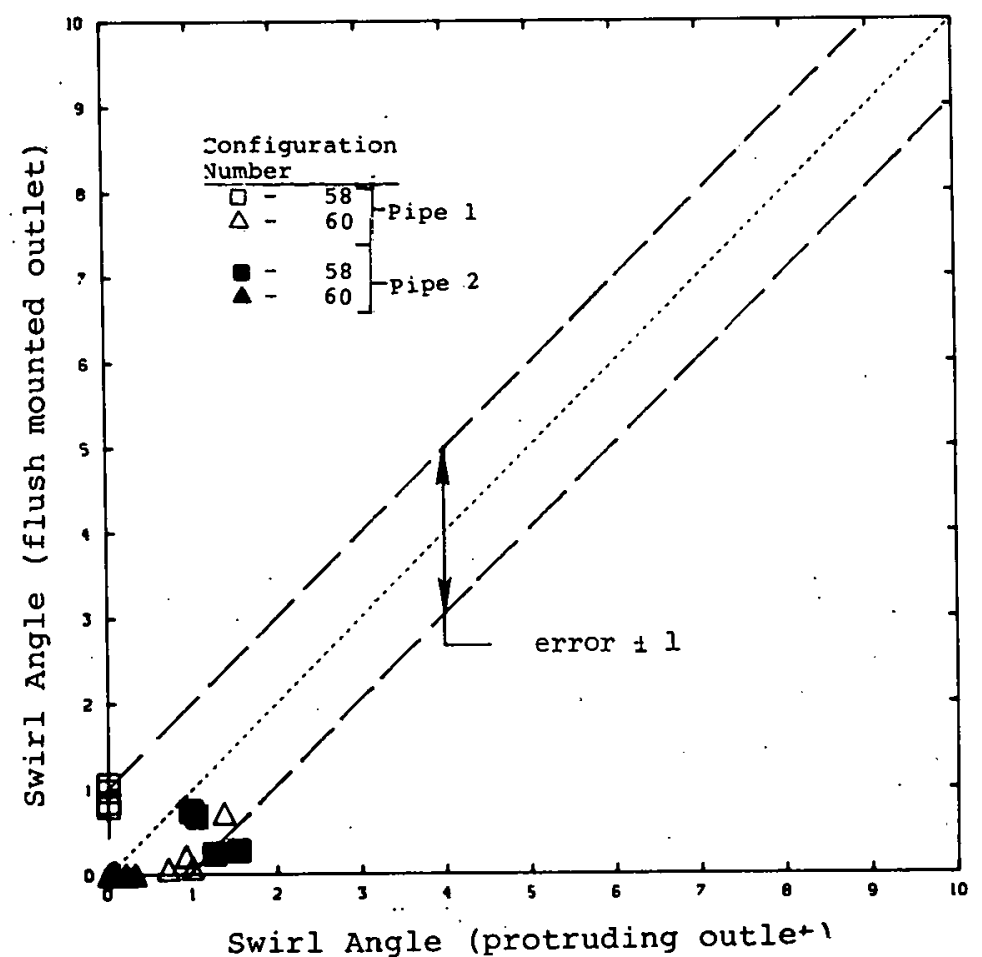

Figure 4.32 The Effect of Outlet Protrusion on Swirl Angle Performance 


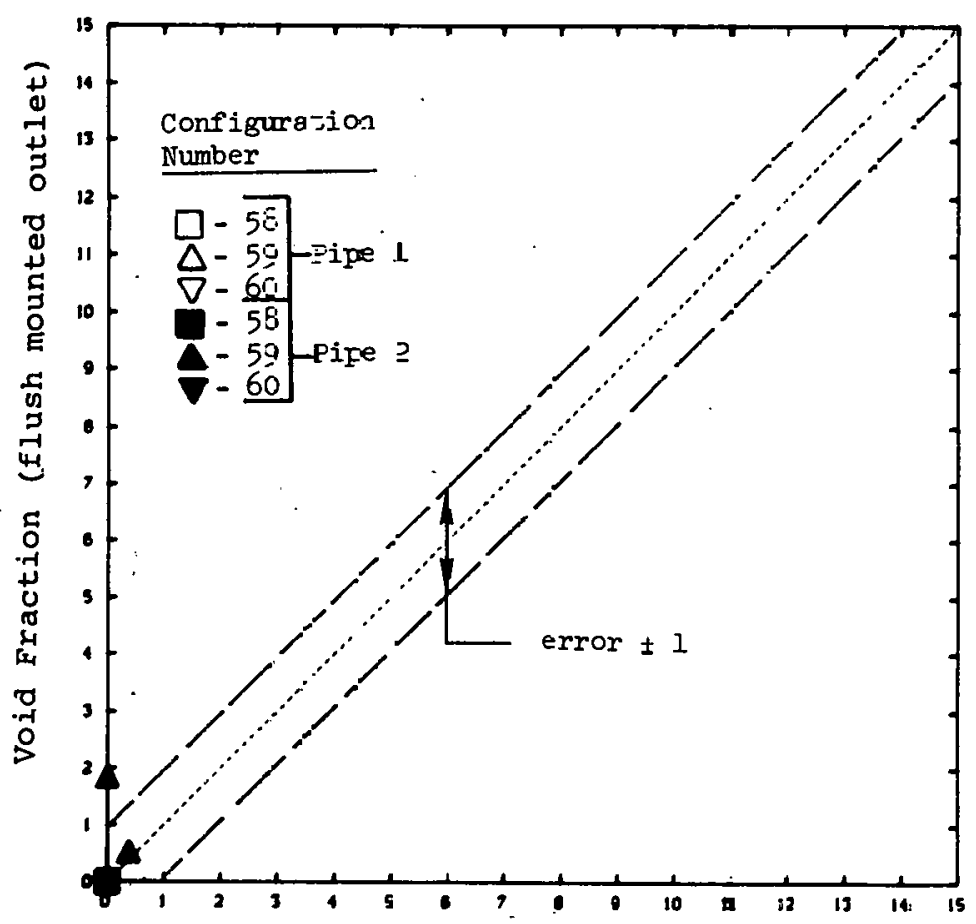

Void Fraction, of Air (protruding outle-)

Figure 4.33 The EEfect of Outlet Protrusic.n on Void Fraction Performance

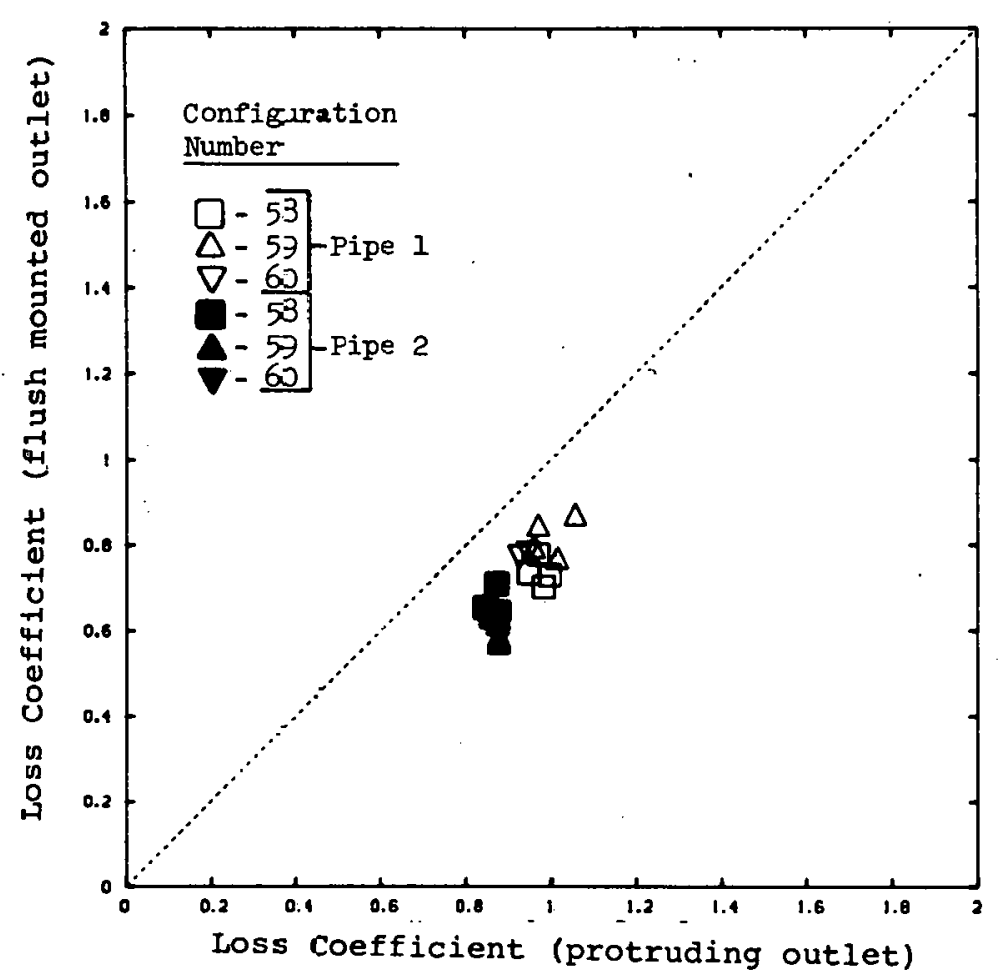

Figure 4.34 Tre Effect of Outlet Protrusion on Loss Caeificient Performance 


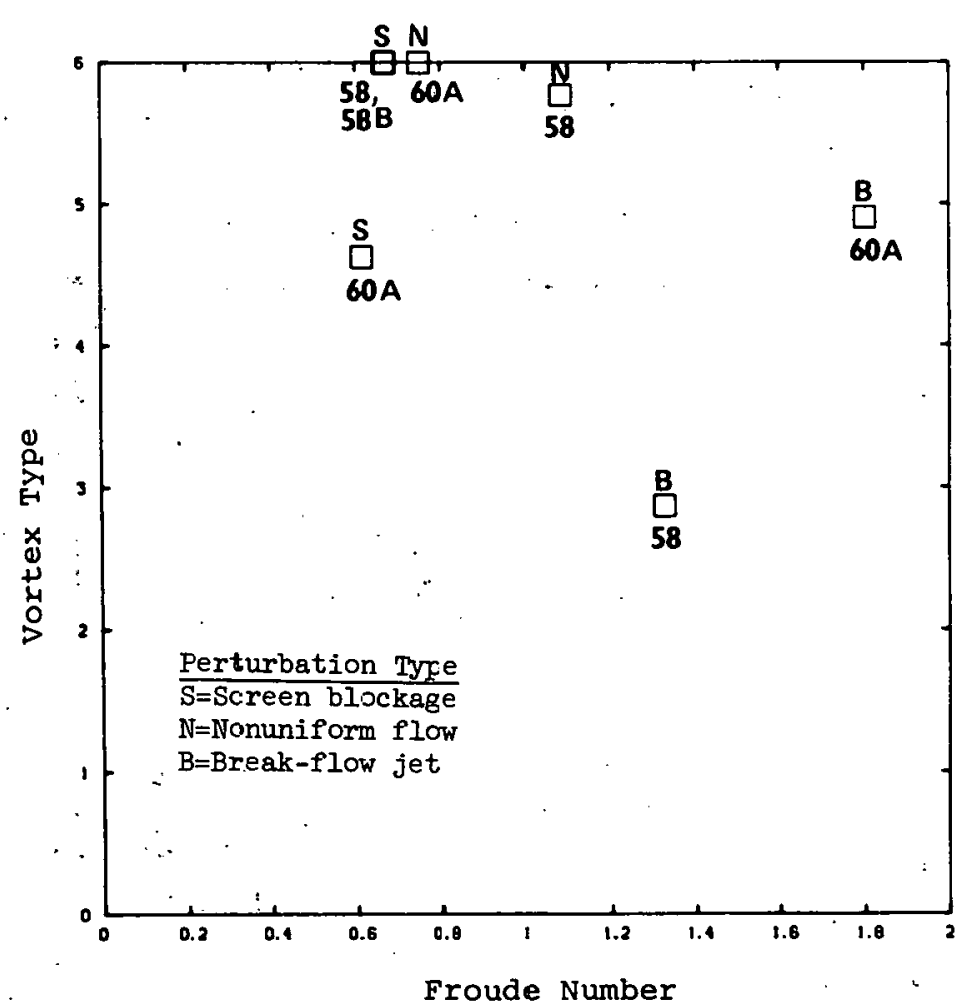

Figure 4.35 Maximum Vortex Type as a Function of the Froude Number for Perturbed Flow Conditions

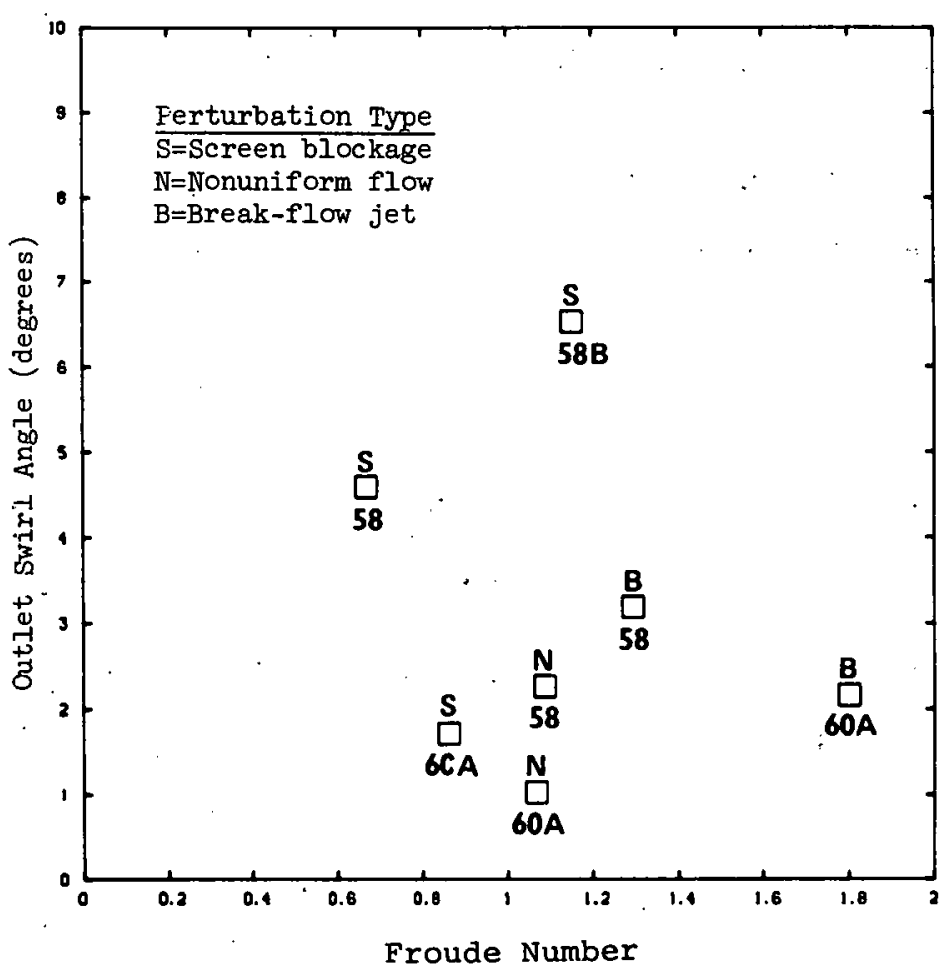

Figure 4.3\% Maximum Outlet Swirl Angle as a Function of the Froude Number for Perturbed Flow Conditions 


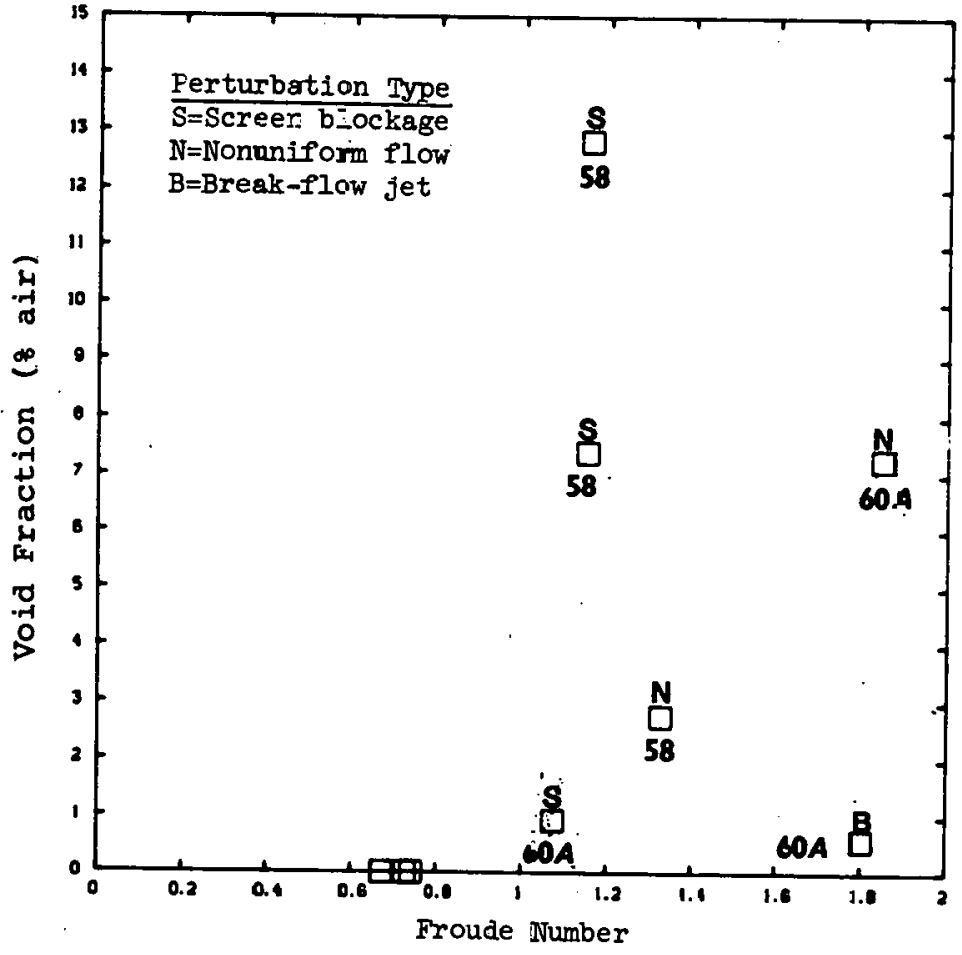

Figure 4.37 Maximum Void Fraction as a Funcion cf the Frolide Number for Perturbed Flow Conditions

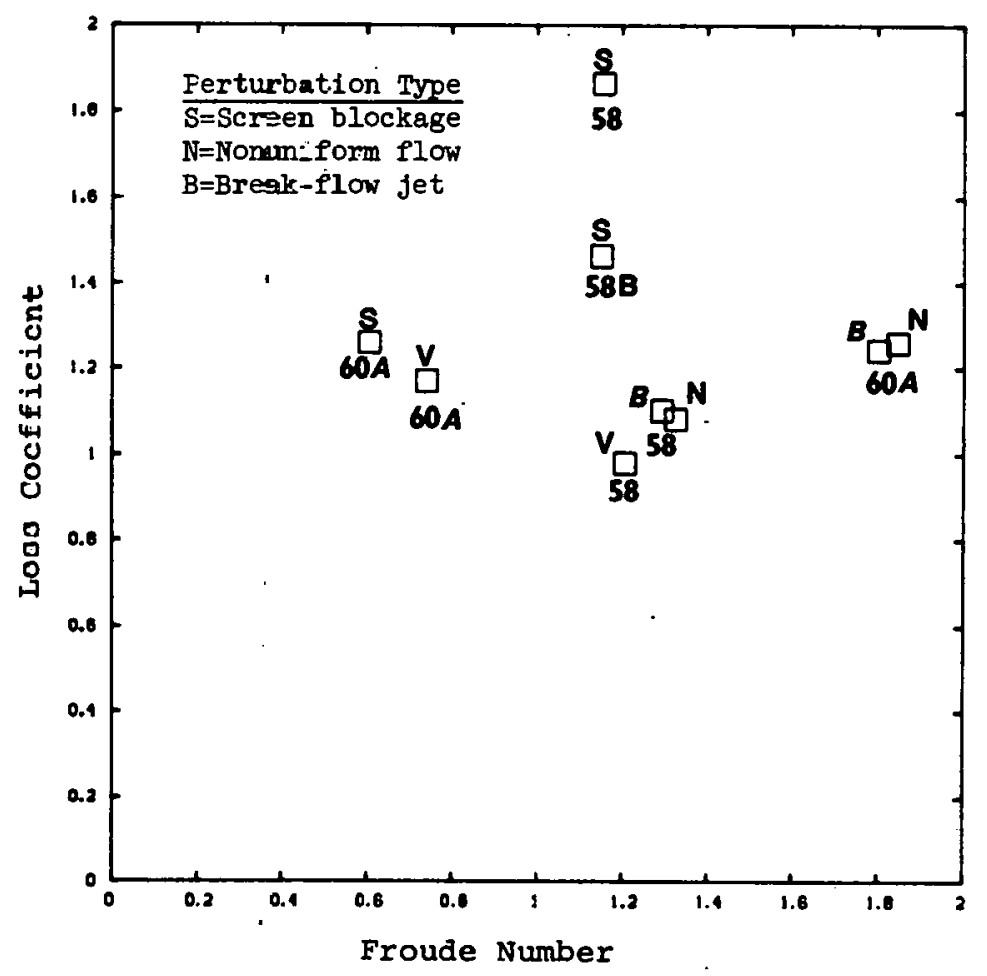

Figure 4.38 Daximum Loss Coefficient as a Function of the Froude Number for Perturbed Flow Conditions 
Sump response parameters, under conditions of blocked screens have been plotted as a function of the Froude number in Figures 4.39 through 4.42. The four screen blockage schemes used were shown in Figure 3.3. A direct comparison between the performance of a sump with and without screen blockage is given in Figures 4.47 through 4.50. The effects of screen blockage are clearly evident from these plots.

Four circulation patterns of sump approach flow were purposely induced during the nonuniform approach flow test series. These circulations were given on Figure 3.3 , and include patterns of swirl, couple, streaming and double swirl. The performance of the sump under these conditions of circulation is presented as a function of the Froude number in Figures 4.51 through 4.54 and in a comparative manner where uniform flow performance has been plotted against nonuniform flow performance in Figures 4.55 through 4.58 . The effects of break-flow jet impingement were tested with a single, falling jet of water with flow rates corresponding to either 40 percent or 60 percent of the total sump flow rate. The comparative plots of Figures 4.59 through 4.62 give the results of the tests.

Finally, the effects of flow cycling such as would occur during pump start up, switchover and shut down are presented in Figures 4.63 and 4.64 .

\subsubsection{Maximum Response in Perturbed. Flow Sumps}

The maximum 30-minute average observed responses, by configuration and by perturbation type, are given in Figures 4.35 through 4.38. (In these Figures, the configuration number has been placed below the symbol and the perturbation type, $s=$ screen blockage, $N=$ nonuniform approach flow, and $B=$ break-flow jet impingement, has been placed above the symbol.)

Maximum surface vortex type, as a function of the Froude number, is shown on Figure 4.35. No trend of increased vortex severity with increased Froude number is evident. The three tests found to produce Type 6 air-core vortices all occurred for relatively low Froude numbers (below $F=.8$ ) during either screen blockage tests or nonuniform approach flow tests. The maximum values for break-flow jet impingement were found to occur for high Froude numbers $(F=1.2)$.

Perturbed flow swirl angle maxima are shown as a function of the Froude number in Figure 4.36. Screen blockage tests of Configurations 58 and $58 \mathrm{~B}$ produced the highest 30 -minute average outlet swirl angles; 6.5 degrees for Configuration 58B, at a Froude number of 1.19 , and 4.5 degrees for Configuration 58, Froude number, $F=0.67$. All other outlet swirl maxima remained below 3 degrees.

Maximum air ingestion levels greater than 1 percent void fraction, were found to occur only for Froude numbers greater than $F=1.0$. Figure 4.37 shows the maximum 30-minute average air ingestion data plotted as a function of the Froude number. The greatest air ingestion measurement made for all of the vertical outlet tests was about 13 percent void fraction and occurred during a screen blockage test of Configuration 58 (flowrate $=5300$ $\mathrm{gpm} / \mathrm{pipe}$, submergence $=5 \mathrm{ft}$ ). 


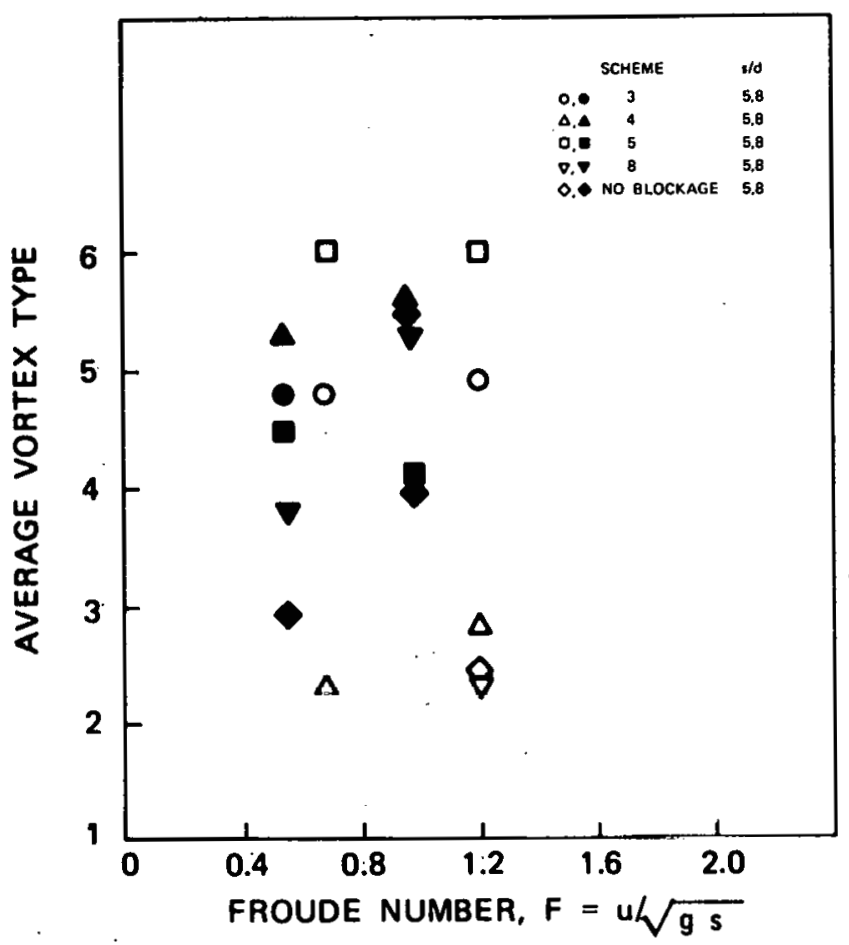

Figure 4.39 Average Vortex Type as a Function of the Froude Number for Screen Blockage, Configuration 58 .

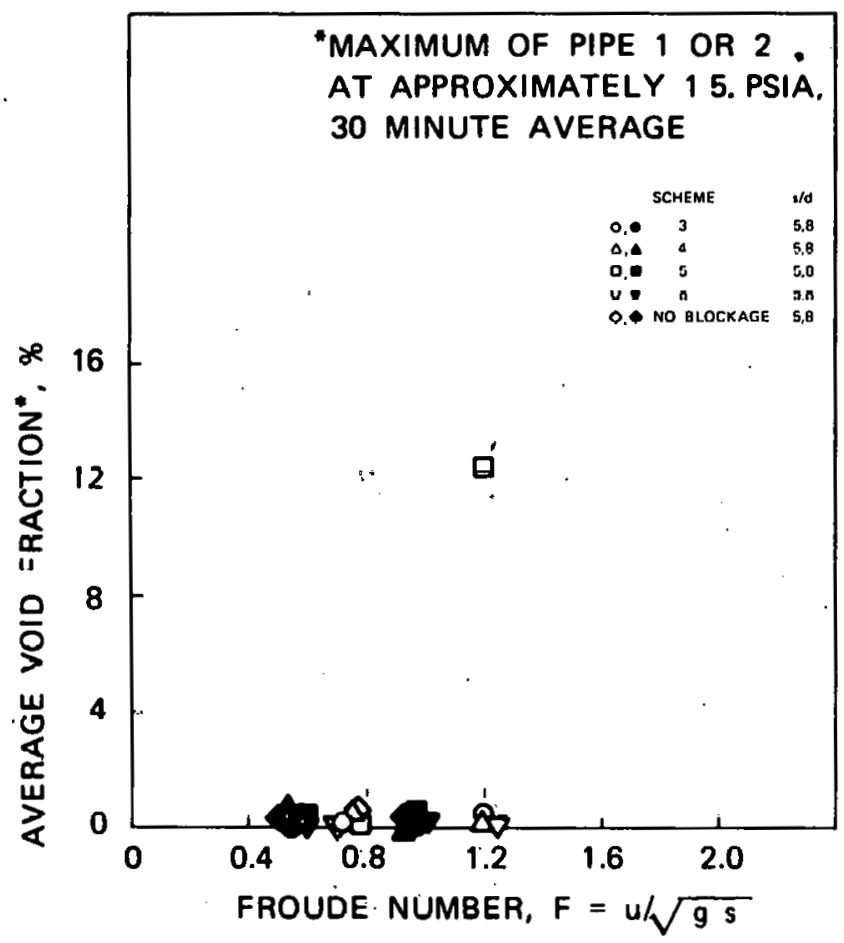

Figure 4.40 Averaige Void Fraction as a Function of the Froude Number for Screen Blockage, Configuration 58 


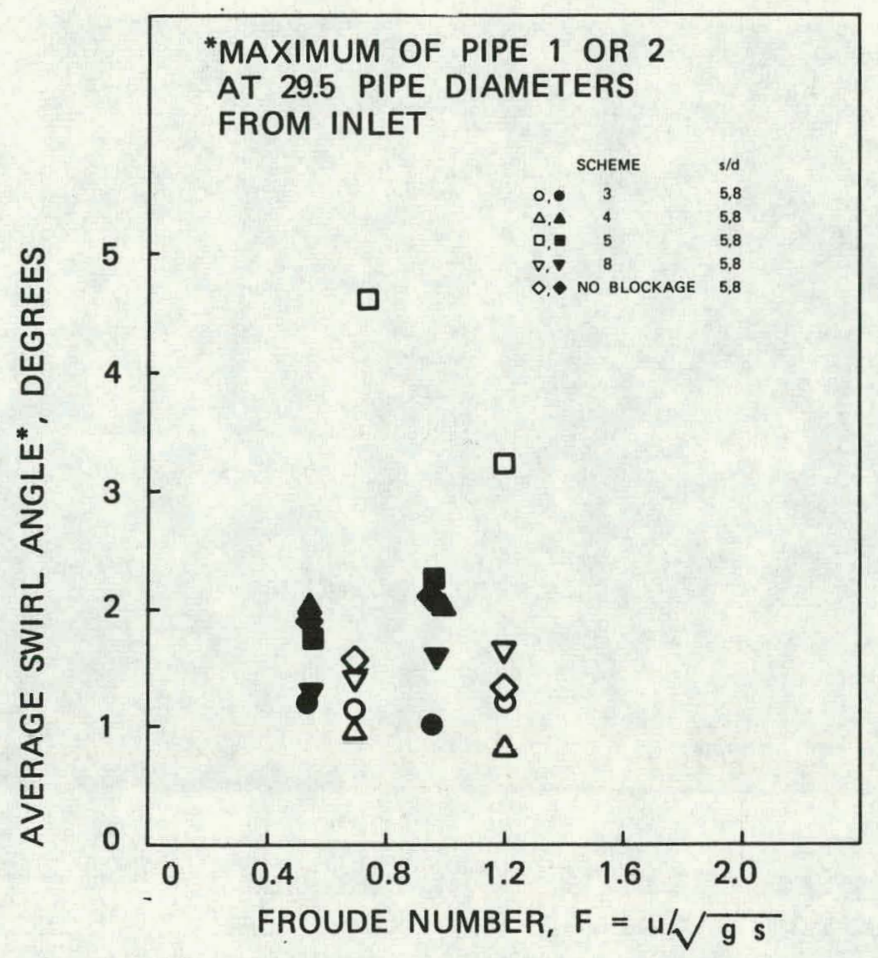

Figure 4.41 Average Swirl Angle as a Function of the Froude Number for Screen Blockage, Configuration 58

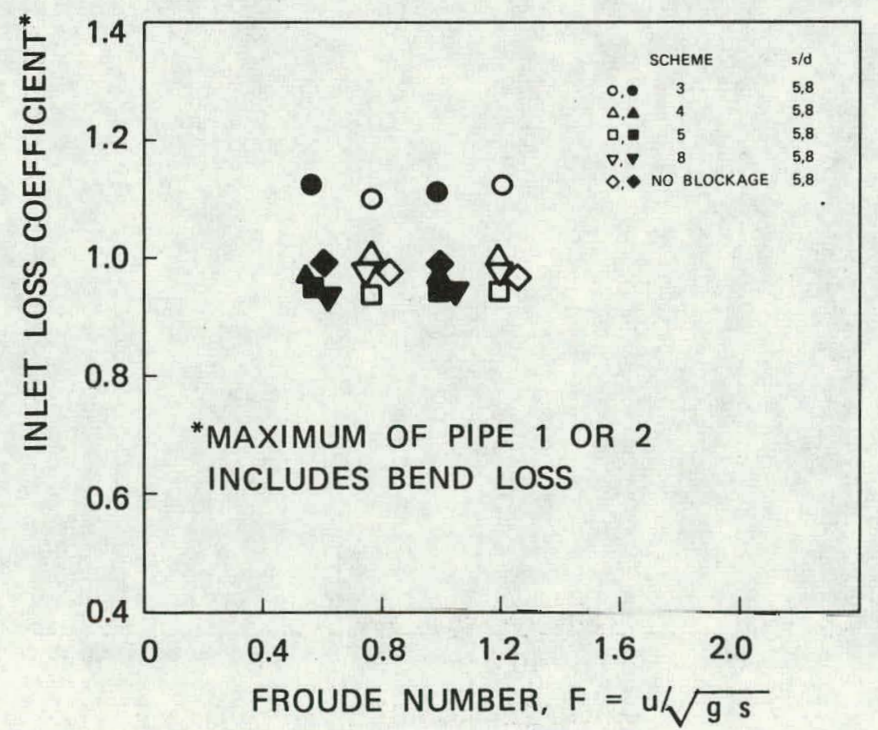

Figure 4.42 Loss Coefficient as a Function of the Froude Number for Screen Blockage, Configuration 58 


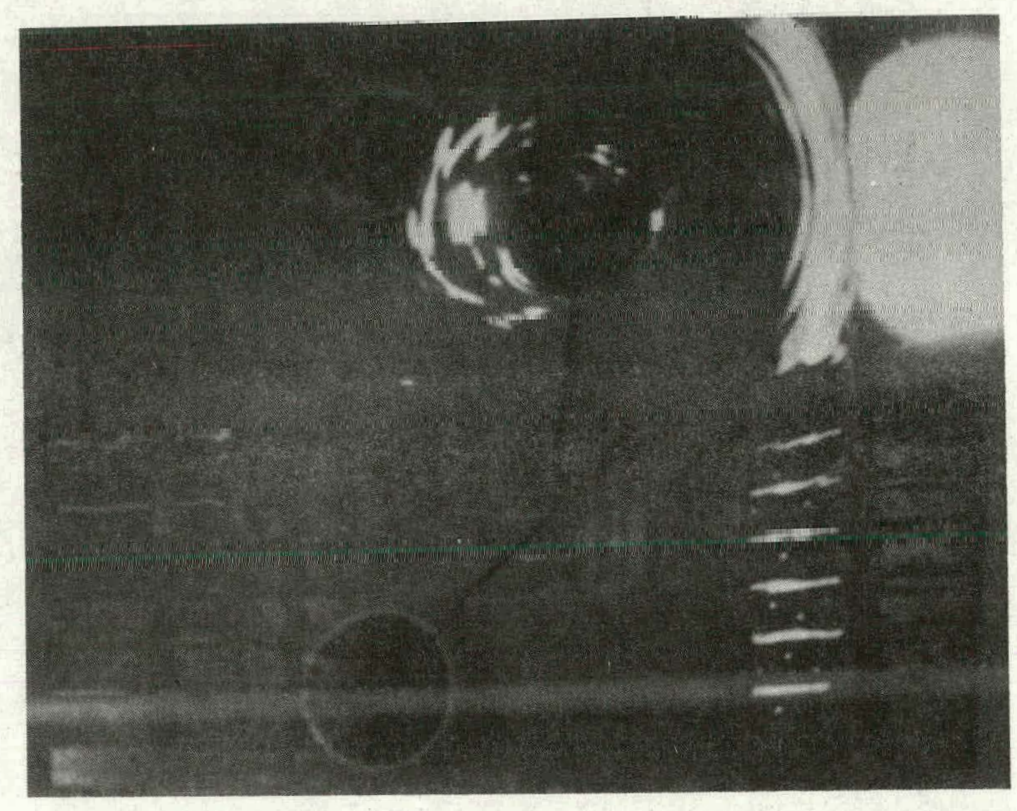

Figure 4.43 Typical Air-Core Vortex in Configuration 58 Luring a Screen Blockage Test. Submergence $=8 \mathrm{ft}$ and flowrate $=5300 \mathrm{gpm} / \mathrm{pipe}$. Void fraction $<0.3 \%$.

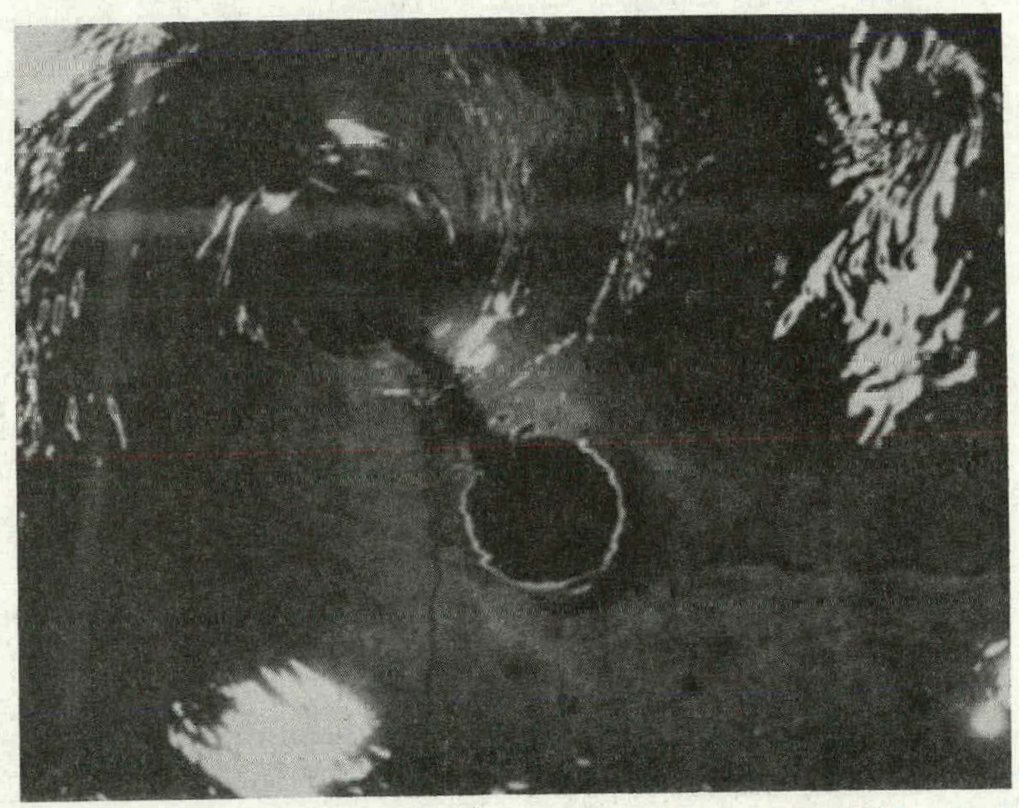

Figure 4.44 Typical Air-Core Vortex in Configuration 58 During a Screen Blockage Test. Submergence $=5 \mathrm{ft}$ and flowrate $=5300 \mathrm{gpm} / \mathrm{pipe}$. Void fraction $<0.3 \%$. 


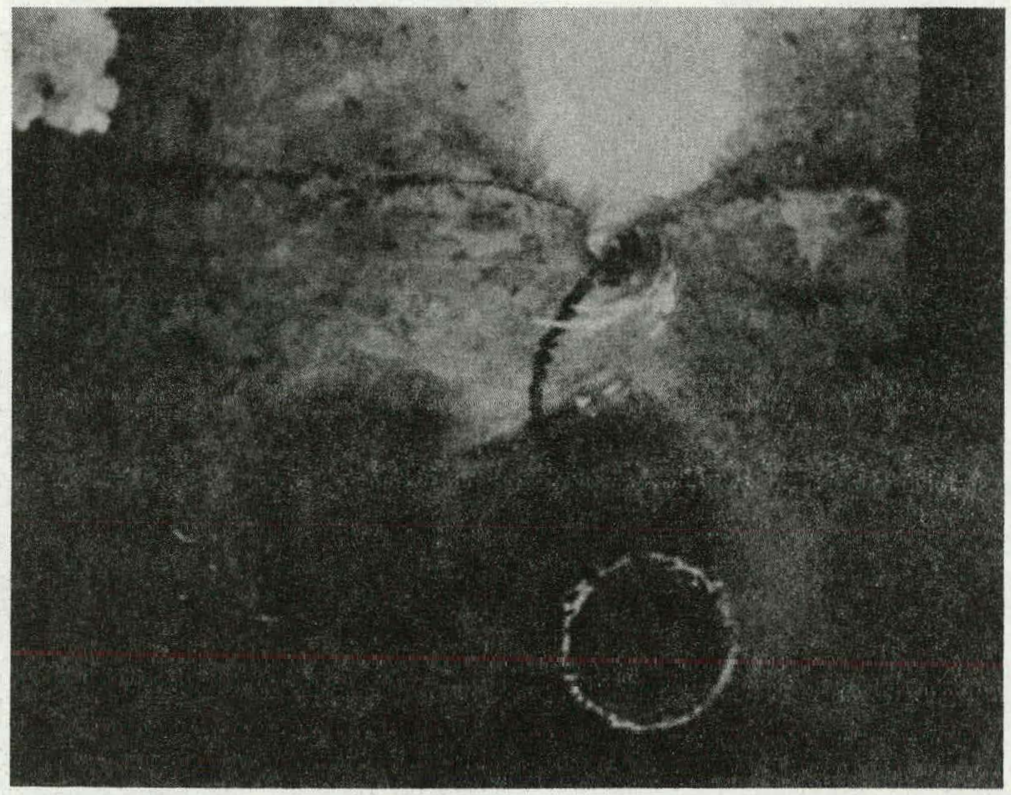

Figure 4.45 Typical Air-Core Vortex in Configuration 60A During a Screen Blockage Test. Submergence $=3 \mathrm{ft}$ and flowrate $=5300 \mathrm{gpm} / \mathrm{pipe}$. Void fraction $<0.3 \%$.

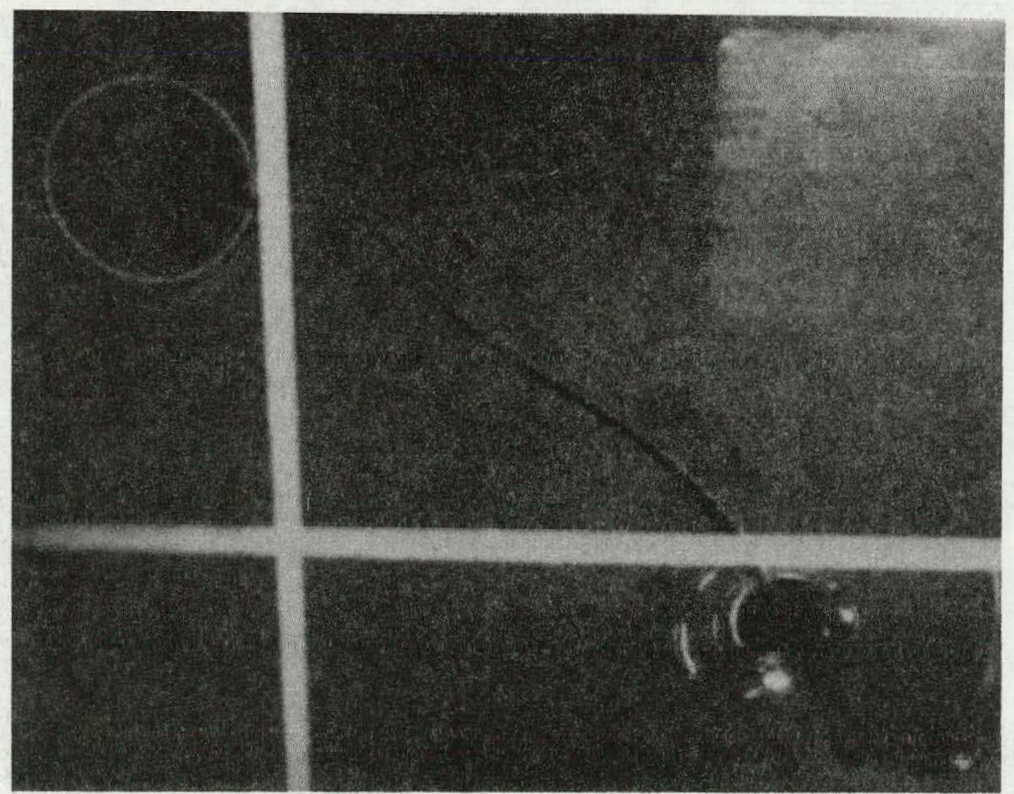

Figure 4.46 Typical Air-Core Vortex in Configuration $60 \mathrm{~A}$ During a Screen Blockage Test. Submergence $=6 \mathrm{ft}$ and flowrate $=5300 \mathrm{gpm} / \mathrm{pipe}$. Void fraction $<0.3 \%$. 


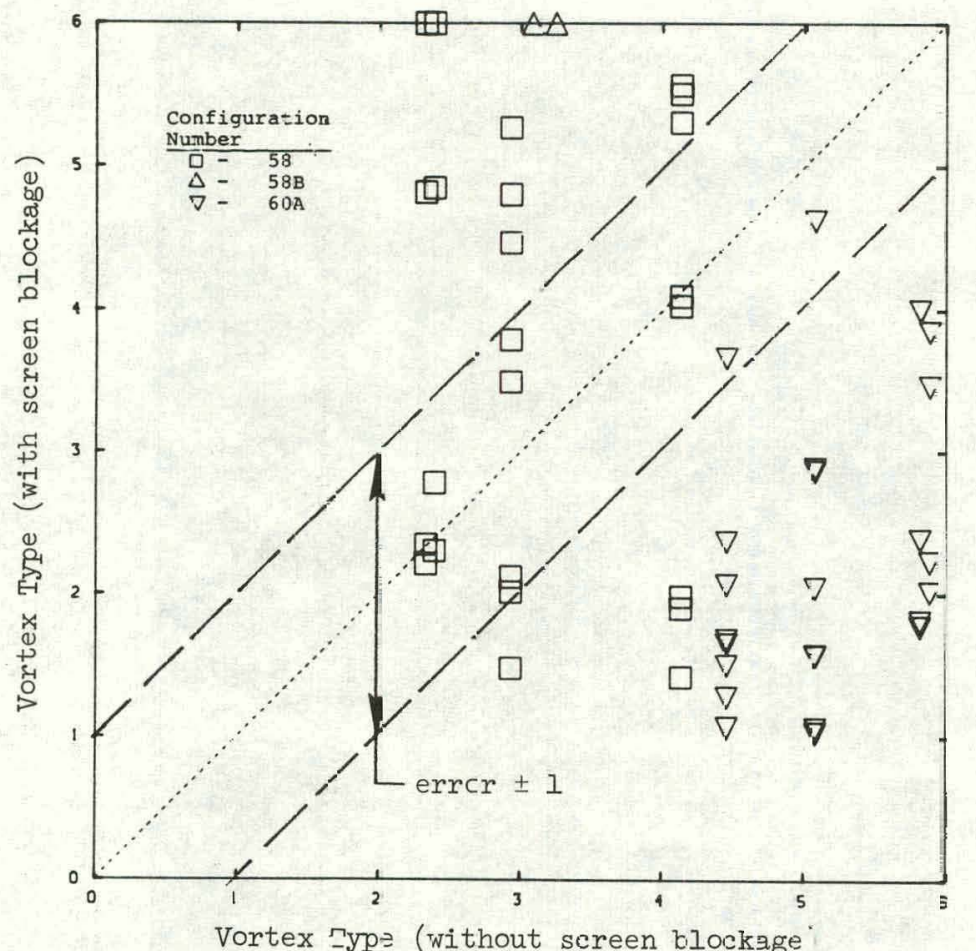

Figure 4.47 The Effect of Screen Blockage on Vortex Severity

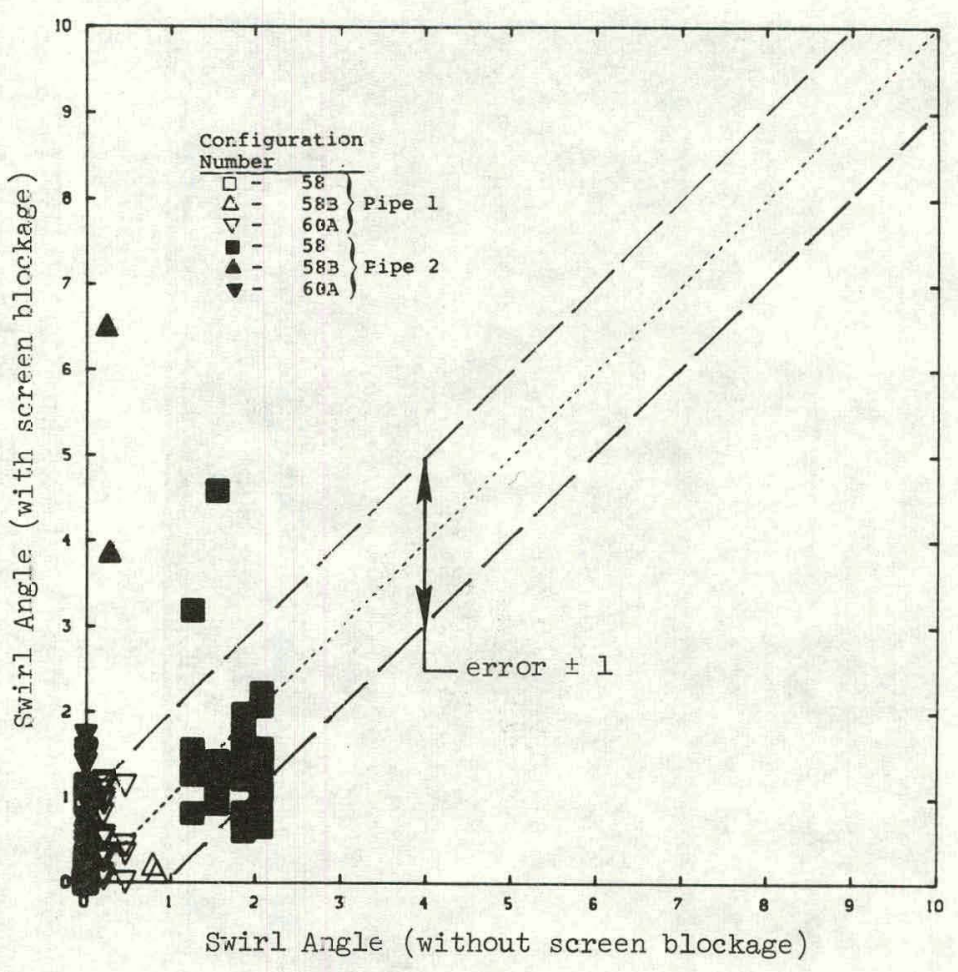

Figure 4.48 The Effect of Screen Blockage on Outlet Swirl Angle Performance 


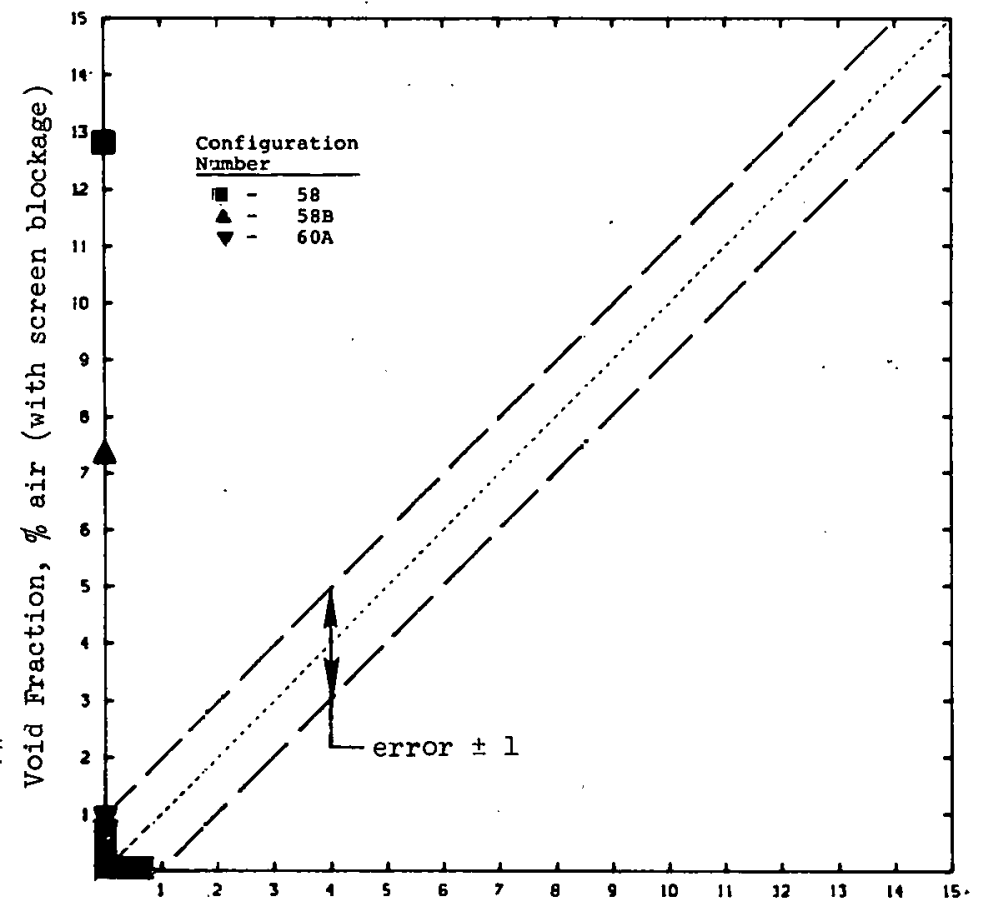

Void Fraction, $z$ air (without screen blockage)

Figure 4.49 The effect of Screen Bloskage on Void

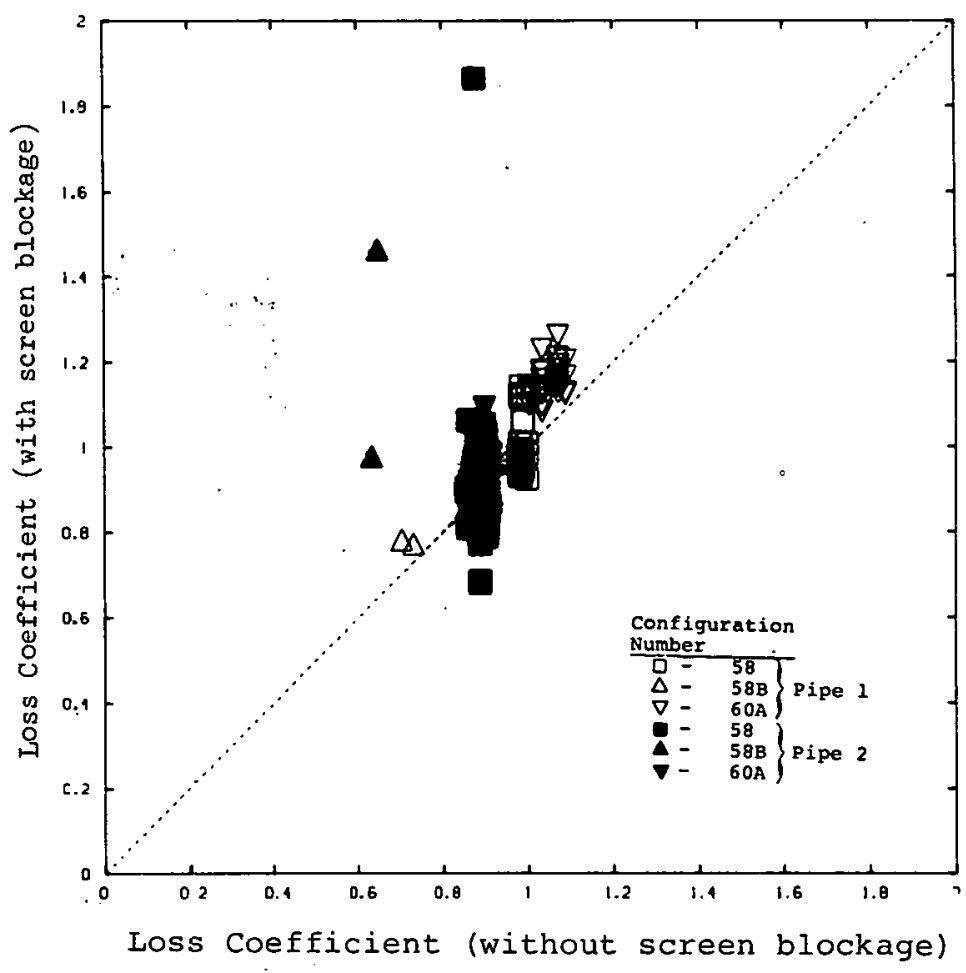

Figure 4.50 The Effect of Screen Blockage on Loss Fraction Performance 


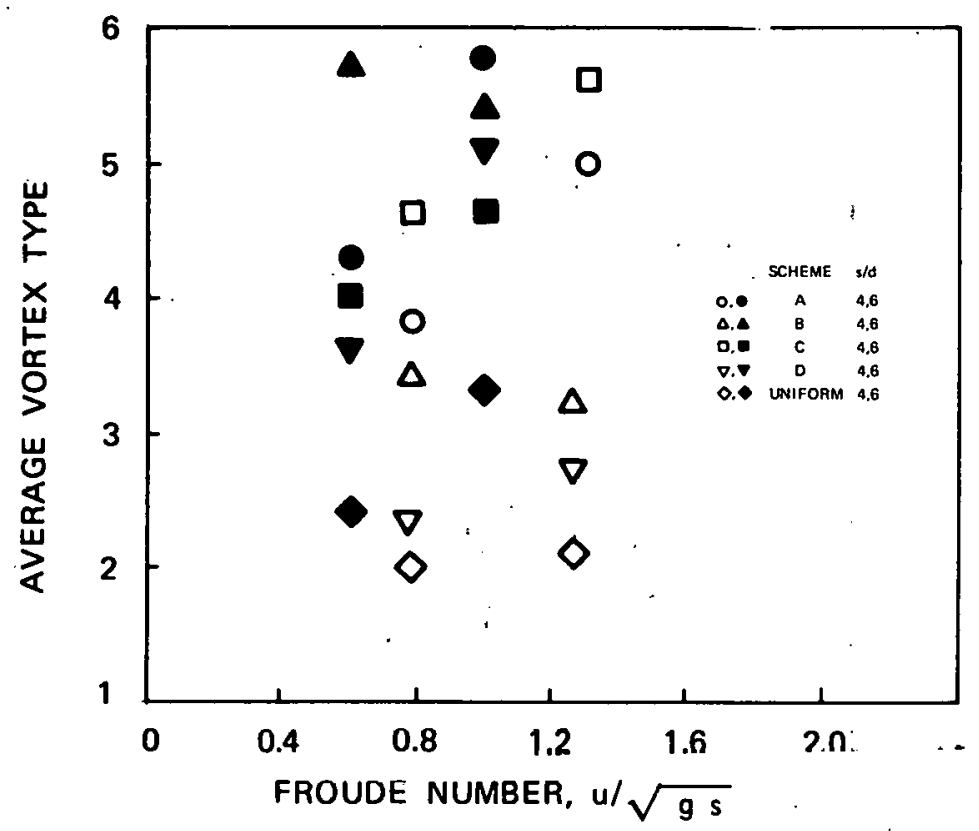

Figure 4.51 Vortex Type as a Function of the Froude Number for Nonuniform Approach Flow Conditions

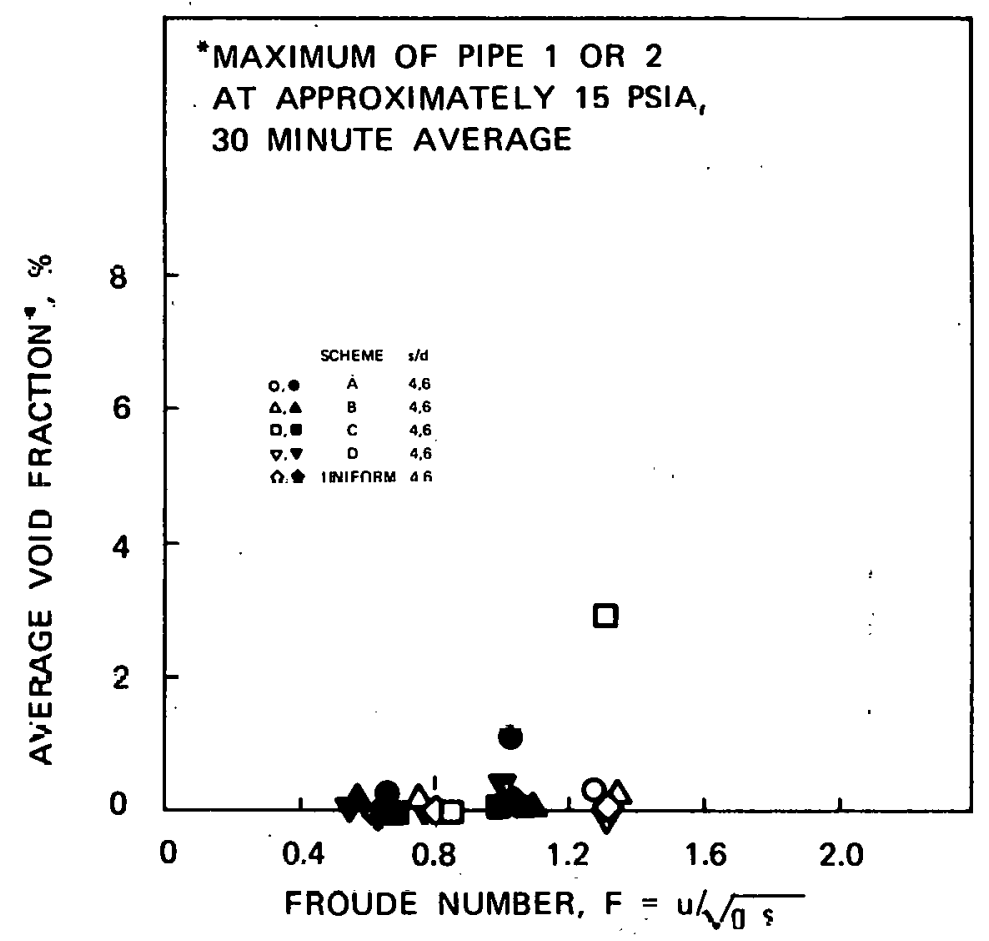

Figure 4.52 Void Fraction as a Function of the Froude Number for. Nonuniform Approach Flow Conditions 


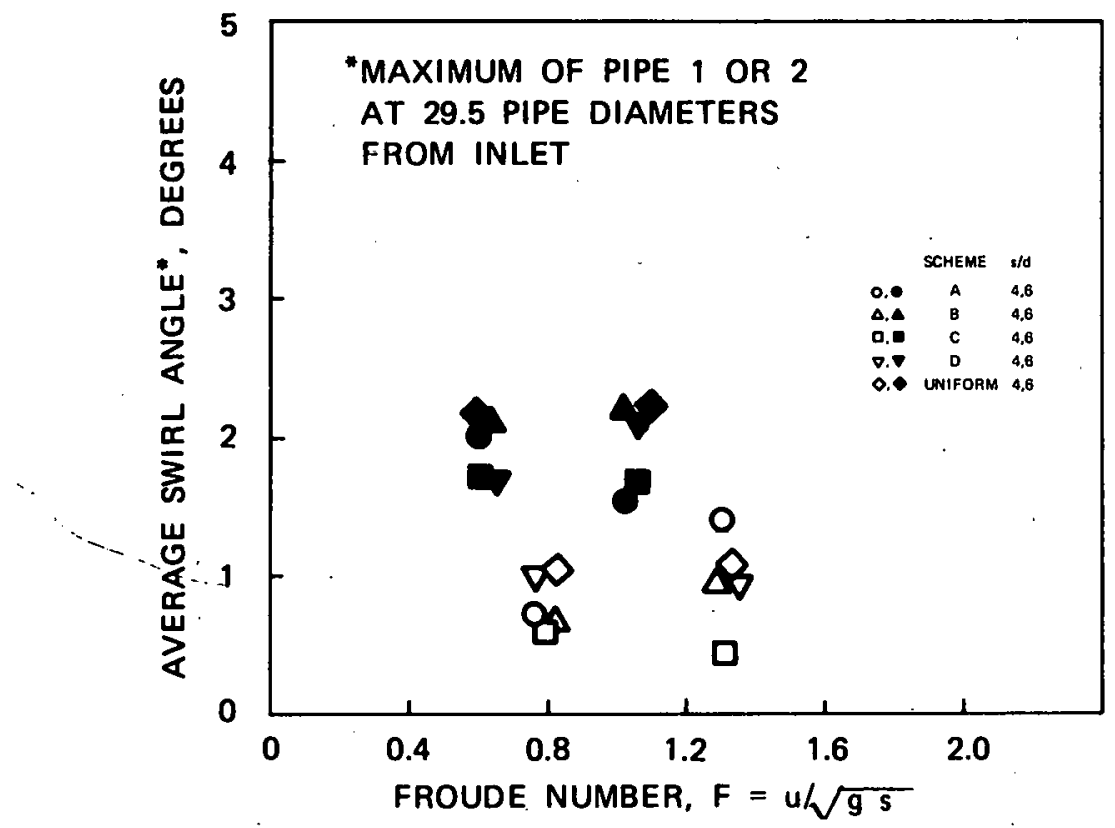

Figure 4.53 Outlet Swirl Angle as a Function of the Froude Number for Nonuniform Approach Flow Conditions

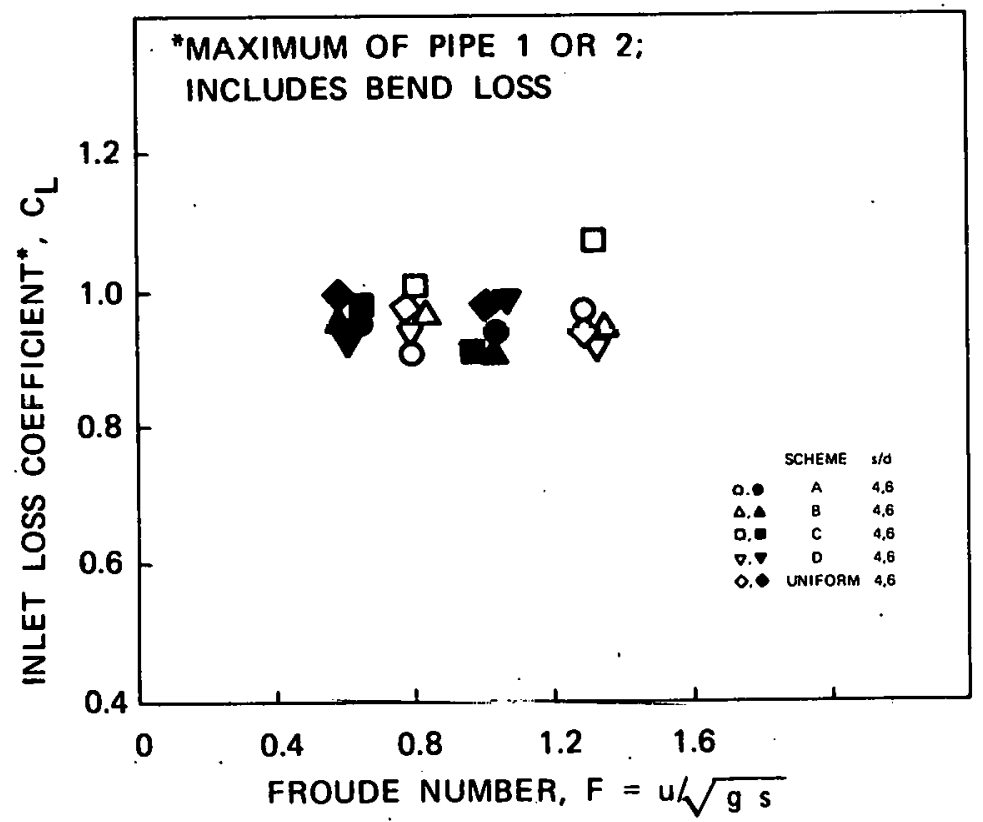

Figure 4.51 Loss Coefficient as a Function of the Froude Number fur Nonuniform Approach Flow Conditions 


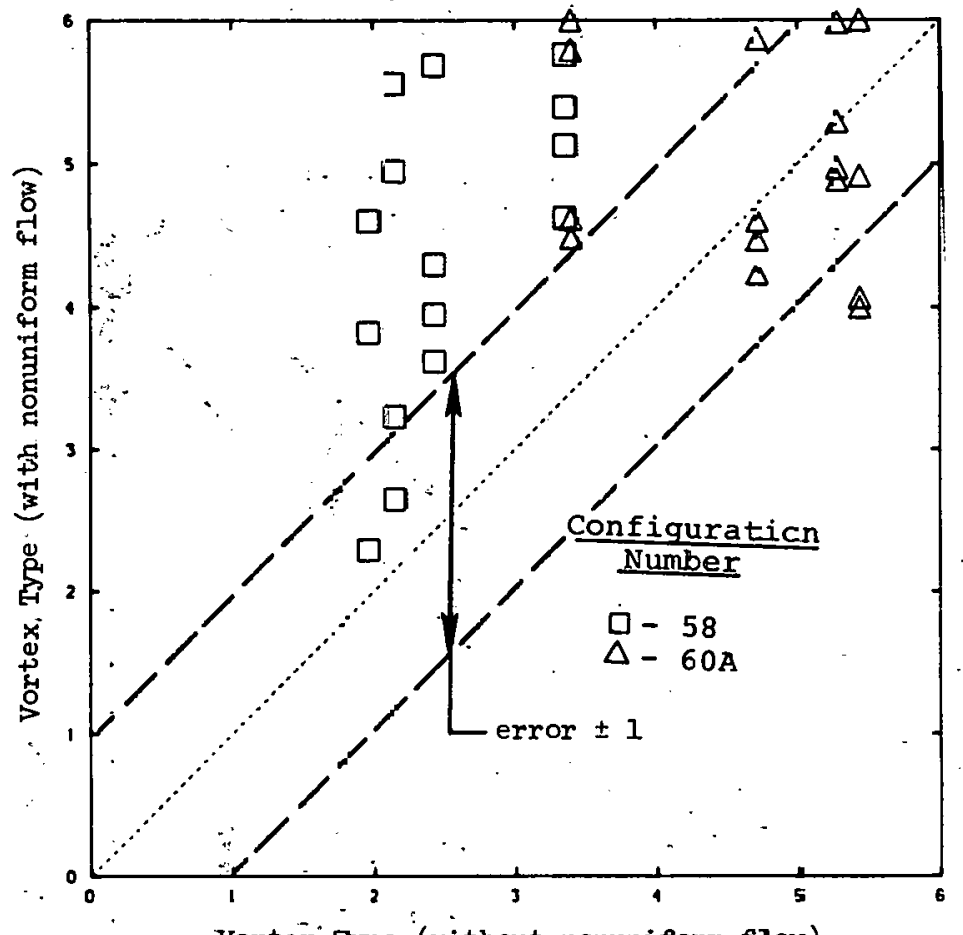

Vortex type (without nonuniform flow)

Figure 4.55 The Effect of Nonuniform F.pproach Flow on Vortex Severity

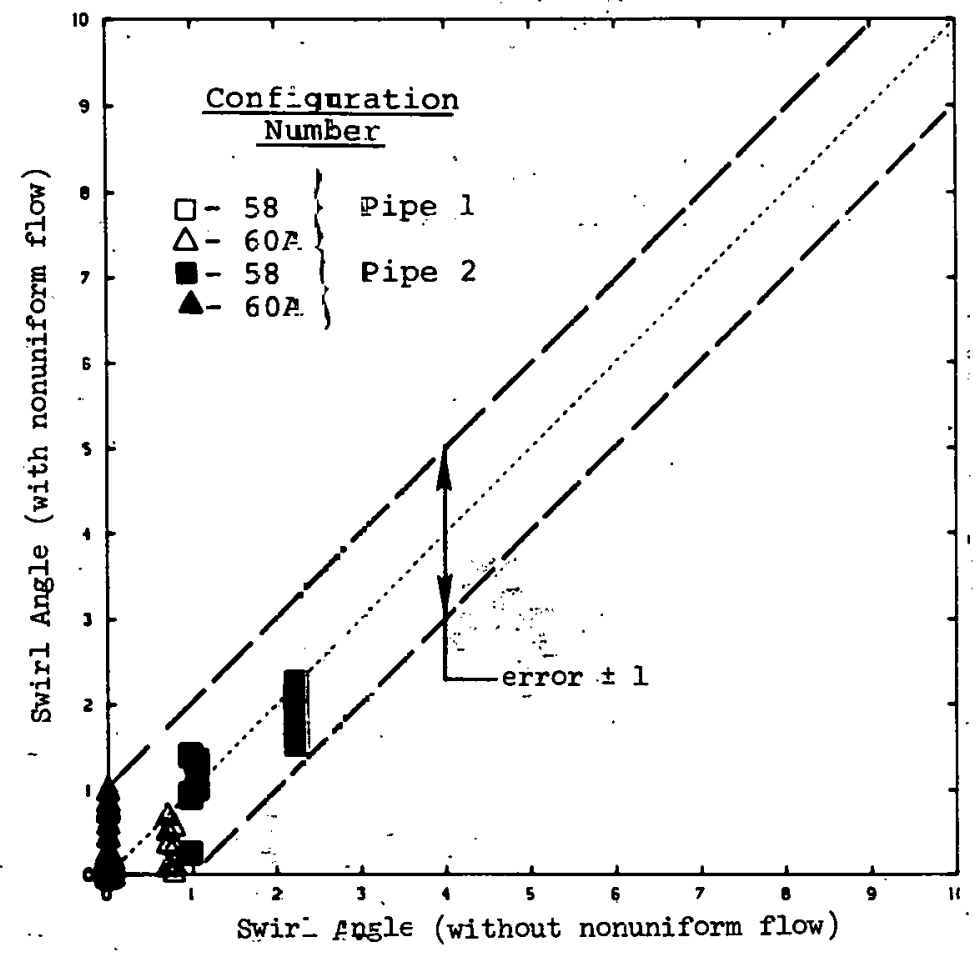

Figure 4.56 The Effect of Nonuniform Approach Flow o.ltlet Swirl Angle 


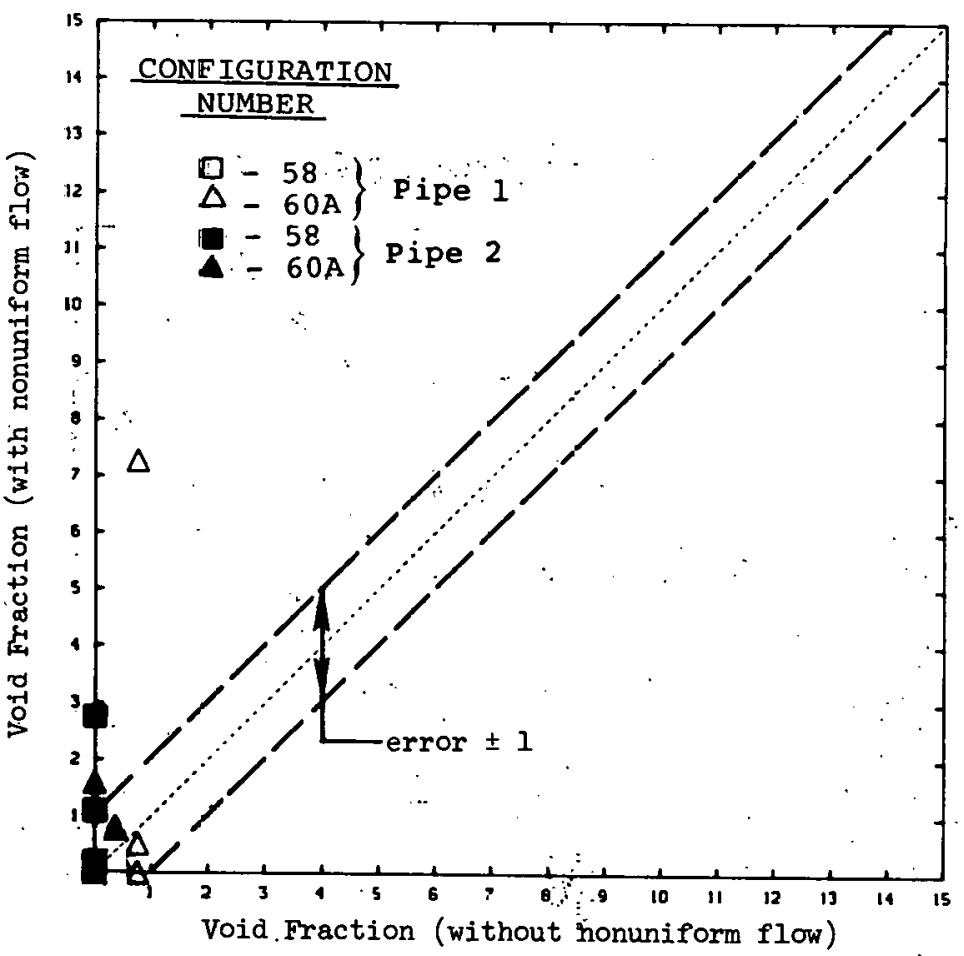

Figure 4.57 The Effect of Nonuniform Approach Flow on Void Fraction

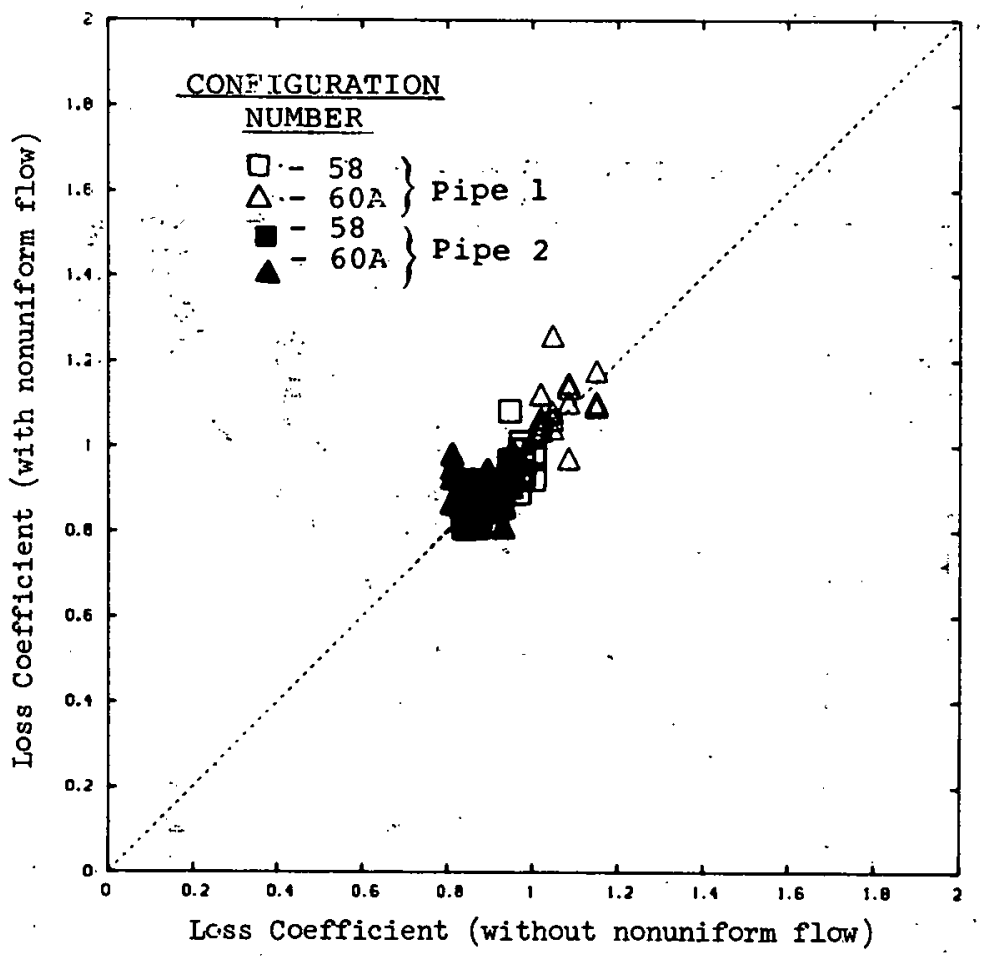

Figure 4.5E The Effect of Nonuniform Approach Flow on Loss Coefficient 


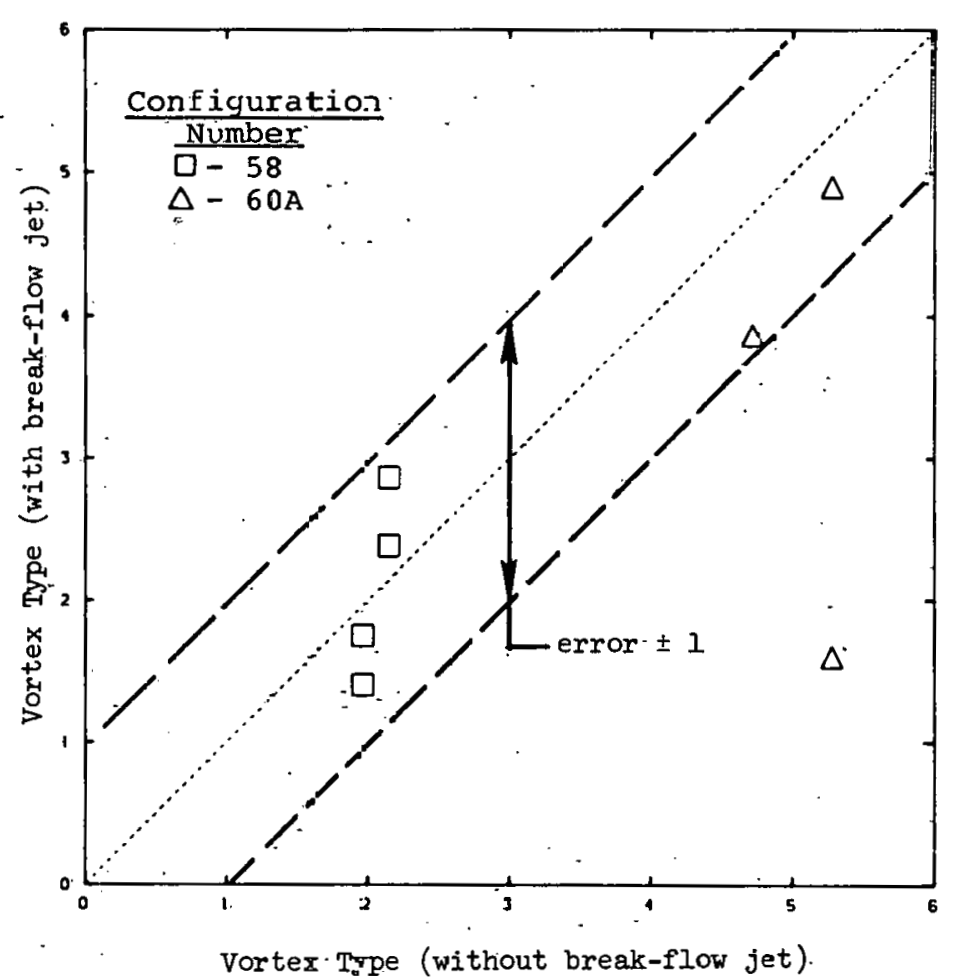

Figure 4.59 The Ejfect of Break-Flow Jet Impingement on Vortex severity

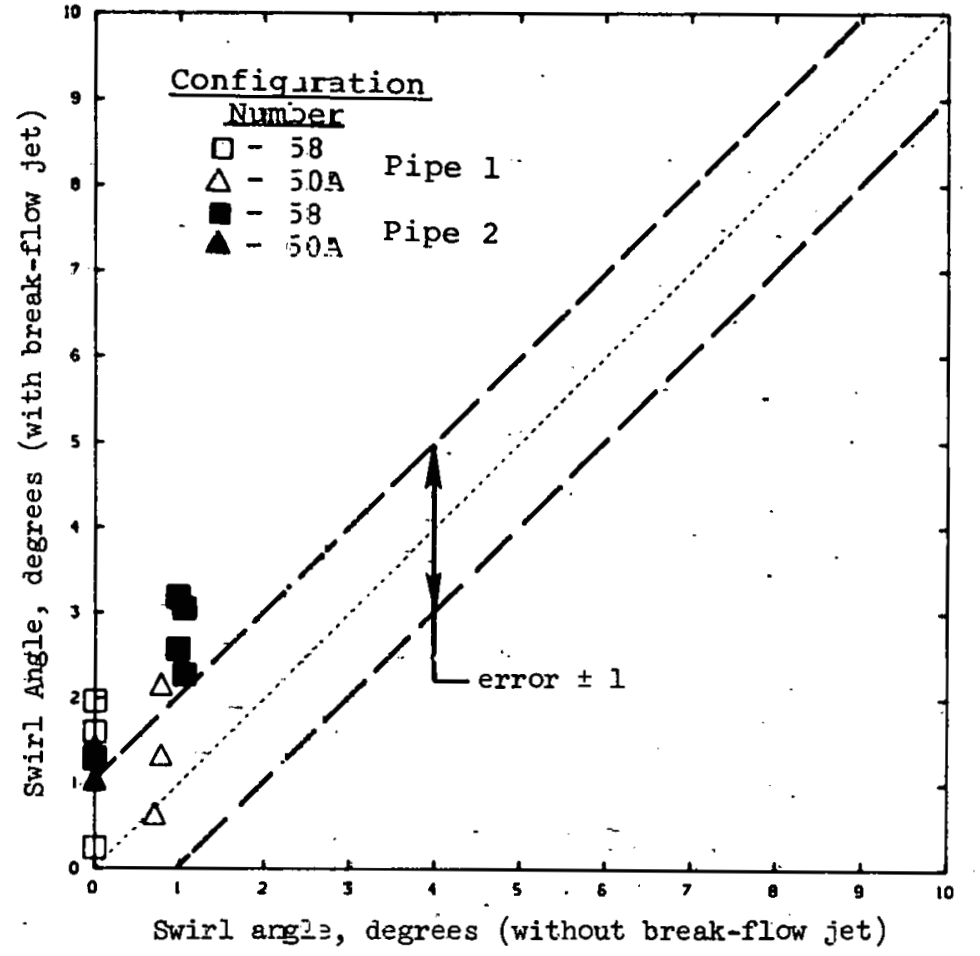

Figure 4.60 The Effect of Break-Flow Jet Impingement c.n Outlet Swirl Angle 


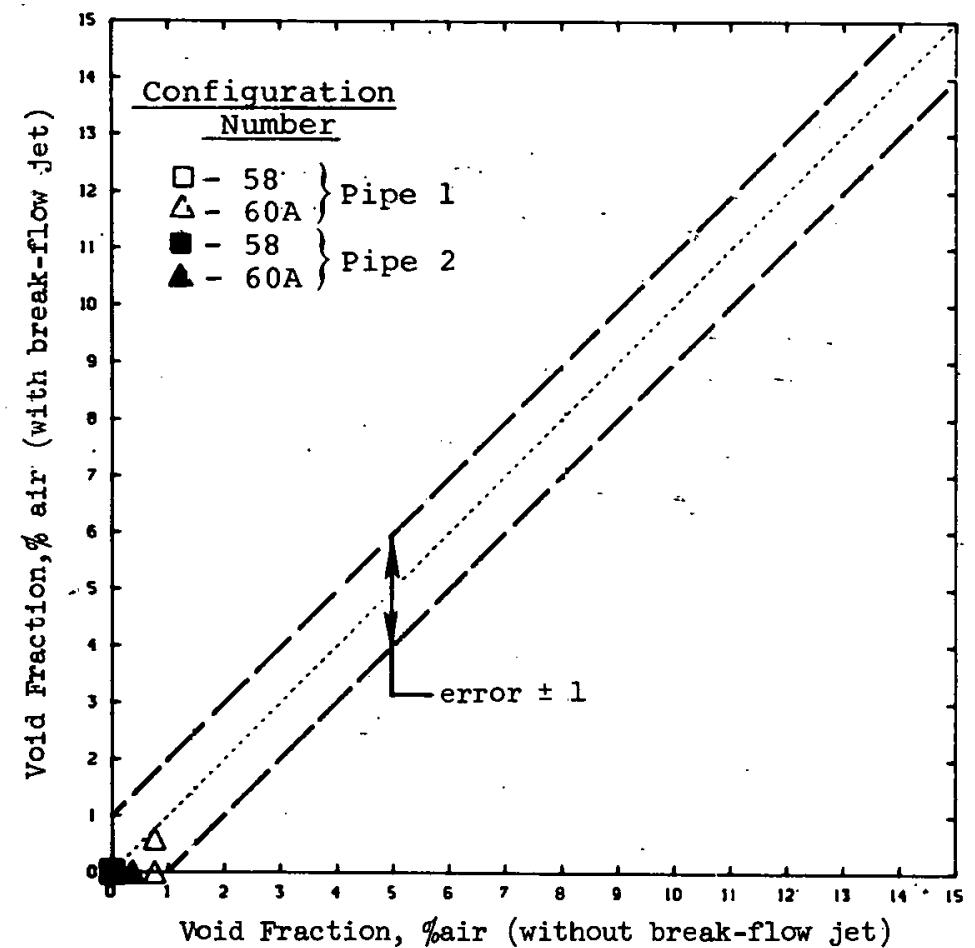

Figure 4.51 The Effect of Break-Flow Jet Impingement on Void Fraction

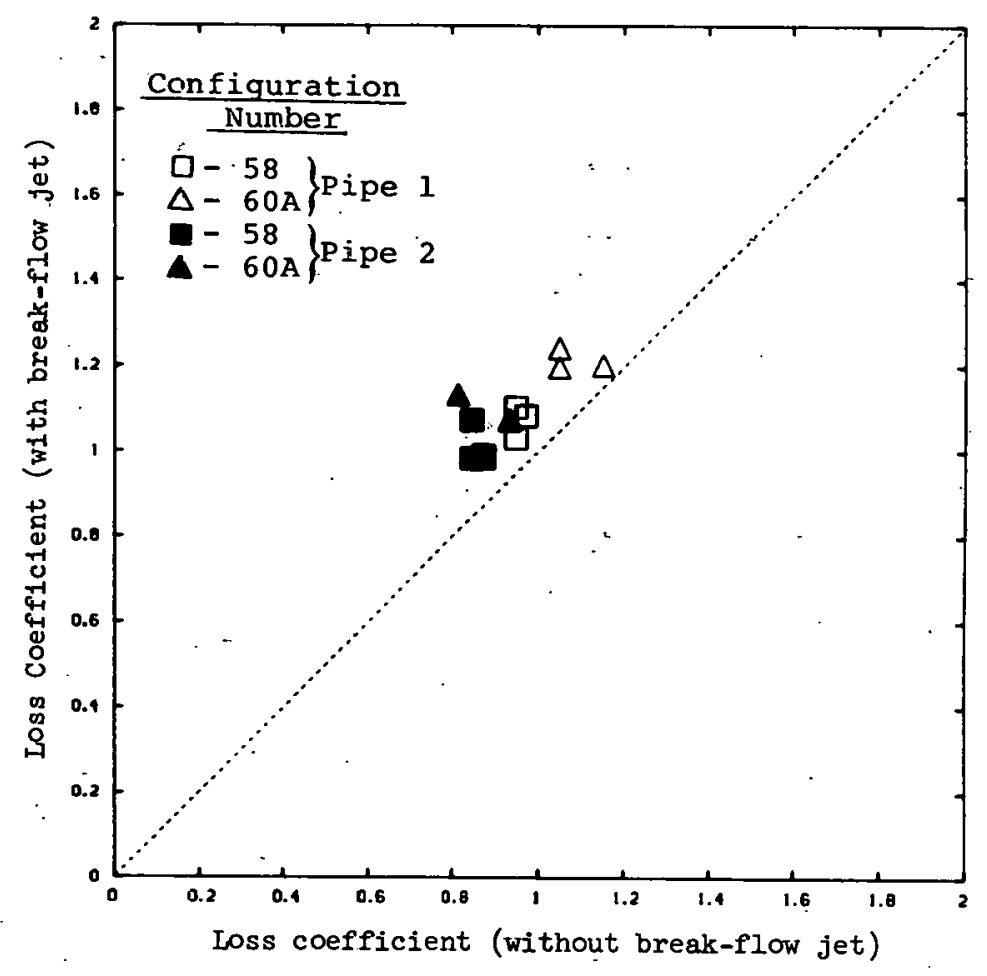

Figure 4.62 The Effect of Break-Flow Jet Impingement on Loss Coefficient 

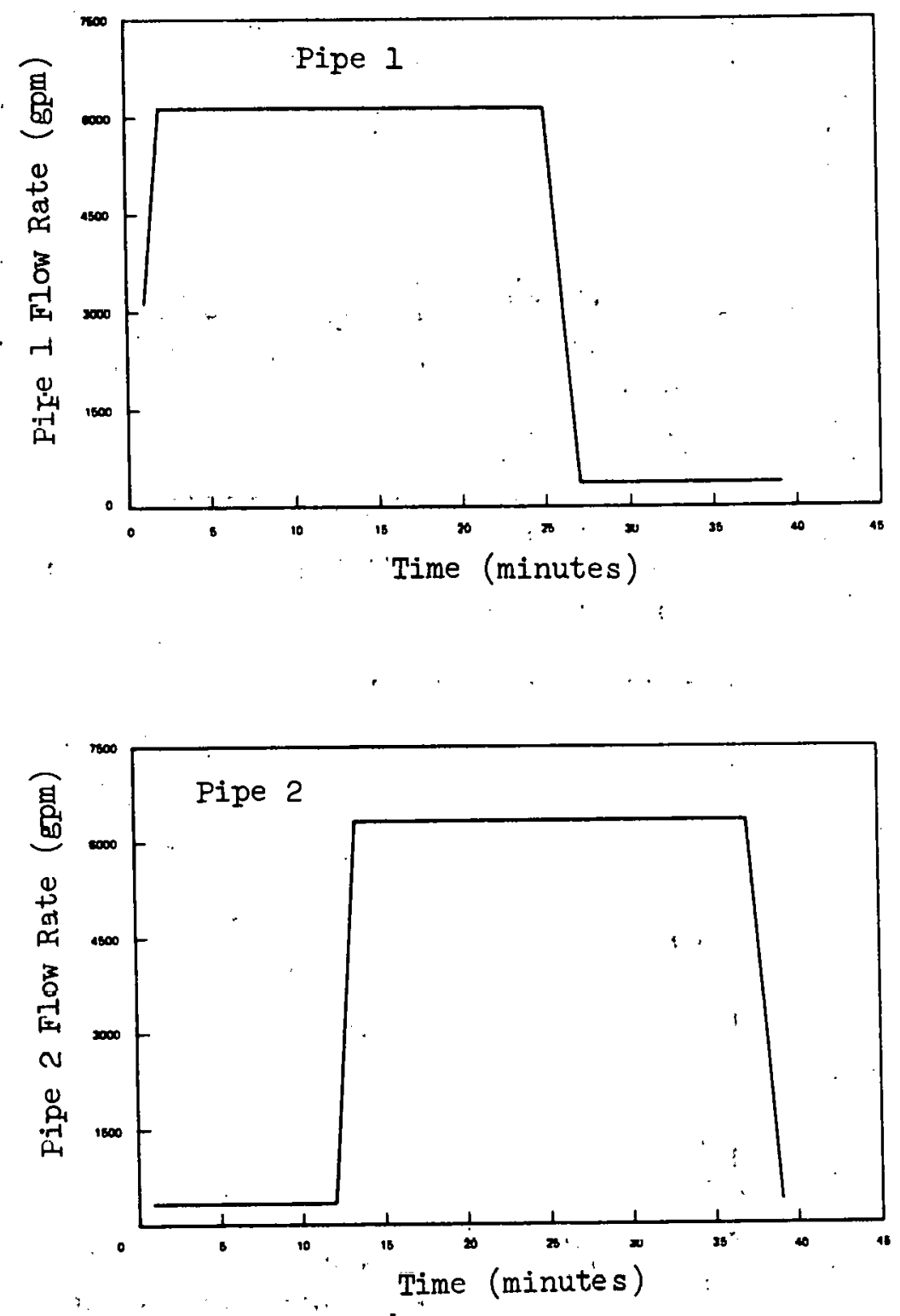

Figure 4.63 Flow Rate Versus Time Schedule for Transient Flnw Tests 


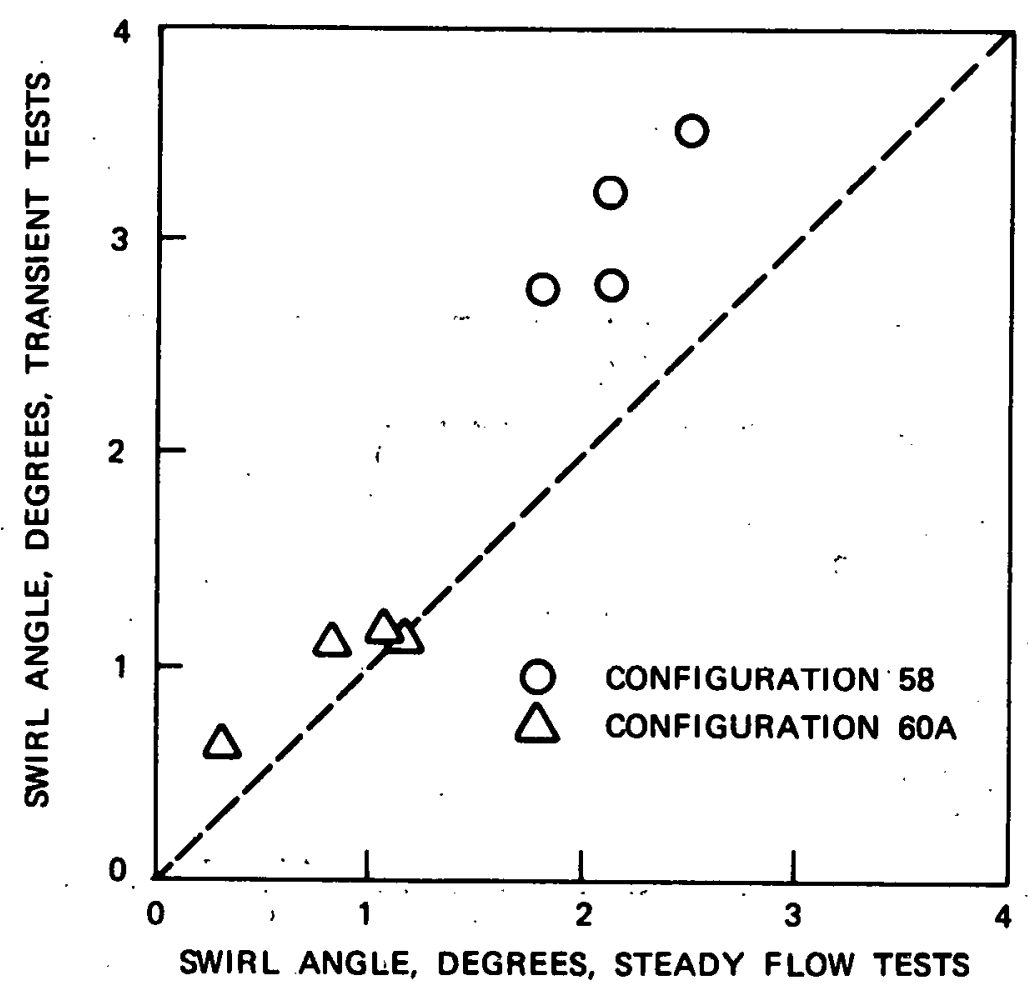

A. 30 SECOND AVERAGE SWIRL ANGLES

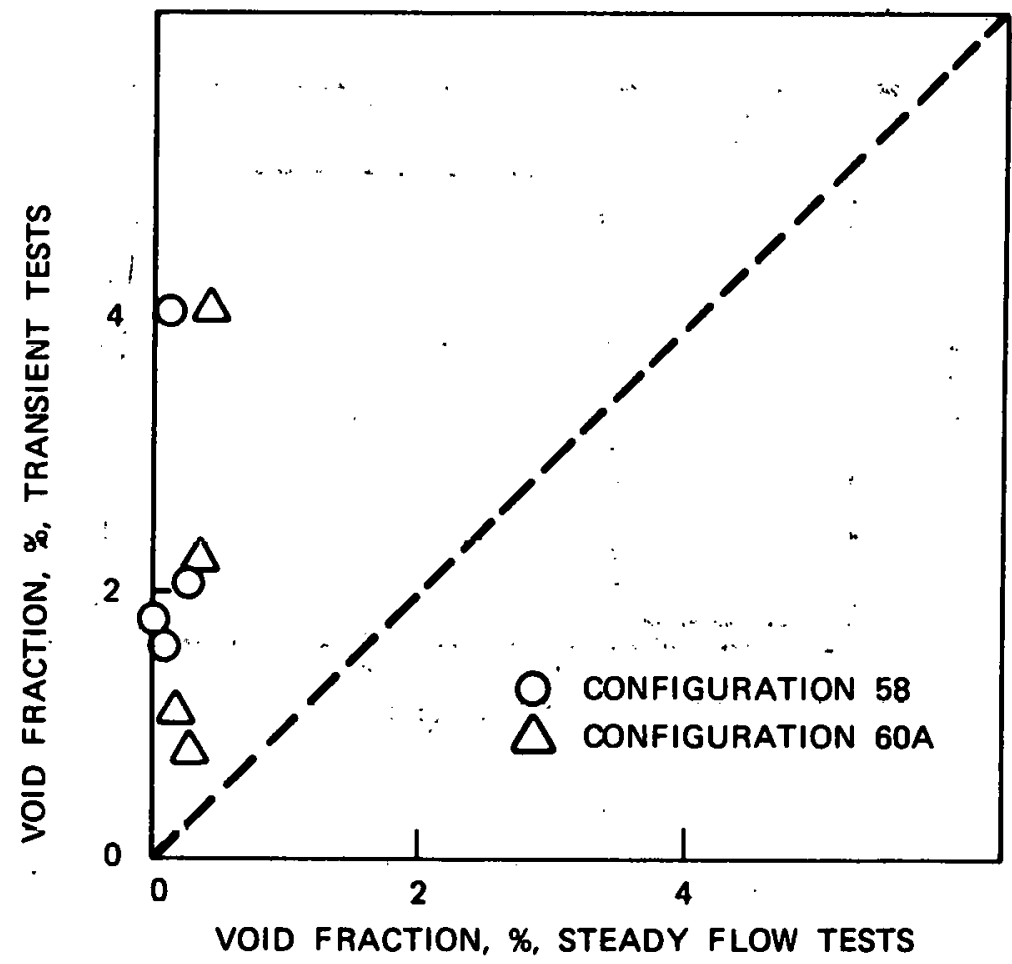

B. 30 SECOND AVERAGE VOID FRACTIONS

Figure 4.64 The Effect of Transient Flow Conditions on Outlet Swirl Angle and Void Fraction 
Figure 4.38 shows the loss coefficient maxima recorded for perturbed flow testing. The two high values of loss coefficient correspond to the high values of air ingestion shown on Figure 4.37 and also to the high values of outlet swirl shown on Figure 4.36 .

\subsubsection{The Effects of Screen Blockage}

Vortex severity for test Configuration 58, during screen blockage perturbations, is shown as a function of the Froude number in Figure 4.39. Screen blockage was not found to induce any Froude number dependence on vortex activity.

Air ingestion levels for Configuration 58 remained very small (<1 percent void fraction) for all but one test. The air ingestion data is shown on Figure 4.40. The single largest air ingestion observed, at approximately 13 percent void fraction, occurred for screen blockage scheme 5 at a flow $r$ ate of 5300 $\mathrm{gpm} / \mathrm{pipe}$ and for a submergence of $5 \mathrm{ft}$.

Figure 4.41 shows the outlet swirl angles for Configuration 58 as a function of the Froude number. Most of the swirl angles recorded during screen blockage tests remained below 2 dcgrcce. The large swirl angle, about 4.5 degrees, corresponds to the same test that produced the type 6 vortex of Figure 4.39 .

Loss coefficient data for Configuration 58 was found to be generally unaffected by screen blockage. This result is shown in Figure 4.42. A substantial difference in flow patterns at the outlet may be responsible for the slightly higher loss coefficient measurements for blockage scheme 3; vortexing and swirl levels for blockage scheme 3 were less than that for other blockage schemes.

(The performance of Configuration 60A, under conditions of screen blockage, was similar to that of Configuration 58. Also, screen blockage tests were performed on Configuration 58B and Configuration $60 \mathrm{~B}$, both with the outlet mounted flush with the sump floor. Each of the two configurations were tested at a flow rate of $5300 \mathrm{gpm} / \mathrm{pipe}$ with submergences of $\mathrm{s}=5 \mathrm{ft}$ and $\mathrm{s}=3 \mathrm{ft}$ for screen blockage scheme 5 . Both conflgurations produced air core vortices with 30-minute average air ingestions of 7 percent voia fraction for configuration $58 \mathrm{~B}$ and 13 percent void traction for Configuration 60B.)

Figures 4.43 through 4.46 show photographs of several air core vortices resulting from the screen blockage test series.

The plot of Figure 4.47 gives a comparison of the vortex type performance between uniform fiow tests and the blocked-screen versions of the same tests. The diagonal 1 ine indicates identical performance. The region on the plot that lies above the diagonal ine indicates a detrimental effect resulting from blocked screens, while the region below the diagonal indicates lower vortex activity as a result of blocked screens. Screen blockage was found to produce a consistent reduction in vortex severity for configuration 60A, as shown in Figure 4.47. No other general effects were observed.

The swirl angle comparison of Figure 4.48 shows a slight decrease in the outlet swirl for most of the Configuration 58 data. Some increases in outlet swirl occurred for Configuration $60 \mathrm{~A}$, although the majority of tests remained within the expected error bounds of $1^{\circ}$. Tests of Configuration 58B showed increases in swirl as a result of screen blockage. 
A comparison of air ingestion levels, shown on Figure 4.49, indicates no general increase in air ingestion as a result of most screen blockage tests. Two specific blockage tests exhibited substantially higher air ingestion than that which was measured during unperturbed tests: Configuration 58 with an air ingestion level of about 13 percent void fraction and Configuration 58B with an air ingestion level of about 7 percent void fraction.

In general, loss coefficients remained unaffected by flow perturbations such as screen blockage. The loss coefficient comparison is shown on Figure 4.50 .

\subsubsection{The Effects of Nonuniform Approach Flow}

Results from the nonuniform approach flow experiments (Figure 3.3 ) conducted with the geometry of Configuration 58 are shown in Figures 4.51 through 4.54. The results from the nonuniform approach flow experiments utilizing Configuration 60A, although not shown, were found to be similar to those for Configuration 58 .

No trends of vortex severity were seen to result from nonuniform approach flows. Vortex type is plotted as a function of Froude number in Figure 4.51. The streaming approach flow produced the most severe vortices at the highest Froude number, while the couple produced the most severe vortex activity at the lowest Froude number. (Results from the two uniform flow tests are shown as diamond symbols on Figure 4.51. A comparison of sump performance between unperturbed and perturbed flow conditions is given later in this section).

Figure 4.52 shows that generally low levels of air ingestion $(<1$ percent) resulted from the nonuniform approach flow testing of Configuration 58. The maximum air ingestion level observed was about 3 percent void fraction. This occurred at a high Froude number, $F=1.33$.

Swirl angle performance under conditions of nonuniform approach flow is shown in Figure 4.53. Swirl angles, including contributions made by the $90^{\circ}$ elbow downstream of the outlet, remained small. The largest swirl angles observed were about 2 degrees.

Measurements of loss coefficients indicated that this parameter was unaffected by flow perturbations: values of the loss coefficient for test conditions in Configuration 58 are shown as a function of the Froude number in Figure 4.54 .

The direct comparison of vortex severity under nonuniform flow and uniform flow conditions is shown in Figure 4.55. A general increase in vortex severity was found to result from nonuniform approach flows for both Configurations 58 and $60 \mathrm{~A}$. A number of Configuration $60 \mathrm{~A}$ tests, however, remained well within the error bands and showed essentially no change in vortex severity over that ohserved for uniform approach flow.

Although large circulations were induced in the approach flow to the sump, essentially none of the induced swirl appeared in the outlet pipes. Figure 4.56 shows that the effect of induced circulation on outlet swirl angle is minimal. Virtually all of the data fell within the expected error bands. 
Air ingestion levels, as a result of increased vortex severity, were found to be slightly greater for most nonuniform flow tests. Figure 4.57 shows the se increased air ingestion levels for nonuniform approach flow experiments. The maximum 30-minute average air ingestion that resulted from nonuniform approach flow tests was about 7 percent void fraction. It occurred for Configuration 60A during a streaming test. The majority of the nonuniform air ingestion levels remained within the expected error limits indicating no change from those values obtained for uniform flow conditions.

A comparison of loss coefficient data is shown in Figure 4.58 . Nonuniform approach flow perturbations had no effect on the values obtained for loss coefficients.

\subsubsection{The Effects of Break-Flow Jet Impingement}

Figure 4.59 shows no adverse break-flow jet impingement effects on vortex severity for tests conducted using either configurations 58 or $60 \mathrm{~A}$. Surface turbulence caused by the impacting jet may have been responsible for the attenuation of vortex activity.

Outlet swirl angle was found to increase somewhat as a result of break-flow jet implngement. Figure 4.60 shows this effect. Alterations of the outlet approach flow, resulting from the impacting jet may be responsible for the general increase in swirl angles shown in Figure 4.60. Swirl angles generally remained below 3 degrees despite the increases resulting from break-flow jet impingement.

Although a considerable quantity of surface air entrainment occurred as a result of the impacting jet, no change in air ingestion was recorded when compared with those levels observed for the unperturbed sump. Air ingestion comparisons are shown in Figure 4.61. Break-flow jet impingement had no effect on loss coefficient, as shown in Figure 4.62 .

\subsubsection{The Effects of Transient Flow Conditions}

The flow rate schedule imposed on the sump for the transient flow tests, using both outlet pipes, is shown versus test time on Figure 4.63: The flow in pipe 1 was raised from 0 to about 6000 $\mathrm{gpm}$ in 2 minutes and allowed to remain unchanged at $6000 \mathrm{gpm}$ for 10 minutes. The flow in pipe 2 was then started and brought up to $6000 \mathrm{gpm}$ in 2 minutes. Both pipes were then left in operation for 10 minutes, at which time the flow in the pipe 1 was shut down over a period of 2 minutes: Ten minutes later, the flow in pipe 2 was shut down over a 2-minute period.

The 30-second averaye swirl anglce and air ingestion levels observed during this test are shown compared with steady-state tests in Figure 4.64. The time averaged values of air ingestion over these short intervals were consistently higher during transient flow tests than those corresponding averaged values observed for comparable steady-state tests. The high values of air ingestion measured during the transient tests were brief and intermittent in that the test average value (about 40 . minutes). was very low. ' The maximum recorded 40-minute average air ingestion was about 1 percent void fraction.) Transient flow testing did not affect values of observed.swirl angle relative to steady. state tests. 
In summary, severe perturbations to the normal sump approach flow were found to result in some increased levels of vortex activity, outlet swirl angle and air ingestion. Screen blockage, in particular, produced the greatest adverse effects on air ingestion and outlet swirl angle. Nonuniform approach flow produced the most consistant increase in vortex activity. No similar effect, however, was observed for air ingestion under nonuniform approach flow conditions. Large, induced circulations produced in the approach flow were not observed as increased swirl in the outlet pipes. Break-flow jet impingement had no effect on sump performance. Transient flow conditions produced strong aircore vortices that dissipated quickly. These resulted in slightly higher values of air ingestion and outlet swirl angle when compared to those values obtained during steady flow tests.

\subsection{Vortex Suppressors}

The effectiveness of two vortex suppression devices has been established and is presented in this section. The first device was a cage-type vortex suppressor (Figure 3.5) similar to that used during the horizontal outlet test program [1]. Two of these cage-type vortex suppressors were fabricated from standard 1-1/2 inch floor grating and placed over each of the outlet pipes. The second type of vortex suppressor consisted of a single piece of 1-1/2 inch floor grating laid horizontally over the entire sump area at a level which remained below the water level at all times.

Vortex suppression tests were performed under conditions that had produced the single worst test for each of the two perturbed flow configurations. The vortex suppression test for configuration 58 was performed using screen blockage Scheme 5 , at a submergence of $5 \mathrm{ft}$, and a flow rate of $5300 \mathrm{gpm} / \mathrm{pipe.} \mathrm{This} \mathrm{test} \mathrm{produced} \mathrm{a}$ Type 6 air-core vortex, a 30-minute average air ingestion of about 13 percent, and a relatively high swirl angle of 3 degrees. The vortex suppression tests were also performed for Configuration 60A with streaming approach flow, at a flow rate of $5300 \mathrm{gpm} / \mathrm{pipe}$, and a submergence of $2 \mathrm{ft}$. This test produced a Type 6 air-core vortex and 7 percent air ingestion (30-minute average). Table 4.1 shows the complete effectiveness of both vortex suppression devices; Type 6 air-core vortices were reduced to Type 2 surface swirls and all air ingestion was reduced to zero. Reductions in swirl angle were observed for Configuration 58 and both configurations indicated lower loss coefficients when the vortex suppressors were installed.

\subsection{Comparison with Horizontal Outlet Results}

The vertical outlet test program was designed to permit direct comparison.with the results obtained from the horizontal outlet test program. Three comparsion types have been made and are shown on Figure 4.65. The comparison analysis is given for conditions of similar sump size, sump depth, submergence, flow rate, and, for the case of flow perturbation, similar perturbation types. All of the figures have been shown with the vertical outlet results plotted on the vertical axis and the horizontal outlet results plotted on the horizontal axis. (The region above the diagonal 1 ine indicates greater vertical outlet response while the region below the diagonal line indicates greater horizontal outlet response.) 
A. Configuration 58 With Screen Blockage Scheme 5 $Q=5300 \mathrm{gpm} / \mathrm{pipe} ; \mathrm{s}=5 \mathrm{ft}$

\begin{tabular}{|c|c|c|c|}
\hline Item & $\begin{array}{c}\text { No } \\
\text { Suppressor }\end{array}$ & $\begin{array}{c}\text { With Cage } \\
\text { Type Suppressor }\end{array}$ & $\begin{array}{l}\text { With } \\
\text { Horizontal } \\
\text { Suppressor } \\
\end{array}$ \\
\hline Average Vortex Type & 6.0 & 1.9 & 1.9 \\
\hline $\begin{array}{l}\text { 30-Minute Average Void } \\
\text { Fraction, \& }\end{array}$ & 12.8 & 0.0 & 0.0 \\
\hline $\begin{array}{l}\text { 30-Minute Average Swirl } \\
\text { Angle, degrees }\end{array}$ & 3.2 & 1.5 & 0.0 \\
\hline Average Loss coefficient & 1.86 & 0.88 & 0.90 \\
\hline
\end{tabular}

B. Configuration $60 \mathrm{~A}$ With streaming Approach Flow $Q=5300 \mathrm{gpm} / \mathrm{plpe} ; s=2 \mathrm{ft}$

$\begin{array}{llll}\text { Average Vortex Type } & 6.0 & 1.8 & 1.8 \\ \begin{array}{l}\text { 30-Minute Average Void } \\ \text { Fraction, \& }\end{array} & 7.3 & 0.0 & 0.0 \\ \begin{array}{l}\text { 30-Minute Average Swirl } \\ \text { Angle, degrees }\end{array} & 0.3 & 0.0 & 1.9 \\ \text { Average Loss Coefficient } & 1.24 & 1.06 & 1.12\end{array}$




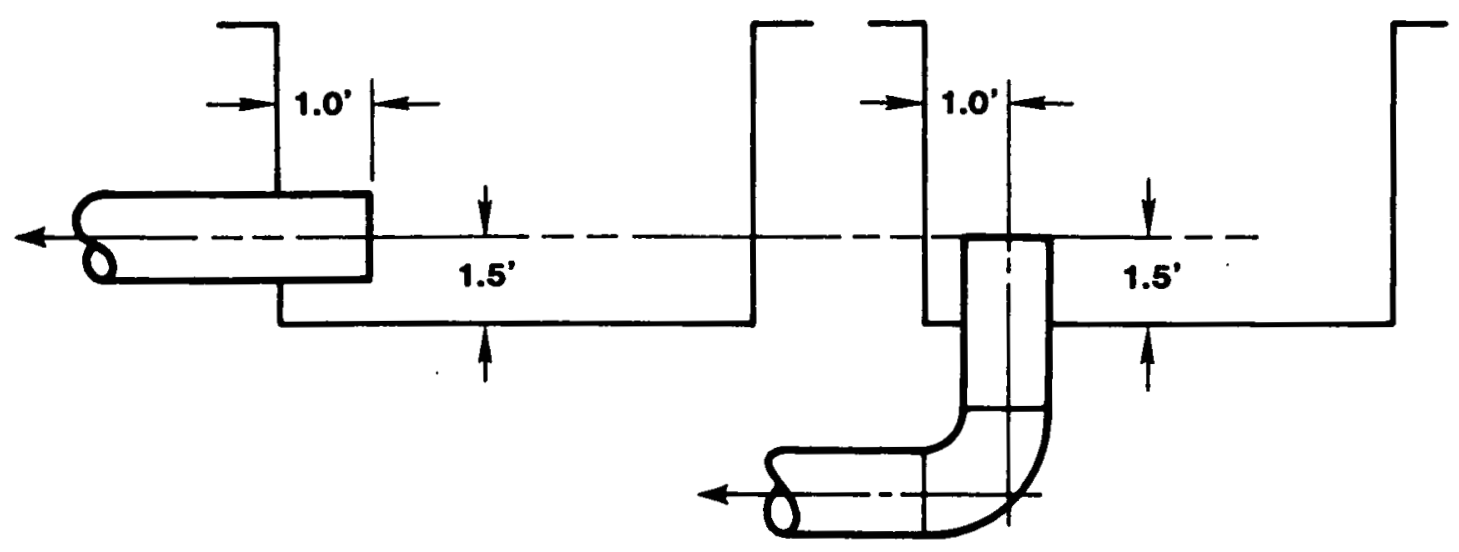

COMPARISON TYPE A

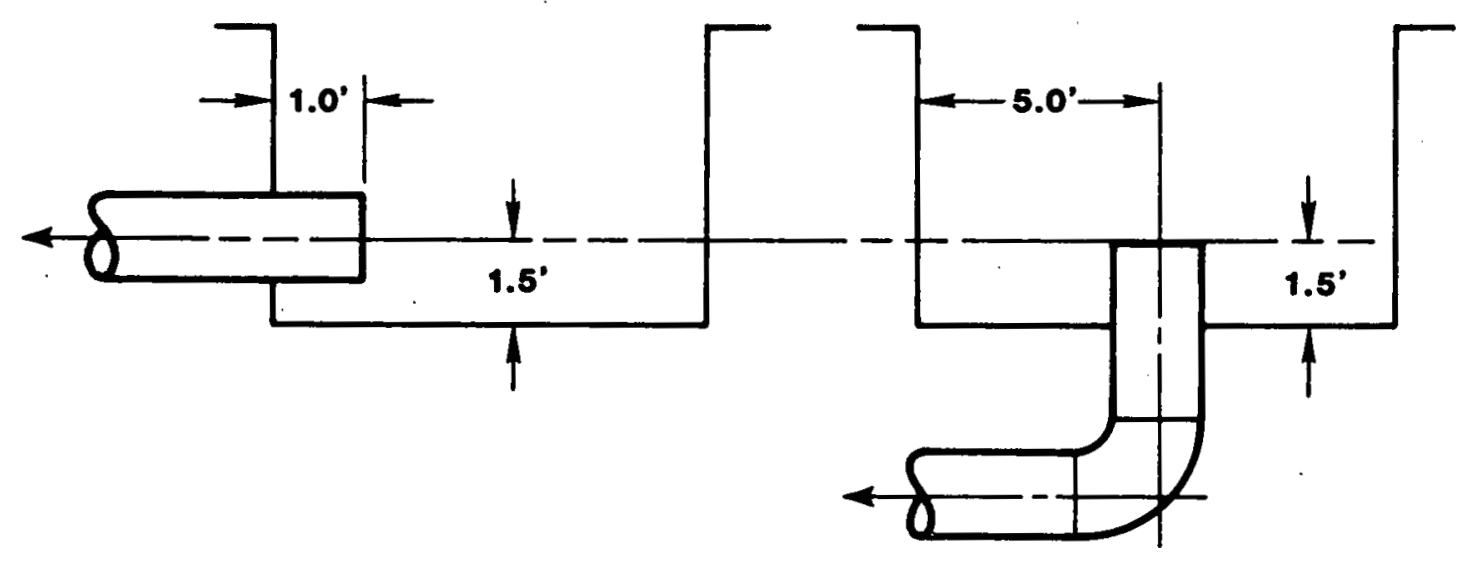

COMPARISON TYPE B

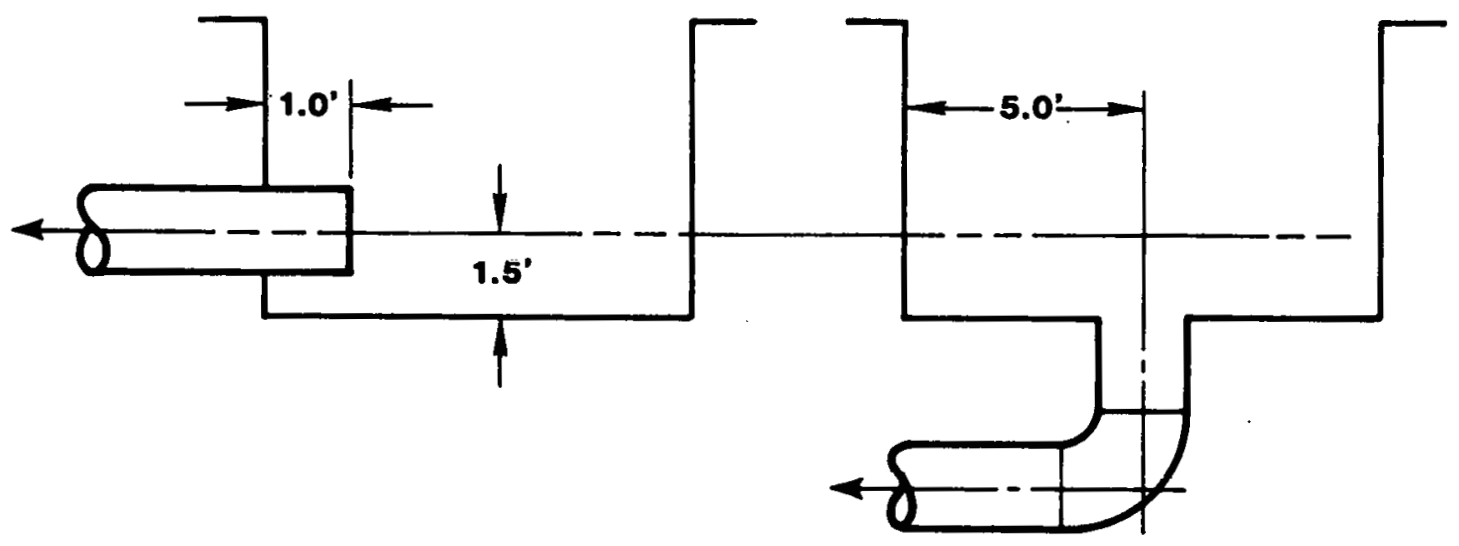

COMPARISON TYPE C

Figure 4.65 Performance Comparisons Between Vertical and Horizontal outlet Configurations 
Comparison Type A (Figure 4.65): Three vertical outlet Configurations, 58A, 59A, and 60A (see Table 3.2) have been compared with similar horizontal outlet tests under conditions of uniform approach flow. (Configurations 2, 5 and 24, see Reference 1). The results given in Figure 4.66 do not show any consistant differences between the vortex behavior of vertical outlet sumps and that of horizontal outlet sumps. Specific configurations do, however, exhibit some trends; vertical outlet configuration 59A, shown on Figure 4.66 as apex-up triangles, was found to be less prone to vortex activity than was its comparable horizontal outlet configuration.

Vertical outlet Configuration 58A, represented by the squares on Figure 4.66, was found to produce vortex types that were slightly greater than those produced in the horizontal configuration of the same test. Similar results were observed for vertical configuration 60A, the data of which is plotted as apexdown triangles.

Swifl angle pertormance comparisons, between vertical and horizontal outlet tests; are shown on Figure 4.67. The majority of tests indicated very little difference in the outlet swirl performance between vertical and horizontal outlet configurations. Several tests (Configuration 58A) resulted in considerably lower levels of outlet swirl for the vertical oullet sump.

The air ingestion comparison is shown on Figure 4.68. The majority of this data indicates low levels of air ingestion--below 1 percent void fraction. The vertical outlet tests showed a slight reduction in 30-minute average air ingestion over those levels recorded for comparable horizontal outlet tests: Air ingestion level, ( $>2$ percent void fraction), recorded during a horizontal outlet test was reduced to zero under conditions of the equivalent vertical outlet test. Loss coefficient data remained generally unaffected in the change between vertical and horizontal outlet configurations. The upward shift of loss coefficient data, shown on the comparison plot of Figure 4.69 resulted from the additional losses produced by the $90^{\circ}$ elbow downstream of the outlet for vertical outlet tests $\left(C_{I}=0.2-0.3\right.$ for $90^{\circ}$ short $r$ adius bend). Comparison Type B (Figure 4.65): The 30-minute average observations of vortex type for vertical outlet sumps, for the Type B comparison geometry of Figure 4.65, indicated a decreased vurtex activity for the vertical outlet configuration over that of horizontal outlet sumps. This finding is shown on Figure 4.70. Vertical outlet Configuration 59 (apex-up triangles in Figure 4.70), in particular, indicated a subotantial reduction in the 30minute average vortex severity relative to the horizontal outlct test data.

Vertical outlet configurations were generally found to produce greater levels of outlet swirl than was found to occur in horizontal outlet tests. This result is shown in Figure 4.71 . This trend is not consistent, however, in that several tests shown on Figure 4.71 showed the opposite trend. The vertical outlet sumps exhibited up to 3 degrees greater outlet swirl than that which was observed for horizontal outlet sumps. 
Comparison Type A

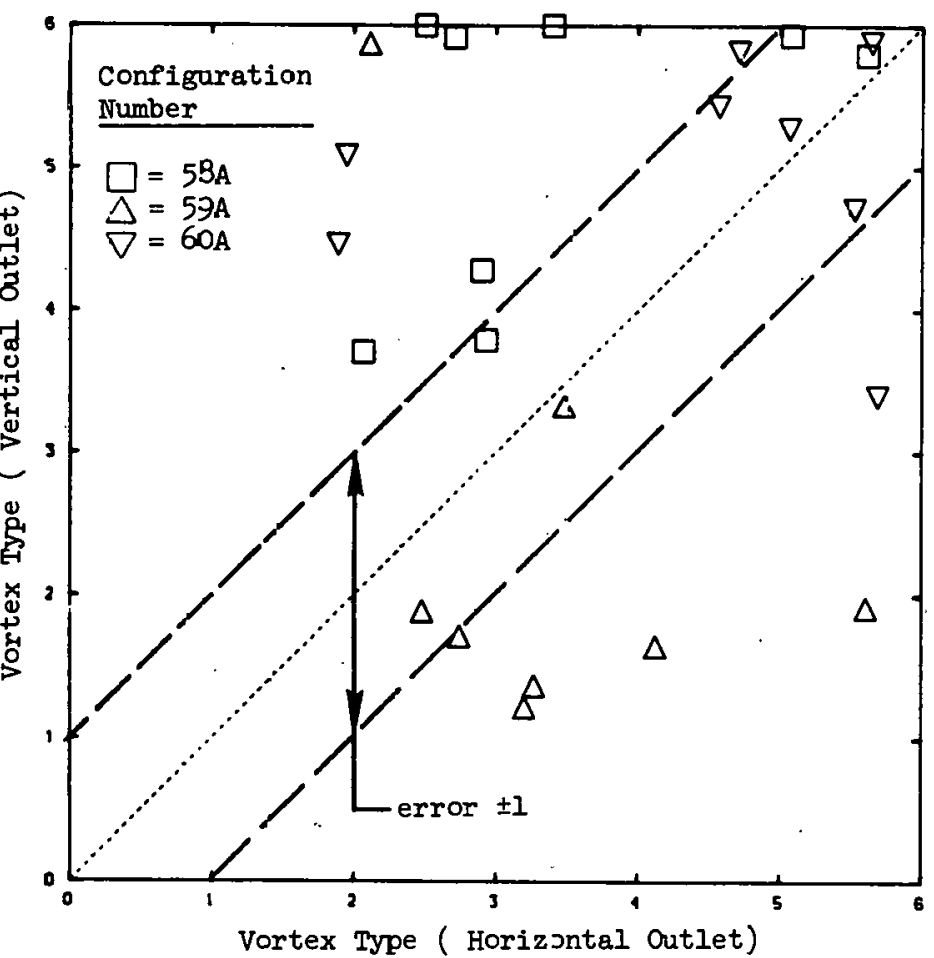

Figure 4.66 Comparison of Vortex Type Between Vertical and Horizontal outlet Sumps for Comparison Type A

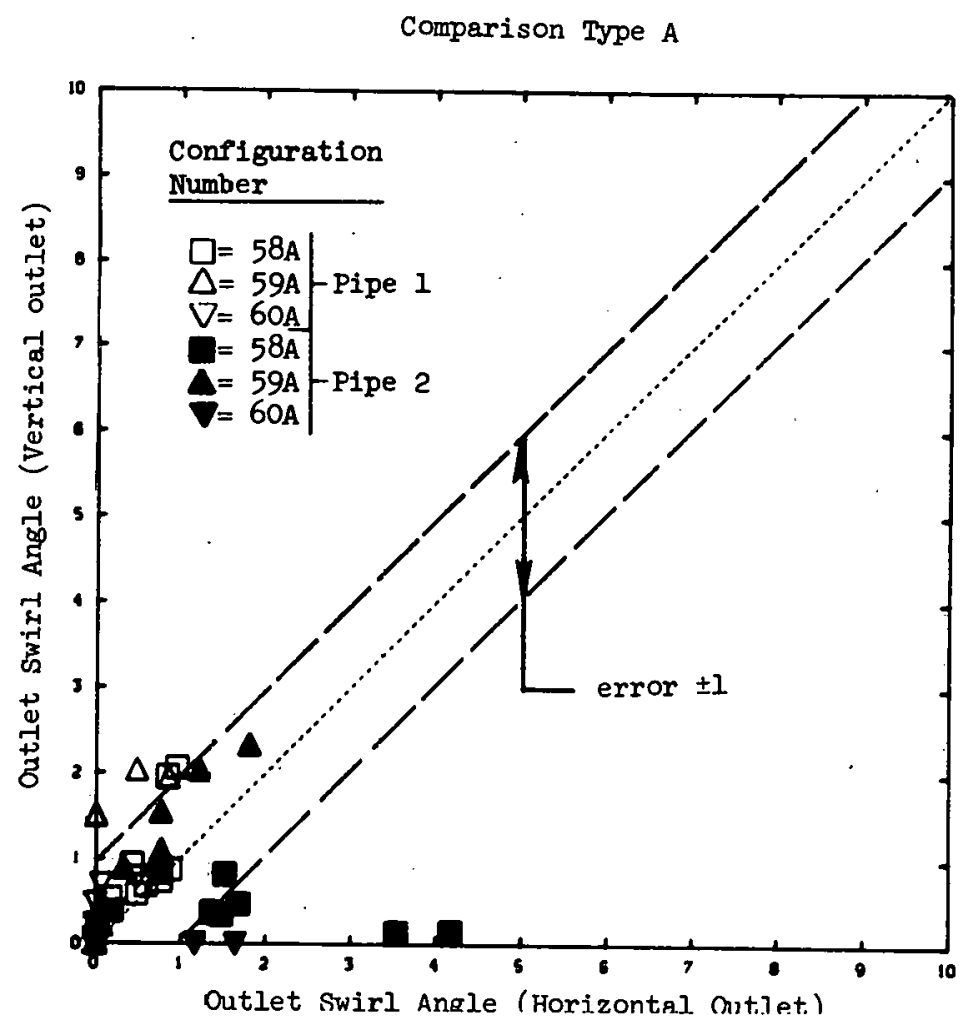

Figure 4.67 Zomparison of Outlet Swirl Angle Performance Between Vertical and Horizontal outlet Sumps for Comparison Type A 
Comparison Type A

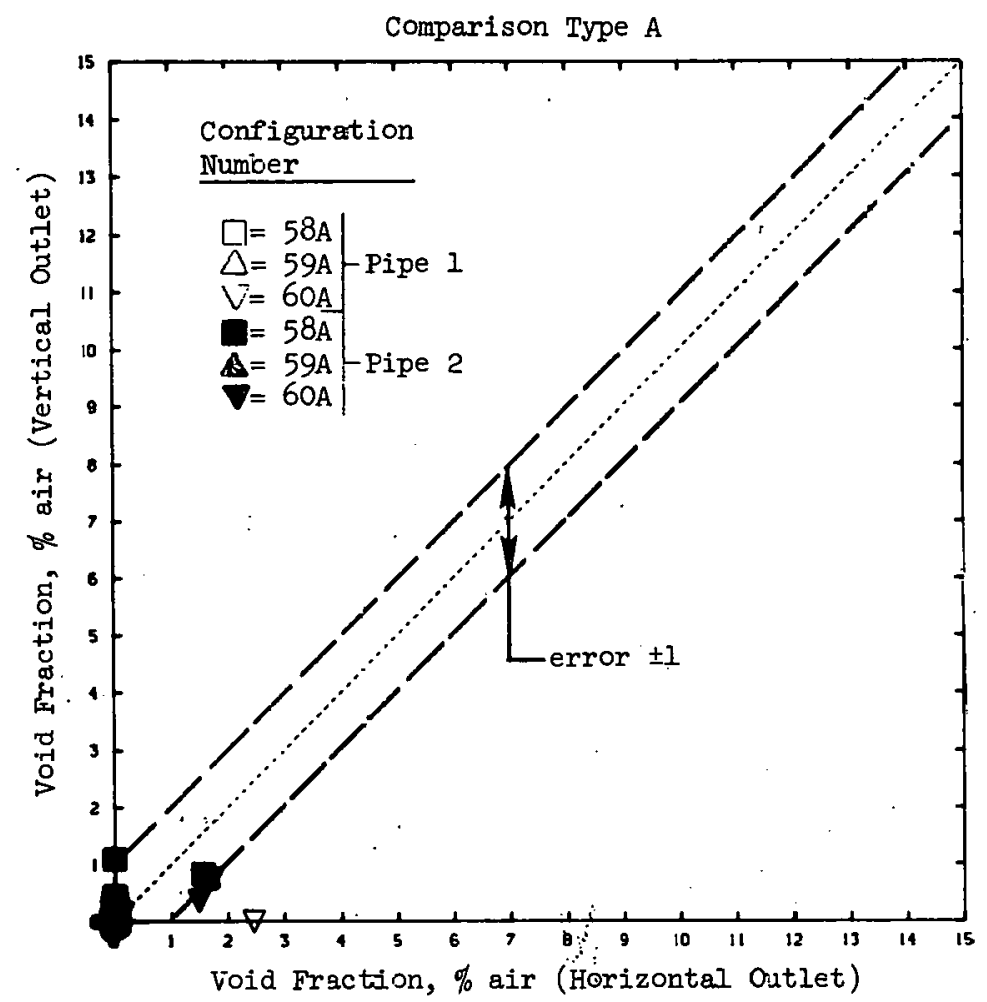

Figure, 4.68 Comparison of Void Fraction Perfornance Between Vertical and Horizontal outlet Sumps for Comparison Type A

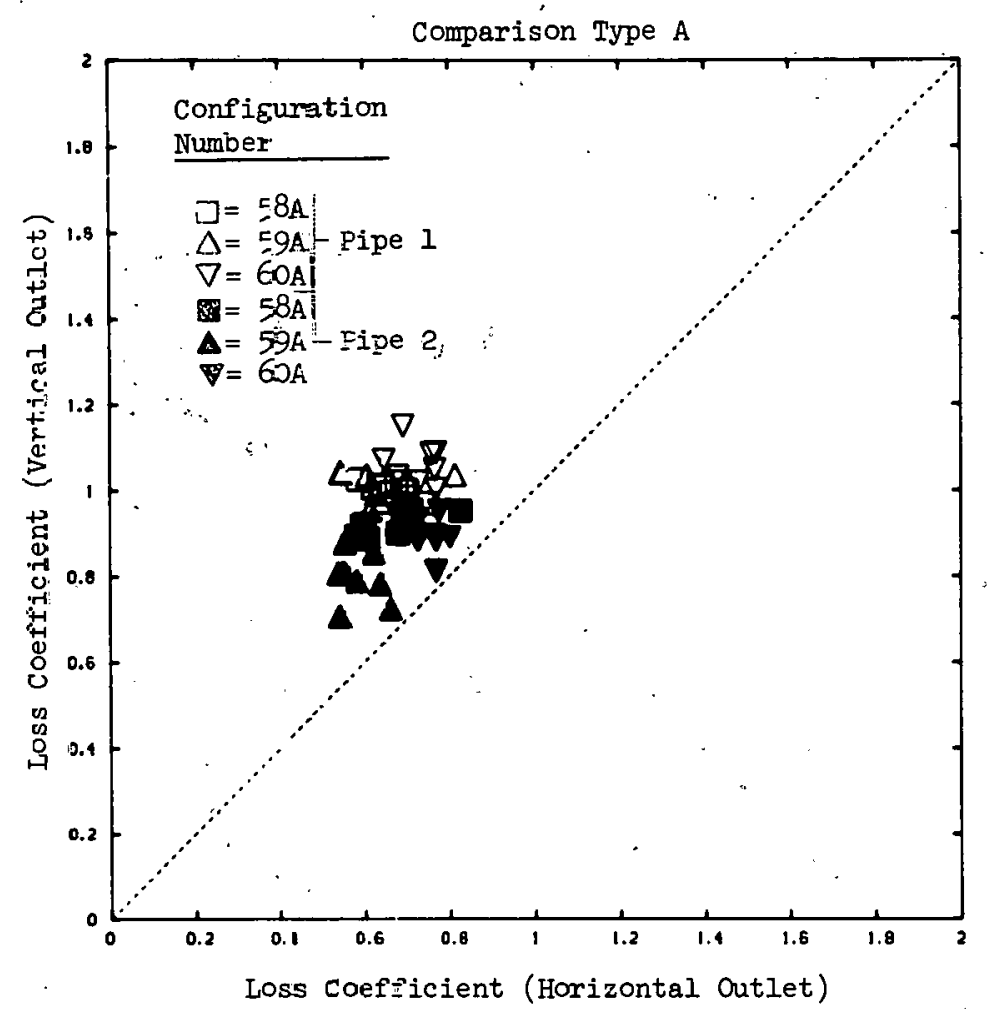

Figure 4.69 Compazison of Loss Coefficient Performance Between Vertical and Horizontal outlet Sumps for Comparison. Type $A$ 


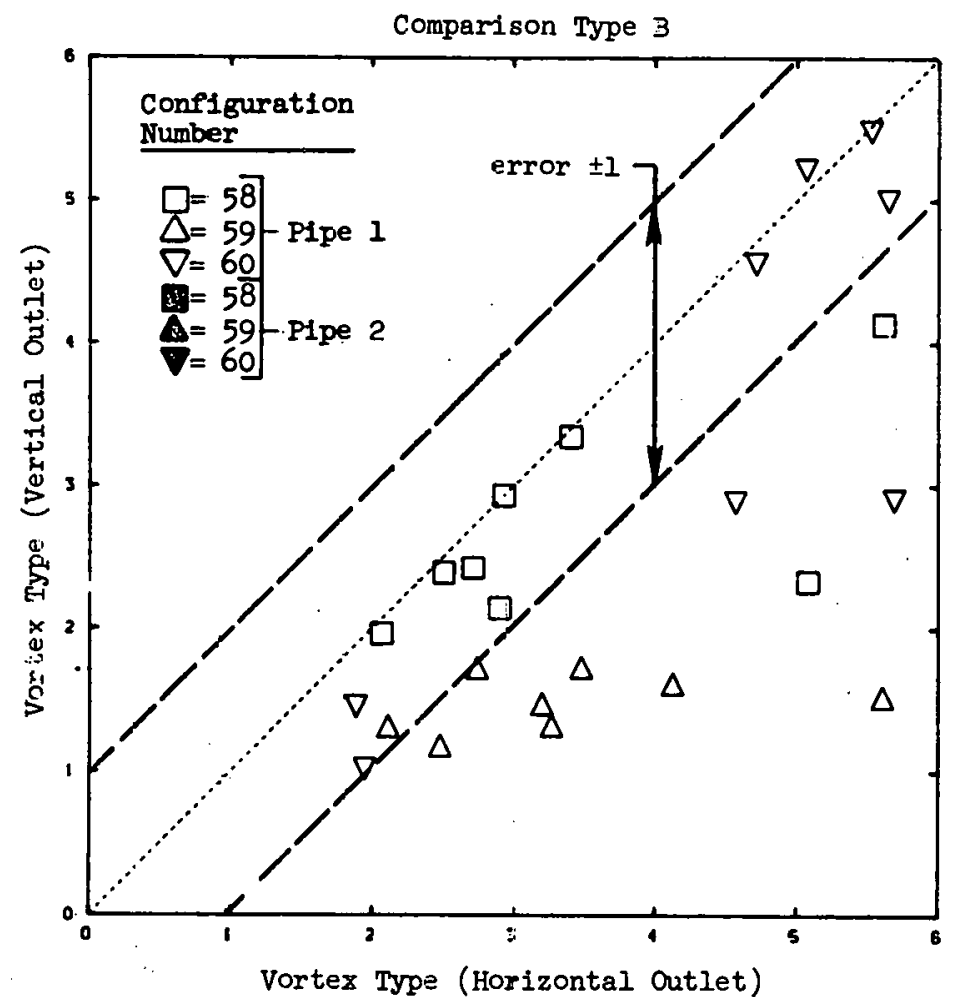

Figure 4.70 Comparison of Vcrtex Type Between Vertical and Horizontal Cutlet Sumps for Comparison TYPe B.

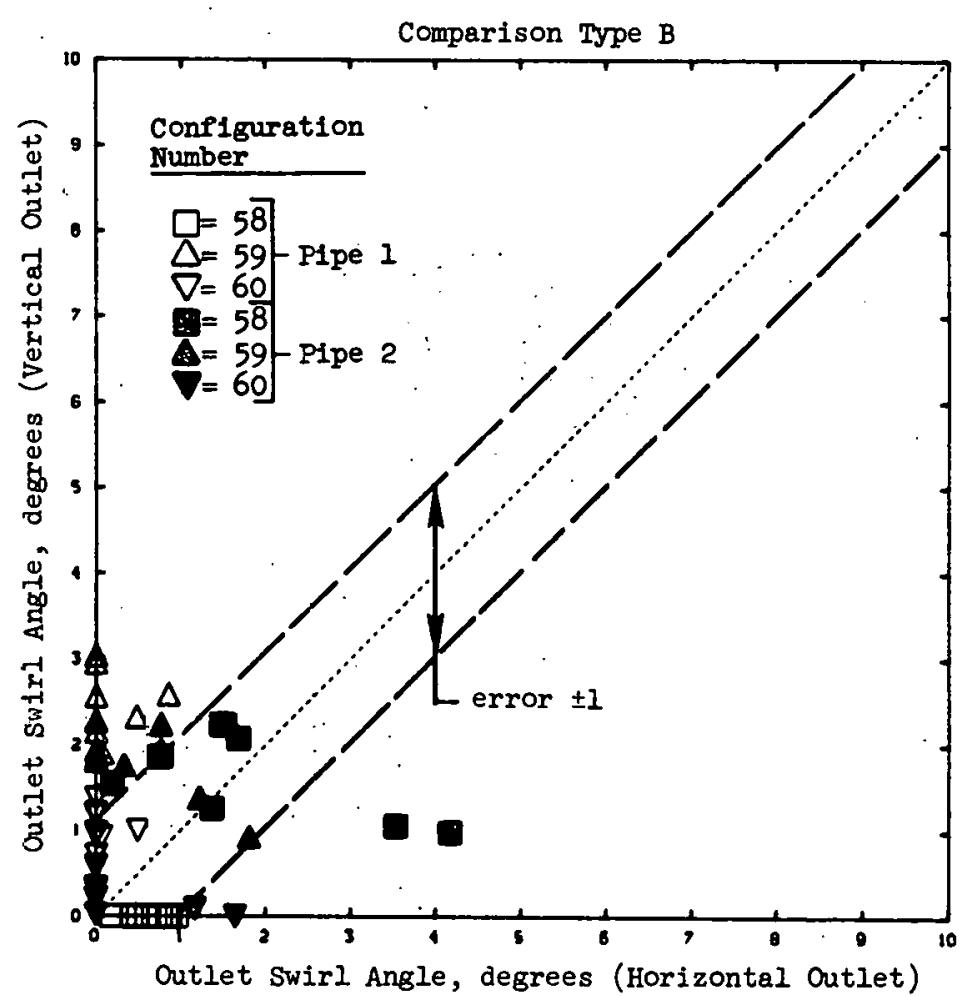

Figure 4.71. Comparison of Outlet Swirl Angle Performance Between Vertical and Horizontal outlet Sumps for Comparison Type B 
The 30-minute average air ingestion results, shown on Figure 4.72, indicate lower air ingestion levels for vertical outlet sumps than those levels recorded for comparable horizontal outlet sumps. Loss coefficients observed for vertical outlet sumps were found to be unchanged from those recorded for tests of horizontal outlet sumps. The loss coefficient comparison is shown in Figure 4.73. (The upward shift of the data of Figure 4.73 is due to the presence of a $90^{\circ}$ elbow in the vertical outlet test facility.)

Comparison Type C (Figure 4.65): The results of the final uniform flow Comparison Type C, are given in Figures 4.74 through 4.77 .

Fewer tests were performed using the flush-mounted vertical outlet. (Note that vertical Configuration 60 was not tested with the flushmounted outlet.) No appreciable difference in vortex activity was found between the vertical and horizontal outlet sumps in this comparison. Figure 4.74 shows the similar vortex type performance between the two outlet pipe orientations.

The flush-mounted vertical outlet orientation resulted in a slight reduction in outlet swirl angle for some tests when compared with the horizontal outlet. This slightly improved vertical outlet. performance is shown on Figure 4.75 .

The comparison of air ingestion levels given in Figure 4.76 indicates some cases of similar performance and some cases of improved performance through the use of flush-mounted vertical outlets. Two vertical tests of Configuration 59B showed less air ingestion than tests of their horizontal outlet counterparts 10 percent void fraction for vertical outlets as opposed to 1.75 and 2.5 percent void fraction for horizontal outlets). Another test recorded an air ingestion level of approximately 2 percent void fraction for both outlet orientations.

Loss coefficients were seen to remain generally constant for the two outlet orientations. A comparison between vertical outlet losses and horizontal outlet losses is given in Figure 4.77. The increased hydraulic efficiency of the flush-mounted entrance, as compared with a reentrant entrance, tended to offset the loss coefficient contribution of a $90^{\circ}$ elbow in the vertical outlet tests. This effect is shown in Figure 4.77 (compare Figure 4.77 with Figures 4.73 and 4.69 ).

In general, the uniform approach flow performance of vertical outlet sumps was found to be similar to the performance of horizontal outlet sumps, under conditions of similar flow rate, submergence and sump size. The most notable difference between the performance of vertical and horizontal outlet sumps appeared in terms of vortex severity: Vertical outlet sumps, of the type shown in Figure 4.65B, were found to produce consistently lower values of vortex type than their horizontal outlet counterparts.

\subsubsection{Perturbed Flow Comparisons}

Results from the two vertical outlet Configurations used for perturbed flow tests have been compared with those from tests of horizontal outlet sumps under similar conditions of submergence, flow rate and perturbation. The results of this comparison, based upon the three comparison types that were shown in Figure 4.65, aregiven in Figures 4.78 through 4.89 . The data in these Figures have been plotted without regard to configuration number or perturbation type. 


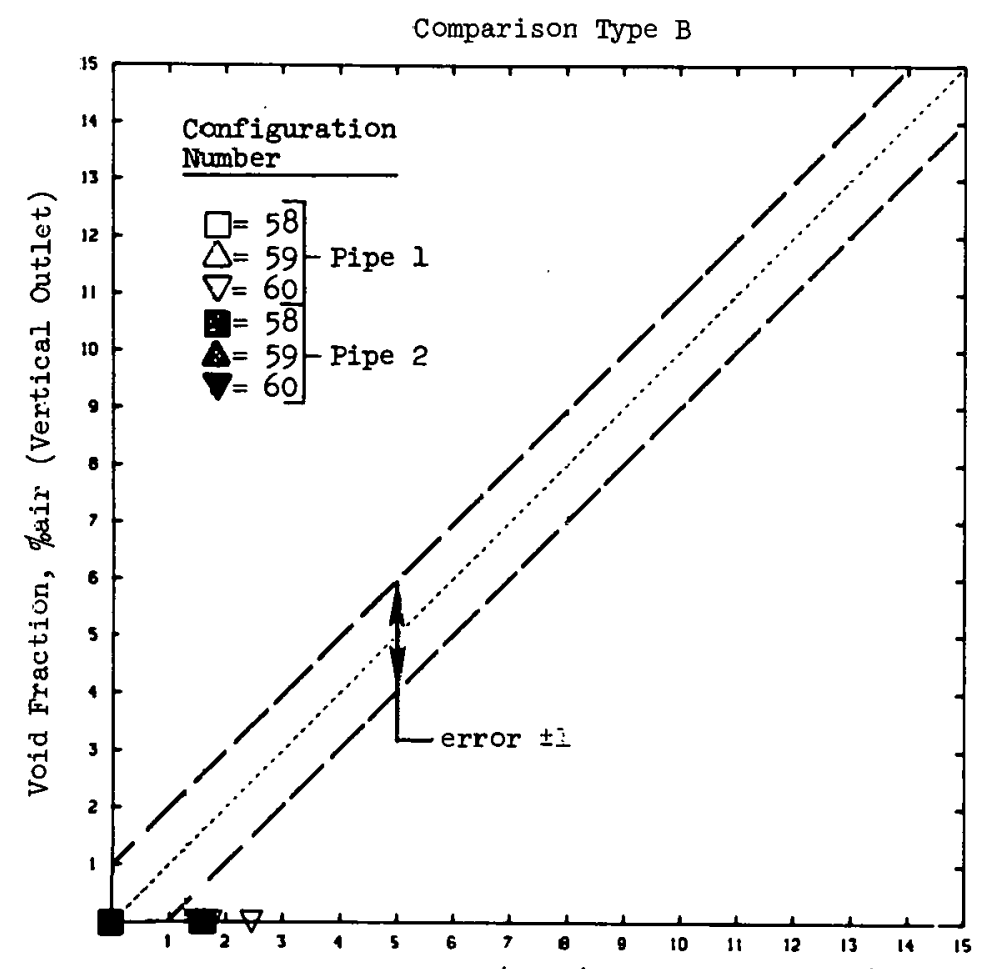

Void Fraction, \%air (Horizontal outlet)

Figure 4.72 Comparison of Void Fraction Performance Between Vertical and Horizontal Outlet Sumps for Comparison Type B

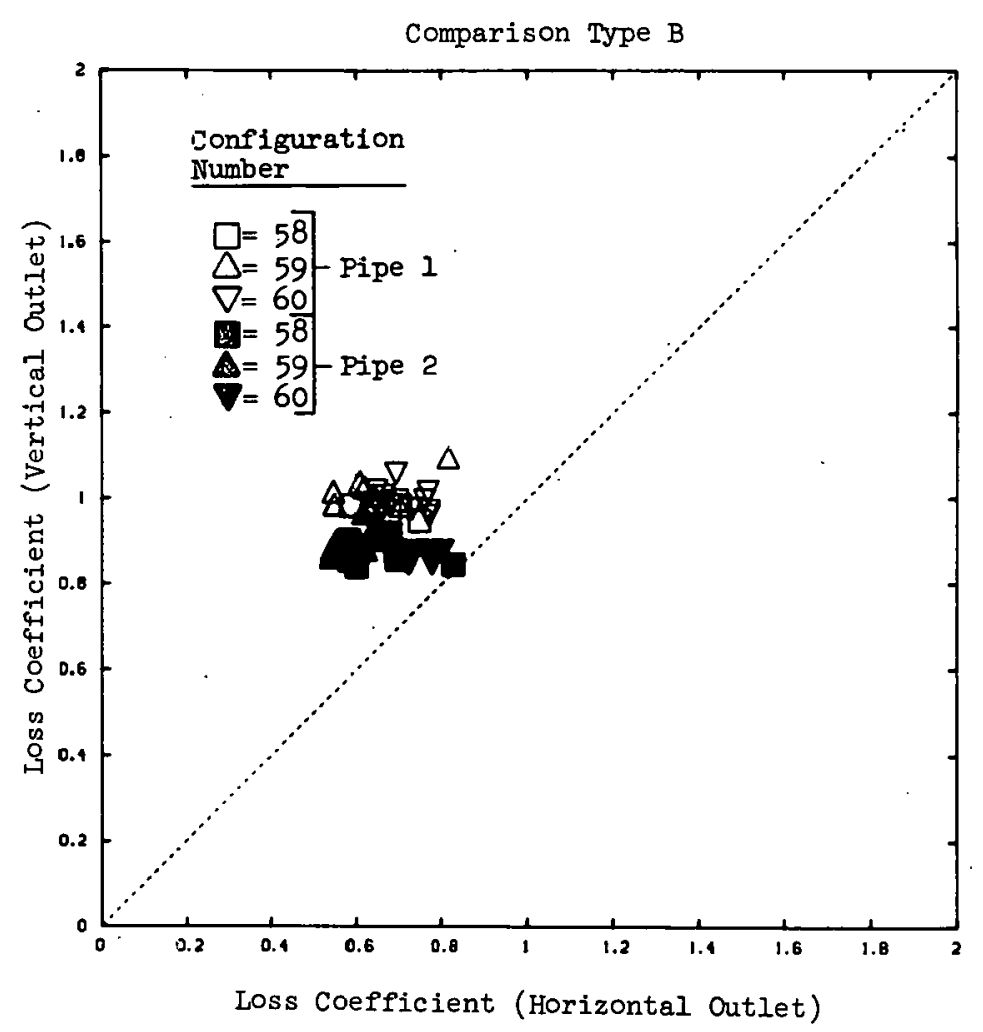

Figure 4.73 Comparison of Loss Coefficient Performance Between Vertical and Horizontal Outlet Sumps for Comparison Type B 


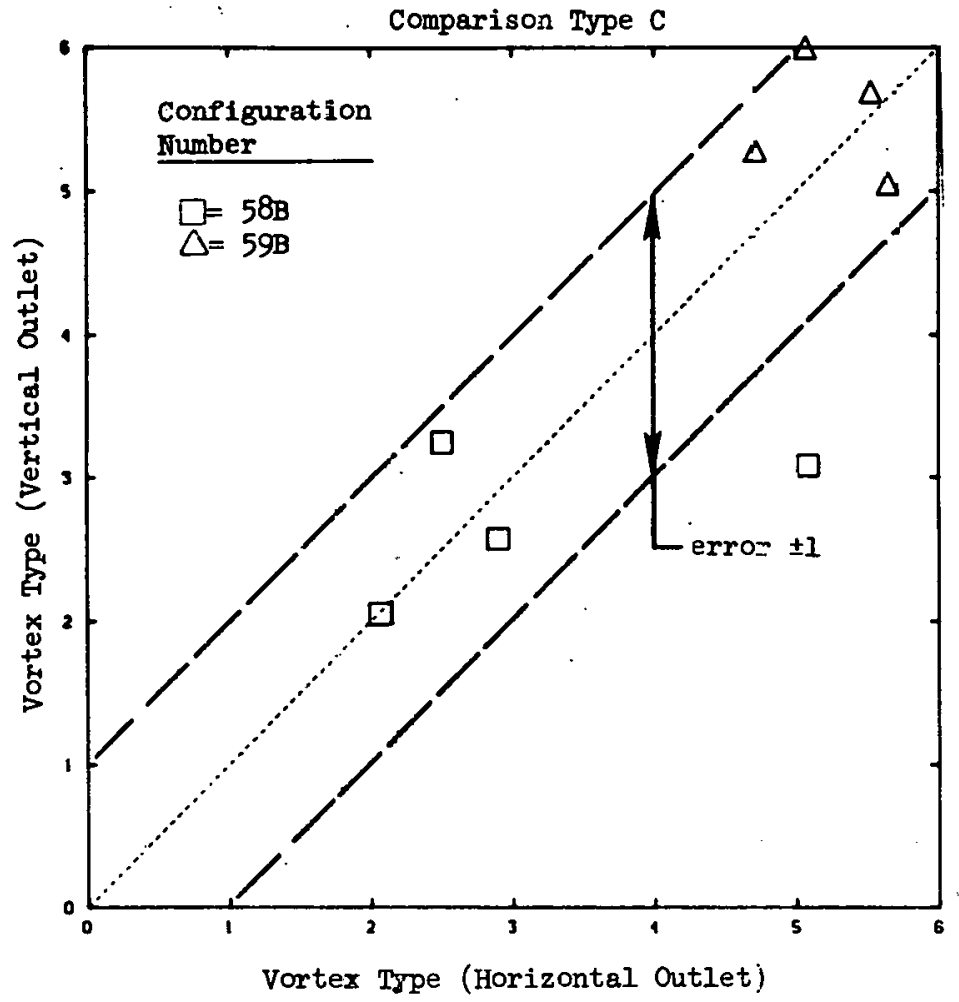

Figure 4.74 Comparison of Vortex Between Vertical and Horizontal outlet Sumps for Comparison Type $\mathrm{C}$

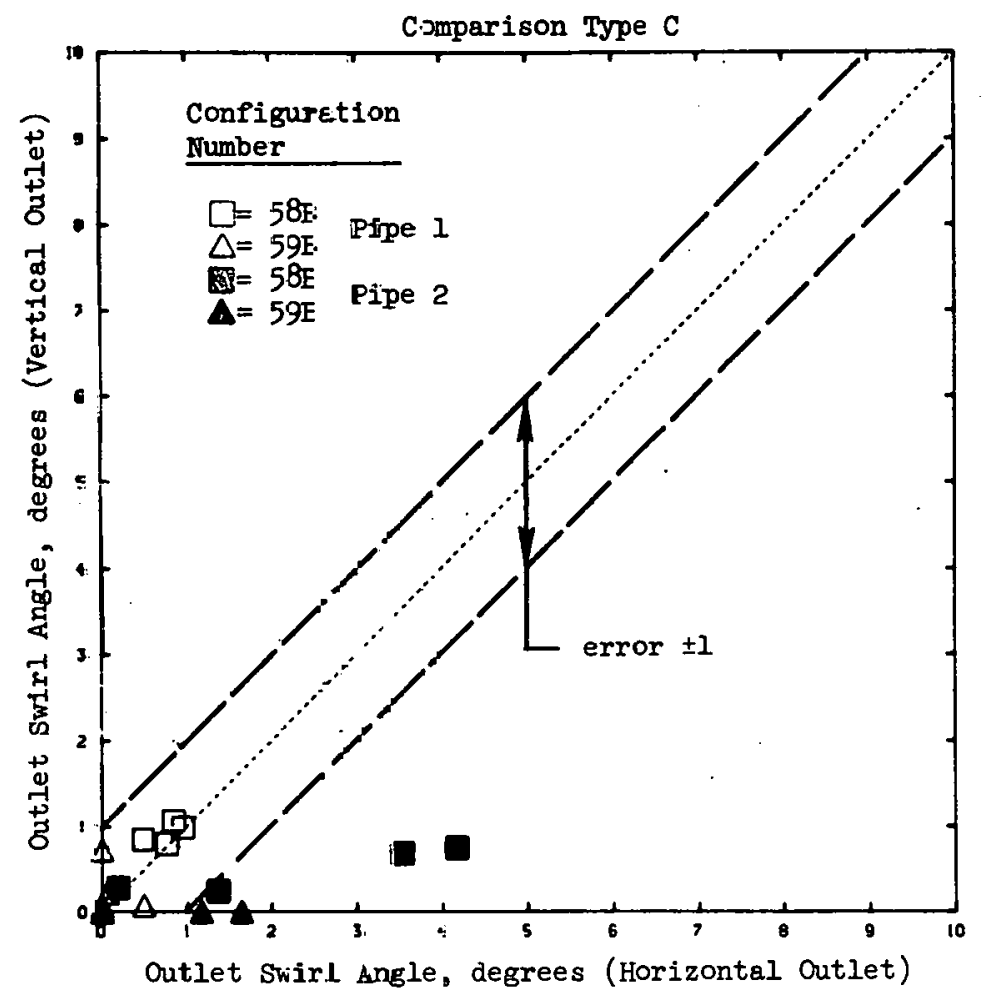

Figure 4.75 Comparison of Outlet Swirl Angle Performance Between Vertizal and Horizontal outlet Sumps for Compazison Type $C$ 


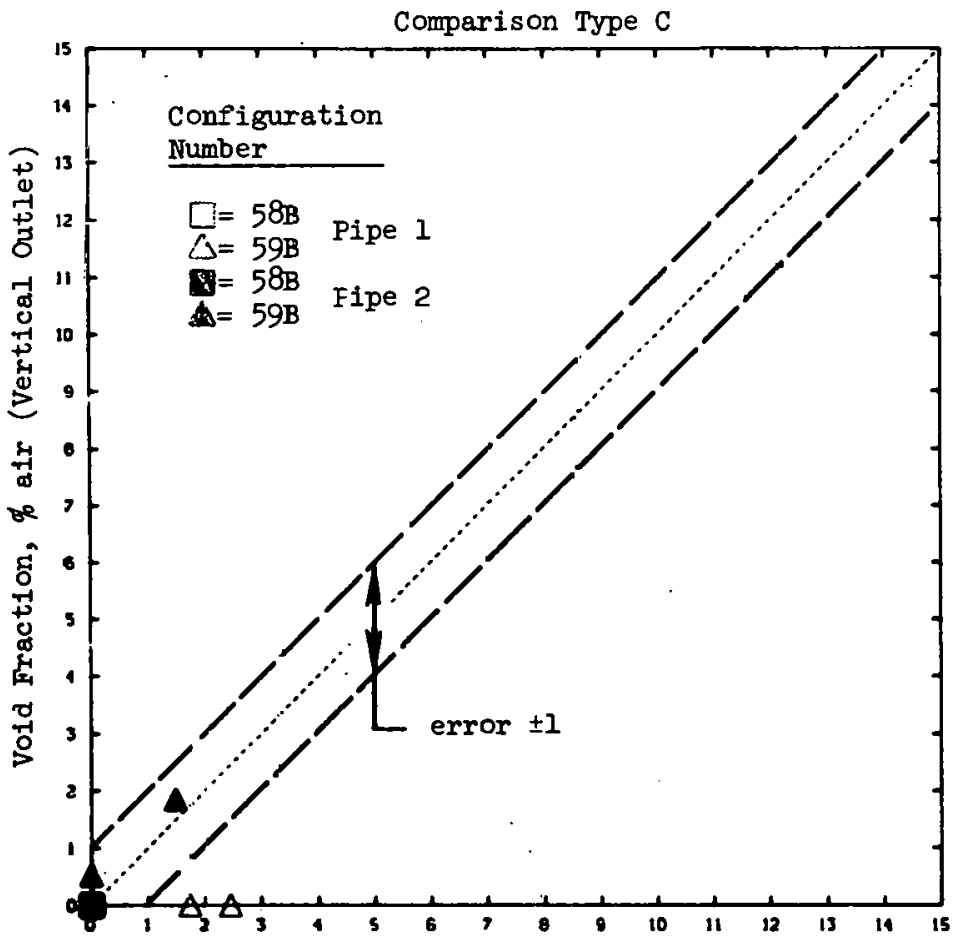

void Fraction, \% air (Gorizontal outlet)

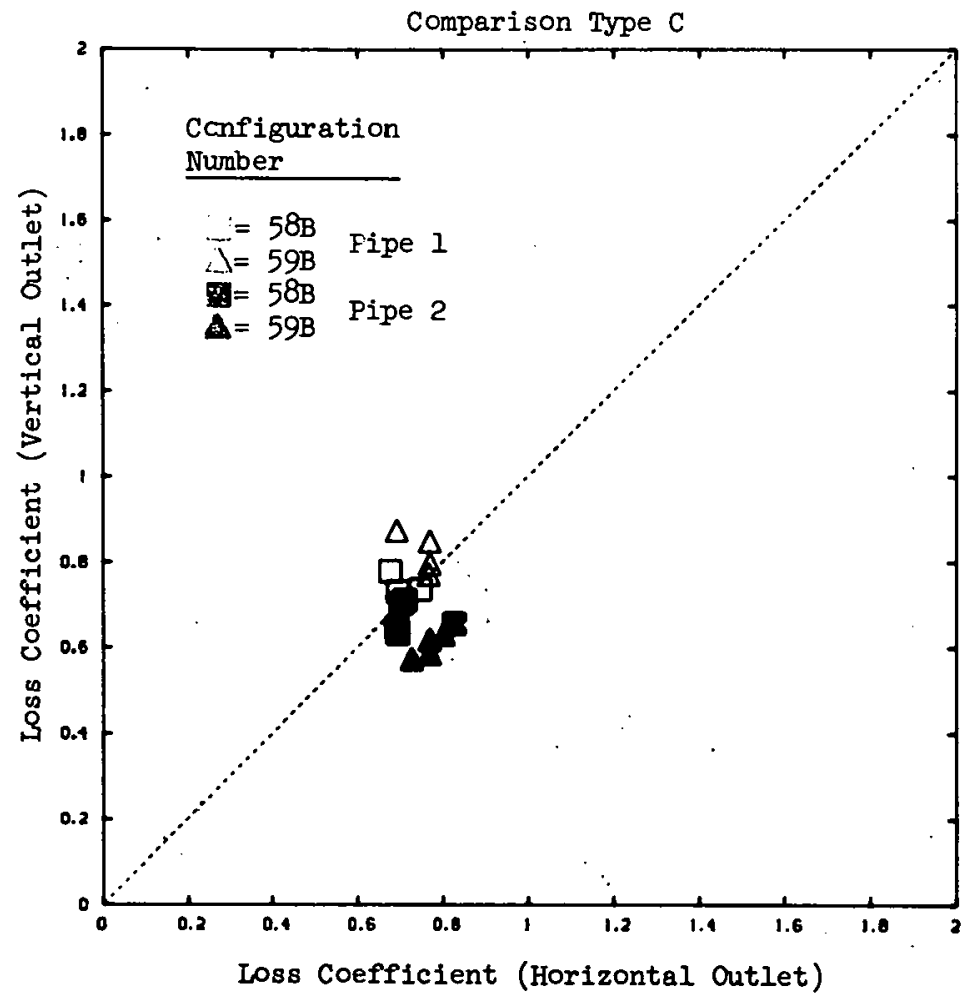

Figure 4.76 Comparison of Void Fraction Performance Between Vertical and Horizontal outlet Sumps for Comparison Type C

Figure 4.77 Comparison of Loss Coefficient Performance Eetween Vertical and Horizontal Outlet sumps for Comparison Type C 


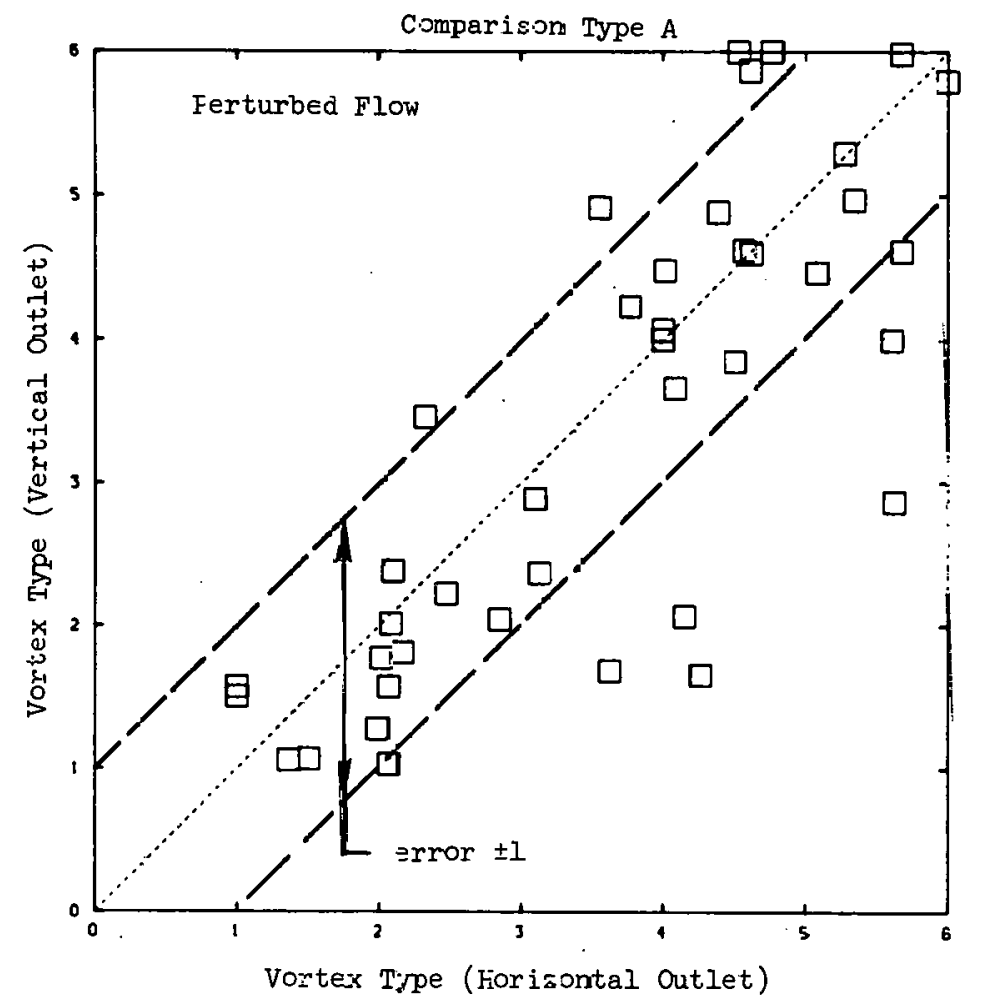

Figure 1.78 Comparison of Vortex Type Jnder Perturbed Flow Conditions between Vertical anc Horizonzal Outlet Sumps for Comparison TyFe A

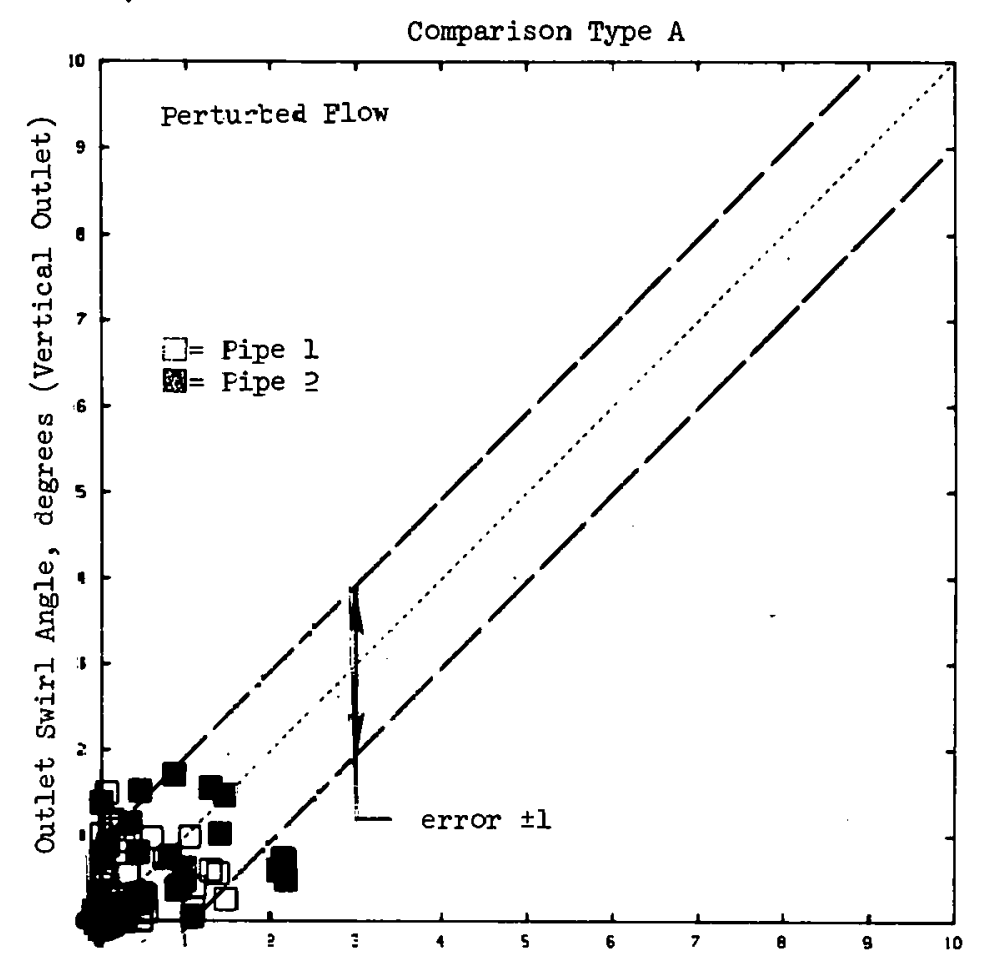

Outlet sirirl Angle, degrees (Horizontal outlet)

Figure 4.79 Conpaziscn of Outlet Swirl Angle Performance Uncer Perturbed Flow Conditions Between Vertical and Horizontal outlet sumps for Corpazison Type A 
Comparison iype A

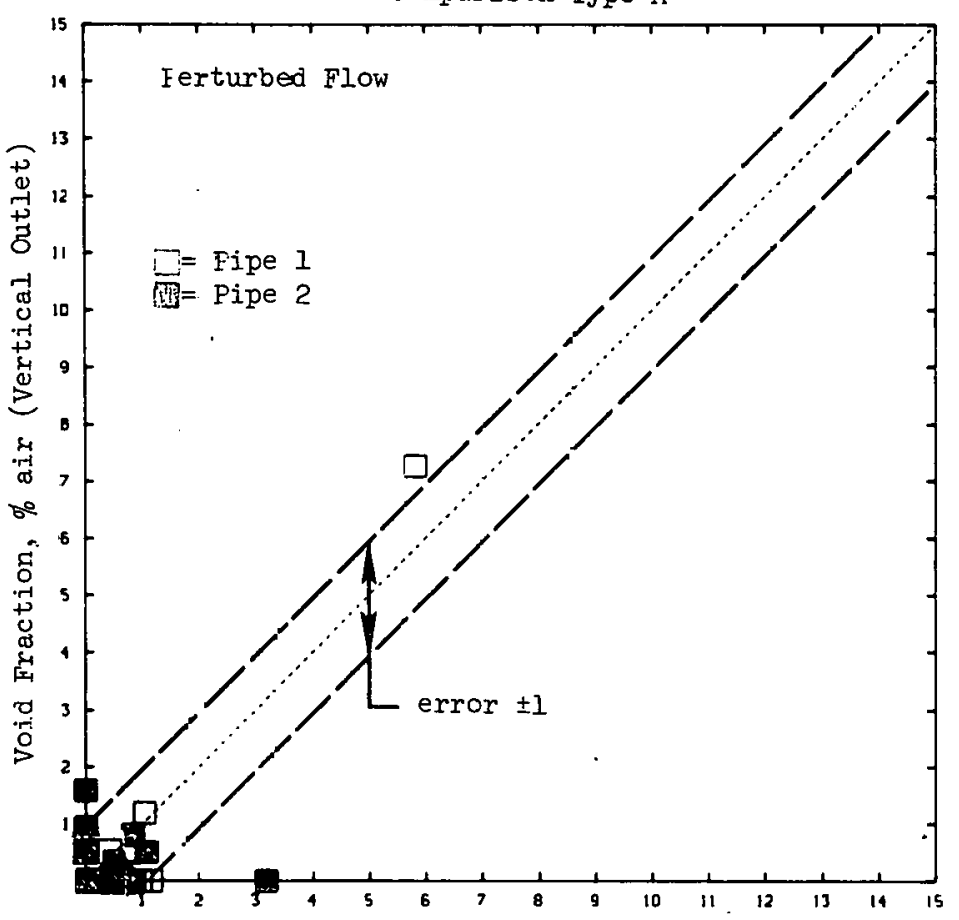

Void Fraction, \%air (Forizontal Outlet)

Figure $4.8 \mathrm{j}$ Comparison of Void Fraction Performance Under Perturbed Flow Conditions Between Vertical and Horizontal Outlet Sumps for Comparison Type A

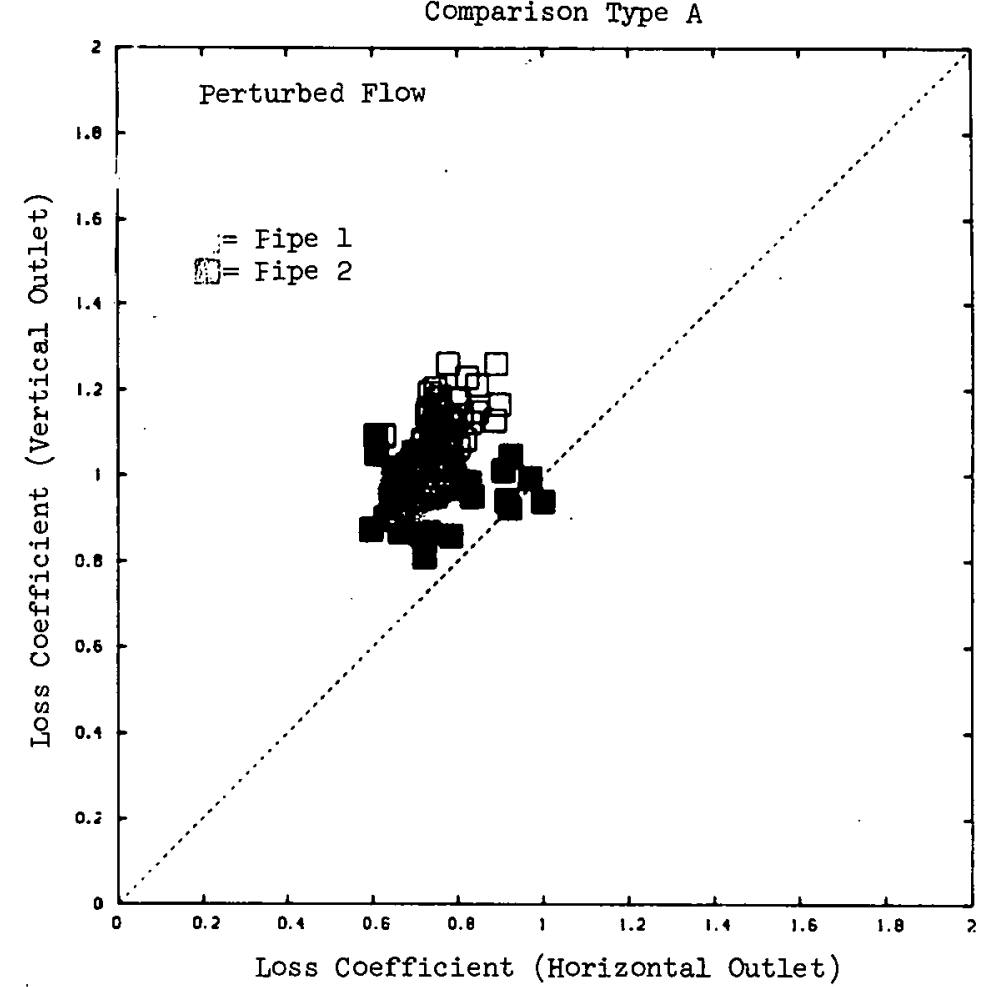

Figure 4.81 Comparison of Loss Coefficient Performance Under Perturbed Flow Conditions Between Vertical and Horizontal outlet Sumps for Comparison Type A 
Comparison Type B

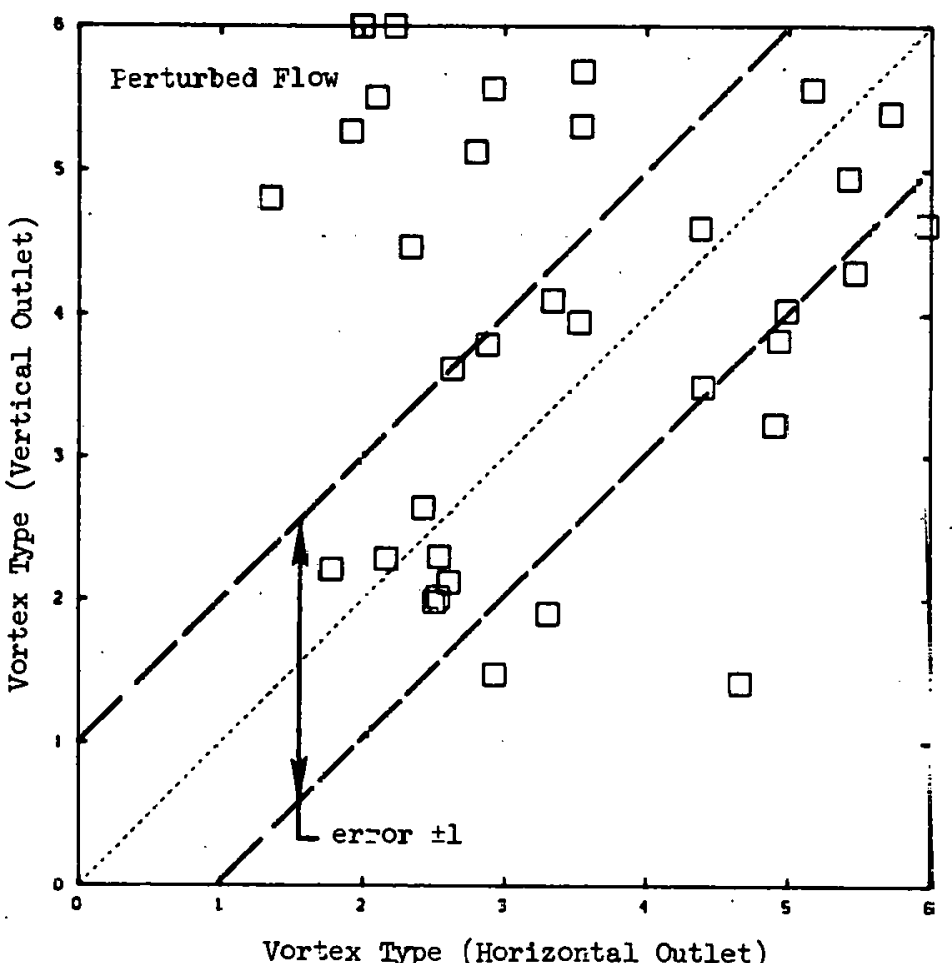

Figure 4.82 Comparison of Vortex Type Under Ferturbed Flow Conditions Between Vertical an. Horizortal Outlet Sumps for Comparison Type B
Comparison Type B

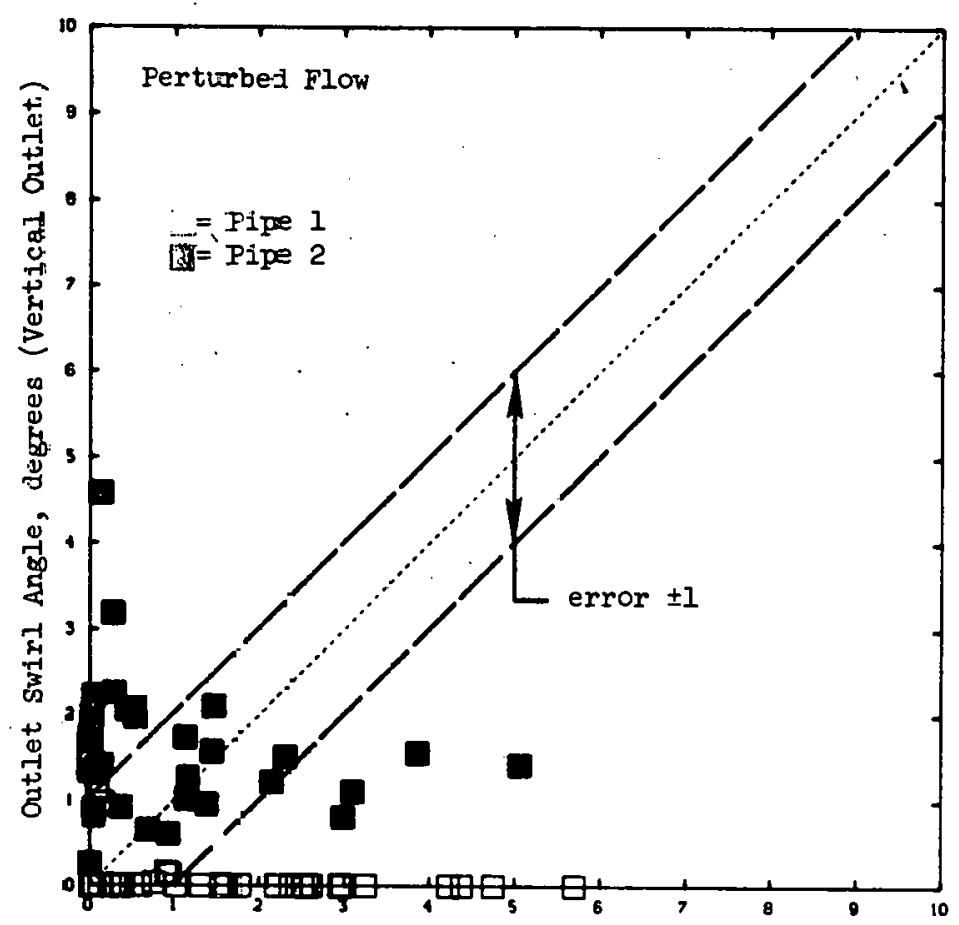

Outlet Swirl Angle, degrees (Horizontal Outlet)

Figure 4.83 Comparison of Outlet Swirl Angle Performance Under Perturbed Flow Conditions Between Vertical and Horizontal outlet Sumps for Comparison Type B 


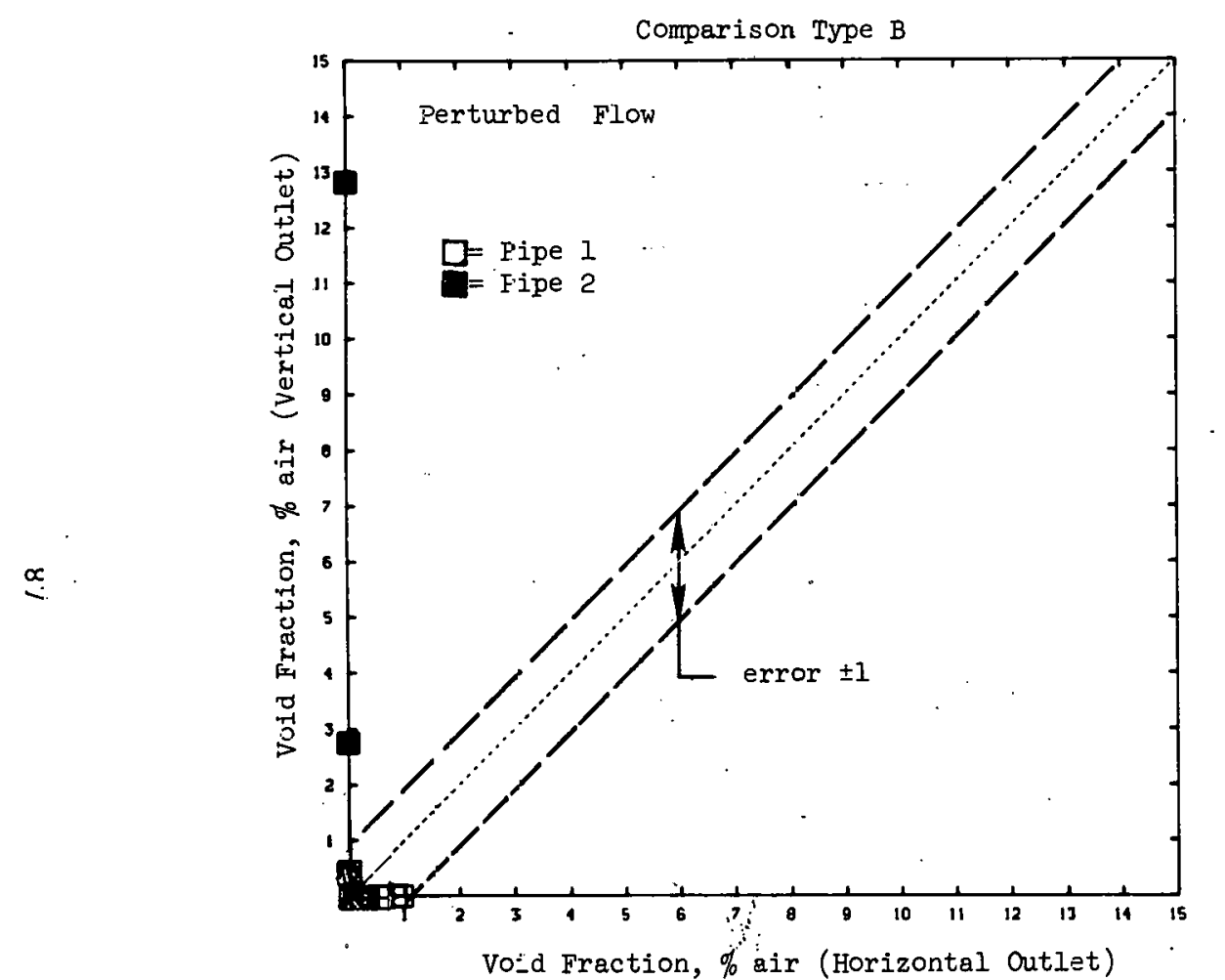

Figure 4.84 Comparison of Void Fraction Performance Under Perturbed Flow Conditions Between Vertical and Horizontal outlet sumps for Comparison Type: B

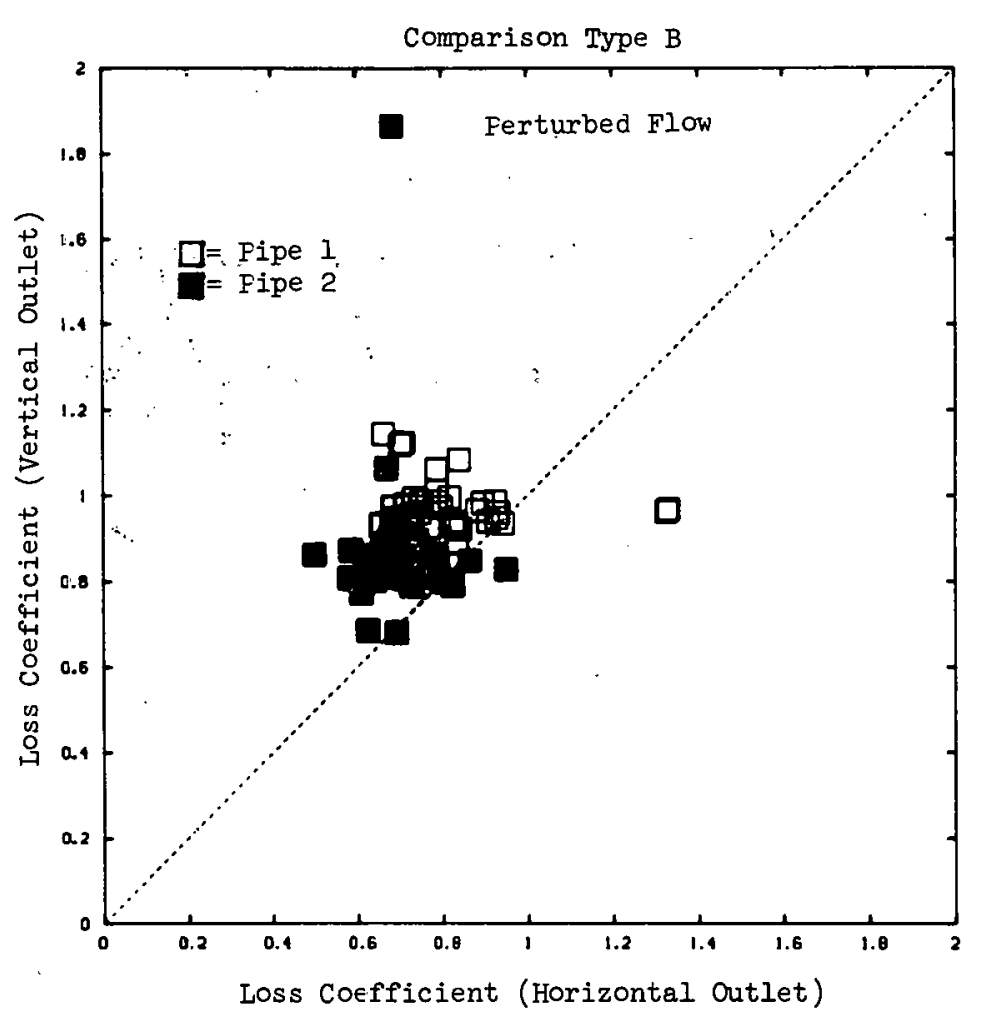

Figure 4.85 Comparison of Loss Coefficient Performance Under Perturbed Flow Conditions Between Vertical and Horizontal outlet sumps for Comparison Type B. 
Comparison Type C

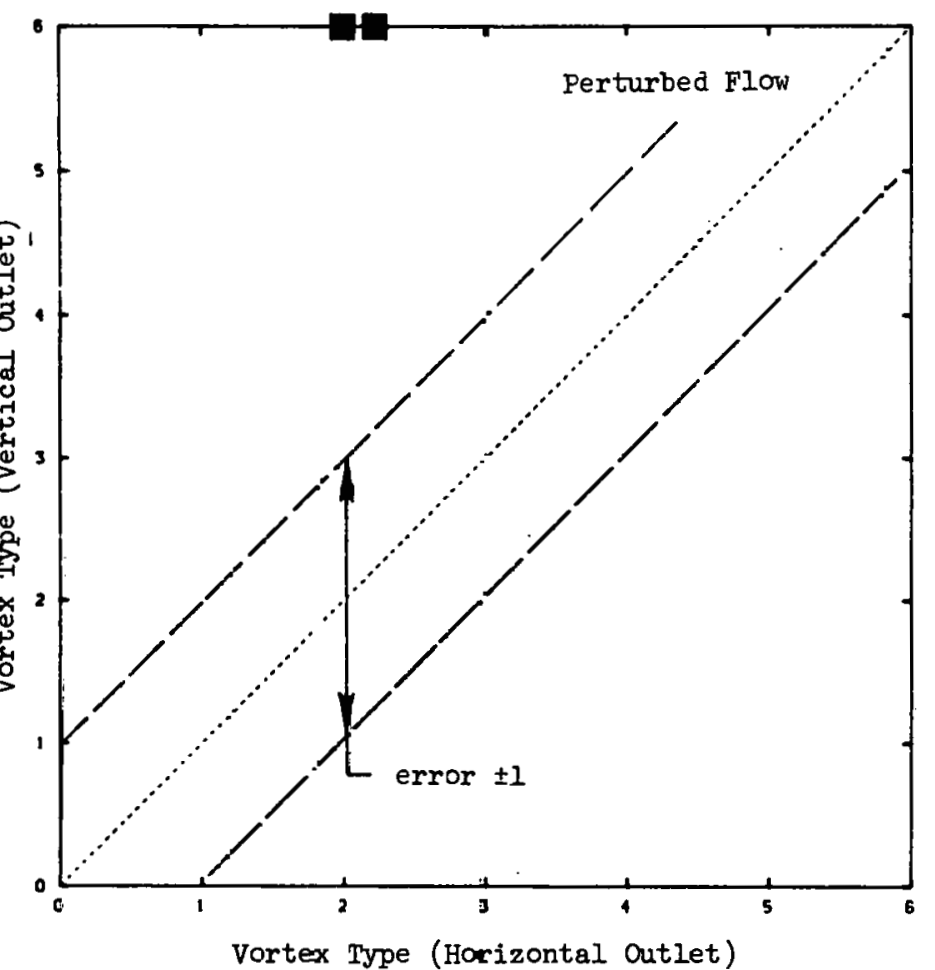

Figure 4.86 Comparison of Jortex Type Under Perturbed Flow Conditions Between Vertical and Horizóntál Outlet Sumps for Comparison Type C
Comparison Type C

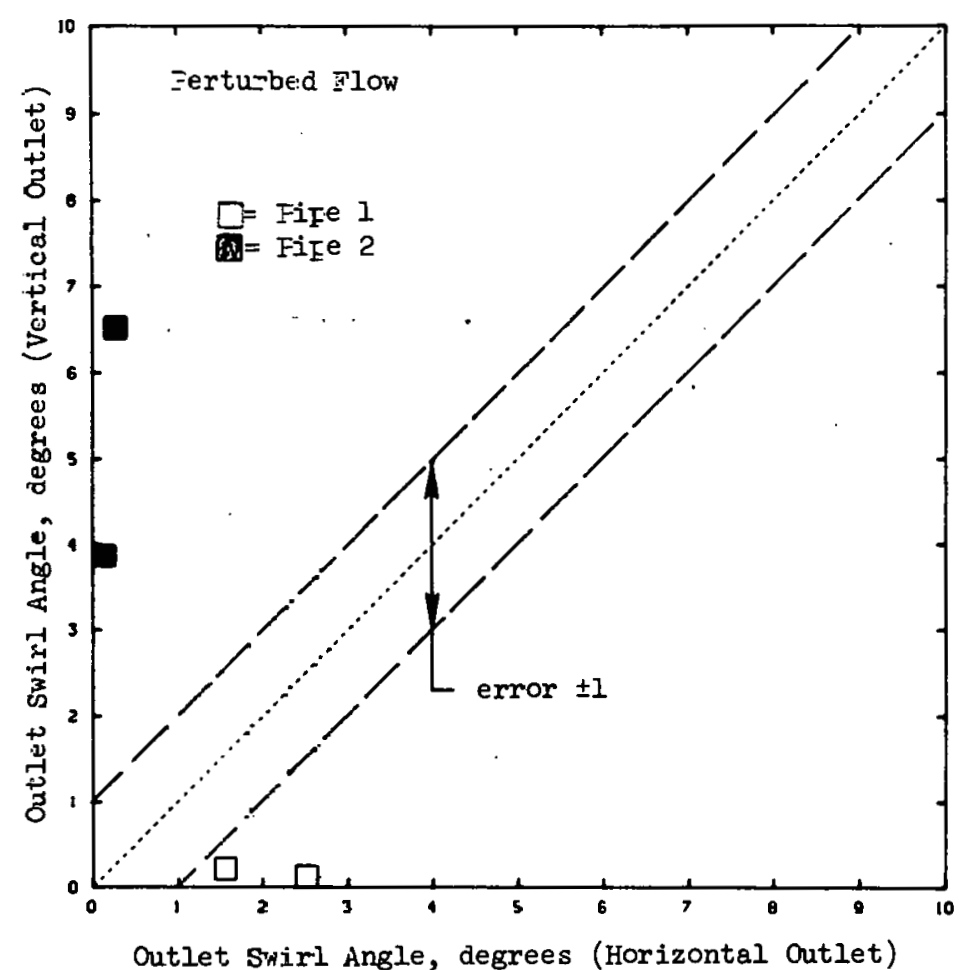

Figure 4.87 Comparison of Outlet Swirl Angle Performance Uncer Perturbed Flow Conditions Between Vertical and Horizontal outlet Sumps for Conparison Type C 


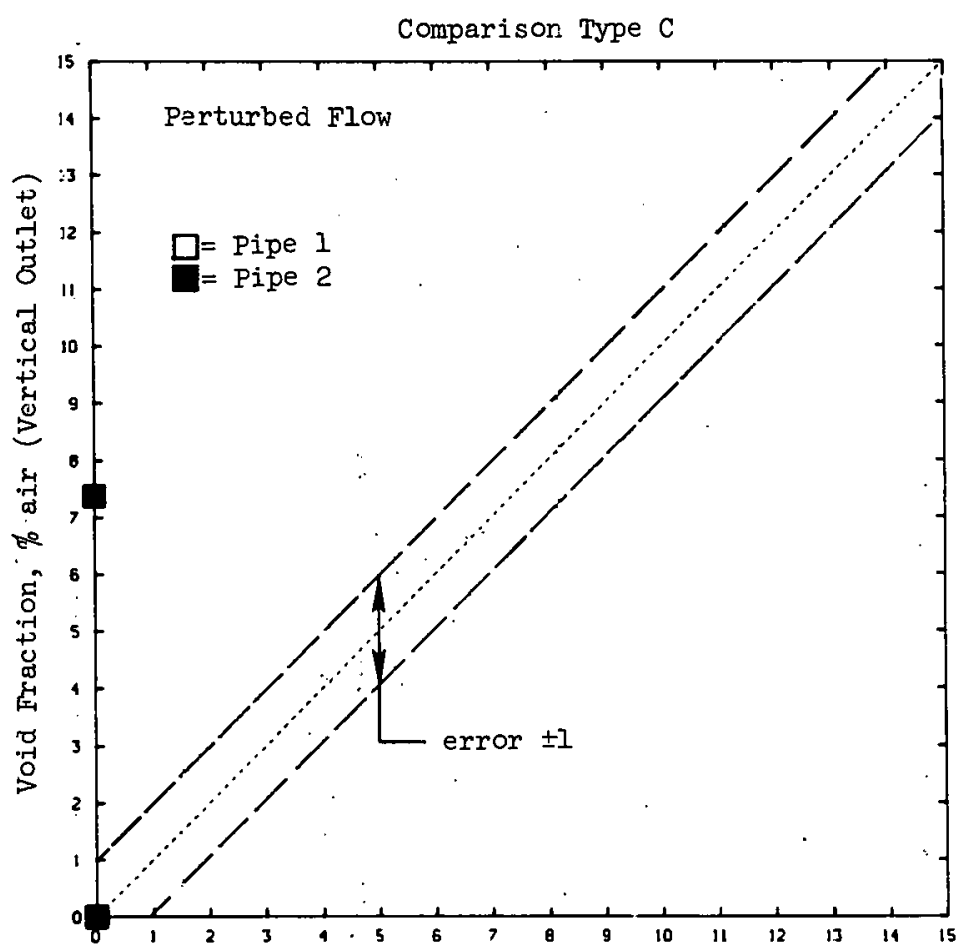

Void Fraction, \% air (Horizontal outlet)

Figure 4.88 Comparison of void Fraction Performance Under Perturbed Flow Conditions Between Vertical and Horizontal outlet Sumps for Comparison Type $C$

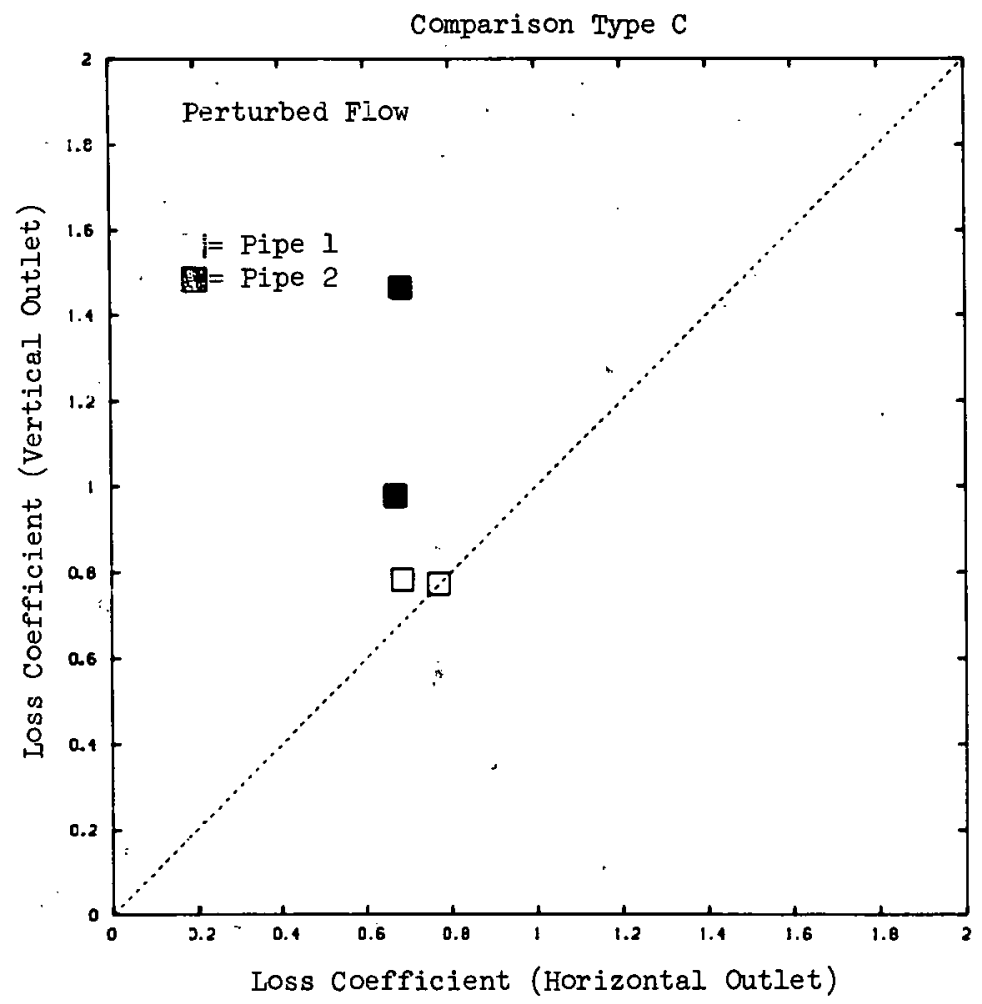

Figure 4.89 Comparison of Loss Coefficient Performance Under Perturbed Flow Conditions Between Vertical and Horizontal Outlet Sumps for 
Comparison Type A (Figure 4.65): Vortex type behavior for vertical outlet sumps was found to be similar to that of horizontal outlet sumps. Figure 4.78 indicates the similar vortex type performance during perturbed flow tests. The majority of the data of Figure 4.78 was found to fall within the expected error bands.

No significant differences in the levels of swirl angle were found between vertical and horizontal outlet sumps during perturbed flow conditions. The majority of the outlet swirl angle test data, as seen in Figure 4.79 fell within the expected error bands.

Air ingestion levels observed in both outlet orientations were similar with the exception of a few tests--one of which resulted in greater air ingestion for a horizontal outlet sump and the other of which resulted in greater air ingestion for a vertical outlet sump (Figure 4.80).

The loss coefficient data, shown in Figure 4.81 , remained unchanged (excluding the contributions by the vertical outlet $90^{\circ}$ elbow) from that of the horizontal loss coefficient data. Comparison Type B (Figure 4.65): Figure 4.82 shows vertical and horizontal outlet vortex severity for Comparison Type $B$. No consistent behavior is seen in Figure 4.82: Many of the tests produced 30-minute average vortex types that fell within the expected error bands. Some vertical outlet tests produced results indicating greater vortex type than those produced during horizontal outlet tests, while other tests resulted in lower vertical outlet vortex types.

Outlet swirl angles, for this comparison type, were attenuated in the vertical outlet sump for a large number of points when compared with the swirl angles recorded during tests of horizontal outlet sumps. This trend is not, however, consistent in that a number of tests showed the opposite behavior (Figure 4.82).

Vertical outlet sumps produced two substantial increases in 30-minute average air ingestion levels over those levels experienced by comparable horizontal outlet sumps. Figure 4.84 shows one vertical outlet test exhibited an air ingestion of 13 percent void fraction while a second test yielded an air ingestion value of about 3 percent void fraction. Similar tests with horizontal outlets resulted in air ingestions less than 0.3 percent void fraction.

Loss coefficient comparisons, shown in Figure 4.85, exhibited no behavior that differed from any other loss coefficient data. Comparison Type C (Figure 4.65): Only two perturbed flow tests using a flush mounted vertical outlet were conducted. The flush mounted vertical outlets resulted in Type 6 air-core vortices where as the comparable horizontal outlets were found to produce only Type 2 vortices. This increased vortex activity for the vertical outlet sump is shown in Figure 4.86 .

Similar results were found for the outlet swirl comparisons shown in Figure 4.87. The vertical outlet sump produced greater levels of outlet swirl angles than those produced in the comparable horizontal outlet tests.

Flgure 4.88 shows an air ingestion for a vertical outlet test of greater than 7 percent void fraction while the horizontal outlet sump produced an air ingestion value for the same test of less than 0.3 percent void fraction. 
A comparison of the loss coefficient data, shown in Figure 4.89, indicates that one of the two vertical outlet tests produced a value of loss coefficient that was substantially higher than that recorded for the comparable horizontal outlet test (including the effects of the $90^{\circ}$ elbow in the vertical outlet test).

In summary, the performance of vertical outlet sumps is similar to the performance of horizontal outlet sumps under the same conditions of uniform approach flow. Some minor differences in performance were, however, found to exist between vertical and horizontal outlets under perturbed flow conditions, some larger differences in performance where noted between the two outlet orientations. These were observed swirl angles in the comparision types $B$ and $C$ and for void fraction. A number of large ( $>3$ degrees) reductions in outlet swirl angles were recorded in the vertical outlet sumps when compared with the swirl angles measured in the comprable horizontal outlet sumps. Many increases in outlet swirl angle for the vertical outlet sump over those observed for horizontal outlet sumps were, however, also recorded. There were no cases of consistantly differing performance for either outlet orientation in terms of the swirl angle. Void fraction performance remained, for the most part, similar for the two outlet orientations under comparable perturbed flows. One very large increase in air ingestion occurred during a vertical outlet test when compared with the comparable horizontal outlet test (the horizontal outlet test exhibited an air ingestion of $<0.3$ percent void fraction while the vertical outlet test yielded an air ingestion measurement of about 13 percent void fraction at a Froude number greater than 1.0). One additional case of increased air ingestion in the vertical outlet sump was recorded. Excepting these cases, the vertical outlet sump was found to act no differently to flow perturbations than the horizontal outlet sump. 


\section{References}

1. Weigand, G. G., Krein M. S., Wester, M. J., Padmanabhan, M., "A parametric study of Containment Emergency Sump Performance" NUREG/CR-2758, SAND82-0624, ARL-46-82, Sandia National Laboratories, Alden Research Laboratory, July 1982.

2. Durgin, W. W., Padmanabhan, M., Janik, C. R., "The Experimental Facility for Containment sump Reliability Studies". Alden Research Laboratory, ALO-132, December 1980.

3. Padmanabhan, M., "Report on Results of Vertical outlet Sump Tests," Draft Report, Alden Research Laboratory, January 1982. 


\section{Appendix A}

Facility Measurement Techniques, and Data Aquisition.

A brief description of the ECCS sump test facility and the adaptation of the facility to allow testing of vertical suction sumps has been given in this appendix. Detailed facility descriptions can be found in references 1 and 2 .

A plan view and several section views of the sump test facility are shown in Figure A.1. The piping layout that provided the connection between the sump outlet and the circulation pumps is shown in Figure A.2. The piping arrangement provided means for the attachment of a flow meter, void fraction meter, vortimeter and pressure grade line taps. The locations of this instrumentation is shown on Figure A.2. The bend effects have been included in the data measurement. Two pipe lines, like the one shown in Figure A.2, were installed in the facility; one line for each outlet. The sump tank itself was constructed in a manner that permitted changes in sump size and outlet location. This feature allowed testing under a broad range of geometric parameters.

Sump performance was determined by four response parameters which consisted of both instrumentation readings and operator observations:

Vortex type data was taken every 30 seconds by an observer who classified surface vortex activity according to a scale which ranged from a Type 1 vortex (incoherent surface swirl) to a Type 6 vortex (fully developed air-core to the outlet). Intermediate numerical values were assigned to discernable stages of vortex development. The vortex type classification scale has been given in Figure A.3. Further documentation of vortex type data was made through photographs, movies and video recordings.

Outlet swirl angle was measured by crossed vane swirl meters. These devices rotated about the central axis of the pipe. The vanes of the swirl meters spanned about 75 percent of the pipe diameter. The total number of rotations per 30 seconds, along with the direction of rotation, were monitored and used to define the outlet swirl angle. Figure A.4 shows a swirl meter installed in a 12 inch diameter pipe.

The loss coefficient was calculated from measurements of the hydraulic grade linc. The grade 1 ine was established by 10 pressure taps located in the horizontal section of each outlet pipe. Pressure at each tap was averaged every 1 minute. Figure A. 5 demonstrates the method used to calculate the sump loss coefficient.

Void fraction resulting from ingested air in each outlet pipe was measured with a conductivity meter of the rotating electric field type. This device measured the average cross sectional conductivity of the flow. The conductivity of the flow is proportional to quantity of air within the outlet pipe. Void fraction measurements were average over 1 minute, 5 minutes and 30 minutes. The calibration data given for this device by the manufacturer indicated a standard deviation of 1 percent void fraction. 


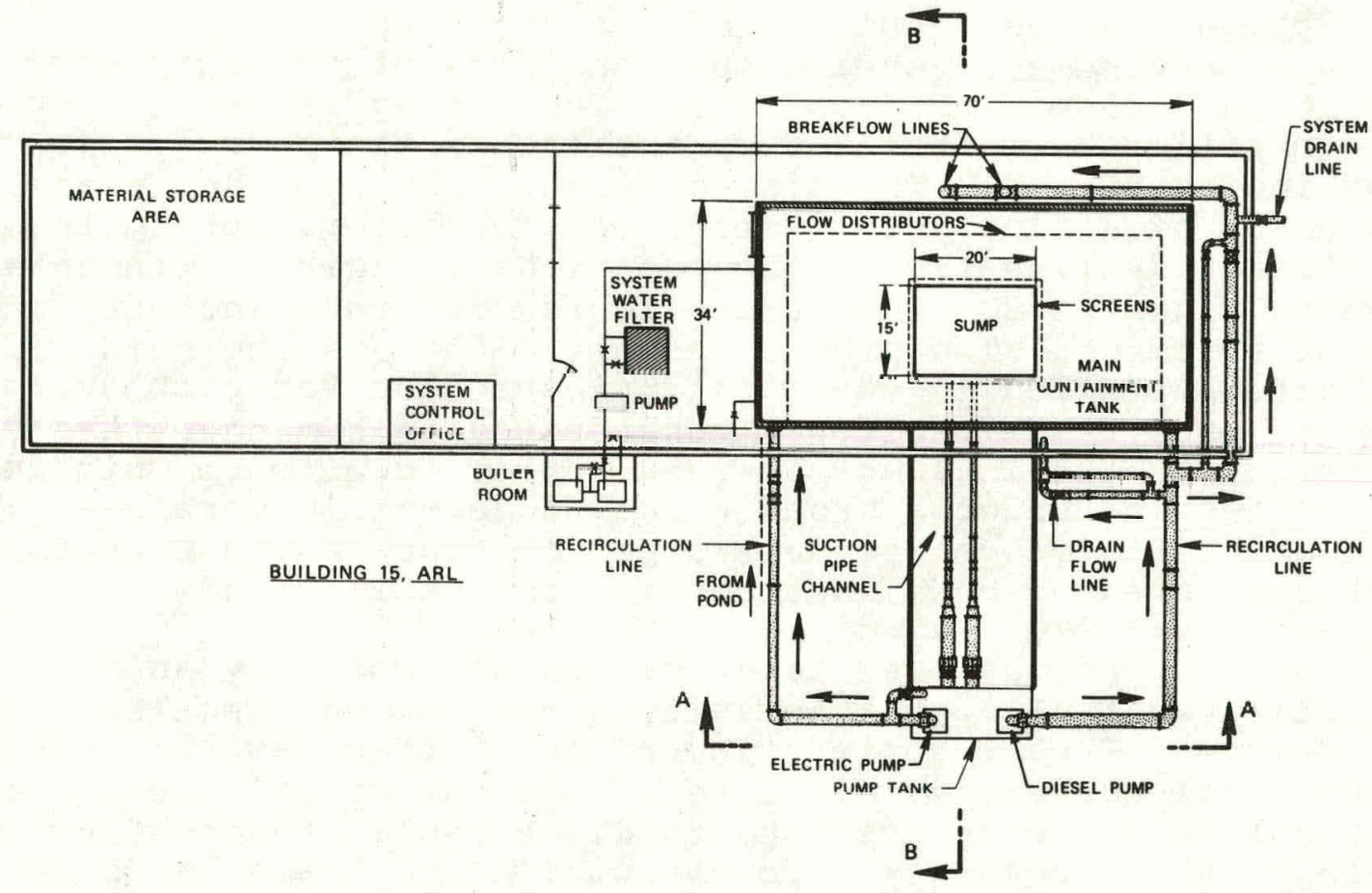

a PI AN OF FACIIITY

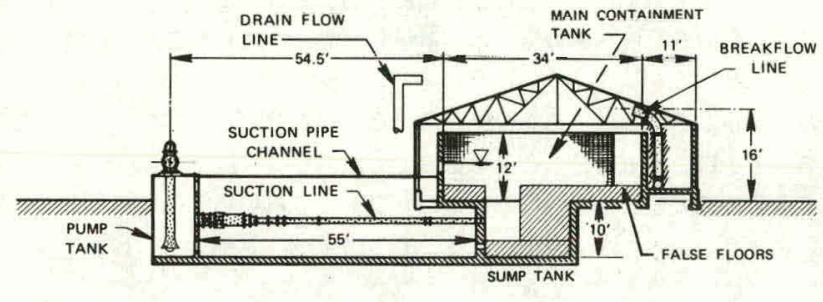

SECTION B-B

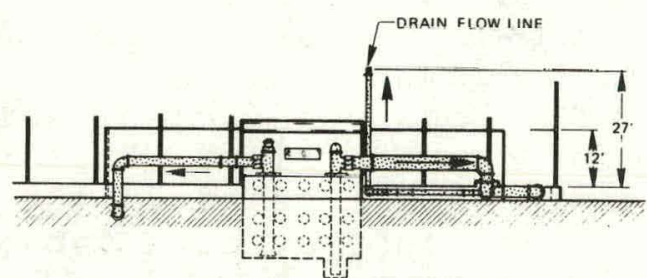

SECTION A-A

b SECTIONAL VIEWS OF FACILITY

Figure A.1 Details of the Sump Test Facility 


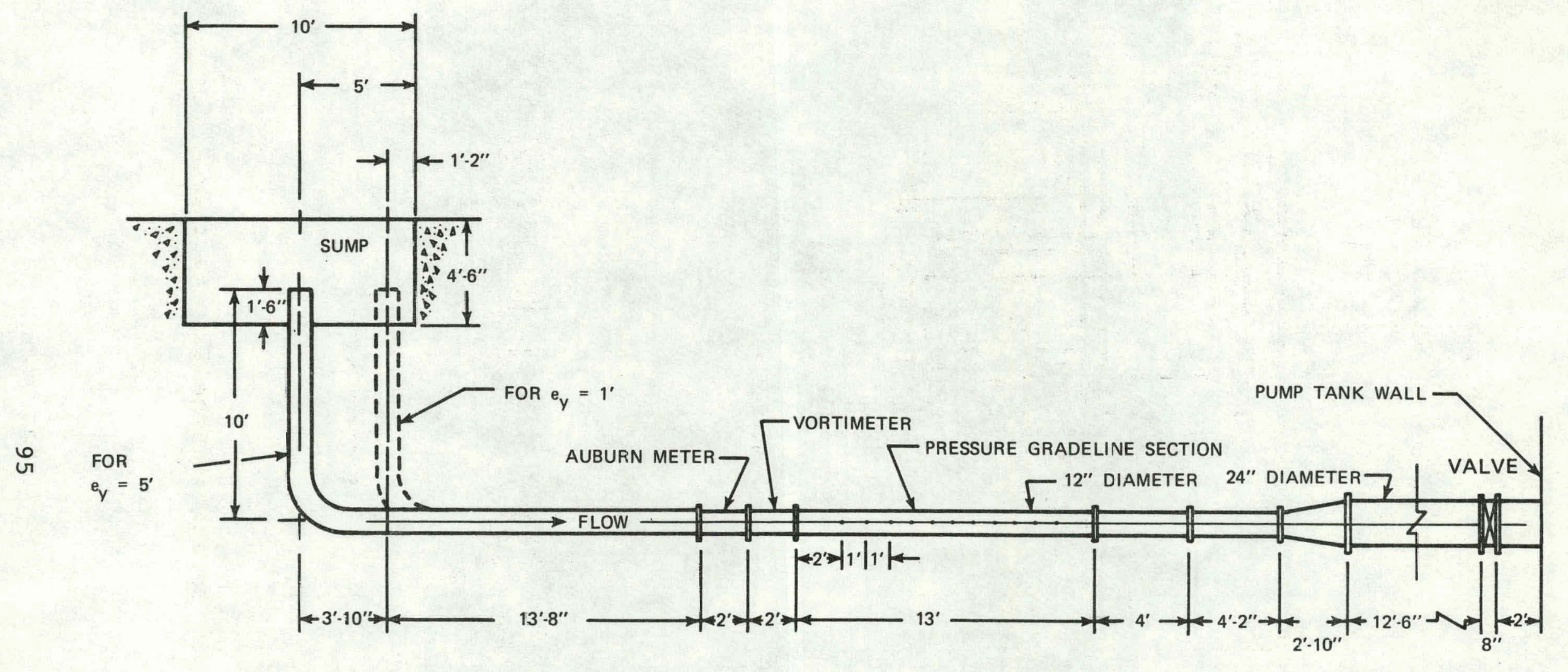

Figure A.2 Typical Piping Arrangement for Vertical Outlet Sumps 


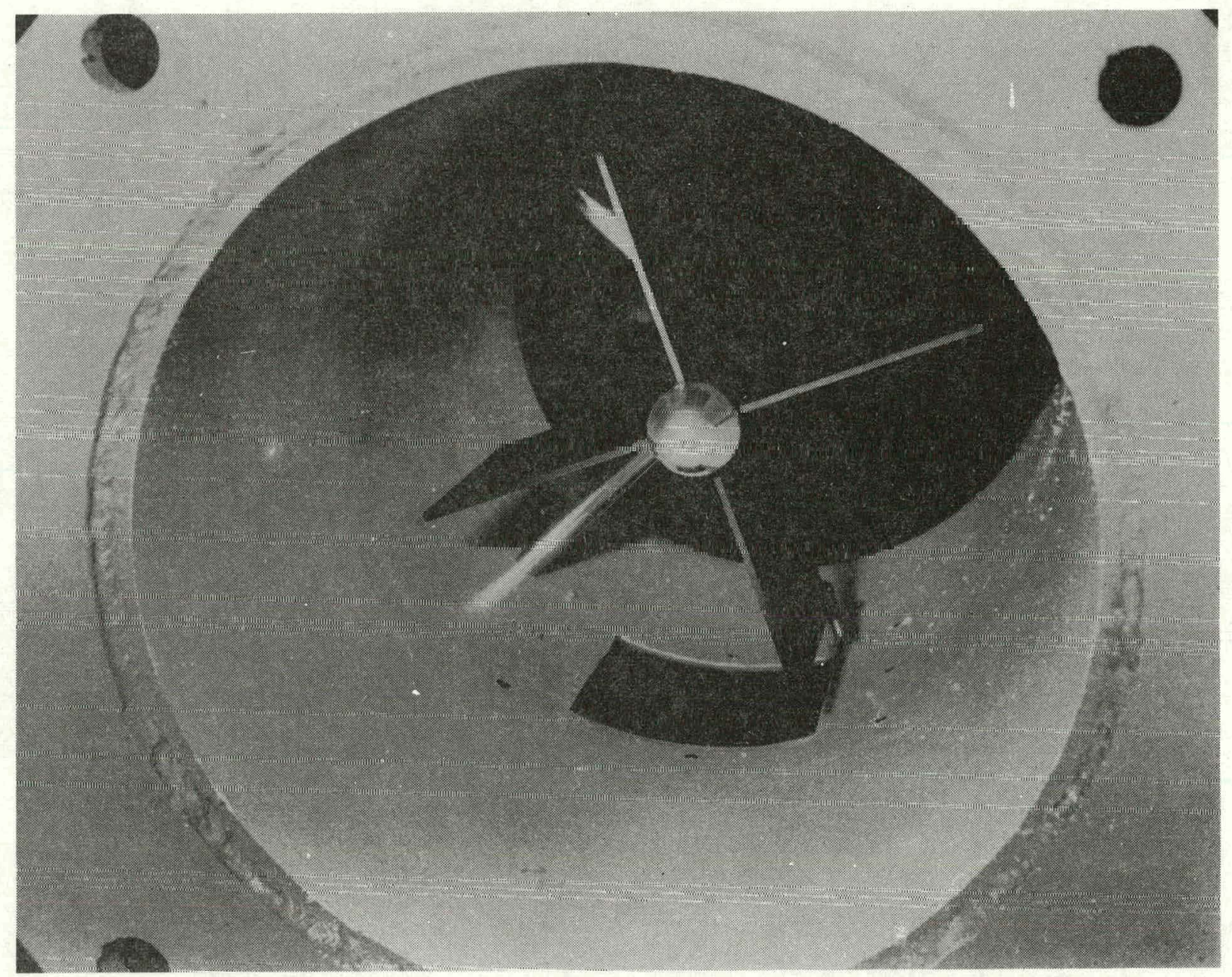

Figure A.3 Swirl Meter Installed in Pipe 


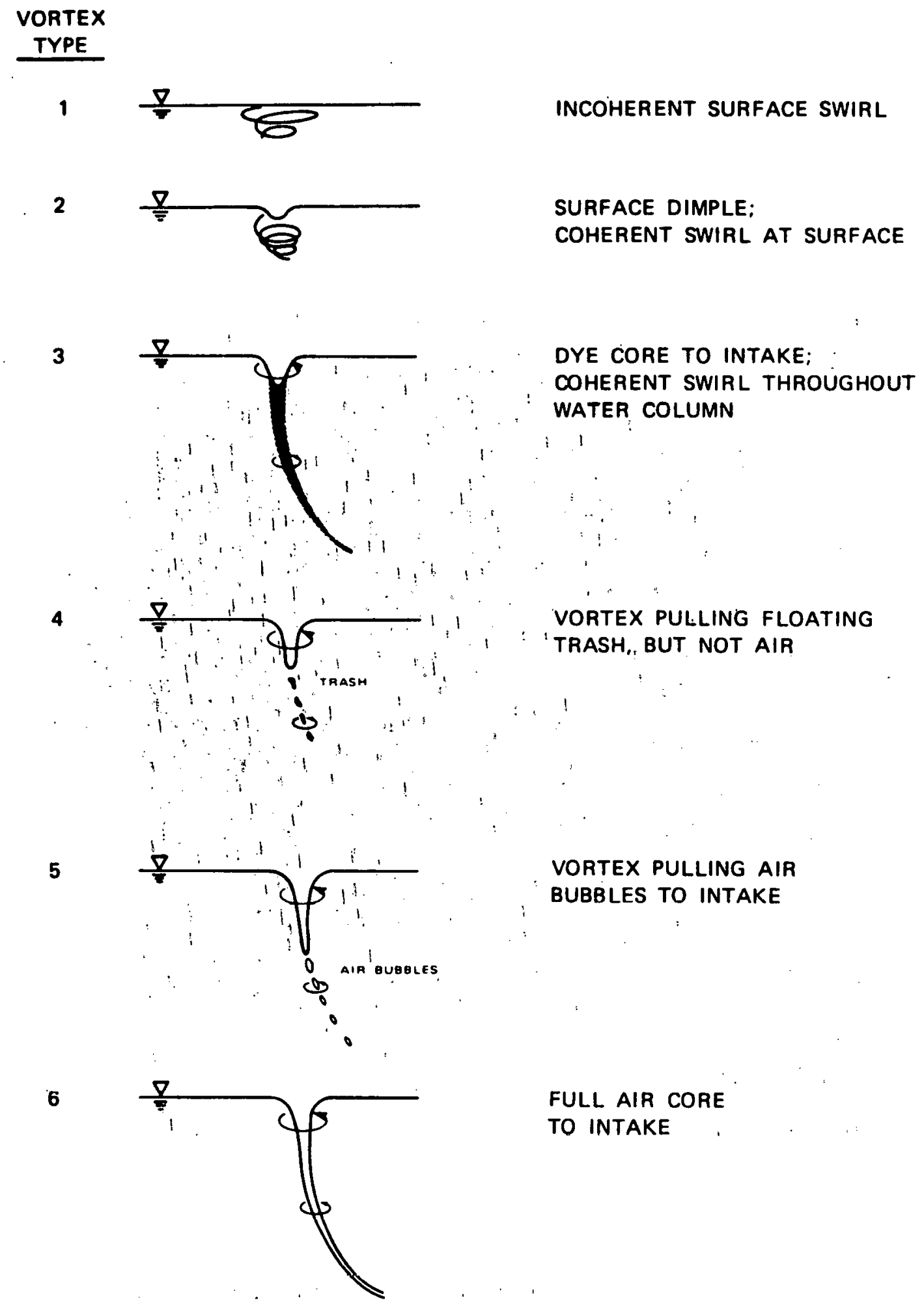

Figure A.4 Vortex Type Classification Scale 


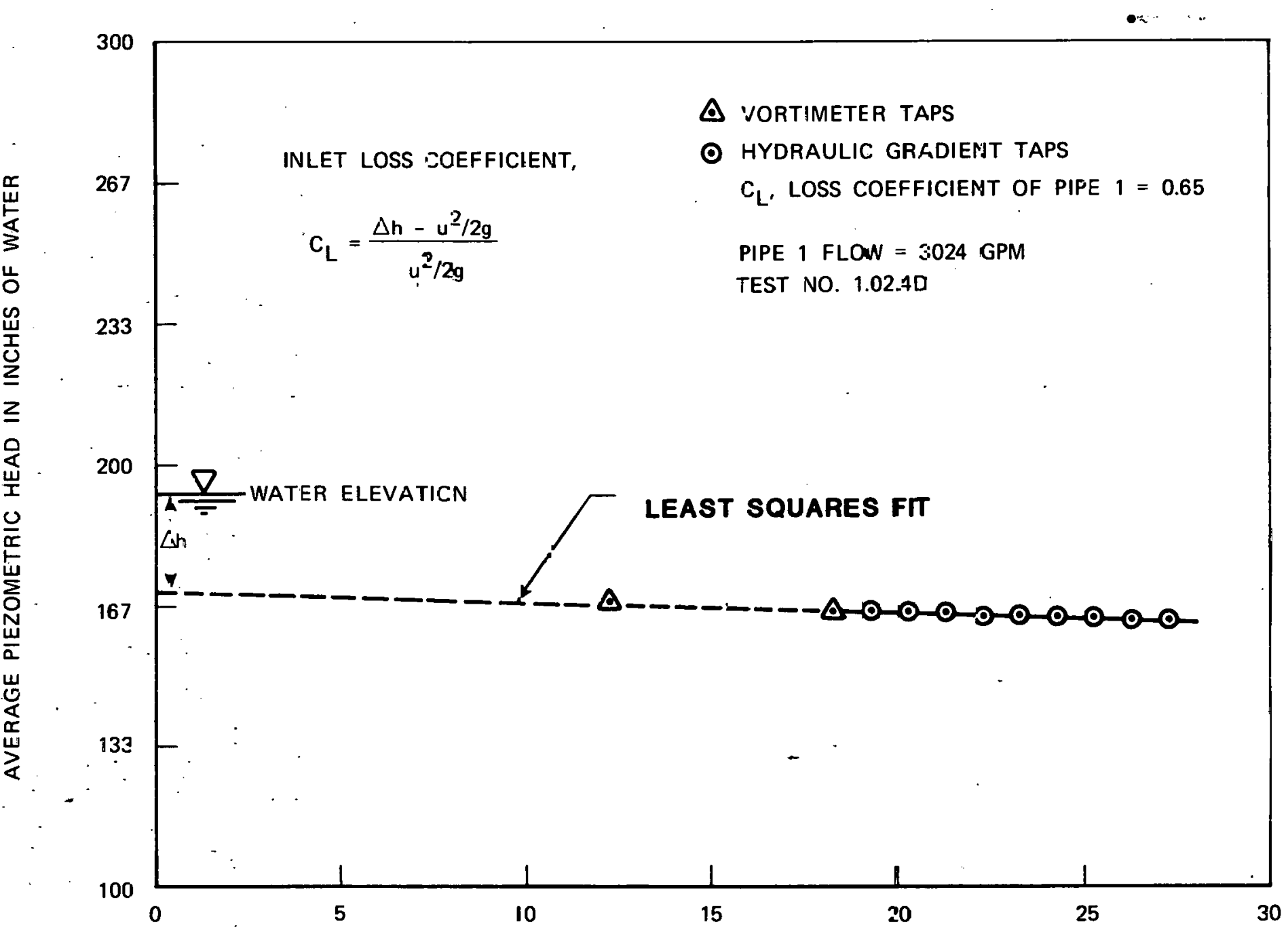

DETANCE IN PIPE DIAMETERS

Figure A.5 Method fcr the Determination of Outlet Loss Coefficient 
A mini-computer based data acquisition system was used to record measurements and observations for each test, as shown in Figure A.6. At intervals of 30 seconds, an observer entered the vortex type and location using a small terminal, and for the same interval, the system counted the number and direction of vortimeter revolutions in each test 1 ine. The pressure taps for pressure gradients were monitored for five seconds each including some allowance for settling and averaging of the signal. With two auxiliary pressure measurements, for each system, the gradeline for each pipe was established every 60 seconds. A similar pressure scanning system was used to monitor seven differential flow meters on a 30 second cycle. The analog output from the void fraction meters was sampled every 5 seconds and the water temperature sampled every 30 seconds. The data were displayed on a video terminal in suitable formats to aid the operators in setting up test runs. At the end of each test run, all data were transferred to disc files for storage and further processing and display. 


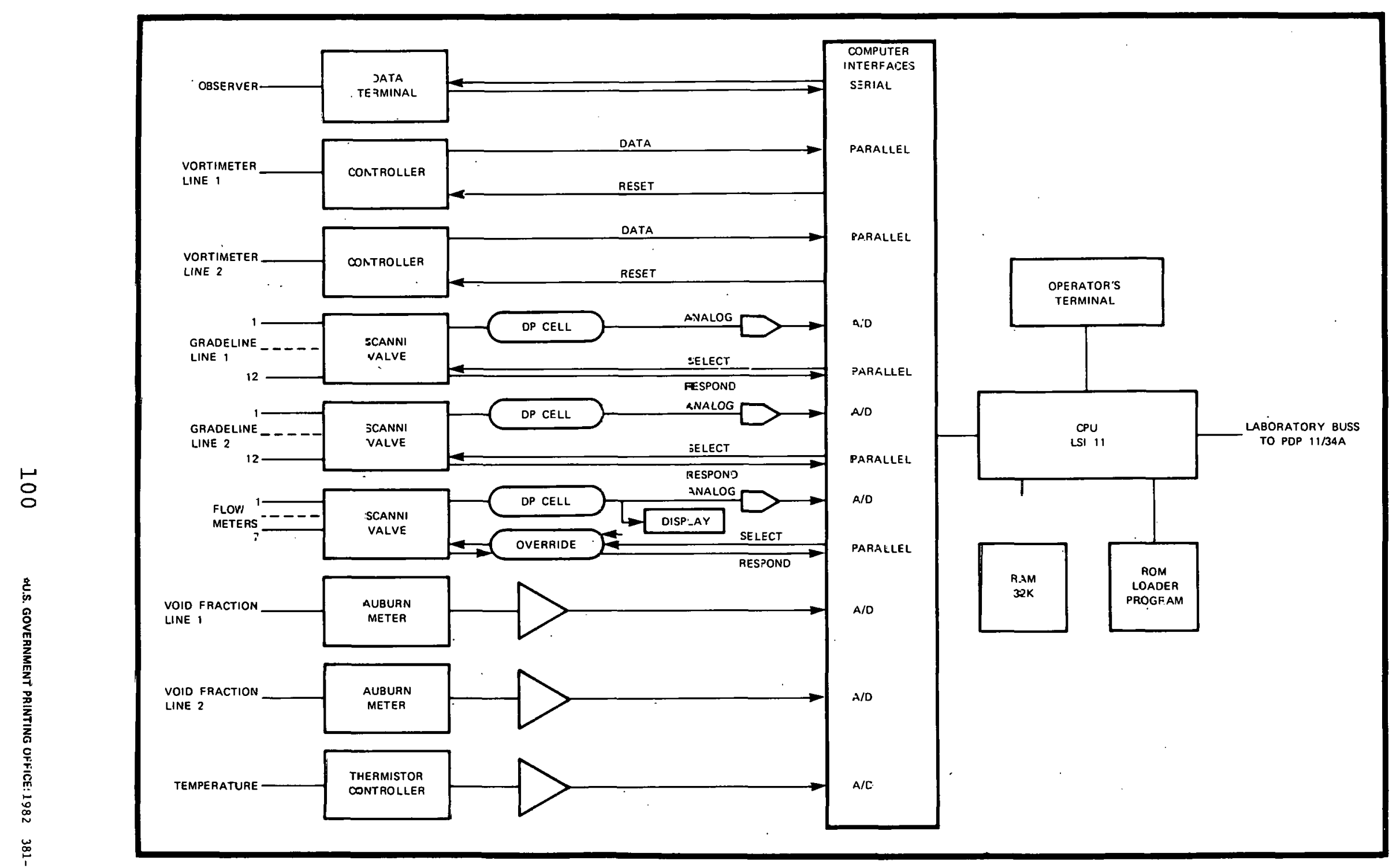

Figure A.6 Data Aquisition Scherie 
WASHINGTON, D.C. 20555

OFFICIAL BUSINESS

PENALTY FOR PRIVATE USE, $\$ 300$

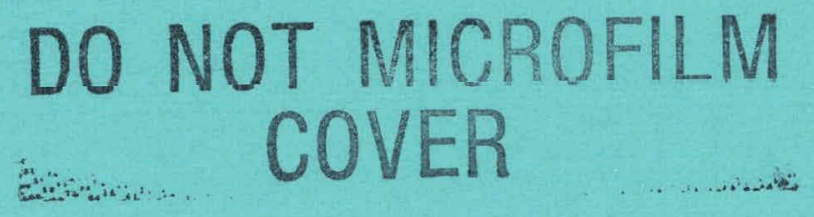

